MULTITEMPORAL IMAGE ANALYSIS FOR MONITORING FUZZY SHORELINES

Ratna Sari Dewi 
Graduation committee:

\section{Chairman/Secretary}

Prof.dr.ir. A. Veldkamp University of Twente

\section{Supervisor}

Prof.dr.ir. A. Stein University of Twente

\section{Co-supervisors}

dr.ir. W. Bijker

Prof.Dr.rer.nat. M.A. Marfai

University of Twente

University of Gadjah Mada

\section{Members}

Prof.dr. D. van der Wal

University of Twente

Prof.dr. K.M. Wijnberg

University of Twente

Prof.dr. P. Hoekstra

University of Utrecht

Prof.dr. M. Herold

University of Wageningen

Dr. B. Deronde

VITO NV

ITC dissertation number 331

ITC, P.O. Box 217, 7500 AE Enschede, The Netherlands

ISBN 978-90-365-4633-1

DOI $10.3990 / 1.9789036546331$

Cover designed by Fahrul Hidayat

Printed by ITC Printing Department

Copyright (c) 2018 by

11 CACULTy OF GEO-INFORMATION SCIENCE AND EARTH OBSERVATION 


\title{
MULTITEMPORAL IMAGE ANALYSIS FOR MONITORING FUZZY SHORELINES
}

\author{
DISSERTATION
}

to obtain

the degree of doctor at the University of Twente, on the authority of the rector magnificus, prof.dr. T.T.M. Palstra, on account of the decision of the graduation committee, to be publicly defended

on Thursday, October 4, 2018 at 16.45 hrs

by

Ratna Sari Dewi

born on October 23, 1973

in Jakarta, Indonesia 
This thesis has been approved by

Prof.dr.ir. A. Stein, supervisor

dr.ir. W. Bijker, co-supervisor

Prof.Dr.rer.nat. M.A. Marfai, co-supervisor 
To my family 



\section{Summary}

Rapid development and population growth in coastal areas always bring a risk of coastal damage. In this situation, monitoring of shoreline position plays an important role in achieving a balanced condition between economic development and coastal protection. For this purpose, local authorities and coastal planners require information on shoreline changes for coastal land use planning and disaster risk management. Monitoring shoreline change for larger areas and longer time spans, however, is challenging due to limited data availability and high cost. Remote sensing and specific image processing methods for the identification and monitoring of shorelines are needed, especially methods that can handle the uncertainty in shoreline positions. This dissertation investigates and develops image analysis methods from remote sensing images to provide information for the sustainable coastal development. It focuses on using a fuzzy classification and a change detection technique to identify shorelines and monitor their changes. Emphasis is given on data quality and the estimation of uncertainty. The methods proposed in this dissertation are applied on a series of images to identify shoreline positions in the northern part of the Central Java Province, Indonesia which experienced a severe change of shoreline position over three decades.

First, an unsupervised fuzzy c-means (FCM) classification is presented to observe the shoreline positions by taking the gradual transition between water and land into account. The FCM is a clustering method that separates data clusters with class means and fuzzy boundaries allowing for partial membership. Two methods to generate shorelines are proposed. The first method derives the shoreline as a single line by applying a threshold of 0.5 on the water membership images. The second method derives shorelines as an area or a margin, presented as a crisp object with a boundary determined by threshold values resulting from parameter estimation. Crisp and fuzzy methods are combined for change detection. The post-classification comparison method is implemented to distinguish abrupt and gradual changes at the object level and provide the change uncertainty at the pixel level. Two perspectives of uncertainty are addressed: uncertainty that is inherent to shoreline positions as observed from remote sensing images, and the uncertainty that propagates from object extraction and implementation of shoreline change detection method. Shoreline and its changes are presented 
as crisp sub-areas. The changed areas are thus associated with the spatial distribution of change uncertainty.

Second, the possibility of using fuzzy-crisp objects to derive shoreline positions as the transition zone between the classes water and non-water is addressed. Pixels at which the membership value $(\mu)$ exceeds 0.99 are the core of a class, for example the water class, whereas pixels with $0.01<$ $\mu<0.99$ belong to transition zones or shoreline class, and pixels with $\mu<0.01$ do not belong to objects of water or shoreline. A change detection method for shorelines which accounts for their fuzzy character in remote sensing images is proposed and implemented. The change of shoreline is explained in terms of change magnitude and change direction using change vector analysis (CVA). Information provided by CVA allows us to see the trend of the fluctuating shoreline over time. The analysis of information provided by the change magnitude and direction reveals that each change combination represents one specific type of change process. It shows a multi-year pattern of water membership changes over the observation periods that could indicate certain coastal processes, for instance, erosion and accretion. Based on these results, it can be concluded that the proposed method can assess changes in a shoreline by taking into account that it is a fuzzy boundary.

Third, uncertainty modelling of shorelines by comparing fuzzy sets and random sets is presented. Both methods quantify extensional uncertainty of shorelines extracted from remote sensing images. Two datasets are tested: pan-sharpened Pleiades with four bands (Pleiades) and pan-sharpened Pleiades stacked with elevation data as the fifth band (Pleiades + DTM). Both fuzzy sets and random sets model the spatial extent of shoreline including its uncertainty. Fuzzy sets represent shorelines as a margin and their uncertainty as confusion indices. They do not consider randomness. Random sets fit a mixed Gaussian model to the image histogram. The random sets represent shorelines as a transition zone between water and non-water. Their extensional uncertainty is assessed by the covering function. The results show that fuzzy sets and random sets result in shorelines that are closely similar. Kappa values are slightly different and McNemar's test shows high $p$ values indicating a similar accuracy. Inclusion of the DTM (digital terrain model) improves the classification results, especially for roofs, inundated houses and inundated land. The shoreline model using Pleiades + DTM performs better than that of using Pleiades only, when using either fuzzy sets or random sets. It achieves $\kappa$ values above $80 \%$.

Fourth, the transferability and upscaling of a fuzzy classification of shoreline changes to a different area and towards larger area is investigated. Three strategies are conducted: (i) optimizing two FCM parameters based on the predominant land use/cover of the reference subset; (ii) adopting the class 
mean and number of classes resulting from the classification of reference subset to perform FCM on target subsets; and iii) estimating the optimal level of fuzziness of target subsets. From the experimental results, $m$ values in the range from 1.3 to 1.9 are obtained for seven land use/cover classes that have been analysed. For the ten images used in this research, $m=1.8$ is obtained as optimal value. For a coast with similar characteristics, this $m$ value can be adopted and the relation between land use/cover and the two FCM parameters can help to shorten the time needed to optimize the parameters. The proposed method for upscaling and transferring the classification method to a larger and to different areas is promising, showing $\kappa$ values $>0.80$ and agreement of water membership values $>0.82$ between the reference and target subsets.

To summarize, this dissertation focuses on modelling shoreline as an object with vague boundaries using multi-temporal remote sensing images. The associated uncertainties are estimated by means of possibility and necessity measures, and by confusion index. In this sense, this dissertation contributes to the monitoring of shorelines trough the development and the implementation of image analysis methods to quantify and monitor the changes of shorelines and related change uncertainty using remote sensing images. 


\section{Samenvatting}

Een snelle ontwikkeling van kustgebieden en een snelle bevolkingsgroei brengen altijd een risico van schade aan de kust met zich mee. Om in deze situatie een balans tussen economische ontwikkeling en kustbescherming te bereiken, speelt monitoring van de positie van de kustlijn een belangrijke rol. Voor dit doel hebben lokale autoriteiten en planners informatie nodig over veranderingen aan de kustlijn, voor de planning van het grondgebruik aan de kust en risicobeheersing met betrekking tot rampen. Voor grotere gebieden en langere tijdspannen is het monitoren van veranderingen aan de kustlijn echter een uitdaging vanwege de beperkte beschikbaarheid van gegevens en de hoge kosten. Aardobservatie en specifieke beeldverwerkingsmethoden voor de identificatie en monitoring van kustlijnen zijn nodig, met name methoden die de onzekerheid in de positie van de kustlijn kunnen hanteren. Dit proefschrift onderzoekt en ontwikkelt analysemethoden voor aardobservatie beelden om informatie te verschaffen voor de duurzame ontwikkeling van kustgebieden. Het richt zich op het gebruik van een fuzzy classificatie en een detectietechniek om kustlijnen te identificeren en hun veranderingen te volgen. De nadruk wordt gelegd op de kwaliteit van de gegevens en de schatting van de onzekerheid. De methoden die in dit proefschrift worden beschreven, worden toegepast op een reeks beelden om de posities van de kustlijn te identificeren in het noordelijke deel van de provincie Midden-Java, Indonesië, die gedurende drie decennia een belangrijke verandering in de positie van de kustlijn heeft doorgemaakt.

De eerste studie behelst een ongesuperviseerde fuzzy c-means (FCM) classificatie om de posities van de kustlijn te observeren door rekening te houden met de geleidelijke overgang tussen water en land. De FCM is een clustermethode die gegevensclusters scheidt op basis van klassegemiddelden en vage (fuzzy) grenzen die gedeeltelijk lidmaatschap van meerdere klassen mogelijk maken. Er worden twee methoden beschreven om kustlijnen te genereren. De eerste methode leidt de kustlijn af als een enkele lijn door een drempel van 0,5 toe te passen op de beelden met water lidmaatschap. De tweede methode leidt een kustlijn af als een gebied of marge, gepresenteerd als een duidelijk begrensd (crisp) voorwerp waarvan de grens bepaald wordt door drempelwaarden die resulteren uit parameterschatting. Crisp en fuzzy methoden worden gecombineerd voor de detectie van verandering. Na classificatie wordt een vergelijkingsmethode geïmplementeerd om abrupte en geleidelijke veranderingen op objectniveau 
te onderscheiden en de onzekerheid van de verandering op pixelniveau weer te geven. Twee perspectieven op onzekerheid worden opgepakt: de onzekerheid die inherent is aan de posities van de kustlijn zoals waargenomen in aardobservatie beelden, en de onzekerheid die voortkomt uit objectextractie en implementatie van de detectiemethode voor veranderingen in de kustlijn. Kustlijnen en de bijbehorende veranderingen worden gepresenteerd als duidelijk begrensde deelgebieden. De veranderde gebieden houden dus verband met de ruimtelijke verdeling van de onzekerheid van de verandering.

Als tweede studie wordt de mogelijkheid behandeld om fuzzy-crisp-objecten te gebruiken om posities van kustlijnen af te leiden als de overgangszone tussen de klassen water en niet-water. Pixels waarbij de lidmaatschapswaarde $(\mu)$ hoger is dan 0,99 , vormen de kern van een klasse, bijvoorbeeld de waterklasse, terwijl pixels met $0,01<\mu<0,99$ behoren tot overgangszones of kustlijn klasse, en pixels met $\mu<0,01$ behoren niet tot objecten van water of kustlijn. Een detectiemethode voor veranderingen in kustlijnen, die hun vage karakter in aardobservatie beelden in acht neemt, wordt besproken en geïmplementeerd. De verandering van de kustlijn wordt uitgelegd in termen van grootte en richting van de verandering met behulp van veranderings-vector analyse (CVA). Informatie uit CVA stelt ons in staat om in de loop van de tijd de trend de fluctuerende kustlijn te zien. De analyse van informatie over de veranderingen in grootte en richting onthult dat elke combinatie van veranderingen een specifiek type veranderingsproces vertegenwoordigt. Het toont gedurende de observatieperioden een meerjarig patroon van veranderingen in het lidmaatschap van de waterklasse, dat kan wijzen op bepaalde processen aan de kust, bijvoorbeeld erosie en aanwas. Op basis van deze resultaten kan worden geconcludeerd dat de voorgestelde methode veranderingen in een kustlijn kan beoordelen door er rekening mee te houden dat het een vage grens is.

In de derde studie wordt onzekerheidsmodellering van kustlijnen door een vergelijking van fuzzy sets en random sets beschreven. Beide methoden kwantificeren extensionele onzekerheid van kustlijnen via extractie uit aardobservatie beelden. Twee datasets worden getest: (pansharpened) Pleiades met vier banden, waarbij de panchromatische band gebruikt is om de vier multispectrale banden een hogere resolutie te geven (Pleiades) en (pansharpened) Pleiades met de toevoeging van hoogtegegevens als de vijfde band (Pleiades + DTM). Zowel fuzzy sets als random sets modelleren de ruimtelijke extensie van de kustlijn inclusief de onzekerheid. Fuzzy sets geven kustlijnen weer als een marge en hun onzekerheid als confusie-indices. Ze houden geen rekening met toeval. Random sets passen op een gemengd Gauss-model van het histogram van het beeld. Random sets geven kustlijnen weer als een overgangszone tussen water en niet-water. Hun extensionele 
onzekerheid wordt vastgesteld door de dekkingsfunctie. De resultaten laten zien dat fuzzy sets en random sets resulteren in kustlijnen die sterk op elkaar lijken. Kappa-waarden zijn slechts enigszins verschillend en de test van McNemar toont hoge $p$-waarden die een vergelijkbare nauwkeurigheid aangeven. Toevoeging van het DTM (digitaal terrein model) verbetert de classificatieresultaten, vooral voor daken, overstroomde huizen en overstroomde grond. Het kustlijnmodel met Pleiades + DTM presteert beter dan het model waarbij alleen Pleiades gebruikt wordt, zowel wanneer fuzzy sets als wanneer random sets worden gebruikt. Het bereikt $k$-waarden van meer dan $80 \%$.

De vierde studie onderzoekt de overdraagbaarheid en de opschaling van een fuzzy classificatie van veranderingen in de kustlijn naar een ander gebied en naar een groter gebied. Er worden drie strategieën toegepast: (i) het optimaliseren van twee FCM-parameters op basis van het overheersende landgebruik / landbedekking van de referentiesubset; (ii) het gebruiken van het klassengemiddelde en het aantal klassen die resulteren uit de classificatie van een referentie-subset om FCM op de doel-subset uit te voeren; en iii) het schatten van het optimale niveau van vaagheid (fuzziness) van doel-subsets. Uit de experimentele resultaten worden $m$ waarden in het bereik van 1,3 tot 1,9 verkregen voor zeven landgebruiks- / landbedekkingsklassen die zijn geanalyseerd. Voor de tien beelden die in dit onderzoek worden gebruikt, wordt $m=1,8$ verkregen als optimale waarde. Deze $m$ waarde kan worden gebruikt voor een kust met vergelijkbare kenmerken en de relatie tussen landgebruik / landbedekking en de twee FCM-parameters kan helpen om de tijd te verkorten, die nodig is om de parameters te optimaliseren. De beschreven methode voor het opschalen en overdragen van de classificatiemethode naar een groter- en naar andere gebieden is veelbelovend, toont $\mathrm{k}$-waarden $>0,80$ en een overeenstemming $>0,82$ tussen de water lidmaatschapswaardes van de referentie- en de doelsubsets.

Samenvattend richt dit proefschrift zich op het modelleren van de kustlijn als een object met vage grenzen, met behulp van multi-temporele aardobservatie beelden. De bijbehorende onzekerheden worden geschat als mate van mogelijkheid en mate van noodzakelijkheid en door de confusieindex. Op deze manier draagt dit proefschrift bij tot de monitoring van kustlijnen door middel van de ontwikkeling en de implementatie van methoden voor de analyse van aardobservatie beelden, die de veranderingen van kustlijnen en de daarmee samenhangende onzekerheid van die veranderingen kwantificeren en monitoren. 


\section{Acknowledgments}

Praises and thanks to Allah for giving me strength, ability and opportunity to undertake this research and to complete it satisfactorily. Without His blessings, this achievement would not have been possible.

I am sitting down quietly in front of my laptop which has accompanied me for four and a half years when people and things come to my mind. Finally, it's time for me to write a thank you note to all of them who helped me out of all kinds of troubles, and supported me through the hard times. Completion of this work was possible with support of many people and organizations. My sincere appreciation is for all their support and collaboration throughout the long path of my research. To name them all here is not possible. I would miss wonderful persons who have crossed my path during my studies. For the people who are not mentioned here, please also accept my sincere appreciation.

I would like to express my most appreciation to my promoter Prof.dr.ir. Alfred Stein for his continuous guidance and support. His vast experience and critical reviews helped me to gain confidence and the right direction which enabled me to successfully complete the work. He taught me how to write an English document in a scientific way and gave feedback of my documents within a short period of time. He is the most knowledgeable and efficient person that I have worked with. He encouraged me to work harder and efficient with the optimal results. He always goes deep to the problems and asks questions to the point. Sometimes, it was hard to convince him and it forced me to read more references and did more experiments. However, in the end I found that he was right. I get the confidence that if I can convince him, I can convince the world as well.

Dr. ir. Wietske Bijker, my daily supervisor, has been extremely helpful to me during the entire period of my studies in ITC. As my supervisor, she worked closely with me during the proposal writing and during the period of my dissertation. Words are not enough to express my appreciation and gratitude for many insightful conversations during my research. Our discussion and meeting were very valuable. I thank her for inspiring me to challenge the new research topic, having fast response to my requests, and contributing constructive comments to every publication. I also remembered her 
encouragements when I came across hard times during my research and her cheerful congratulations for every achievement that I had. It was indeed a great pleasure to meet and work with her for four and a half years, during which time I have learnt a lot.

I would also like to thank my Indonesian supervisor, Prof.Dr.rer.nat. M.A. Marfai. I thank him for his concern and understanding during my studies in the Netherlands. I thank him for providing research materials and arranging pre-fieldwork in Semarang. Without his support, I would not be able to complete this work.

My gratitude to Dr. Valentyn A. Tolpekin for allowing me to use his script codes for my research. I also thank him for the most valuable discussions and constructive comments. I would further like to express special thanks to Dr. Mengmeng Li. I thank him for his valuable suggestions for my research, especially for discussions on remote sensing image analysis, also for our chats during the coffee break or when we met in the hallway.

Thanks to my office-mates: Sara, Vera and JR. I really like to work with you all in the wonderful and quiet office atmosphere. We discussed our research, talked about our worries and concerns, encouraged each other, and cheered for every progress. Especially to JR, I thank him for his assistance on providing script code for my third paper. Thanks to Teresa Brefeld for helping me with administrative matters and finding the English editor for my last paper. I thank her also for all management and consulting supports. Thanks to Dr. Adugna Girma, Dr. Rahul Raj, Dr. Biao Xiong, Dr. Sudan Xu, Shima, Andrea, Caroline, Zenchao, Julia, Milad, Frank, Phuong, Zill, Shayan, Diogo, Fashui and many others. Thank you all for accompanying me and bringing happiness during the long research time. My special thanks are also extended to Dr. Riswan Sianturi, Novi Rahmawati, Xiaoling Wang, Matthew, Dr. Xi Zhu, Oliver, and Sonia for sharing stories since I first came to ITC. I wish you all a bright and prosperous future.

Many thanks go to the colleagues in the EOS Department of ITC for their supports and raising questions during the EOS meetings. It is a great pleasure to work in such nice environment with a group of educated people. Thanks to all the ITC staff for their supporting role and ensuring that all resources and facilities were present for the execution of my research: Loes Colenbrander, Theresa van den Boogaard, Roelof, ITC printing, helpdesk and library staff.

My sincere appreciation goes to Dr. Asep Karsidi, former Head of Indonesia Geospatial Information Agency (BIG) for trusting me to pursue this PhD. I thank him for valuable discussions in the very beginning phase of my study. 
I thank his email which was full of encouragement, when I felt so depressed during my proposal writing. I would not have had the chance to study abroad and complete this dissertation without his support. Many thanks go to the people who provided valuable contributions to my research. To Dr. Ibnu Sofian, I thank him for valuable discussions on tides and hydrodynamic processes, and his help in providing script codes to make my life easier. Special thanks to Dr. Ade Komara, for providing convenience in obtaining the data to support my research. I remembered his advice on how to survive PhD by not giving up easily. I thank him for sharing and encouragement. Thanks to Dr. Hadi Bun (from Aalto University School of Engineering) for discussion on remote sensing image analysis. I thank him for his generous help when I have difficulties in reading some journals. To my dear friend, Dr. Tuba Zahra, I thank her for her support and her warm and comfort words. Thanks to Devara Prawira for discussions on the McNemar's test and for sharing knowledge on remote sensing image analysis. Thanks to Aldino Rizaldy for helping me with random sets source code. I wish you all much success in your further carrier. My special thanks go to Dr. Wiwin Ambarwulan, Prof. Junun Sartohadi, Prof. Dewayani Sutrisno, Prof. Jan Sopaheluwakan, Dr. Idwan Suhardi, Dr. Heru Santoso for the most valuable discussions. Thanks also to Dr. Muhammad Helmi for his generous offer to supply images and data for my research. I would like to thank the following companies for their assistance with the collection of my data: Anang Widhi Nirwansyah, Mahmuda, Annisa, and Herry Kusmaywanto. I thank Widhi for hosting me in his home in Semarang. Special thanks for Widhi's mom for providing food during my fieldwork activities and for supporting me with her silent pray.

The Indonesian student community in Esnchede is like a big family. I like to thank all my Indonesia friends with whom I spent an unforgettable time: Aji, Aulia, Rizka, Armen, Ratna, Intan, Ayu, Jarot, Deby Fajar, Heksi, Pak Dadhang, Asti, Andri, July, mbak Dwi, Dr. Habiburrahman, Muthia, and Dr. Hero Marhaento. I would like to thanks all ITC master students from Indonesia that I can not mention you all here, please accept my sincere appreciations. Beyond the scientific world, my heartfelt thanks go to Ibu Dewi Nurhammad for welcoming me in her home and who helped make my stay in Enschede so memorable. I enjoyed wonderful moments that we spent together: cooking, gardening, shopping, and many more. I thank her for her endless support to ensure that I succeed in my study. I wish her a happy life.

I wish to express my gratitude to my family for their physical and mental supports. My heartfelt thanks are to my husband Hermawan Dwi Harnanto for his love and everything he did for me and our children. I also thank my children, Nina and Alief, for their great understanding and support through some difficult times. I thank my brothers and sisters for their support and their good wishes. 


\section{Table of contents}

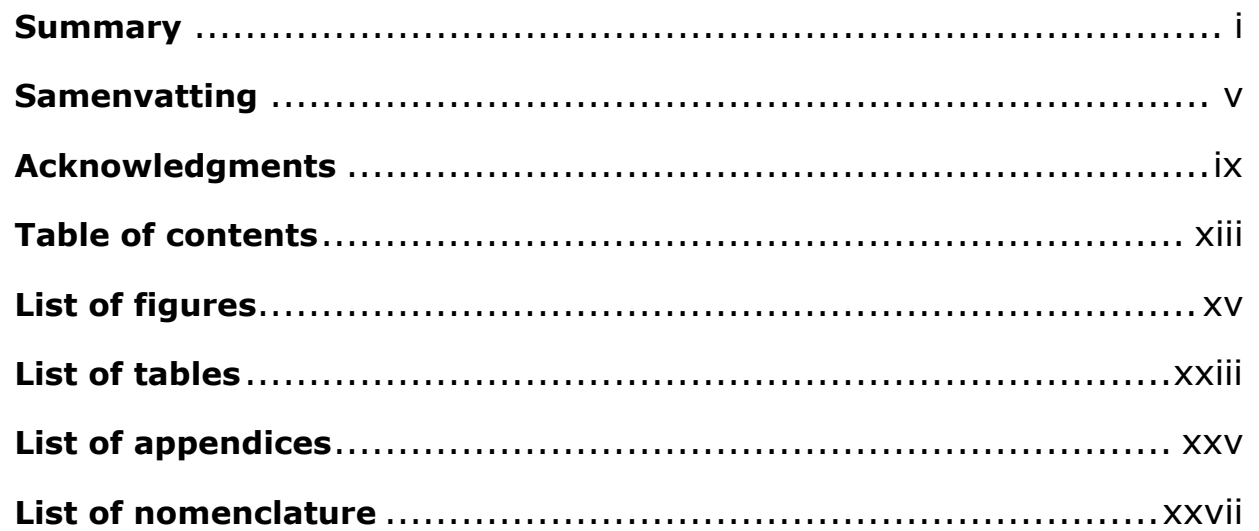

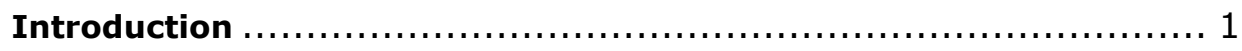

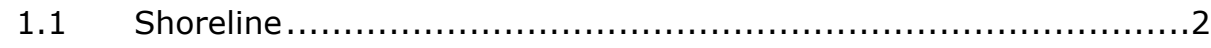

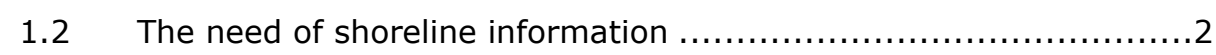

1.3 Monitoring of shoreline change ..........................................

1.4 Methods for shoreline monitoring .................................... 4

1.5 Uncertainty associated with remote sensing classification products

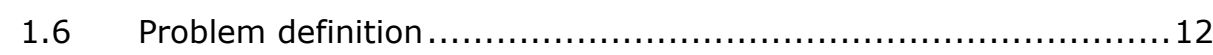

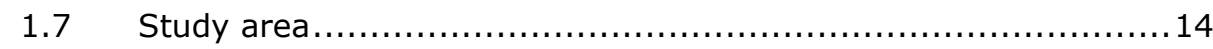

1.8 Research objectives and questions .............................. 16

1.9 Thesis outline ......................................................... 17

Fuzzy Classification for Shorelines Change Monitoring ..............19

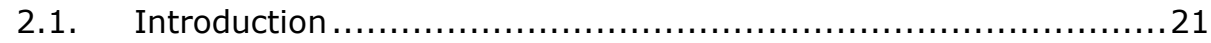

2.2. Fuzzy method for shorelines identification ...........................23

2.3. Shoreline results and the uncertainty estimation ..................... 32 


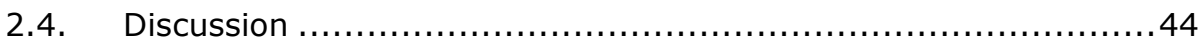

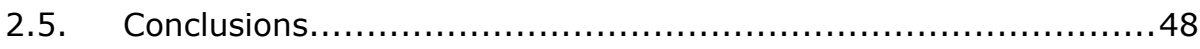

Monitoring Shorelines with Change Vector Analysis ................. 51

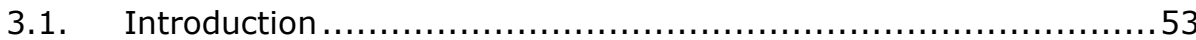

3.2. Shoreline monitoring using fuzzy-crisp object model and CVA......56

3.3. Change detection results and the estimation of uncertainty .........66

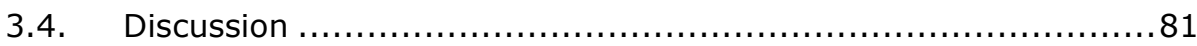

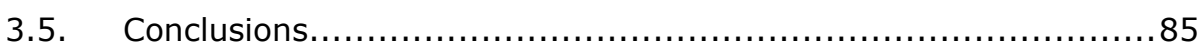

Modeling the Uncertainty of Fuzzy Shorelines ....................... 87

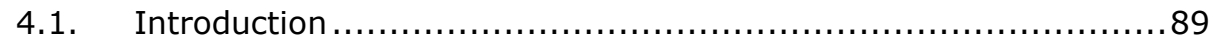

4.2. Modeling shoreline using fuzzy sets and random sets ...............91

4.3. Results and classification comparison............................... 100

4.4. Discussion ....................................................... 110

4.5. Conclusions........................................................... 113

Transferability and Upscaling of Fuzzy Classification .............. 115

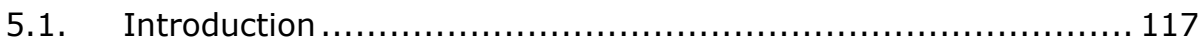

5.2. Transferability and upscaling methods ........................... 118

5.3. Results and assessment of accuracy .............................. 126

5.4. Discussion ....................................................... 136

5.5. Conclusion ........................................................ 140

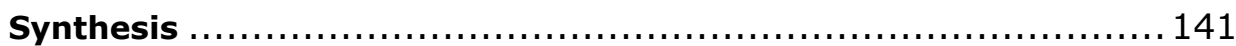

6.1. Research findings and conclusions .............................. 142

6.2. Reflections ....................................................... 147

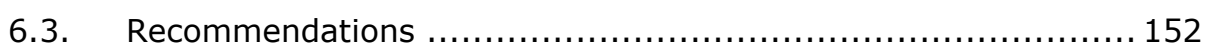

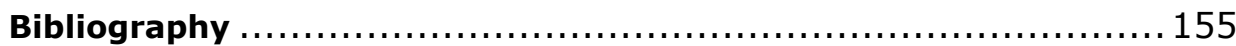

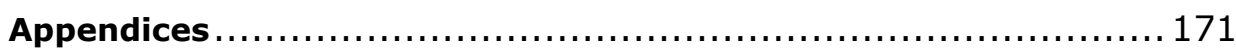




\section{List of figures}

Figure 1.1 Location of the study area, coastal area of Central Java Province. Indonesia. Area 1 was used as the study area in Chapter 2 and 3, while area 2 was used as a test case in Chapter 4. The transferability and upscaling of the methods (Chapter 5) was tested at the whole study area 15

Figure 2.1 Trapezoidal membership function. Area between $\mathrm{b}$ and $\mathrm{c}$ is a core zone which has a membership value equal to 1 to the water class. Area a-b and c-d are transition zones or boundaries which have value between 0 and 1 to the water class, while the pixels with 0 memberships do not belong to the water class ............................................................. 25

Figure 2.2 Topological relationships between two sub-areas. Green polygons represent sub-area $R_{t 1}$ and blue polygons represent

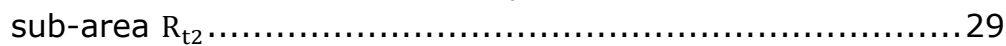

Figure 2.3 (a) Shoreline at time $t_{1}$; (b) Shoreline at time $t_{2}$; (c) Shoreline change estimation considering two categories of changed areas, namely: (A) water to non-water, and (B) non-water to water. Solid lines represent shoreline at $t_{1}$ whereas dashed lines refer to shoreline at $\mathrm{t}_{2}$ 31

Figure 2.4 (a) Shoreline margin at time $t_{1}$; (b) Shoreline margin at time $\mathrm{t}_{2}$; (c) Shoreline change estimation considering six changed areas, namely: (A) shoreline to non-water, (B) water to shoreline, (C) water to non-water, (D) non-water to shoreline, (E) shoreline to water, and (F) non-water to water. Solid lines represent shoreline margins at $\mathrm{t}_{1}$ whereas dashed lines refer to shoreline margins at $\mathrm{t}_{2}$

Figure 2.5 The accuracy assessment results of water class images, generated by applying FCM classification followed by thresholding on the water membership image. The highest $\kappa$ values were obtained from $d=0.5$ for all images, and $d=0.3$ and 0.7 gave a nearly constant $\kappa$ value .......................... 34

Figure $2.6(a-n)$ FCM results show the membership of water class $(a, c, e, g, i, k, m)$, and classified images of water class by setting $d=0.5(b, d, f, h, j, l, n)$. The shrinking of non-water sub-areas over two decades can be identified by the change of the shape 
of the non-water class from wide strips to the thin elongated shapes over the series of images (see $(a-n)$; e.g., grid cells C3). Whereas non-water sub-areas emerged when mangroves were planted (see (i) grid cells C2), and in coastal reclamation areas $($ see $(a, c)$ grid cells A5) ..................................... 35

Figure 2.7 (a-d) The illustration of shoreline as a line; (a) Shorelines (in red colour) created by setting $d=0.5$; (b) the uncertainty of pixels classified as water at the uncertainty level $\leq 0.5$. Generally, pixels closer to the shoreline have a higher uncertainty value (see (d) grid cells C2 and D2) ...............36

Figure 2.8 The illustration of shoreline as a margin; (a) Shoreline margin (blue polygons) generated by giving $d=0.3$ and 0.7 ; (b) the uncertainty of shoreline margin from Equation 2.12; (c) zooming in sub-areas in yellow rectangle based on Figure 2.8a. Shoreline margin was assessed through different levels of uncertainty (UC): (d) $\leq 0.1$; (e) $\leq 0.2$; (f) $\leq 0.3$; and (g) $\leq 0.4$ 37

Figure 2.9 (a-f) Shoreline change analysis at $d=0.5$ Two changes were identified, namely non-water to water and water to non-water. Large areas changed from non-water to water such as due to inundation and erosion which were indicated between 1994 and 2000 (a). Whereas large areas changed from water to non-water and were distinguished between 2000 and 2002 (b)

38

Figure 2.10 (a) Shoreline change uncertainty at $d=0.5$. (b-f) Change uncertainty is highlighted at different levels for the period 1994-2000 for the yellow rectangle site. The number of red pixels indicates that the change uncertainty from water to non-water increase with the increase of uncertainty values, as also can be seen for the blue pixels. 39

Figure 2.11 (a-f) Shoreline change uncertainty at $d=0.5$ and $C U \leq 0.1$ for the period 1994-2015. The extensive inundation has been indicated from 1994 to 2000 (a) and the largest change to non-water occurred in the period 2000-2002 (b)...............40

Figure 2.12 (a-f) The changes of shoreline margin, water and non-water. Six changes were identified including abrupt and gradual changes. An extensive inundation has been indicated from 1994 to 2000 (a), while the large change to non-water occurred in the period 2000-2002 (b) .........................42

Figure 2.13 (a) Shoreline change uncertainty for the period 1994-2000; (b-f) Change uncertainty was measured at different levels for yellow rectangle site. A number of pixels (red, green, and 
blue) increases with the increase in the level of uncertainty. Changes from non-water to shoreline and from water to shoreline were grouped under one label and are presented in shades of green, while changes from shoreline and water to non-water are presented in shades of red. Changes from nonwater and shoreline to water are represented as shades of blue............................................................ 42

Figure 2.14 (a-f) Change uncertainty of shoreline margins and their associated sub-areas at CU level $\leq 0.1$ in the period 19942015. (a) The largest coastal inundation occurred in the period 1994-2000. It was dominated by light blue pixels indicated low change uncertainty values to water. (b) The largest increase in non-water occurred in the period 2000-2002 represented by light red pixels indicated low change

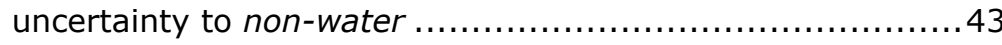

Figure 3.1 Example of classification results using: $\operatorname{FCM}(a, b, c) ; \quad M L C$ classifier $(d, e, f)$; and hardened classification $(g, h, i) .(a-i)$ are the detail presentations of yellow rectangle site in the insert map. Hard classification resulted from alternative methods are of limited use in identifying the transition zone between water and non-water, for example, see grid cells, e.g., B1 and B2 .67

Figure 3.2 FCM results show the membership of: water $(a, b, c)$; and nonwater $(\mathrm{d}, \mathrm{e}, \mathrm{f})$. To derive shoreline position, we combined both membership images using fuzzy-crisp object model $(g, h, i)$. Blue pixels indicate core of water, orange pixels represent the core of non-water and shoreline is represented by light green pixels.

Figure 3.3 The representation of fuzzy-crisp object model: (a) the core of water and non-water objects, and shorelines; (b) confusion index values considered for the quantification of classification uncertainty; and (c) shoreline image with fuzziness represented by confusion index. Detailed presentation of shorelines in red rectangle sites are displayed in (d-f). .......69

Figure 3.4 The magnitude of shoreline change during: 2013-2014 $(a, b)$; and 2014-2015 (c,d). The magnitude values vary from high magnitude represented by dark blue pixels up to low magnitude represented by light blue pixels, whereas light yellow pixels show the no-change areas ..........................70

Figure 3.5 The fuzziness of the shoreline is represented by change confusion values in the periods: 2013-2014 (a,b); and 20142015 (c,d). The change confusion values vary from high values represented by dark orange pixels up to low values 
represented by light orange pixels, whereas light yellow pixels show the no-change areas ................................ 70

Figure 3.6 The representation of shoreline change direction: in the period 2013-2014 (a,b); and in the period 2014-2015 (c,d). Darker colour pixels show a higher frequency of change to a certain direction. Shades of violet pixels depict a positive direction to water membership while shades of green pixels illustrate a negative direction to water membership. Figures in the second row show the magnitude of each change direction category in the period 2013-2014 (e,f); and in the period 2014-2015 $(\mathrm{g}, \mathrm{h})$. Darker colour pixels represent a higher change magnitude while lighter colour pixels show a lower change

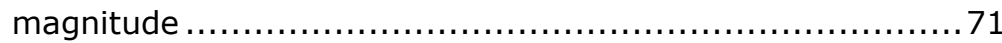

Figure 3.7 Total intensity of confusion indices for each change direction category: in the period 2013-2014 (a,b); and in the period 2014-2015 (c,d). Shades of orange pixels represent change confusion values for the area with positive direction, and shades of grey pixels show change confusion values for the area with negative direction. The change confusion values for the unclear direction category are represented by shades of green, whereas no-change category is depicted by light yellow colour

Figure 3.8 Change detection of shorelines using post classification comparison of MLC results; (a-c) the change of shorelines in three consecutive dates in 2013; (d) shoreline changes from 2013 to 2014; and (e) shoreline changes from 2014 to 2015. Blue polygons show the changes of non-water to water and red polygons display the changes from water to non-water. No-change areas of water and non-water are represented by white and black polygons, respectively 74

Figure 3.9 Post classification comparison of shoreline as the results of hardened classification: $(\mathrm{a}-\mathrm{c})$ the changes of shoreline in three consecutive dates in 2013; (d) shoreline changes from 2013 to 2014; and (e) from 2014 to 2015

Figure 3.10 An example of comparison results between post classification comparison and CVA method. Both methods agree on change results of the area in yellow polygons that show a change from water to non-water ( $a, b)$ which equal to negative direction $(c, d)$ with high change magnitude $(e, f)$ .75

Figure 3.11 Multi-year pattern of water membership changes showing a high change direction to positive direction (see dark violet pixels in black-dashed polygons in $(a, b)$ ) and high change magnitude (see dark blue pixels in black-dashed polygons in 
$(c, d))$. RGB 542 of Landsat images show a decrease of vegetation coverage from 2013 to 2015 (see white-dashed ellipses in $(e-g))$ 76

Figure 3.12 Water membership changes showing a continuous change to negative direction (see dark green pixels in black-dashed circles in $(a, b)$ ) with high change magnitude (see dark red pixels in black-dashed circle in $(c, d))$. RGB 542 of Landsat images show an increase of sediment and mangrove coverage from 2013 to 2015 (see white-dashed circle in $(\mathrm{e}-\mathrm{g})$ ) .........77

Figure 3.13 The location shows an unclear direction (see pink pixels in black-dashed circle in (a)), while in the period 2014-2015 the location shows a low change to positive direction (light violet pixels in black-dashed circle in (b)). The change magnitude values were low in the period 2013-2014 (c), while in the period of 2014-2015 the values were high (see dark blue pixels in black-dashed circle in (d)). Images made available by Google Earth $(\mathrm{e}-\mathrm{g})$ show the decrease of mangrove coverage .78

Figure 3.14 The embankment (shown by red arrows) for protecting the settlements $(a-c)$. (c) shows the river and settlements built on the river banks prone to high tides from both the sea and the river .79

Figure 3.15 Water membership changes showing a higher change to positive direction (see dark violet pixels in black rectangle sites in $(a, b)$ ) with low change magnitude values (see dark blue pixels in black rectangle sites in $(c, d))$ 80

Figure 3.16 Water membership changes show a low change direction to positive direction in the period 2013-2014 (a); and to negative direction in the period 2014-2015 (b). The change magnitude values were low in both periods $(c, d)$. This type of change was also observed as small patches of the coastal land (see black rectangle sites in $(b, d)$ ) 80

Figure 4.1 Study area is presented here as a false colour composite of a Pleiades image with red colour representing the vegetation, bluish green showing water area, and greyish and white pixels showing the built-up area. Yellow rectangles represent several the selected sites for this work, and black-dashed rectangles show four groups of subsets. 94

Figure 4.2 Density functions of shoreline object and related mixed Gaussian model ............................................. 96

Figure 4.3 Focal elements with their equal uncertainty assignments $\mathrm{u} 1=$ $\mathrm{u} 2=\mathrm{u} 3$ to construct a realization of random sets $(a)$; and 
covering function of the random sets (b). These figures are adapted from Zhao et al. (2010)............................... 99

Figure 4.4 Comparison of the fuzzy classification results between: Pleiades $(\mathrm{a}, \mathrm{c})$; and Pleiades + DTM (b,d). Pleiades $0.5 \mathrm{~m}(\mathrm{e})$; and elevation data (f) are displayed to interpret the attribute of yellow points. In $(\mathrm{c}, \mathrm{d})$, we can see that Pleiades misclassified pixels as water instead of roofs (non-water), as can be seen in (e) 102

Figure 4.5 An example of inundated land that was: incorrectly classified by Pleiades $(a, c)$; and classified successfully by Pleiades + DTM (b,d). Pleiades $0.5 \mathrm{~m}(\mathrm{e})$; and elevation data (f) are presented to interpret the yellow points

102

Figure 4.6 The shoreline as the transition zone between water and nonwater (a); the fuzziness of the shoreline is represented by the confusion index denoting the uncertainty of pixels to be classified to the largest membership (b); zooming into the white-dashed rectangle sites (c); and shoreline image with fuzziness represented by the confusion index (d). 104

Figure 4.7 Estimation of threshold interval for random sets based on the optimal $n$ selected for each subset. Threshold interval $=0.3-$ 0.7 generally produced the highest $\kappa$ value. $\mathrm{S}_{\mathrm{a}-\mathrm{b}}$ : the name of subsets, $a$ is the group number $(a=1, \ldots, 4)$ and $b$ is the subset number $(b=1, \ldots, 13)$ 104

Figure 4.8 The curve of differences between two successive standardized core sets $\delta_{\mathrm{i}}$. When $\delta_{\mathrm{i}}$ is in the range -1 to +1 , we determined this $\varphi$ value for performing random sets (see notations in Figure 4.7 for the name of subsets) 105

Figure 4.9 Samples of the random sets with various extents and their covering function. (a-e) Samples are at $\mu w k=0.3-0.7$. Pixels in white indicate the water area and pixels in black indicate the non-water area. (f) The related covering functions, where 0 indicates a low probability and 1 indicates a high probability to be covered by the random sets. Various extents of focal elements at each binary map can be seen when zooming into the yellow rectangle site. 106

Figure 4.10 Statistical distribution of area of focal elements sampled from 13 random sets (see notations in Figure 4.7 for the name of subsets) 106

Figure 4.11 The set-theoretic variance (a); some examples of the contour of $\Gamma_{1}, \Gamma 0.5$ and $\Gamma_{0}$ (b); and a detail representing the yellow rectangle sites as an example of contours with a broad 
variation (c); and contours with a small variation indicating a narrow shoreline $(\mathrm{d})$.

Figure 4.12 An example of a random set: the core set $\Gamma_{1}$ and its contour (a); the support set $\Gamma_{0}$ and its contour (b); the set-theoretic variance image (c); the transition zone between water and non-water represented by the set-theoretic variance values (d); and zoom-in to the yellow rectangle site (e). 109

Figure 5.1 Location of subsets for each land use/cover class in the city of Semarang, Kendal and Demak... 120

Figure 5.2 Four subsets with various sizes were used to upscale the method to a larger study area. Subset $s_{1}(a)$ is a reference subset while the others are target subsets (b-d). False natural colour composite of 2017 Landsat image is used for visualisation. Dark blue represents water area, green refers to vegetation, and shades of pink refer to built-up. 122

Figure 5.3 Three subsets to test the transferability of the method to different areas. $s_{1}$ and $s_{5}$ are dominated by water and agriculture area while $\mathrm{s}_{1}$ is dominated by water and urban area. 123

Figure 5.4 $\kappa$ values to estimate threshold interval for generating the shoreline margin. The curves show that values of $\mathrm{d}$ larger than 0.7 and lower than 0.3 produced more erratic curves indicating low $\kappa$ values. Threshold interval [0.3, 0.7] generally provides high $\kappa$ values. Similar curves were obtained when estimated the $\kappa$ for all images $\left(I_{1}\right.$ up to $\left.I_{10}\right)$ 126

Figure 5.5 Image $I_{10}$ is used to show the comparison of shoreline images developed at the reference subset (a) and the target subsets (b-d). We zoom into an area in the red rectangle site (e-h) to see a variation of shoreline margins (in turquoise) each time we upscaled the method to a larger area. The larger the area, the larger the deviation of shoreline margin from its reference subset.... 128

Figure 5.6 The comparison of the resulting class means of subsets $s_{1}$ up $\mathrm{s}_{4}$ to for image $\mathrm{I}_{10}$. The mean values of water class are slightly decreasing when we upscaled the method to larger areas both in NIR and SWIR bands. Whereas, mean values of non-water class are decreasing in NIR band and increasing in SWIR band for subsets $s_{1}$ up to $s_{3}$ 128

Figure 5.7 Shoreline margin generated by transferring the shoreline model to target subsets for image $\mathrm{I}_{10}$. Subset $\mathrm{s}_{1}$ (a) as the reference subset is used to estimate FCM parameter at target 
subsets (b-c). We zoom into an area in the red rectangle site $(d-f)$ to see a variation of shoreline margin 129

Figure 5.8 The comparison of the initial and final $V_{i}$ when we transfer the method from subset $s_{1}$ to subsets $s_{5}$ and $s_{6}$. FCM update the initial $V_{i}$ considering the existing land use/cover of the area. The decrease of $V_{i}$ of water class in NIR band is related to the increase of clear water and the increase of $\mathrm{V}_{\mathrm{i}}$ of non-water class in SWIR band might be due to the increase of built-up area in subset $s_{6}$ 130

Figure 5.9 Subset $s_{6}(a)$ is used as the reference subset to estimate FCM parameter of subsets $s_{1}$ and $s_{5}(b-c)$. We zoom into red rectangle sites to see detailed representation of the area (d-f). The applied method failed to identify water area in subset $s_{1}$ (e) for e.g., grid cells A2, A3, and B2 and also failed to identify shoreline margin in subset $s_{5}$ (f) near vegetation areas for e.g., grid cells A1 and B1 .................................... 130

Figure 5.10 The comparison of the initial and final $V_{i}$ when we transfer the method from subset $s_{6}$ to subsets $s_{1}$ and $s_{5}$. There is a small variation of the water class means both in NIR and SWIR band from the reference subset to both target subsets. Meanwhile, there is a large variation of the non-water class specifically the non-water 2 in NIR band from subset $s_{6}$ to subsets $s_{1} \ldots \ldots . .131$

Figure 5.11 The spatial distribution of shoreline changes in the east section of the study area for consecutive dates. The changed area was getting larger in the recent images from 2000 up to 2017 reflecting the severity of inundation in the area.

Figure 5.13 Shoreline change (a-b) and its related change certainty (c-d) between 1988 and 2017. Large changes from non-water into water (turquoise) indicating a permanent inundation of the area are mostly related to the high certainty of change into water (dark green), whereas large changes of non-water into shoreline (red) might indicate the area which was inundated gradually. 136 


\section{List of tables}

Table 2.1 Landsat images from three different sensors (Thematic Mapper, Enhanced Thematic Mapper, Operational Land Imager/Thermal Infrared Sensor) supplemented by astronomical tide level, and reference data. All images were captured in the low tides ........2 24

Table 2.2 Mean vector of two subsets in the infrared bands of 2015 Landsat image. The labelling of $c_{1}$ or $c_{2}$ as water was determined by assessing the sum of the mean vector cluster .....................26

Table 2.3 The accuracy of unsupervised FCM classification applied at selected parameter $m=1.7$ and $d=0.3,0.5$ and 0.7 . For all images, $\mathrm{d}=0.5$ obtained the highest $\kappa$ values, $\mathrm{d}=0.7$ produced slightly lower $\kappa$ values, and $d=0.3$ resulted in the lowest $\kappa$ values ........ 33

Table 2.4 Changed area (in number of pixels) between water and nonwater at different change uncertainty levels (see yellow rectangle site in Figure 2.10a). The number of pixels increases with the increase of change uncertainty values. Obvious changes were observed by a change uncertainty value $\leq 0.1$

Table 2.5 Changed area (in ha) between water and non-water at $\mathrm{d}=0.5$ and $\mathrm{CU} \leq 0.1$ during the period 1994-2015. Inundation has been distinguished during four periods (1994-2000, 2002-2003, 2003-2013 and 2014-2015), while change to non-water has been identified for two periods (2000-2002 and 2013-2014) ...40

Table 2.6 Changed area (in the number of pixels) between shoreline margin, water and non-water at different uncertainty levels (see yellow rectangle site in Figure 2.13a). Obvious changes were observed for a level of uncertainty $\leq 0.1$

Table 2.7 Changed area (in ha) at $C U \leq 0.1$ in the period 1994-2015. The largest change from non-water to water due to coastal inundation occurred in the period 1994-2000, and the largest change from water to non-water due to different planting periods in an agricultural area occurred in the period $2000-2002 \ldots \ldots \ldots \ldots \ldots .44$

Table 3.1 Landsat 8 OLI/TIRS images captured in the low tides supplemented by tide level and reference images used in the accuracy assessment purpose for each period .56 
Table 3.2 The spectral band information of Landsat 8 OLI/TIRS used in image classifications, Pleiades, SPOT 6 and Sentinel 2 used as reference images 57

Table 3.3 The procedure to estimate change directions of shoreline. It quantifies the variation of water membership in each pixel and shows how frequent the changes have occurred 64

Table 3.4 Summary of the overall classification accuracy using FCM, MLC and hardened classification

Table 3.5 Change area (in ha) for each change category in the period of 2013-2014 and 2014-2015. 72

Table 4.1 The characteristics of Pleiades image used......................92

Table 4.2 The statistical parameter of random sets .......................99

Table 4.3 The accuracy comparison between Pleiades and Pleiades + DTM using FCM classification with thresholding $(c=2, m=1.6, d=0.5)$. The inclusion of DTM in classifications clearly improved the classification results. $\mathrm{S}_{\mathrm{a}-\mathrm{b}}$ : the name of subsets, $\mathrm{a}$ is the group number $(a=1, \ldots, 4)$ and $b$ is the subset number $(b=1, \ldots, 13) \ldots 103$

Table 4.4 The quantification of the extensional uncertainty of the all subsets (the SV is the sum of variance, and CV denotes the coefficient of variance). See notations in Table 4.3 for the name of subsets 107

Table 4.5 The accuracy comparison between Pleiades and Pleiades + DTM by random sets (see notations in Table 4.3 for the name of subsets) 110

Table 5.1 Images used in this study and their related reference data .... 119

Table 5.2 The overall accuracy indicating the water membership agreement between the reference subset $s_{1}$ and the target subsets $\left(s_{2}\right.$ up to $s_{4}$ ) estimated using fuzzy error matrix for images $I_{1}, I_{6}$, and $I_{10}$

Table 5.3 The accuracy assessment results of shoreline images at threshold $\mathrm{d}=0.5$ generated from two reference subsets $\left(\mathrm{s}_{1}\right.$ and $\left.\mathrm{s}_{6}\right)$ 131

Table 5.4 The accuracy assessment results after thresholding at thresholds $\mathrm{d}=0.5$ for the whole study area

Table 5.5 Changed area (in number of pixels) between shoreline margin, water and non-water at different levels of certainty for the east section

Table 5.6 Change area in $\mathrm{km}^{2}$ in the period 1988 up to 2017 with change certainty level $\geq 0.1$. Changes to water indicate erosion and changes to non-water show accumulation. The coastal area in the east section experienced the largest lost of land in three decades 


\section{List of appendices}

Figure 4A.1 The estimation results of $c$ and $m$ for FCM classification ..... 173

Figure 4A.2 The estimation of threshold interval for $\mathrm{c}=2$ and various $\mathrm{m}$ values for FCM classification ........................... 175

Figure 4A.3 The shoreline as the transition zone between water and nonwater (Column 1); confusion index images (Column 2); zooming into the white-dashed rectangle sites (Column 3); shoreline images with fuzziness represented by the confusion index (Column 4)

Figure 4A.4 The curve of differences between two successive standardized core sets $\delta \mathrm{i}_{\mathrm{i}}$ 179

Figure 4A.5 Samples of the random sets with various extents and their covering functions 181

Figure 4A.6 The set-theoretic variance and the contour of random sets 183

Figure 4A.7 An example of random sets; the core set $\Gamma_{1}$ and its contour (column 1); the support set $\Gamma_{0}$ and its contour (column 2); the transition zone between water and non-water represented by the set-theoretic variance (column 3); zooming into the yellow rectangle sites (column 4 ) 185

Figure 5A.1 Histograms of optimal values of $m$ (left) and c (right) obtained after performing cluster validity measures on seven land

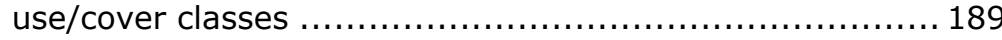

Figure 5A.2 The optimal $m$ values of the reference subset $\left(s_{1}\right)$ with $c=2$ as the optimal c chosen by CVI for all images.... 190

Figure 5A.3 The optimal $\mathrm{m}$ values as a result of upscaling towards larger areas by using $s_{1}$ as the reference subset and the optimal $c=2$ was obtained for all these target subsets. 190

Figure 5A.4 The optimal $m$ values as a result of transferability to other areas by using $s_{1}$ as the reference subset. We obtained $c=2$ as the optimal $\mathrm{c}$ value for all images....

Figure 5A.5 Shoreline images of the east section. The extent of non-water area has decreased over three decades, while water area has expanded. In this section, coastal erosion and inundation has caused a substantial loss of coastal land 192 
Figure 5A.6 Shoreline images of the middle section. An extensive change of shoreline is obvious due to reclamation activities for e.g. in the western part of the images while some other places gradually eroded started from 1994

Figure 5A.7 Shoreline images of the west section. The changes of shoreline position in this section are relatively small, however small gain of non-water area can be seen in the eastern part of the image due to land reclamation project 194

Figure 5A.8 The spatial distribution of shoreline changes in the middle section for consecutive dates. A large gain of non-water areas (in green) was obvious in the periods 1988-1991 and 19941997 (see the west part of the site), while a subtle change into water (in turquoise) was shown in the period 1997-2000 and 2009-2013. 195

Figure 5A.9 The spatial distribution of shoreline changes in the west section for consecutive dates. A small gain of non-water can be seen in the periods 1988-1991 and 2013-2017 at the eastern part of the site while erosion due to the changes into water are visible in the periods 1997-2000 and 2009-2013. In general, the areas show small changes of non-water, water and shoreline margin indicating a steady condition of the coastal environment. 196

Table 4A.1 The cluster validity index showing the compactness and the separateness among all clusters (applied using $m=1.6$ ) $\ldots . .173$

Table 4A.2 The results of McNemar's test showing the significance of the different accuracies given by Pleiades and Pleiades + DTM $(\alpha=0.05)$ in FCM classification with thresholding ............ 176

Table 4A.3 The optimal $\varphi$ selected for each threshold interval and the related $\kappa$ values for generation of random sets 179

Table 4A.4 The results of McNemar's test showing the significance of the different accuracies given by Pleiades and Pleiades + DTM $(\alpha=0.05)$ in random sets (see notations in Table 4A.2 for $f_{11}$,

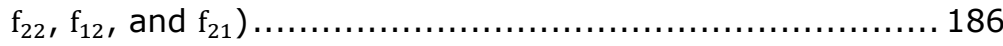

Table 4A.5 The results of McNemar's test showing the significance of the difference given by fuzzy sets and random sets $(\alpha=0.05)$ by using Pleiades .... 187

Table 4A.6 The results of McNemar's test showing the significance of the difference given by fuzzy sets and random sets $(\alpha=0.05)$ using Pleiades + DTM data (see notations in Table 4A.5 for f11, f22, f12, and f21) 188

Table 5A.1 The overall accuracy indicating water membership agreement between the reference $\left(s_{1}\right)$ and target subsets ( $s_{2}$ up to $s_{4}$ ) estimated using the fuzzy error matrix. 


\section{List of nomenclature}

\section{Abbreviation}

AHHW

ASTER

AWEI

CVA

DTM

DVEL

ETM

EVI

FCM

FERM

GCP

GIS

GPS

HWL

IR

ISODATA

LIDAR

LSWI

MDGs

MHW

MLC

MLLW

MODIS

MIR

MSL

NDWI

NIR

NOAA

NOS

$\mathrm{OA}$

OLI/TIR

RMSE
Approximated higher high water

Advanced Spaceborne Thermal Emission and Reflection

Radiometer

Automatic water extraction index

Change vector analysis

Digital terrain model

Difference Value between EVI and LSWI

Enhanced thematic mapper

Enhanced vegetation index

Fuzzy c-mean

Fuzzy error matrix

Ground control point

Geographic information system

Global positioning system

High water line

Infrared

Iterative self-organizing data analysis

Light detection and ranging

Land surface water index

Millennium development goals

Mean high water

Maximum likelihood classification

Mean lower low water

Moderate resolution imaging spectroradiometer

Middle infrared

Mean sea level

Normalized difference water index

Near infrared

National Oceanographic and Atmospheric Administration

National Ocean Service

Overall accuracy

Operational land imager/thermal infrared sensor

Root mean square error 
SDGs

SIM

SPOT

SRM

SVM

SWIR

TM

USGS
Sustainable development goals

Semantic import model

Satellite Pour I'Observation de la Terre

Similarity relation model

Support vector machines

Shortwave infrared

Thematic mapper

United States Geological Survey

\section{Symbols}

$A_{i=j}$

$A(k)$

$\beta$

$B\left(R_{t 1}\right)$

$C$

CC

$\mathrm{CH}_{t_{1}, \mathrm{t}_{2}}$

CI

$C U_{t_{1}, t_{2}}$

CVI

$C_{i}$

$C_{w}$

CV

$\delta$

d

$D$

$d_{w k}$

$\Delta C V$

$\|\Delta C V\|$

$E\left(R_{t 1}\right)$

$E A(\Gamma)$

$f(k)$

$f_{11}$

$f_{12}$

xxviii
Agreement between classified and reference images

Change area of a specific change category

Area of pixel $k$ equal to $30 \times 30\left(\mathrm{~m}^{2}\right)$

Image number

Boundary of area $R_{t 1}$ identified at $t_{1}$

Number of clusters

Number of change combinations when using CVA

Net shoreline changes between $t_{1}$ and $t_{2}$

Confusion index

Uncertainty of pixels belonging to the specified sub-

areas in $t_{1}$ and $t_{2}$

Cluster validity index

Class $i$ for random set

Water class image

Coefficient of variation

Differences between two successive standardized core

sets

Threshold value for shoreline generation

The types of change direction for CVA

Decision function for water class of pixel $k$

Change vector of shoreline image between two years

Total membership differences between two years

representing magnitude of the changes

Exterior of area $R_{t 1}$ identified at $t_{1}$

Mean area of random set

Intensity value of an image

Number of samples with incorrect classification using

both methods

Number of samples that are incorrectly classified by the 


\begin{tabular}{|c|c|}
\hline$f_{21}$ & $\begin{array}{l}\text { Number of samples that are correctly classified by the } \\
\text { first method or the first image but incorrectly classified } \\
\text { by the second method or the second image }\end{array}$ \\
\hline$f_{22}$ & $\begin{array}{l}\text { Number of samples with correct classification using both } \\
\text { methods }\end{array}$ \\
\hline$F$ & Random sets \\
\hline$G$ & Stack of shoreline images within year $t_{1}$ \\
\hline$\Gamma$ & Random set \\
\hline$\Gamma_{\mathrm{m}}$ & Mean set of random sets \\
\hline$\Gamma_{\mathrm{v}}$ & Set theoretic variance of random sets \\
\hline$\Gamma_{\alpha}$ & The $\alpha$-set of random sets \\
\hline$\Gamma_{1}$ & Core set of random sets \\
\hline$\Gamma_{0.5}$ & Median set of random sets \\
\hline$H$ & Stack of shoreline images within year $t_{2}$ \\
\hline$I\left(R_{t 1}\right)$ & Interior of area $R_{t 1}$ identified at $t_{1}$ \\
\hline I & Image within window $W$ \\
\hline$k_{s}$ & $\begin{array}{l}\text { Number of pixels used to generate the fuzzy error } \\
\text { matrix }\end{array}$ \\
\hline K & Kappa \\
\hline$\mu_{i k}$ & $\begin{array}{l}\text { Membership value of } k^{t h} \text { pixel to class } i \text { in the classified } \\
\text { image }\end{array}$ \\
\hline$\mu_{i k}^{1}, \mu_{i k}^{2}$ & $\begin{array}{l}\text { The first and the second highest membership values of } \\
\text { class } i \text { in pixel } k\end{array}$ \\
\hline$\mu_{j l}$ & $\begin{array}{l}\text { Membership values of } l^{\text {th }} \text { pixel for class } j \text { in the reference } \\
\text { images }\end{array}$ \\
\hline$\mu_{w k}$ & Water membership value of pixel $k$ \\
\hline$m$ & Level of fuzziness \\
\hline $\min _{i, k}\left\|V_{i}-V_{k}\right\|$ & Minimum distance between the means of the classes \\
\hline$M$ & Intersection matrix \\
\hline$M_{i}$ & Mean value of class $i$ for random sets \\
\hline$n$ & Number of bands in an image \\
\hline$\varphi$ & Number of focal elements \\
\hline$N$ & Number of pixels \\
\hline $\mathrm{N}$ & Normal distribution \\
\hline$O_{i}$ & Focal element of random set for class $i$ \\
\hline$\pi_{x}(u)$ & Degree of possibility \\
\hline$\Pi_{C}, N_{C}$ & $\begin{array}{l}\text { Possibility and necessity measures related to the } \\
\text { imprecise position of the shoreline }\end{array}$ \\
\hline$P_{k}(C h)$ & $\begin{array}{l}\text { Number of pixels belonging to the area of a specific } \\
\text { change category }\end{array}$ \\
\hline$P_{k}\left(C h_{A}\right), P_{k}\left(C h_{B}\right)$ & Number of pixels belonging to the change area $A$ and $B$ \\
\hline $\operatorname{Pr}_{\Gamma}$ & Covering function of random sets \\
\hline
\end{tabular}

first method or the first image but correctly classified by the second method or the second image first method or the first image but incorrectly classified by the second method or the second image methods

Random sets

Stack of shoreline images within year $t_{1}$

Set theoretic variance of random sets

$\alpha$-set of random sets

Stack of shoreline images within year $t_{2}$ Interior of area $R_{t 1}$ identified at $t_{1}$

Image within window $W$

Number of pixels used to generate the fuzzy error matrix

Membership value of $k^{\text {th }}$ pixel to class $i$ in the classified image class $i$ in pixel $k$

Membership values of $l^{\text {th }}$ pixel for class $j$ in the reference images

Water membership value of pixel $k$

Level of fuzziness

Minimum distance between the means of the classe

Intersection matrix

Mean value of class $i$ for random sets

Number of bands in an image

Number of focal elements

Number of pixels

al distribution

Degree of possibility

Possibility and necessity measures related to the change category

Covering function of random sets 


$p$
$Q$
$R$
$\mathcal{R}$
$\mathcal{R}_{i}, \ldots, \mathcal{R}_{n}$
$\Sigma_{i}$
$S_{a-b}$
$S V$
$\Theta_{i}$
$T C V$
$t_{1}, t_{2}$
$u_{i}$
$U_{c}\left(R_{t 1}\right)$
$v_{i}$
$\left(v i_{c 1}\right)_{I R}$
$\left(v i_{c 2}\right)_{I R}$
$V_{i}$
$W$
$X$
$\chi^{2}$
$Z$
$Z$

Number of shoreline image pairs

Stack of confusion images within year $t_{1}$ Stack of confusion images within year $t_{2}$ Random variable

Threshold values to generate random sets Standard deviation of class $i$ for random sets

Name of subsets, $a$ as group number, and $b$ as subset number

Sum of variance

Weight coefficient for $C_{i}$ for random sets

Total change vector Image recorded at date 1 and 2 for change detection Uncertainty assignments

Uncertainty of pixel $k$ belonging to sub-area $R_{t 1}$ at $t_{1}$ Mean vector for class $i$

Sum of mean vector for the first class in the infrared bands

Sum of mean vector for the second class in the infrared bands

Mean of the classes

Window

Sample of the $N$ pixels on an image

McNemar's test

The number of shoreline images for CVA

Intensity value of an image 


\section{Introduction}

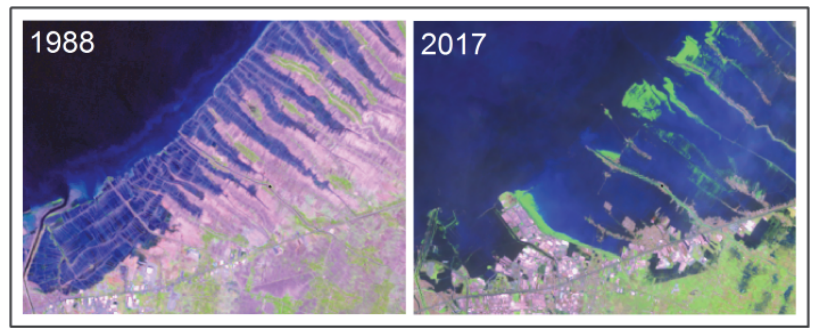

This chapter motivates the scope of this work in terms of the importance of shoreline monitoring and the information that is needed to enable their sustainable. It defines shoreline and mentions a number of benefits derived from monitoring of shoreline positions. It continuous with a description of methods applied for shoreline identification. This proceeds with the introduction of the challenges constraining the identification of shoreline in remote sensing images. The chapter ends by setting objectives and research questions to be addressed throughout the rest of the thesis. 


\subsection{Shoreline}

A shoreline represents the boundary where the land meets the sea. It is a dynamic environment as the land and sea are changing in response to natural (e.g., erosion, accretion, waves, daily tides and sea-storms) and human-induced (such as coastal development) factors (French, 2001). The positions of the shoreline could vary between a few centimetres to a few metres on short term, depending on beach profile, the tidal range and the prevailing wave. On a longer term, the position of the shoreline could vary by hundreds of metres (Boak and Turner, 2005; Stive et al., 2002b).

In the literature, the terms shoreline and coastline are found. The strips of land adjacent to shorelines and coastlines are shores and coasts, respectively. The shore denotes a relatively narrow strip of land adjacent to water bodies, whereas the coast is a strip of land that extends from a body of water inland to a regional break in terrain features (Bird, 1985; Oertel, 2005). Bird (1985) stated that the shore is usually occupied by salt-marshes and mangrove swamps found at various inter-tidal levels and the coastline is equivalent to the high spring tides shoreline. Furthermore, Oertel (2005) mentioned that the shoreline demarks the boundary between the shore and the water varying between the low and the high tides.

In this thesis, the term shoreline is italized when it denotes class name during an image classification. Italizing is applied in similar way for other land use/cover classes such as water, non-water and builtup.

\subsection{The need of shoreline information}

The dynamic interfaces between the coastal land and the sea are commonly sites of high density residential and commercial development. Coastal areas are popular for settlement, because of their beauty, access to relatively flat, low lying land for agriculture and water for fisheries and transport. However, natural hazards frequently occur such as flooding, storm, coastal erosion, and tsunami. Some shoreline changes have resulted from these human activities, such as land reclamation for industry, housing, recreation site, farmland and airport; and dredging to create and deepen harbours. Furthermore, coastal communities tend to keep the 
boundary of land and sea in the same location to protect their belongings by introducing structures such as groynes and breakwaters intended to stabilize features.

The increase in the number of inhabitants and the related increase of infrastructure have an impact on the coastal processes that further shape the shoreline. In fact, coastal processes in one part of the shore have a close link to those in its neighbourhood with respect to sediment budget (French, 2001). While coastal populations continue growing and infrastructures are threatened by coastal hazards, the need for shoreline information is increasing.

Both coastal management and coastal engineering require information about the shoreline and its changing position. Shoreline information is required for the design of coastal protection, coastal planning and development and safe navigation. Furthermore, the current and historical positions of the shoreline are key information to understand coastal processes, anticipate climate change and prevent any development in high risk areas. By analysing data over a period of time, we can determine where and how fast the coast has changed, which can help coastal planning in the future.

\subsection{Monitoring of shoreline change}

Monitoring of shoreline position is an important element of planning and management of the coast. Monitoring can be undertaken on various spatial and temporal levels since shorelines can change over a wide range of different temporal and/or spatial scales (Hayden et al., 1979; Stive et al., 2002a). On a short term, the shoreline can change over periods ranging from days to seasons for instance due to waves, winds, tides, and storms. Meanwhile on a long term, the changes may be caused by a rise in sea level, land subsidence, and a change in natural sediment supply. This long term variation can only be observed after several years (in decades to centuries) and results in more predictable trends (Dolan et al., 1991). Given these facts, monitoring of shoreline changes should have sufficient temporal frequency and duration to differentiate short term from longer term variability (Bracs et al., 2016).

Shoreline position is one of the primary geo-indicators for monitoring coastal changes as the shoreline is sensitive to natural processes (e.g., fluvial processes, water quality, sea level and sediment supply) 
and anthropogenic alteration (e.g., construction of coastal structures, construction of river dams, and mining of coastal materials). A long term natural advance of shoreline position implies a decrease in wave energy, an increase in sediment supply, or a low relative sea level. On the contrary, a natural retreat of shoreline position indicates an increase in wave energy, a decrease in sediment supply, a rise in sea level, or a combination of those causes (Morton, 2002). Monitoring the changes of shoreline position over a long time span will enable coastal planners and resources managers to provide such information that play an important role in balancing the demand for exploitation and preservation of the coastal environment. Furthermore, the significance of shoreline position as coastal geo-indicators increases when they are integrated with human safety for example for coastal hazard maps and risk analysis in the context of disaster risk reduction. Before being able to reduce risk, we need to understand the hazards. Hazard maps (e.g., coastal erosion and inundation maps) are used to identify high-risk zones and safe places for a community, for instance for relocating exposed people and assets away from an area highly effected by erosion or flooding.

The frequency of monitoring of shoreline changes can vary from place to place depending on shoreline conditions. Much of the shoreline remains in a relatively undisturbed condition so that it can be monitored less frequently. In contrast, other shorelines may be situated in a highly urbanized area with greater threat from erosion and coastal floods, which may require more frequent monitoring. The frequency of monitoring can also be influenced by the need of observation. For example, a swash zone study may need to observe shoreline positions in seconds, while a long-term analysis of shoreline change may require a 10-year observation. In the Netherlands, for coastal defence monitoring, coastline position is measured and compared to the reference standard annually as a basis for the annual sand nourishment programme (Anonymous, 2006b). Meanwhile, for the national assessment of shoreline change in the United States, the U.S. Geological Survey plans to report on shoreline changes every five to ten years (Morton et al., 2004).

\subsection{Methods for shoreline monitoring}

Shoreline position can be extracted from various data sources. Historical shoreline positions may be derived from old topographic maps or may be digitized from aerial photographs based on physical 
features (Pajak and Leatherman, 2002). Shoreline can be interpolated from cross-shore profile measured by beach surveys (Anonymous, 2006a). Furthermore, shoreline can also be derived from remote sensing imagery.

Shoreline position can be identified based on different shoreline indicators or proxies depending on topography of the area, the sources of data, and scientific preferences. For example, for navigational purposes, the National Oceanographic and Atmospheric Administration (NOAA) publishes nautical charts with shoreline is positioned at mean lower low water (MLLW) line (NOAA, 2018). Meanwhile, for the National Shoreline, US.Geologic Survey publishes topographic quadrangle with the shoreline positioned at mean high water (MHW) line (Li et al., 2002; Oertel, 2005).

The most common shoreline indicators can be summarized as follows (Boak and Turner, 2005; Crowell et al., 1991):

a) Distinguished coastal features which can be classified based on the alignment of man-made structures e.g., landward edge of shore protection structures; morphological features (berm crest, vegetation line, dune toe, and dune crest); and a selected waterline (high water line/HWL or previous high tide level, and wet/dry line or wet and sand line). These features are delineated from aerial photographs or very high resolution images.

b) Tidal datum based indicators (tide-coordinated shoreline) e.g., MHW or MLLW lines. It is determined by intersecting the coastal profiles with a certain vertical elevation defined by tidal components. This information can be derived from LIDAR data and ground surveys data (cross-shore profile).

c) Shoreline features extracted by image processing techniques from remote sensing imageries e.g., water/non-water pixels or wet/sand pixels. This shoreline is considered as an instantaneous shoreline and can be derived from hyperspectral, multispectral and RADAR imageries.

Shoreline position can be monitored using a range of methods as described below.

\subsubsection{Ground survey-based method}

In the early years, ground survey-based method to derive shorelines in the United States used devices e.g., plane tables, which can obtain a high accuracy. In this surveys, the direction and distance of shoreline features were observed and determined by at least four 
persons on beach with the plane table and rod (Graham et al., 2003). The shorelines were drawn through series of measured points. At this time, the HWL was considered as the best indicator of the land-water interface. It was mapped by NOS (National Ocean Service) topographer as the shoreline position in the Topographic sheet (Crowell et al., 1991). Other equipment for this method may include kinematic differential Global Positioning System (GPS) mounted on a vehicle, which is driven at a constant speed along the visibly distinguished line of interest (Morton et al., 1993). The advantage of this method compared to use of plane tables is that it is a relatively rapid method (Stockdon et al., 2002).

Survey data can provide accurate shoreline positions, however, the historical data tend to be limited both spatially and temporally (Boak and Turner, 2005). Moreover, they are high-cost (both in time and money) and labour-intensive methods (Anonymous, 2006b; Morton et al., 1993).

\subsubsection{Aerial photograph-based method}

Since the late 1920s, aerial photograph-based method started to replace ground survey-based methods to monitor shoreline changes, but only since the late 1930s stereo aerial photographs became available. This method became the primary technique since it can cover wider areas with good accuracy (Li et al., 2004; Moore, 2000).

In the early days, the method included visual interpretation of shoreline features from aerial photographs and manually digitized shorelines. The shoreline obtained from the photographs is based on a visually distinguished feature such as the MHW line (Graham et al., 2003), the wet and sand line (Fisher and Overton, 1994), and the edge of vegetation (Ford, 2013). This line was determined more from physical appearance (approximated the line of the MHW) rather than precisely measured ( $\mathrm{Li}$ et al., 2002). In fact, the MHW line is determined by running levels along the coast and it estimates the average height of the high water level (HWL) over the period of 18.6 years (Pugh, 1987).

At present, modern photogrammetry allows a scanned pair of aerial photo to be converted into a three-dimensional digital terrain model and a georectified orthophoto (Boak and Turner, 2005). Hence, a tide-coordinated shoreline can be determined accurately. However, aerial photographs taken at these water levels are more expensive than remote sensing imageries ( $\mathrm{Li}$ et al., 2004) and the temporal 
coverage is site specific (Boak and Turner, 2005). Furthermore, the process of shoreline identification from aerial photographs has several potential sources of error, for instance the distortion of the photographs, the georeferencing of permanent features, and human error in measuring and digitizing (Crowell et al., 1991; Fisher and Overton, 1994; Moore, 2000; Thieler and Danforth, 1994). At present time, shorelines are still determined through interpretation of the stereo-photogrammetric models of aerial photographs, however, new methods for monitoring of shoreline changes are increasingly available (Liu, 2009).

\subsubsection{LIDAR-based method}

Airborne LIDAR (Light Detection and Ranging) is an active remote sensing system which has the ability to cover a wide coast area in a short time. The United States has been mapping shoreline using LIDAR since 1996 (NOAA, 2014). The LIDAR system is operated by using laser light to illuminate the terrain and measures a highly accurate elevation. LIDAR acquisition should be planned at a low tide condition (e.g., neap tides) with a calm and low wave (Stockdon et al., 2002). Shoreline position can be extracted by intersecting the digital elevation model derived from LIDAR data with the desired tidal datum (tide-coordinated) or tide level indicators. Robertson et al. (2004) derived shorelines by generating contours on a DEM derived from LIDAR based on tide level (high water/HW) and tidal datums (mean higher high water/MHHW and MHW lines) obtained from nearby tide gauges. Kim et al. (2017) analyzed shoreline changes by using airborne LIDAR bathymetry and derived MHHW (approximated higher high water/AHHW) shorelines. In this regard, the choice of the specific datum depends on the use of the LIDAR-derived shorelines. If this LIDAR-derived shoreline will be compared with other historical shorelines, then the same datum should be used accordingly (Stockdon et al., 2002). Despite the main advantage of LIDAR that can cover a large area in a short amount of time, this data source is generally limited in its temporal and spatial availability because it is costly. Furthermore, weather conditions can affect the recording of the LIDAR system (Anonymous, 2006b; Boak and Turner, 2005).

\subsubsection{Satellite image-based method}

Nowadays, remote sensing data have become increasingly popular for the monitoring of shoreline changes due to their large coverage and low cost. Remote sensing data can extract shoreline features e.g., water/non-water or wet/dry pixels to derive shorelines. 
Shorelines derived from remote sensing imageries are considered as instantaneous shorelines since the time of acquisition of those images barely corresponds with a specific tidal datum (e.g., MHW or MHHW). However, remote sensing techniques can objectively define a proxy (not only visually distinguished) of shoreline features (Boak and Turner, 2005). In the end, this will support the robustness and repeatability of the extraction of shoreline methods.

Several image classification techniques exist to identify shoreline features. A review of methods for identification of shoreline features permits to identify three approaches as described below.

\section{a) Band ratios}

Ratios of different spectral bands from the same image have been used to identify shoreline proxies in remote sensing images. This is because band ratios can enhance spectral reflectance characteristics for certain features such as water, soil and vegetation (Richards, 2013). For the case of shoreline extraction, the presence of water features is enhanced while other features are minimized. In the estimation, the band ratio method uses visible and infrared bands of multi-spectral images. Further, a histogram thresholding approach is applied in the determination of foreground and background pixels which represent shoreline features (water and land). Unfortunately, using two bands for band ratios can only enhance water without removing completely the non-water features (Xu, 2006).

Several works have investigated this approach to monitor shoreline changes using different combination of band for example ratioing band 5 and band 2 (b5/b2) of Landsat TM and ETM (Ervita and Marfai, 2017; Kuleli, 2010; Sarwar and Woodroffe, 2013), and combination of band 2 and band 4 (b2/b4) and band 2 and band 5 (b2/b5) of Landsat TM (Masria et al., 2015; Ozturk et al., 2015).

\section{b) Water index method}

McFeeters (1996) proposed normalized difference water index (NDWI) to discriminate open water. The method uses the green band (band 2) and near-infrared/NIR (band 4) of Landsat TM. It assists to enhance the presence of water, while simultaneously eliminating soil and terrestrial vegetation. In the results, water features have positive values; whereas soil and vegetation features have zero and negative value, respectively. Xu (2006) proposed modified NDWI by replacing the NIR band with the middle infra red band (MIR) in order to remove the noise from built-up in the coastal area. Further, Feyisa et al. 
(2014) proposed a new automatic water extraction index (AWEI) to improve the classification accuracy for shadow and dark surfaces.

In literature, these methods have been used to extract shoreline features and develop binary images consisting of water and land. To derive shoreline position from these water indices images, many studies used threshold segmentation e.g., the OTSU method (Choung and Jo, 2016; Kuleli, 2010; Liu et al., 2017), manual digitizing (Ghosh et al., 2015), and Kittler algorithm (Wang et al., 2014). However, the choice of threshold in defining water and land is still a problem (Feyisa et al., 2014; Sunder et al., 2017) that causes the classification to be more time-consuming.

\section{c) Unsupervised and supervised classification methods}

Various unsupervised and supervised methods are used to monitor the changes of shoreline. The principal idea of unsupervised classification is that pixels within a group have intensities with similar spectral pattern. ISODATA (Iterative Self-Organizing Data Analysis) is the most common unsupervised classification that has been used to identify the shoreline proxies e.g., the wet and dry sand (GarcíaRubio et al., 2015; Sekovski et al., 2014). ISODATA is a clustering algorithm that requires the user to set values for various classification parameters. It is suggested to set a higher number of classes for coastal areas with various land covers and lower number of classes for those areas with only a few land cover types (Liu et al., 2011a). However, a problem may arise when the spectral separability among classes is low (Andrieu, 2018).

Meanwhile, another group of image classification to generate shoreline position and its changes is supervised classification which requires relevant training areas based on a priori knowledge of the users of study area characteristics. Several studies on this method include support vector machines (SVM) (Hannv et al., 2013; Kalkana et al., 2013; Yin and He, 2011) and maximum likelihood classification (MLC) (Duru, 2017; Sekovski et al., 2014; Tamassoki et al., 2014). Since supervised classification takes advantage of information provided from training samples, the classification works effectively. However, to collect a sufficient number of reliable training samples is time-consuming and costly in operational scenarios which in the end can affect the final accuracy of the products (Demir et al., 2014). 


\subsection{Uncertainty associated with remote sensing classification products}

The concept of uncertainty arises when discussing the imperfection that is inherent to all remote sensing products. Heuvelink (1998) indicates that uncertainty is "...synonymous with error". Atkinson and Foody (2002) argue that uncertainty is "...a general concept and one that actually conveys little information". Meanwhile, Shi (2010) refers uncertainty to "...vagueness, ambiguity, or anything that is undetermined".

Uncertainty may exist for many reasons. Taylor (1982) mentioned that the uncertainty arises because of a problem in definition. Uncertainty can also occur due to inability to measure precisely. Fisher (1999) divides the nature of uncertainty into vagueness, ambiguity and error. Vagueness is associated with fuzziness (Atkinson and Foody, 2002), and lack of clarity in meaning (Klir and Wiennan, 1999; Shi, 2010) thus it should be handled with fuzzy sets (Fisher, 1999; Klir and Wiennan, 1999). Ambiguity refers to uncertainty due to the difference in classification system and perception of objects (Fisher, 1999) and is related to crisp sets (Atkinson and Foody, 2002). Meanwhile, Heuvelink (1998) defines error as the difference between reality and our representation of reality. When objects can be clearly identified then the sources of uncertainty are in data measurements and processing (Atkinson and Foody, 2002; Shi, 2010) and can be handled by the probability theory (Taylor, 1982).

Problems in several stages of processing are associated with the uncertainty in remote sensing products including: the type of information and how to define the information, the scale that is required, the nature of the input and its quality, the area to be mapped and the accuracy of the resulting map (Woodcock, 2002). Meanwhile, Shi (2010) mentioned four sources of uncertainty: inherent uncertainty in the real world, the limitation in human knowledge, the limitation of measurement technology in capturing spatial data, and the potential of generating and propagating uncertainty in the spatial data processing and analysis. Furthermore, uncertainty in remote sensing products is also related to the quality aspect of spatial data. Quality is defined as "...totality of characteristics of a product that bear on its ability to satisfy stated and implied needs" (ISO (2002) citing Oort (2005)). The elements of spatial data quality include for example positional, attribute, and 
semantic accuracies, temporal and variation in quality, logical consistency, lineage, completeness, and resolution (Oort, 2005).

By limiting the discussion to the analysis of shorelines from remote sensing data in this thesis, the uncertainty can be divided into three categories: attribute, existential, and extensional uncertainties. Attribute uncertainty (also termed thematic or categorical uncertainty) shows how close the attribute value of geographic entity is to its reference value (Shi, 2010). Existential uncertainty is uncertainty regarding the existence of the object due to the fact that e.g., image analysis can only suggest that an object might exist without giving definite certainty that it really exists (Molenaar, 2000). Meanwhile, extensional uncertainty refers to the uncertainty related to the spatial extent of the objects (Molenaar, 1998). For shorelines derived from image classification, uncertainties can arise from: (1) the nature of the shoreline, (2) the applied shoreline definition, (3) differences in applied threshold value for segmentation, (4) tide conditions during image acquisition, and (5) the application of image classification and change analysis methods.

The boundary between water and land can not be defined exactly due to for example the degree of wetness of the beaches. Moreover, shoreline is vague in nature as its position is changing through time. In this regard, the existential uncertainty of shoreline will arise when we select a method that does not accommodate the vagueness of the shoreline. For this reason, a fuzzy set-based classification method was selected to represent spatial object with vague properties (Shi, 2010; Zadeh, 1965). In this context, the existence of an object to be observed is measured by a membership function that represents the similarity of an element to a class.

The definition of shoreline applied in this study is a potential source of uncertainty, in particular of attribute uncertainty. Shoreline position in the real world is complex and always changing. We have to select a proxy that can represent shorelines that can be captured by remote sensing. Choosing shoreline as a single line (e.g., HWL) will introduce uncertainty resulting from a short-term natural migration of the shoreline due to e.g., wave and tide actions. Moreover, HWL may appear as a gradational zone of change (Stockdon et al., 2002). In this case, defining shoreline as an area may reduce the uncertainty resulting from the instantaneous position of the shoreline captured by remote sensing images. 
The application of image classification (e.g., the choice of optimal threshold value for shoreline delineation) may cause uncertainties related to the extensional uncertainty. For a crisp object, there are three possible situations that define the boundary to a related object: inside or outside an object or part of the boundary of an object (Molenaar, 1998). Whereas, for a fuzzy object (e.g., fuzzy shorelines), these three situations can not be determined clearly. For this situation, the boundary can only be established for specified certainty (conditional boundary) by selecting certain threshold values (Cheng, 1999).

Attribute uncertainties may also arise from the application of image classification and change analysis. The main uncertainty refers to the attribute accuracy defined as the accuracy of all attributes of a spatial data set by excluding positional and temporal attributes (Oort, 2005). For quantification of this uncertainty, an accuracy assessment i.e. confusion error matrix is frequently used. However, this error matrix does not provide the spatial variation of the accuracy. For shoreline margin in images, uncertainty is expected to be higher towards the boundary then in the core area of the margin. Uncertainty measures at pixel level can provide more information on how the quality of remote sensing products varies spatially. Increasingly studies are interested in the spatial variation of the associated uncertainty (Bogaert et al., 2017; Brown et al., 2009). Failure to characterize uncertainty may cause erroneous and misleading interpretations.

\subsection{Problem definition}

The emergence of new and low-cost satellites that make a large number of satellite images available to a wide community has greatly influenced the advancement of image-based methods for monitoring of shoreline changes. Although several image processing techniques are available, it is still a challenge to implement a soft classificationbased method for shorelines detection and monitoring their changes. Methods used for shoreline extraction from remote sensing images are mostly based on hard classifications while the use of soft classification is very limited. Given the nature of the shoreline, the use of soft classification is a logical choice and this dissertation aims to lessen the hurdles that have prevented the use of soft classification in monitoring application like this. 
Some issues considering shoreline detection and monitoring using remote sensing images are:

\section{a) The nature of shorelines}

A shoreline which represents the boundary between the land and the sea is vague in nature. To determine the exact position of this boundary is problematic since there is no sharp transition from the land to the water for example when defining an instantaneous shoreline from remote sensing images. The instantaneous shoreline is the position of the land-water interface at one moment in time which can be defined as the waterline at various stages of the tides. During the rise and fall of the tide, there are an infinite number of shorelines (Oertel, 2005). Furthermore, the shoreline is vague as its position changes over time due to the dynamics of the water level. The quantification of shoreline positions or the interface between the land and the water may involve a number of assumptions. Therefore, all estimates should include uncertainties associated with e.g., the nature of shoreline, techniques for image analysis and the assumption made regarding the definition of the shoreline.

\section{b) Data availability}

Shoreline can be detected by a range of methods: in-situ geographic positioning systems, airborne LIDAR, and video imaging which provide a highly accurate elevation and nearcontinuous shoreline data. All of those methods are valuable sources for detailed investigation of coastal processes. However, for monitoring coastal areas on a wider spatial scale and a long time span, these systems are relatively costly and limited in coverage. LIDAR data are also not available over long time spans. Moreover, the budget available for purchasing those data (e.g., in developing countries) may be limited. Therefore, it is important to explore alternative ways for extracting shorelines from satellite imagery which can cover wider spatial scales and longer time spans. Landsat missions, for example, have long historical record of space based moderate-resolution remote sensing data, making it possible to assess coastal dynamics over decades and over large areas.

\section{c) Coastal characteristics and land use/cover complexity}

A coastal area is not a constant environment, but it is rather a dynamic place that can change rapidly in response to processes such as seasonal weather patterns and human activities. These 
processes are responsible for shaping and modifying coastal areas by eroding, transporting and depositing sediment. Their dynamic nature results in their diversities. Many types of coasts are found ranging from sandy beaches, muddy coasts, rocky coasts, coral coasts, and arctic coasts. Some of those coasts are heavily populated, while some others have low building and population densities. For this study, these different types of coast with various complexity of land use/land cover correspond to the uncertainty issues with respect to the choice of parameters in image classifications. Therefore, developing a robust shoreline model for different coastal characteristics is challenging.

\subsection{Study area}

The northern part of Java was chosen as the study area in order to demonstrate the usefulness of the developed methods. The area is situated along the north coast of Central Java Province, Indonesia, covering some part of Semarang city in the west and Demak regency in the east (Figure 1.1). The study area is a deltaic plain formed by sand and silt from the rivers. The site is a typical tidal area with a high density of rivers. Rural settlements are found along the riverbanks or adjacent to the shorelines. The rivers have been used for irrigation purposes for centuries since the area is a paddydominated agricultural area. In addition, the area at the northern edge of the land is dominated by fishponds. The Central Java Province is well known as one of the largest milkfish producers in Indonesia.

The coast along the north of Java is categorized as a low waveenergy coast and influenced by the micro-tidal Java Sea (Ongkosongo, 2010) with an average tidal range of approximately $1.0 \mathrm{~m}$ (BIG, 2017). The coast has a mixed semi-diurnal tide with two high tides and two low tides with varying heights. In general, the study area is relatively flat with elevation of less than $10 \mathrm{~m}$ above mean sea level (MSL). It has muddy coast with mudflats at certain locations and a gradual transition between water and land. Intertidal areas (the areas between tide marks) generally extend for about 1 $\mathrm{km}$ with muddy substrate (Winterwerp et al., 2014). 


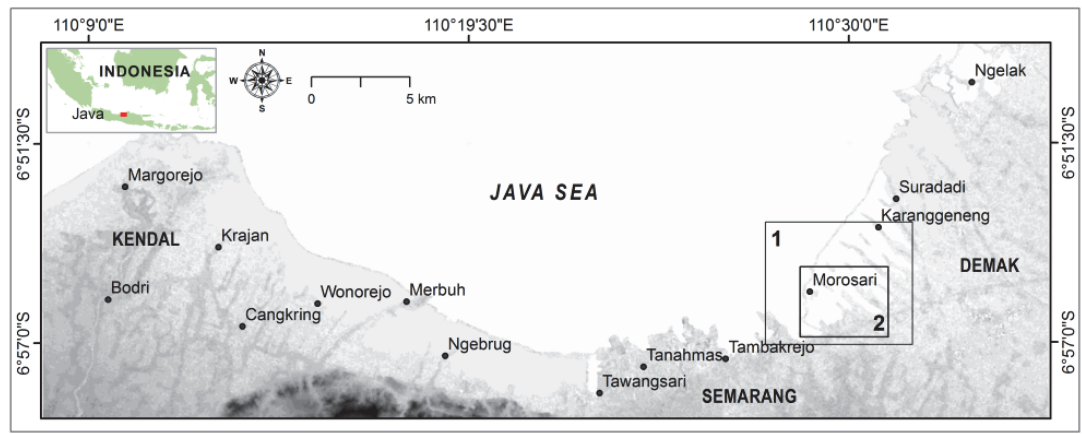

Figure 1.1 Location of the study area, coastal area of Central Java Province. Indonesia. Area 1 was used as the study area in Chapter 2 and 3, while area 2 was used as a test case in Chapter 4 . The transferability and upscaling of the methods (Chapter 5 ) was tested at the whole study area

The study area is prone to frequent inundations at high tide. Two types of flood occur in the area: (a) floods caused by a tidal flood; and (b) floods due to poor drainage systems during rainy seasons (Harwitasari and van Ast, 2011; Marfai et al., 2008b). This contributed to an extensive change of shoreline in the study area over more than 20 years. Furthermore, the change of shoreline position is also caused by other natural processes (e.g., erosion and accretion) and by the development of man-made structures (e.g., beach reclamation and extended seaport). The productive fishponds and rice fields have been submerged and abandoned as swamp areas due to these extensive changes.

The coastal inundation accelerating these changes has increased recently in terms of frequency and duration as a result of many factors, for instance, extreme winds, land subsidence, the rise of sea level, mangrove conversion and excessive ground water extraction (Harwitasari and van Ast, 2011; Kurniawan, 2003; Marfai and King, 2007; Sarbidi, 2001). Several measures have been taken to minimize the impact of large changes of shoreline position. The efforts include for example embankment along the drainage system near the settlements, dredging the drainage channels, elevating roads and house floors, building a permeable dam as sediment traps, and mangrove planting. 


\subsection{Research objectives and questions}

The main objective of this research is to develop and apply image analysis methods to identify shorelines and monitor their changes. To achieve this main objective, the following specific objectives and questions are addressed:

a) Develop a method for detecting shorelines by taking the gradual transition between water and land into account.

Research questions:

i. Can fuzzy sets-based theory be applied effectively to extract a fuzzy shoreline?

ii. Can random sets be applied effectively to extract a fuzzy shoreline?

iii. Can a digital elevation model be used effectively to improve shoreline extraction?

b) Develop a method for spatio-temporal change detection and monitoring of fuzzy shorelines.

Research question:

How can fuzzy approaches be used for spatio-temporal change detection and monitoring fuzzy shorelines?

c) Determine the uncertainty of spatial and temporal information on shoreline positions in objectives 1 and 2 .

Research questions:

i. How can the uncertainty of the developed and implemented methods be estimated?

ii. How can the spatial accuracy of the developed and implemented methods be assessed?

d) Test the transferability and upscaling of the methods developed in objective 1 and 2 to a different area and to a larger area of land.

Research question:

Can the method developed in objective 1 and 2 be transferred and upscaled to another area and towards a larger area? 


\subsection{Thesis outline}

This thesis consists of six chapters. Chapter 1 contains an introduction of the research. Chapters 2 up to 5 are based on the scientific output of the research that has been published by, or submitted to ISI journals. Chapter 6 contains a synthesis of the research. The six chapters are organized as follows:

a) Chapter 1 provides a general introduction of this thesis. It describes definition of shoreline and the importance of shoreline information including a variety of methods available to extract and monitor shoreline changes.

b) Chapter 2 presents a method to identify fuzzy shorelines by taking into account the gradual transition between water and land. Two types of shorelines were presented: shoreline as a single line and shoreline as an area or margin.

c) Chapter 3 describes a change detection method for shorelines which account for their fuzzy character in remote sensing images. The change of shoreline was explained in terms of change magnitude and change direction using change vector analysis.

d) Chapter 4 compares shoreline models developed from a fuzzy classification with random sets. Fuzzy sets theory describes uncertainty associated with the vagueness of shoreline position, whereas random sets deal with uncertainty due to random phenomena.

e) Chapter 5 investigates a framework to test the transferability and upscaling of the developed method to a larger and to a different area.

f) Chapter 6 summarizes the results and conclusions obtained from this research including answers related scientific questions. It describes the main contributions of this study to the shoreline research and to research on monitoring of fuzzy boundaries and gives further recommendation for future studies. 


\section{Fuzzy Classification for Shorelines Change Monitoring}

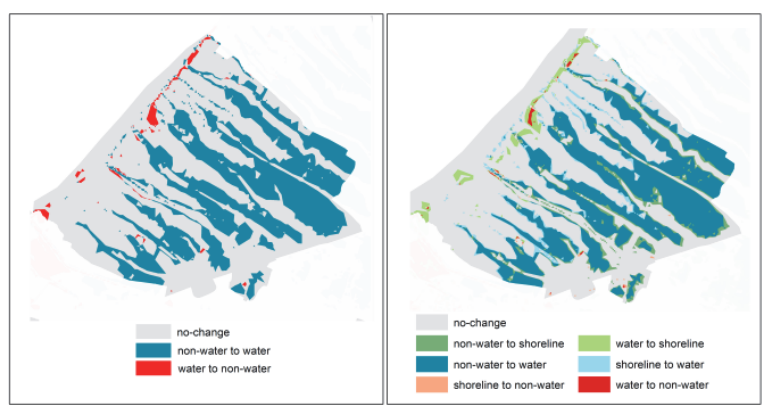

This chapter presents two methods to identify shoreline positions: as a line and as a margin, including a measure of change uncertainty at different epochs. Shoreline changes can be detected by both methods. The shoreline as a margin provides a more detailed estimation of change area than the shoreline as a line. By having shoreline as a margin, its spatial extent can be assessed and its change uncertainty can be measured at different levels of uncertainty.

This chapter is based on the published paper: Dewi, R.S., Bijker, W., Stein, A., Marfai, M.A., Fuzzy Classification for Shoreline Change Monitoring in a Part of the Northern Coastal Area of Java, Indonesia. Remote Sensing. 2016, 8, 190. 


\section{Abstract}

This study presents an unsupervised fuzzy $c$-means classification (FCM) to observe the shoreline positions. We combined crisp and fuzzy methods for change detection. We addressed two perspectives of uncertainty: (1) uncertainty that is inherent to shoreline positions as observed from remote sensing images due to its continuous variation over time; and (2) the uncertainty of the change results propagating from object extraction and implementation of shoreline change detection method. Unsupervised FCM achieved the highest kappa ( $\kappa$ ) value when threshold $(d)$ was set at 0.5 . The highest $\kappa$ values were 0.96 for the 1994 image. For images in 2013, 2014 and 2015, the $\kappa$ values were 0.95. Further, images in 2003, 2002 and 2000 obtained $0.93,0.90$ and 0.86 , respectively. Gradual and abrupt changes were observed, as well as a measure of change uncertainty for the observed objects at the pixel level. These could be associated with inundations from 1994 to 2015 at the northern coastal area of Java, Indonesia. The largest coastal inundations in terms of area occurred between 1994 and 2000, when 739 ha changed from nonwater and shoreline to water and in 2003-2013 for 200 ha. Changes from water and shoreline to non-water occurred between 2000 and 2002 (186 ha) and in 2013-2014 (65 ha). Urban development in flood-prone areas resulted in an increase of flood hazards including inundation and erosion leading to the changes of shoreline position. The proposed methods provided an effective way to present shoreline as a line and as a margin with fuzzy boundary and its associated change uncertainty. Shoreline mapping and monitoring is crucial to understand the spatial distribution of coastal inundation including its trend.

Keywords: shoreline change; fuzzy classification; coastal inundation; uncertainty; Indonesia 


\subsection{Introduction}

Shoreline location and its change in position are critical for understanding coastal structures (Vaidya et al., 2015), safe navigation (Ali, 2010; Li et al., 2002), sustainable coastal resource management (Klemas, 2011), and for flood protection and other risk management (Dean and Dalrymple, 2002; Dolan et al., 1991). Furthermore, shoreline mapping and monitoring can help to understand the spatial distribution of coastal inundation including its trend over time.

In the literature, shoreline is defined as an intersection of coastal land and water surface indicating water edge movements as the tides rise and fall (Bird, 1985; Boak and Turner, 2005; Davidson-Arnott, 2010). Even though shoreline position can be defined as the waterline at various stages of the tides, e.g., high tide, mid tide, and low tide, the shoreline is largely associated with the sea level (Oertel, 2005). Ideally, the shoreline is the physical interface of land and water with its position changing through time (Doland et al. (1980) in Boak and Turner (2005)). Its change results from long-term, cyclic and random variation. Long-term variation includes variation due to sediment storing or due to the relative sea level rise. Cyclic variation is a combination of seasonality and tide, whereas waves, storms and floods cause random variation of a local character.

To properly extract trends from shoreline positions has been a subject of considerable interest. Due to the dynamic nature of the shoreline, shoreline indicators were used as a proxy to represent the "true" shoreline position. Boak and Turner (2005) and Gens (2010) distinguished: (1) a feature that can be distinguished in a coastal imagery; for example, the high water line (HWL) (Gorman et al., 1998; Leatherman and Eskandary, 1999); (2) the intersection of a tidal datum with a coastal profile, such as the mean high water (MHW); and (3) proxy shoreline features extracted from digital images at the coast, e.g., water and non-water pixels following a binary classification (Chen and Chang, 2009; Ghosh et al., 2015).

Ground surveys and photogrammetry have been used widely to detect shoreline position ( $\mathrm{Li}$ et al., 2002). Both methods are relatively expensive and time consuming, hence data derived from remote sensing platforms are widely used nowadays (Boak and Turner, 2005). Wang (2004) and Dewan and Yamaguchi (2008) applied the optimal threshold values to separate water and non-water by giving 
different cut-off values for each dataset of Landsat TM images. Senthilnatha et al. (2012) used a genetic algorithm and particle swarm optimization to distinguish the water from the non-water region, based on time-series analysis of images. Martinis et al. (2013) applied spectral indices EVI (Enhanced Vegetation Index), LSWI (Land Surface Water Index) and DVEL (Difference Value between EVI and LSWI) to detect water on MODIS data. Ouma and Tateishi (2007) and Ghosh et al. (2015) generated a water index to produce a binary class of water and non-water, then manually digitized the result to produce a shoreline map. Other methods such as post-classification comparison (Tamassoki et al., 2014), binary slicing ( $\mathrm{Li}$ and Damen, 2010), masking operation and visual interpretation (Ford, 2013; Marfai et al., 2008a) have been implemented to derive shoreline change maps.

Many studies on shoreline mapping used hard classifications, whereas few studies exist for fuzzy classification of shorelines (Muslim et al., 2006; Taha and Elbeih, 2010). A hard classification assigns a single label to a pixel, thus allocating each pixel to the class to which it has its highest membership. This could be misleading, because a shoreline is by definition the physical interface of coastal land and water surface with its position changing through time. There is a transition zone between water and land, and hence the boundary is imprecise. In addition, manual digitizing methods are time consuming, costly and labour intensive as they are associated with the large amount of image data required for shoreline mapping and monitoring. Because of these limitations, this study explores fuzzy classification in deriving proxy shoreline features from digital images. Moreover, to map the dynamic shoreline positions and to extract their changes requires the handling of uncertainty. Most studies regarding shoreline change detection explored uncertainty modelling with a focus on aerial imagery (RI'o and Gracia, 2013; Yao et al., 2015b) and a statistical uncertainty analysis (Genz et al., 2007; Maiti and Bhattacharya, 2009). Our study focuses on: (1) inherent uncertainty due to continuous variation of a shoreline over time; and (2) uncertainty as it propagates from extraction and implementation of the shoreline change detection method.

To deal with these uncertainties, fuzzy $c$-means classification developed by Bezdek et al. (1984) was applied. Unsupervised FCM for two classes (water and non-water) is expected to support a rapid mapping of shoreline changes and give an accurate shoreline position by allowing multiple memberships for a pixel. The current study extends that approach by including tide condition. Thus, a change 
detection method was implemented to distinguish abrupt and gradual changes at the object level and provide the change uncertainty at the pixel level.

The objective of this study was to develop a fuzzy method that is useful for detecting shoreline changes from multi-temporal images by taking the gradual transition between water and land and the tides into account. The method, based on fuzzy classification and change uncertainty, will be described by means of possibility and necessity measures. The method is applied to an area in Java, where the northern coastal area of Sayung sub-district experienced a severe change of shoreline position.

\subsection{Fuzzy method for shorelines identification}

\subsubsection{Satellite images and data pre-processing}

Landsat images from three different sensors were used to monitor the shoreline change between 1994 and 2015. Landsat has a 16-day revisit time, and passes Indonesia at approximately 02.00-03.00 GMT. Six spectral bands of Landsat TM and ETM and seven spectral bands of Landsat OLI/TIRS were used. Spectral bands of Landsat TM and ETM applied in this research cover the blue $(0.45-0.515 \mu \mathrm{m})$, green $(0.525-0.605 \mu \mathrm{m})$, red $(0.63-0.69 \mu \mathrm{m})$, near infrared $(0.75-$ $0.90 \mu \mathrm{m})$, short wave infrared $1(1.55-1.75 \mu \mathrm{m})$ and shortwave infrared $2(2.09-2.35 \mu \mathrm{m})$ parts of the electromagnetic spectrum. In addition, the spectral bands of Landsat OLI/TIRS included in FCM consisted of coastal and aerosol $(0.43-0.45 \mu \mathrm{m})$, blue $(0.45-0.51$ $\mu \mathrm{m})$, green $(0.53-0.59 \mu \mathrm{m})$, red $(0.64-0.67 \mu \mathrm{m})$, near infrared (0.85-0.88 $\mu \mathrm{m})$, shortwave infrared 1 (1.57-1.65 $\mu \mathrm{m})$ and shortwave infrared $2(2.11-2.29 \mu \mathrm{m})$. Table 2.1 shows the images used in this study supplemented by tidal data. Tidal data in accordance with the time of acquisition of the images was collected from the Indonesia Geospatial Information Agency.

Pre-processing consisted of histogram minimum adjustment to reduce the effect of atmospheric path radiance (Hadjimitsis et al., 2010; Mather, 2004), followed by geo-referencing using >100 ground control points (GCP) that were carefully selected on both Landsat and ortho-rectified WorldView-2 images from road intersections, building corners, wall boundaries, river and other prominent features, and resampling to a $30 \mathrm{~m}$ pixel size using the nearest neighbour resampling 
method and third order polynomial transform algorithm. The root mean square error (RMSE) was less than 0.1 pixels.

Table 2.1 Landsat images from three different sensors (Thematic Mapper, Enhanced Thematic Mapper, Operational Land Imager/Thermal Infrared Sensor) supplemented by astronomical tide level, and reference data. All images were captured in the low tides

\begin{tabular}{|c|c|c|c|c|}
\hline $\begin{array}{l}\text { Acquisition } \\
\text { Date }\end{array}$ & $\begin{array}{l}\text { Acquisition } \\
\text { Time (GMT) }\end{array}$ & Sensor & $\begin{array}{l}\text { Astronomical } \\
\text { Tide Level }(\mathrm{m})\end{array}$ & Reference Data \\
\hline 11 Nov 1994 & $02: 02$ & TM & -0.321 & $\begin{array}{l}\text { Topographic map, } 1994 \\
\text { (published on 2000) }\end{array}$ \\
\hline 5 Dec 2000 & $02: 41$ & ETM & -0.215 & $\begin{array}{l}\text { QuickBird image } \\
\text { acquired on } 3 \text { May } 2003\end{array}$ \\
\hline 11 Dec 2002 & $02: 36$ & ETM & -0.364 & $\begin{array}{l}\text { QuickBird image } \\
\text { acquired on } 3 \text { May } 2003\end{array}$ \\
\hline 2 April 2003 & $02: 36$ & ETM & -0.118 & $\begin{array}{l}\text { QuickBird image } \\
\text { acquired on } 3 \text { May } 2003\end{array}$ \\
\hline $\begin{array}{l}27 \text { August } \\
2013\end{array}$ & $02: 50$ & OLI/TIRS & -0.054 & $\begin{array}{l}\text { Pleiades image acquired } \\
\text { on } 27 \text { February } 2013\end{array}$ \\
\hline 8 April 2014 & $02: 48$ & OLI/TIRS & -0.025 & $\begin{array}{l}\text { Image via Google Earth } \\
\text { acquired on } 1 \text { July } 2014\end{array}$ \\
\hline $\begin{array}{l}26 \text { March } \\
2015\end{array}$ & $02: 47$ & OLI/TIRS & -0.109 & $\begin{array}{l}\text { Field measurement } \\
\text { (2015) }\end{array}$ \\
\hline
\end{tabular}

\subsubsection{Fuzzy c-means classification and parameter estimation}

The FCM iterative clustering method developed by Bezdek et al. (1984) was performed on the images to discriminate the land and water classes. FCM separates data clusters with fuzzy means and fuzzy boundaries allowing for partial membership. Let $X=\left\{x_{1}, x_{2}, \ldots, x_{N}\right\}$ be a sample of the $N$ pixels on an image, with $x_{k} \in R^{n}$ where $n$ is the number of bands in an image, i.e., $n=6$ or $n=7$ for Landsat images used here. Let $c$ denote the number of subsets (clusters or partitions) with $2 \leq c \leq N$. In this research, we have $c=2$ for the classes water and non-water, respectively, since we considered the boundary between these two classes as the shoreline position. FCM minimizes the following objective function $J_{m}$ (Bezdek et al., 1984):

$$
J_{m}=\sum_{k=1}^{N} \sum_{i=1}^{c}\left(\mu_{i k}\right)^{m}\left\|x_{k}-v_{i}\right\|^{2}, 1 \leq m \leq \infty
$$

where $\mu_{i k}$ is the membership value of $k^{\text {th }}$ pixel to class $i, m$ is the fuzzy weight controlling the level of fuzziness, and $v_{i}=\left(v_{i 1}, v_{i 2}, \ldots, v_{i n}\right)$ is the mean vector for class $i$. The membership value $\mu_{i k}$ for class $i$ and pixel $k$ satisfies the following constraints:

$$
0 \leq \mu_{i k} \leq 1 i \in\{1, \ldots, c\}, k \in\{1, \ldots, N\}
$$




$$
\begin{gathered}
\sum_{k=1}^{N} \mu_{i k}>0, i \in\{1, \ldots, c\} \\
\sum_{i=1}^{c} \mu_{i k}=1, k \in\{1, \ldots, N\}
\end{gathered}
$$

There should be at least one class for which the membership value $\mu_{i k}$ of the $k^{\text {th }}$ pixel larger than 0 . Meanwhile, the sum of all memberships $\mu_{i k}$ in a pixel should be equal to 1 . The membership values of the classification corresponding to the pixel value $X$ follow the trapezoidal membership function in Figure 2.1 and Equation 2.5:

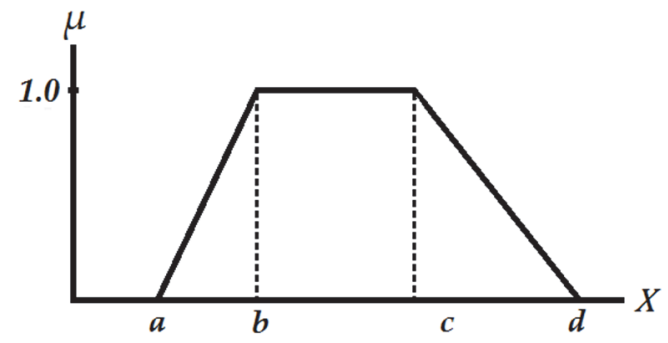

Figure 2.1 Trapezoidal membership function. Area between $b$ and $c$ is a core zone which has a membership value equal to 1 to the water class. Area $a-b$ and $c-d$ are transition zones or boundaries which have value between 0 and 1 to the water class, while the pixels with 0 memberships do not belong to the water class

$$
\mu(x, a, b, c, d)=\left\{\begin{array}{c}
0, x<a, \\
\frac{x-a}{b-a}, a \leq x \leq b \\
1, b<x<c \\
\frac{d-x}{d-c}, c \leq x \leq d \\
0, x>b
\end{array}\right.
$$

If $m$ equals 1 , clusters that minimize the objective function are hard clusters and FCM is a hard classifier. An increase of $m$ tends to an increase in fuzziness. Bezdek et al. (1984) further explained that no evidence distinguishes an optimal $m$, but for most data, $1.5 \leq m \leq 3.0$ give good results. In addition, Foody (1996) stated that in most studies, $m=2.0$ produces an accurate fuzzy classification. In this work, the values $m=1.5,1.6,1.7,1.8,1.9,2.0,2.5$, and 3.0 were used to test the influence of $m$ on the classification results.

FCM was finalized by labelling one of the two membership images resulting from each (unsupervised) FCM as the water membership 
image. To do so, we used the combination of near infrared (NIR) and shortwave infrared (SWIR) of Landsat bands. Infrared bands exhibit a strong contrast between water and land features, because water absorbs these wavelengths while they are reflected by land (Richards, 2013). In the visible part of the spectrum, the differences between land and water are less outspoken, especially if the water contains some sediment. Therefore, the water label was given to the class which has the lowest value of the sum of the cluster means in the infrared bands, defined as:

$$
F C M_{\text {water }}=\operatorname{MIN}\left[\left(v i_{c 1}\right)_{I R},\left(v i_{c 2}\right)_{I R}\right]
$$

where $v i_{c 1}$ is the sum of mean vector for the first class in the infrared bands $I R$, and $v i_{c 2}$ is the sum of mean vector for the second class in the infrared bands IR. Table 2.2 shows an example of cluster means of each subset in the infrared bands. The labelling of $c 1$ or $c 2$ as water was decided by using Equation 2.6. In this example, the water label was given to $c 1$ as it has the lowest value of the sum of the cluster means in the infrared bands.

Table 2.2 Mean vector of two subsets in the infrared bands of 2015 Landsat image. The labelling of $\boldsymbol{c}_{\mathbf{1}}$ or $\boldsymbol{c}_{\mathbf{2}}$ as water was determined by assessing the sum of the mean vector cluster

\begin{tabular}{|c|c|c|c|c|}
\hline \multirow[t]{2}{*}{ Subset } & \multicolumn{3}{|c|}{$\begin{array}{l}\text { Mean vector of the cluster in the infrared } \\
\text { bands (vi) }\end{array}$} & \multirow{2}{*}{$\begin{array}{l}\text { Total (Band5 + } \\
\text { Band6 + Band7) }\end{array}$} \\
\hline & Band5 & Band6 & Band7 & \\
\hline$c_{1}$ & 2085.711 & 925.3242 & 591.7152 & 3602.75 \\
\hline$c_{2}$ & 8824.05 & 7427.402 & 5240.535 & 21491.99 \\
\hline
\end{tabular}

\subsubsection{Deriving water class images}

Water membership images, resulting from the FCM classification, show the membership of pixels to the water class. Thresholding was applied to transform the water membership image into several hard classifications. The class $C_{w}$ in water class images was defined as:

$$
C_{w}=\left\{\begin{array}{l}
1 \text { if } \mu_{i k} \geq d \\
0 \text { otherwise }
\end{array}\right.
$$

where 1 is water class, 0 is non-water class, and $d$ is threshold value. The possible ranges of the threshold values are between 0 and 1 . In this study, we set the value of $d$ between 0.1 and 0.9 to observe the influence of $d$ on the results of classification. The results of thresholding were binary images called water class images. 


\subsubsection{Accuracy assessment}

Reference data are described in Table 2.1. For the 2015 image, reference data were derived from fieldwork conducted at the end of March 2015. In this case, 150 points from fieldwork data were selected based on the same tide condition. Furthermore, an image made available via Google Earth 2014 captured during the high tide, a 2013 Pleiades image during low tide, and a 2003 QuickBird image captured during the rising tide were interpreted visually to generate 150 reference points. Further, because of limited availability of highresolution images and maps, the 2003 QuickBird image was used as well for accuracy assessment of images in 2000 and 2002. Finally, the topographic map published in 2000 and generated from aerial photographs of 1994 was manually digitized on-screen to produce water and non-water classes. For this map, 150 points were randomly selected, and were used as reference data against the classification result of the 1994 image. To evaluate how well the remotely sensed classifications agree with the reference data, error matrices were generated. A kappa ( $\kappa$ ) coefficient was computed for each error matrix (Richards, 2013).

\subsubsection{Shoreline generation}

Two methods were followed to identify the shoreline. The first method determined shoreline as a single line, as has been widely considered in the previous studies, whereas the second method assumed shoreline as a margin, which reflects the possible locations of shoreline influenced by the membership to the water class in a pixel.

\section{Shoreline as a single line}

First, the shoreline was derived by generating water class image and set $d=0.5$. Two sub-areas were identified, namely water and nonwater. Shoreline was located at the boundary of the two sub-areas and obtained by converting the water class image to line features in GIS. For this research, a sub-area was defined as a set of contiguous cells with the same value.

\section{Shoreline as a margin}

Secondly, we considered the shoreline as an area (margin). The shoreline margin was generated by creating a crisp sub-area determined by $d=0.3$ and $d=0.7$ as the lower and upper thresholds obtained in the parameter estimation. Afterwards, each water class image was converted into polygon feature in GIS. Thus, three sub- 
areas were identified, namely water if $\mu_{i k} \geq 0.7$ non-water if $\mu_{i k}<0.3$ and shoreline margin if $0.3 \leq \mu_{i k}<0.7$. Over time, the changes of shoreline position are due to the exchanges between the shoreline margin and water or non-water sub-area.

\subsubsection{Uncertainty estimation}

Considering the imprecise position of the shoreline in remote sensing images and the uncertainty propagated through the change detection method, shoreline margin, water and non-water sub-areas were associated with values reflecting the uncertainty of pixels belonging to any of these classes. Water membership values were used for this purpose. The certainty of pixel $k$ to belong to any class was assessed using possibility and necessity measures (Dubois et al., 2007; Li et al., 2015; Sebari and He, 2013; Zadeh, 1978). If $C$ is a subset of a universe of discourse $U$ and $x \in C$, then $\pi_{x}(u)$ is the degree of possibility that $x$ takes value $u$. The value of $\pi_{x}(u)$ is evaluated by the degree of membership $\mu_{C}(u)$. This can be written as:

$$
\pi_{x}(u)=\mu_{C}(u), \forall u \in U
$$

The value of $x \in C$ is then estimated by assessing possibility measure:

$$
\Pi_{C}=\sup _{u \in C} \pi_{x}(u)
$$

The possibility measure $\Pi_{C}$ corresponds to the element of $C$ that has the highest possibility degree according to $\pi_{x}$. Further, to inform that the event will be realized, the certainty of $C$ is defined as the impossibility of the complement:

$$
\begin{aligned}
& N_{C}=1-\Pi_{\bar{C}} \\
& N_{\bar{C}}=1-\Pi_{C}
\end{aligned}
$$

The $N$ pixels in $X$ are therefore indicated as $C$ if $\Pi_{C}>\Pi_{\bar{C}}$ and $N_{C}>N_{\bar{C}}$. Further, the uncertainty of $C$ is defined as:

$$
U_{C}=1-N_{C}
$$

\subsubsection{Shoreline change detection}

To detect the changes in the positions of the shoreline, shoreline margin, water and non-water areas, results for two dates $t_{1}$ and $t_{2}$ had to be superimposed in GIS. In order to have a detailed "from-to" change trajectory information, the post-classification comparison approach was used (Lu et al., 2014). Topological relation between two sub-areas can be characterized by considering the nine- 
intersection model of interiors and exteriors (Ardila et al., 2012; Egenhofer and Al-Taha, 1992). Based on this method, a sub-area identified at time $t_{1}$ is denoted as $R_{t 1}$, with the boundary $B\left(R_{t 1}\right)$, interior $I\left(R_{t 1}\right)$, and exterior $E\left(R_{t 1}\right)$. It intersects with another sub-area identified in time $t_{2}$ and denoted as $R_{t 2}$, with the boundary $B\left(R_{t 2}\right)$, interior $I\left(R_{t 2}\right)$, and exterior $E\left(R_{t 2}\right)$. These intersections define the nine-intersection matrix as:

$$
M=\left(\begin{array}{ccc}
B\left(R_{t 1}\right) \cap B\left(R_{t 2}\right) & B\left(R_{t 1}\right) \cap I\left(R_{t 2}\right) & B\left(R_{t 1}\right) \cap E\left(R_{t 2}\right) \\
I\left(R_{t 1}\right) \cap B\left(R_{t 2}\right) & I\left(R_{t 1}\right) \cap I\left(R_{t 2}\right) & I\left(R_{t 1}\right) \cap E\left(R_{t 2}\right) \\
E\left(R_{t 1}\right) \cap B\left(R_{t 2}\right) & E\left(R_{t 1}\right) \cap I\left(R_{t 2}\right) & E\left(R_{t 1}\right) \cap E\left(R_{t 2}\right)
\end{array}\right)
$$

with intersections being either empty $(\varnothing)$ or non-empty $(\neg \emptyset)$.

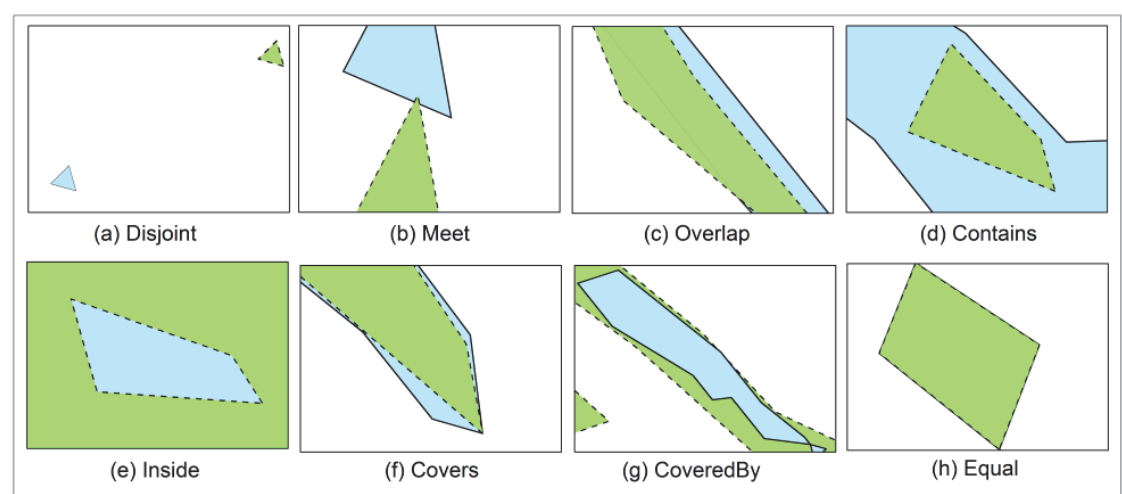

Figure 2.2 Topological relationships between two sub-areas. Green polygons represent sub-area $R_{t 1}$ and blue polygons represent sub-area $R_{t 2}$

Figure 2.2 shows eight topological relationships of two sub-areas for each intersection value in the matrix $M$ including disjoint, meet, overlap, contains, inside, covers, covered by, and equal (Egenhofer and Al-Taha, 1992). Following the aforementioned methods in the shoreline generation, the changes of shoreline and its change uncertainty can be presented as follows:

\section{Shoreline as a single line}

In the first method, the changes of this single shoreline may have occurred as a consequence of changes between water and non-water sub-areas. We determined the changes of these sub-areas at times $t_{1}$ and $t_{2}$ and analyzed the uncertainty of the changes at pixel level. Water class images from two dates $t_{1}$ and $t_{2}$ were superimposed, and abrupt and gradual changes were identified. An abrupt change is defined when a sub-area emerges at $t_{2}$ without a corresponding sub- 
area at $t_{1}$. Also, a sub-area present at $t_{1}$ without a corresponding sub-area at $t_{2}$ indicates an abrupt change. A gradual change specifies an increase or decrease of sub-areas that were both present at $t_{1}$ and $t_{2}$. The process occurs in small stages over a period rather than suddenly. The overlay analysis between images at different epochs permitted the identification of changes categorized as: water to nonwater, and non-water to water. Considering the topological relationship as given in Figure 2.2, disjoint and meet were found where a sub-area emerges or disappears. Meanwhile, any of the other six relationships account for gradual changes.

\section{Shoreline as a margin}

The second method measured the changes of the shoreline margin at different epochs. Change uncertainty was presented at the pixel level. Water class images from times $t_{1}$ and $t_{2}$ were superimposed in a GIS. We distinguished again abrupt and gradual change. In this method, the overlay analysis between water class images at different epochs, however, permitted more changes to be identified categorized as: (1) shoreline to non-water; (2) water to shoreline; (3) water to non-water; (4) non-water to shoreline; (5) shoreline to water; and (6) non-water to water. The changes of a sub-area where sedimentation has taken place resulted in changes of shoreline to non-water, water to shoreline, and water to non-water. These types of changes were considered positive changes to non-water sub-area $(+)$. Coastal inundation led to the changes of non-water to shoreline, shoreline to water, and non-water to water. These types of changes were considered negative changes to non-water sub-area (-). These changes were identified either as abrupt or gradual changes, using the same criteria on corresponding objects as in the previous section.

\subsubsection{Change uncertainty and change area estimation}

Shoreline changes and the related sub-areas were associated with change uncertainty values. Change uncertainty was derived based upon the uncertainty of pixels belonging to the specified sub-areas in $t_{1}$ and $t_{2}$ (Cheng, 1999):

$$
C U_{t_{1}, t_{2}}=\operatorname{MIN}\left[U_{c}\left(R_{t 1}\right), U_{c}\left(R_{t 2}\right)\right]
$$

where $U_{c}\left(R_{t 1}\right)$ is the uncertainty of pixel $k$ belonging to sub-area $R_{t 1}$ at $t_{1}$, and $U_{c}\left(R_{t 2}\right)$ is the uncertainty of pixel $k$ belonging to sub-area $R_{t 2}$ at $t_{2}$. Based upon the results of the change uncertainty estimation, the changed area of a specific change category, e.g., water to nonwater, or shoreline to water was defined as: 


$$
A(C h)=P_{k}(C h) \times A(k)
$$

where $P_{k}(C h)$ is number of pixels belonging to the area of a specific change category, $A(k)$ is area of pixel $k$ equal to $30 \times 30\left(\mathrm{~m}^{2}\right)$.

\section{Change area of shoreline as a single line}

Figure 2.3 illustrates the procedure to estimate the net change between $t_{1}$ and $t_{2}$ defined as:

$$
C H_{t_{1}, t_{2}}=P_{k}\left(C h_{A}\right)-P_{k}\left(C h_{B}\right)
$$

where $\mathrm{A}$ and $\mathrm{B}$ represent the area described in Figure 2.3, and $P_{k}\left(C h_{A}\right)$ and $P_{k}\left(C h_{B}\right)$ are the number of pixels belonging to the change area $A$ and $B$, respectively.

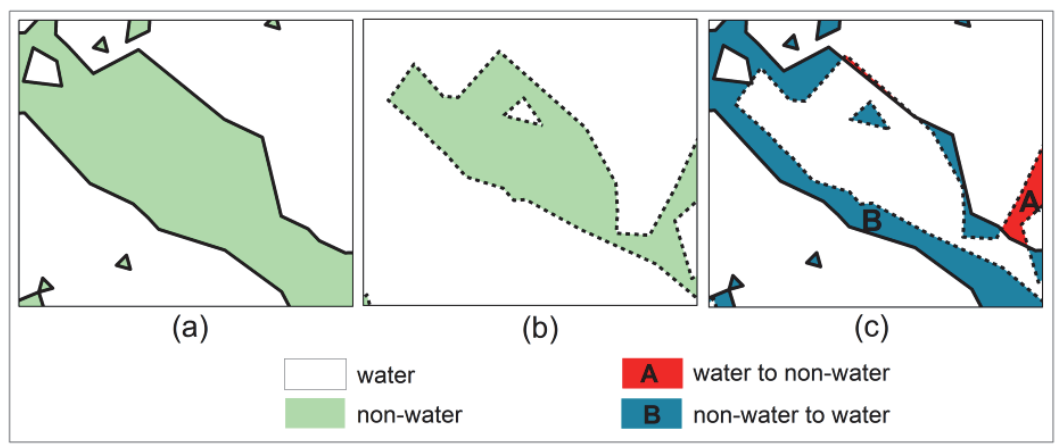

Figure 2.3 (a) Shoreline at time $t_{1}$; (b) Shoreline at time $t_{2} ;$ (c) Shoreline change estimation considering two categories of changed areas, namely: (A) water to non-water, and (B) non-water to water. Solid lines represent shoreline at $t_{1}$ whereas dashed lines refer to shoreline at $t_{2}$

The negative sign ( - ) shows that the change in B categorized as the change from non-water to water has produced a negative change to the non-water area. Meanwhile, the positive sign (+) represents the change in A categorized as the change from water to non-water which has caused a positive change to the non-water area.

\section{Change area of the shoreline as a margin}

Figure 2.4 illustrates the procedure to estimate the total changed area in the second approach. The net changed area was determined as:

$$
C H_{T_{1}, T_{2}}=P_{k}\left(C h_{A}\right)+P_{k}\left(C h_{B}\right)+P_{k}\left(C h_{C}\right)-P_{k}\left(C h_{D}\right)-P_{k}\left(C h_{E}\right)-P_{k}\left(C h_{F}\right)
$$


where A, B, C, D, E, and F represent the area described in Figure 2.4, and $P_{k}\left(C h_{A}\right), P_{k}\left(C h_{B}\right), P_{k}\left(C h_{C}\right), P_{k}\left(C h_{D}\right), P_{k}\left(C h_{E}\right)$ and $P_{k}\left(C h_{F}\right)$ are the number of pixels belonging to changed areas $A, \ldots, F$, respectively.

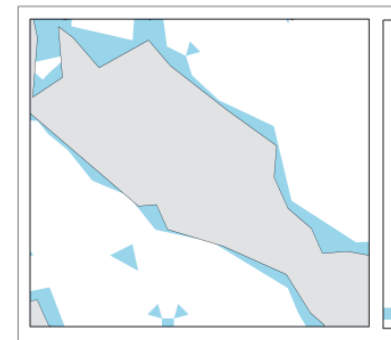

(a)

shoreline

water

non-water

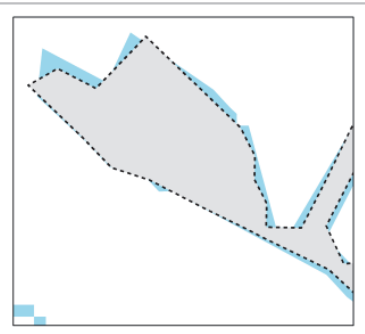

(b)

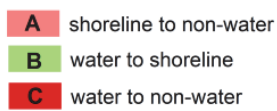

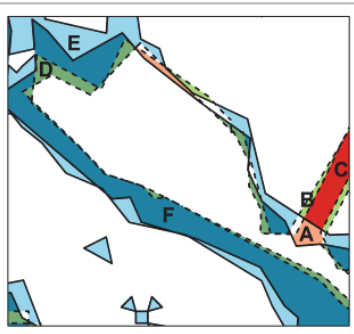

(c)

D non-water to shoreline

E shoreline to water

F non-water to water

Figure 2.4 (a) Shoreline margin at time $t_{1}$; (b) Shoreline margin at time $t_{2}$; (c) Shoreline change estimation considering six changed areas, namely: (A) shoreline to non-water, (B) water to shoreline, (C) water to non-water, (D) non-water to shoreline, (E) shoreline to water, and (F) non-water to water. Solid lines represent shoreline margins at $t_{1}$ whereas dashed lines refer to shoreline margins at $t_{2}$

The positive sign $(+)$ indicates that the changes in $A, B$ and $C$ have caused a positive change to the shoreline margin and non-water areas. On the other hand, the negative sign (-) shows that the changes in $D, E$, and $F$ have induced a negative change to the shoreline margin and non-water areas.

\subsection{Shoreline results and the uncertainty estimation}

\subsubsection{Parameter estimation}

Figure 2.5 provides the results of the $\kappa$ value for parameter estimation of the fuzzy weight $(m)$ conducted on seven images with $d$ values ranging from 0.1 to 0.9 . From the results, we found that the highest $\kappa$ value was obtained for $d=0.5$. The variation in fuzzy weight had little influence on the classification results when the $d$ was set at 0.5 . High $\kappa$ values were obtained for $d$ values between 0.3 and 0.7 , and $m$ values between 1.5 and 3.0. Best results in terms of $\kappa$ values were obtained for $m=1.7$. Furthermore, we selected $d$ values of 0.3 , 
0.5 , and 0.7 as the lower, the middle, and the upper $d$ respectively, as the optimal $d$ values to handle the uncertainty of the water class.

\subsubsection{FCM classification, thresholding and accuracy assessment}

Table 2.3 presents the $\kappa$ values of FCM implemented with $m=1.7$ and $d=0.3,0.5$ and 0.7 , respectively. Unsupervised FCM achieved the highest $\kappa$ value when $d=0.5$. The value of $\kappa$ was slightly lower for $d=0.7$, and the lowest $\kappa$ for $d=0.3$. When comparing images, the lower $\kappa$ values were observed for the images of 2000 and 2002. Such lower accuracies could be due to the use of QuickBird image 2003 as reference data. The acquisition time of the 2003 QuickBird and Landsat images (2000 and 2002) differs more than a year. Therefore, changes of some locations due to village development, seasonal and tide condition could affect the selection of an appropriate sample point.

Table 2.3 The accuracy of unsupervised FCM classification applied at selected parameter $\boldsymbol{m}=1.7$ and $\boldsymbol{d}=0.3,0.5$ and 0.7. For all images, $\boldsymbol{d}=0.5$ obtained the highest $\boldsymbol{\kappa}$ values, $\boldsymbol{d}=0.7$ produced slightly lower $\boldsymbol{\kappa}$ values, and $\boldsymbol{d}=0.3$ resulted in the lowest $\boldsymbol{\kappa}$ values

\begin{tabular}{cccc}
\hline Classified & \multicolumn{3}{c}{ K coefficient for selected $\boldsymbol{d}$ values } \\
\cline { 2 - 4 } images & $\mathbf{0 . 3}$ & $\mathbf{0 . 5}$ & $\mathbf{0 . 7}$ \\
\hline 1994 & 0.95 & 0.96 & 0.96 \\
2000 & 0.81 & 0.86 & 0.81 \\
2002 & 0.85 & 0.90 & 0.85 \\
2003 & 0.87 & 0.93 & 0.89 \\
2013 & 0.86 & 0.95 & 0.90 \\
2014 & 0.83 & 0.95 & 0.90 \\
2015 & 0.90 & 0.95 & 0.92 \\
\hline
\end{tabular}



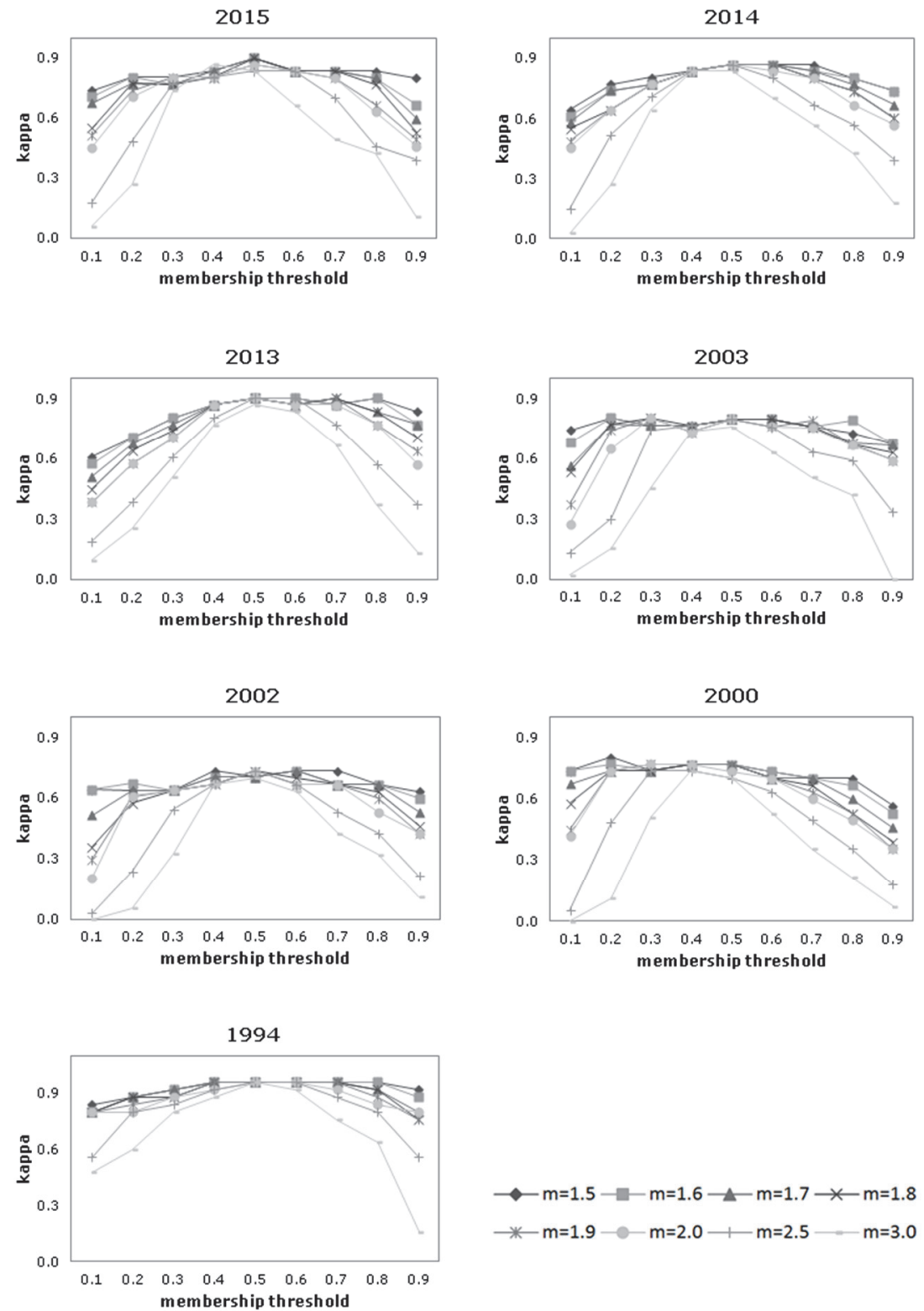

$\because \mathrm{m}=1.9 \longrightarrow \mathrm{m}=2.0 \longrightarrow \mathrm{m}=2.5 \longrightarrow \mathrm{m}=3.0$

Figure 2.5 The accuracy assessment results of water class images, generated by applying FCM classification followed by thresholding on the water membership image. The highest $\mathrm{k}$ values were obtained from $d=0.5$ for all images, and $d=0.3$ and 0.7 gave a nearly constant $\kappa$ value 


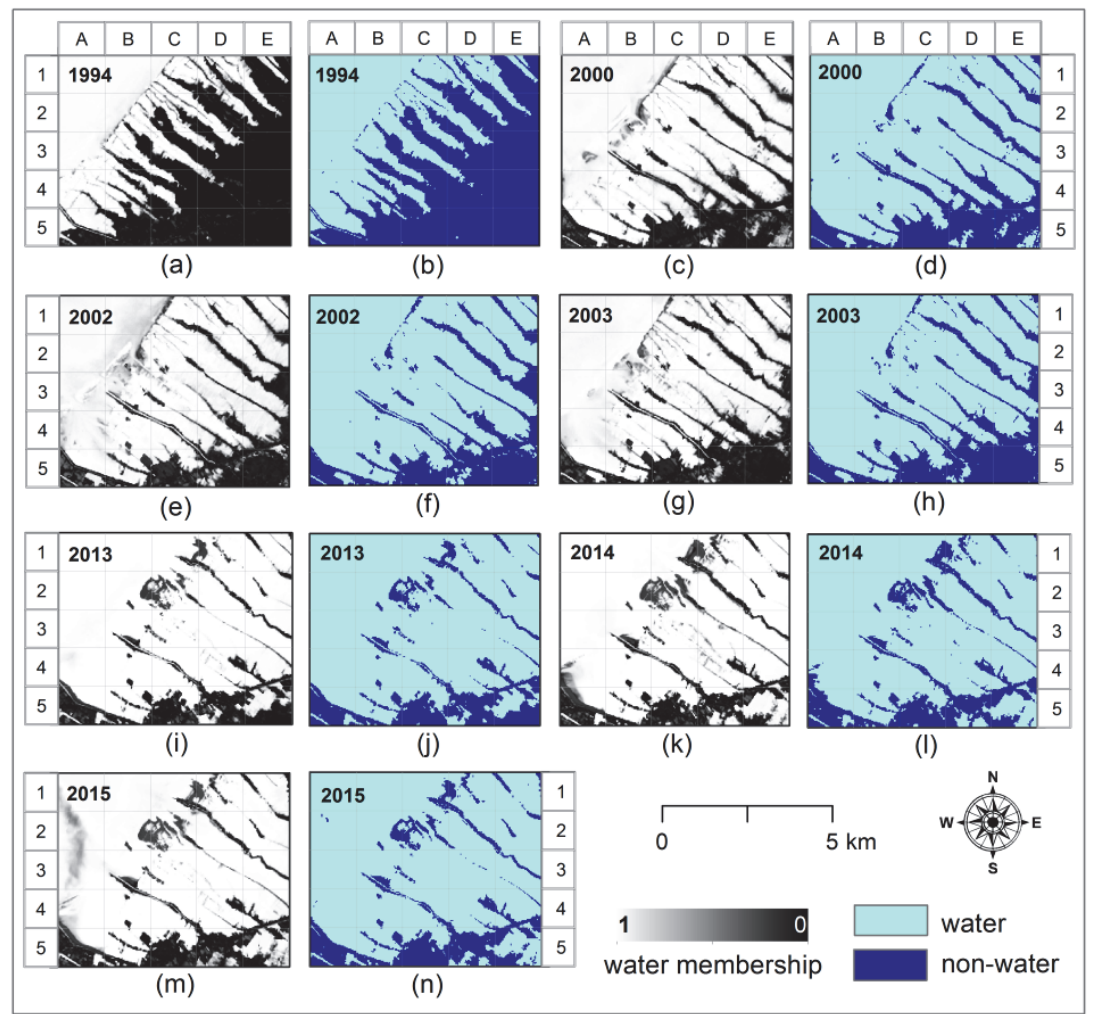

Figure $2.6(a-n)$ FCM results show the membership of water class $(\mathrm{a}, \mathrm{c}, \mathrm{e}, \mathrm{g}, \mathrm{i}, \mathrm{k}, \mathrm{m})$, and classified images of water class by setting $d=0.5$ $(b, d, f, h, j, l, n)$. The shrinking of non-water sub-areas over two decades can be identified by the change of the shape of the non-water class from wide strips to the thin elongated shapes over the series of images (see $(a-n)$; e.g., grid cells ( 3 ). Whereas non-water sub-areas emerged when mangroves were planted (see (i) grid cells C2), and in coastal reclamation areas (see $(a, c)$ grid cells A5)

Figure 2.6 shows FCM results for $m=1.7$ presenting the membership to the water class ranging from 0 to 1 , together with classified images for $d=0.5$. Areas with a high membership to the water class include marine areas; e.g., Figure $2.6 \mathrm{~b}$ grid cell A2, fishponds; e.g., Figure $2.6 \mathrm{n}$ grid cell D3, and water-covered agricultural areas; e.g., Figure 2.6j grid cell E5. Muddy areas are located on the border of water and non-water; e.g., Figure $2.6 \mathrm{k}$ grid cell A4. Further, the shrinking of non-water areas over two decades could also be distinguished. This can be seen by the change of the shape of the non-water class from wide strips to the thin elongated shapes over the series of images in Figure 2.6a-n; e.g., grid cells C3. On the other hand, non-water sub-areas emerged in several locations, such 
as when mangroves were planted; e.g., see Figure $2.6 \mathrm{i}$ grid cells $\mathrm{C2}$, and in reclamation areas; e.g., see Figure $2.6 a, c$ grid cells A5.

\subsubsection{Shoreline and uncertainty estimation}

\section{The results of shoreline as a single line}

Figure 2.7a presents the shoreline positions derived for $d=0.5$. This $d$ value was selected because it yielded the best $\kappa$ result when applying the threshold to derive the water class images from membership images. Shoreline was thus assessed through the uncertainty value of water and non-water sub-areas (see Figure 2.7b). The uncertainty values represent the uncertainty that the pixel belongs to water, determined following Equation 2.12. A dark blue colour indicates a higher uncertainty that the pixels to belong to the water class, whereas a light blue colour denotes pixels having a lower uncertainty to be classified as water. Generally, pixels which are closer to shoreline have a higher uncertainty of belonging to the water class; e.g., see Figure 2.7d grid cells C2 and D2.

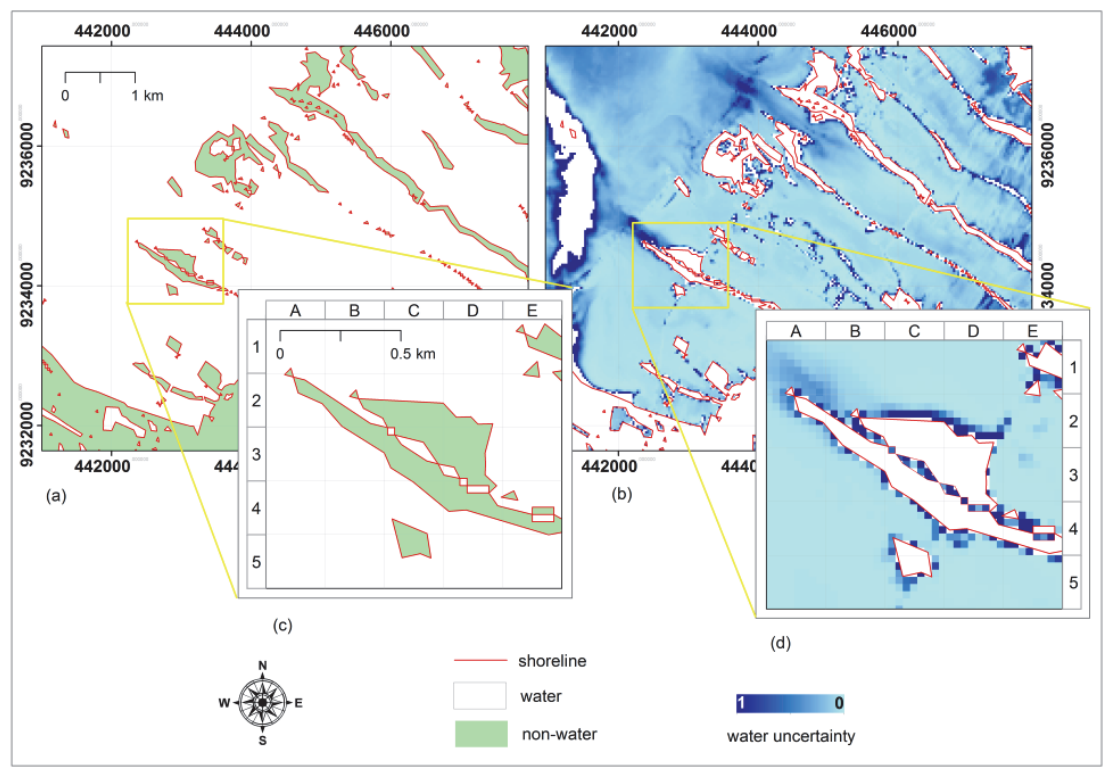

Figure 2.7 (a-d) The illustration of shoreline as a line; (a) Shorelines (in red colour) created by setting $d=0.5$; (b) the uncertainty of pixels classified as water at the uncertainty level $\leq 0.5$. Generally, pixels closer to the shoreline have a higher uncertainty value (see (d) grid cells C2 and D2) 


\section{The results of shoreline as a margin}

Figure 2.8 presents the second method, an illustration of the shoreline margin generated by setting $d=0.3$ and $d=0.7$. Shoreline margin are represented by blue polygons and their width is determined by the shoreline condition. A wider margin shows the more gradual transition from water to non-water occurring for instance in a low-lying muddy area, or near a swamp area; see Figure $2.8 \mathrm{c}$ grid cells C3 and D3. Meanwhile, a narrow margin reflects a more abrupt transition, as for example at a steep coast or at a shoreline with embankment or shoreline protection; see Figure $2.8 \mathrm{c}$ grid cells B2, and B3. Shoreline margin was assessed through different levels of uncertainty (see Figure $2.8 \mathrm{~d}-\mathrm{g}$ ). The uncertainty values represent the uncertainty that a pixel belongs to the water class estimated following Equation 2.12. A dark blue colour indicates a higher uncertainty of pixels to belong to the water class, whereas a light blue colour denotes pixels having lower uncertainty. Generally, pixels which are closer to water have a higher membership to the water class. Consequently, these pixels may have a higher certainty to be classified as water.

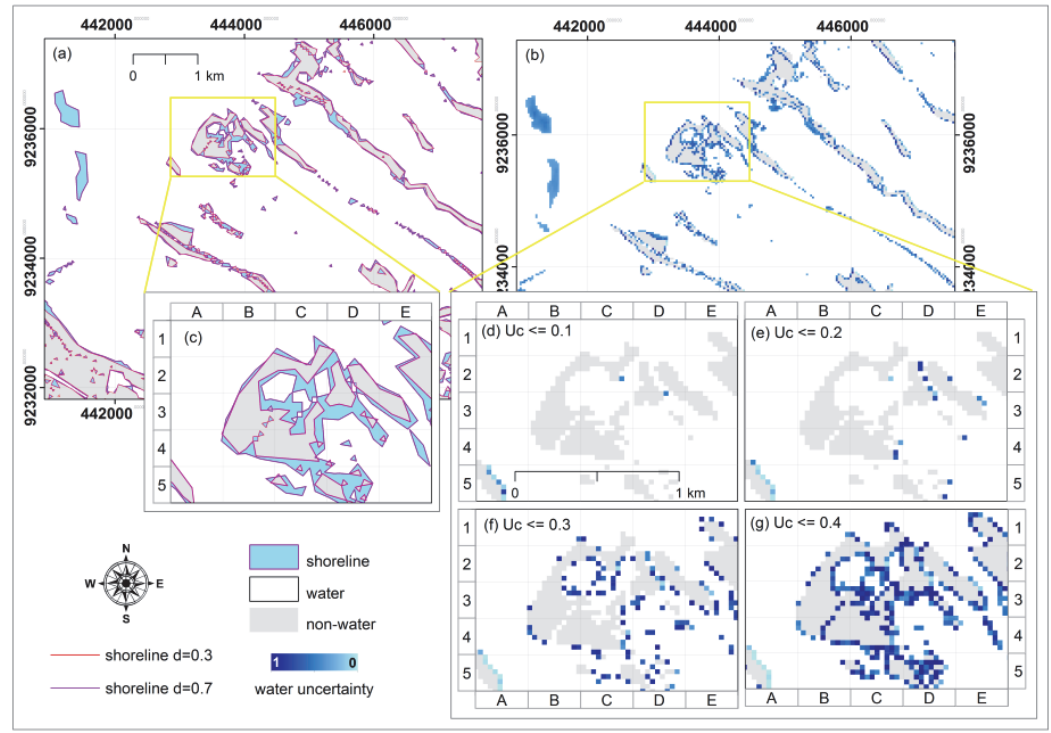

Figure 2.8 The illustration of shoreline as a margin; (a) Shoreline margin (blue polygons) generated by giving $d=0.3$ and 0.7 ; (b) the uncertainty of shoreline margin from Equation 2.12; (c) zooming in sub-areas in yellow rectangle based on Figure 2.8a. Shoreline margin was assessed through different levels of uncertainty $\left(U_{C}\right)$ : (d) $\leq 0.1$; (e) $\leq 0.2$; (f) $\leq 0.3$; and $(\mathrm{g})$ $\leq 0.4$ 


\subsubsection{Shoreline change detection results and change uncertainty}

\section{The results of change for shoreline as a single line}

The results of the first method in shoreline change detection are presented in Figure 2.9. We distinguished two types of change, i.e., water to non-water (red colour), and non-water to water (blue colour).

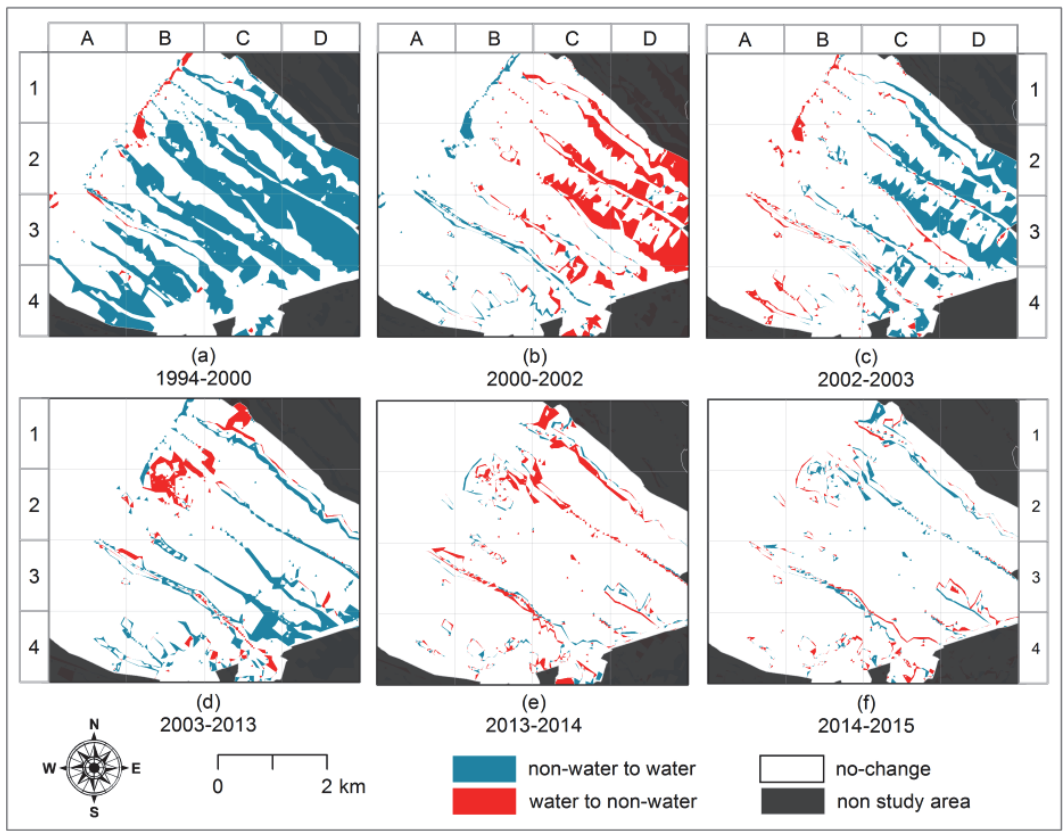

Figure 2.9 (a-f) Shoreline change analysis at $d=0.5$ Two changes were identified, namely non-water to water and water to non-water. Large areas changed from non-water to water such as due to inundation and erosion which were indicated between 1994 and 2000 (a). Whereas large areas changed from water to non-water and were distinguished between 2000 and 2002 (b)

The maps in Figure 2.10 demonstrate shorelines with their associated change uncertainties derived from Equation 2.14. Two categories of change uncertainty were identified: (1) change uncertainty to water (shades of blue); and (2) change uncertainty to non-water (shades of red). For both colours, darker shades indicate a higher change uncertainty than lighter shades. Table 2.4 summarizes the changes in a number of pixels between water and non-water at different levels of uncertainty for site in the yellow rectangle in Figure 2.10a. Number of pixels increase with the increase of change uncertainty values. 


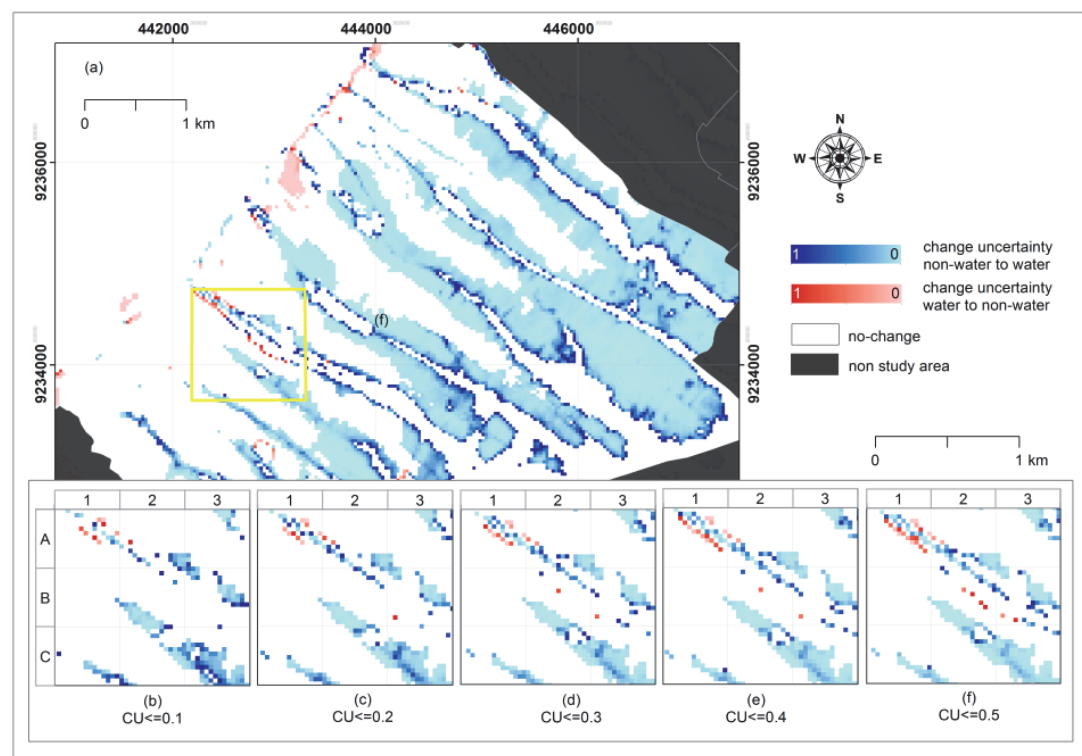

Figure 2.10 (a) Shoreline change uncertainty at $d=0.5$. (b-f) Change uncertainty is highlighted at different levels for the period 1994-2000 for the yellow rectangle site. The number of red pixels indicates that the change uncertainty from water to non-water increase with the increase of uncertainty values, as also can be seen for the blue pixels.

Table 2.4 Changed area (in number of pixels) between water and non-water at different change uncertainty levels (see yellow rectangle site in Figure 2.10a). The number of pixels increases with the increase of change uncertainty values. Obvious changes were observed by a change uncertainty value $\leq 0.1$

\begin{tabular}{crrrrr}
\hline \multirow{2}{*}{ Change Area } & \multicolumn{6}{c}{ CU level } \\
\cline { 2 - 6 } & $\mathbf{0 . 1}$ & $\mathbf{0 . 2}$ & $\mathbf{0 . 3}$ & $\mathbf{0 . 4}$ & $\mathbf{0 . 5}$ \\
\hline Water to non-water & +9 & +12 & +15 & +20 & +27 \\
Non-water to water & -190 & -219 & -235 & -241 & -250 \\
\hline Note: + gain of non-water - loss of non-water
\end{tabular}


Table 2.5 Changed area (in ha) between water and non-water at $\boldsymbol{d}=0.5$ and $\boldsymbol{C U} \leq 0.1$ during the period 1994-2015. Inundation has been distinguished during four periods (1994-2000, 2002-2003, 2003-2013 and 2014-2015), while change to non-water has been identified for two periods (2000-2002 and 2013-2014)

\begin{tabular}{lcccccc}
\hline $\begin{array}{l}\text { Change } \\
\text { area }\end{array}$ & $\mathbf{1 9 9 4 -}$ & $\mathbf{2 0 0 0 -}$ & $\mathbf{2 0 0 2 -}$ & $\mathbf{2 0 0 3 -}$ & $\mathbf{2 0 1 3 -}$ & $\mathbf{2 0 1 4 -}$ \\
\hline $\begin{array}{l}\text { Water to } \\
\text { non-water }\end{array}$ & +20.0 & +197.5 & +23.2 & +51.4 & +64.5 & +21.7 \\
$\begin{array}{l}\text { Non-water } \\
\text { to water }\end{array}$ & -670.1 & -32.0 & -210.1 & -182.8 & -20.3 & -26.8 \\
\hline Net change & -650.2 & +165.5 & -186.8 & -131.4 & +44.3 & -5.1 \\
\hline
\end{tabular}

Note: + gain of non-water, - loss of non-water

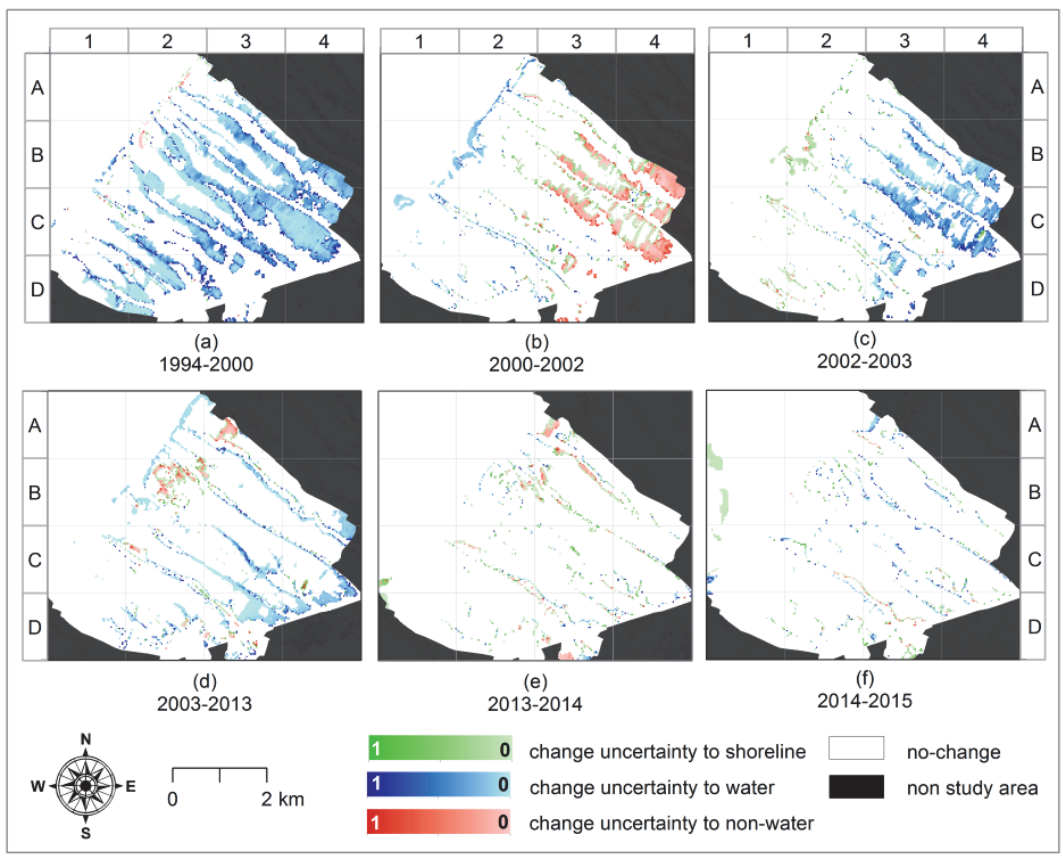

Figure 2.11 (a-f) Shoreline change uncertainty at $d=0.5$ and $C U \leq 0.1$ for the period 1994-2015. The extensive inundation has been indicated from 1994 to 2000 (a) and the largest change to non-water occurred in the period 20002002 (b)

The trend of shoreline changes was thus assessed in the period 1994-2015 (Figure 2.11 and Table 2.5). The changes in water and non-water sub-areas have been observed by comparing values for two consecutive years. The results for changed areas are reported in Table 2.5. Table 2.5 shows that in the period 1994-2000 in which the largest inundation occurred, non-water areas were inundated on one 
side ( -670.1 ha), while a small change to non-water can be found on the other side (e.g., $+20.0 \mathrm{ha})$. The net change was inundation ( -650.2 ha), as shown in Figure 2.11a, e.g., grid cells C3, and D3. Another large change to water $(-186.8$ ha) was identified from 2002 to 2003 (see Figure 2.11c; e.g., grid cells C3, and D3). Whereas extensive change to non-water ( $+165.5 \mathrm{ha}$ ) occurred over the period 2000-2002 (Figure 2.11b; e.g., grid cells C3 and D3).

\section{The results of change for shoreline as a margin}

Figure 2.12 provides change maps of the shoreline margin and related sub-areas in the period 1994-2015, in which we identified six changes. A wider change area from non-water to water (blue colour) can be seen in e.g., Figure 2.12a grid cells C3 and D3. On the other hand, narrow change areas from shoreline to water are present in e.g., Figure 2.12f grid cells C2. Between 2000 and 2002, large areas changed from water and shoreline to non-water, e.g., Figure 2.12b grid cells C2, C3 and D3. Some of those areas changed again to water between 2002 and 2003. Those changes could be due to a different growing phase of crops since this location has an extensive agricultural area such as paddy field (Hartini, 2015). Meanwhile, some areas changed from water and shoreline to non-water in the period 2003-2013 (see Figure 2.12c grid cell B2) which was caused by a successful mangrove planting program in Bedono village.

Change uncertainty of shoreline margin, water and non-water are presented in Figure 2.13. Meanwhile, Table 2.6 shows the changes in the number of pixels between shoreline margin, water and non-water at different levels of uncertainty for the yellow rectangle site in Figure 2.13a. The number of pixels in the change area decreases with a decrease in the level of uncertainty. Obvious changes from shoreline margin to water due to inundation were 88 pixels (see Table 2.6 column 1 and Figure 2.13a). Obvious changes from shoreline margin to non-water due to reclamation or deposition were indicated for one pixel (see Table 2.6 column 1 and Figure 2.13a). 


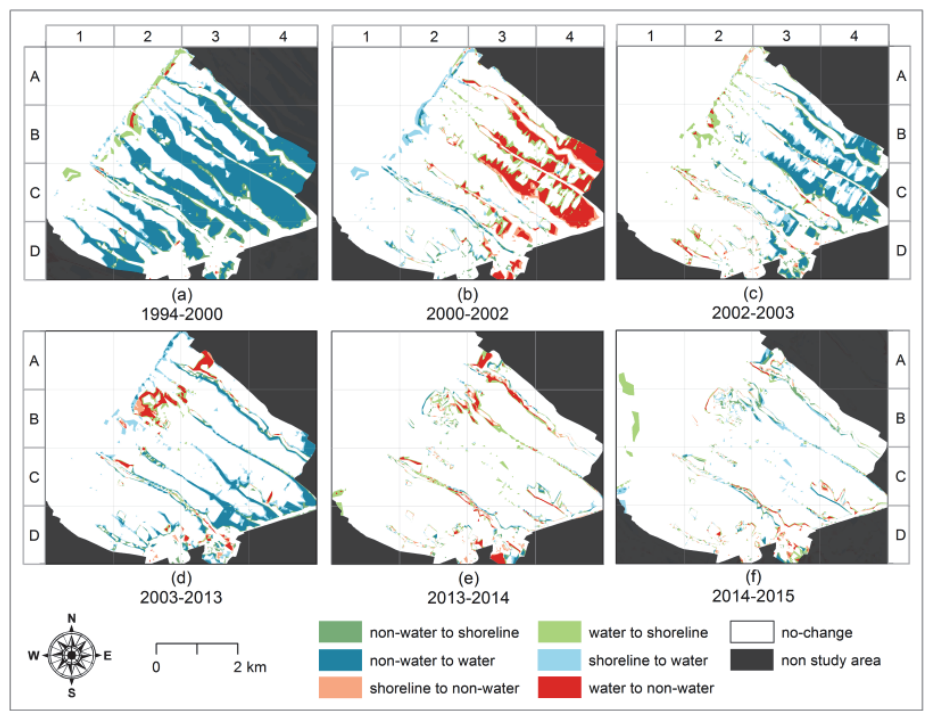

Figure 2.12 (a-f) The changes of shoreline margin, water and non-water. Six changes were identified including abrupt and gradual changes. An extensive inundation has been indicated from 1994 to 2000 (a), while the large change to non-water occurred in the period 2000-2002 (b).

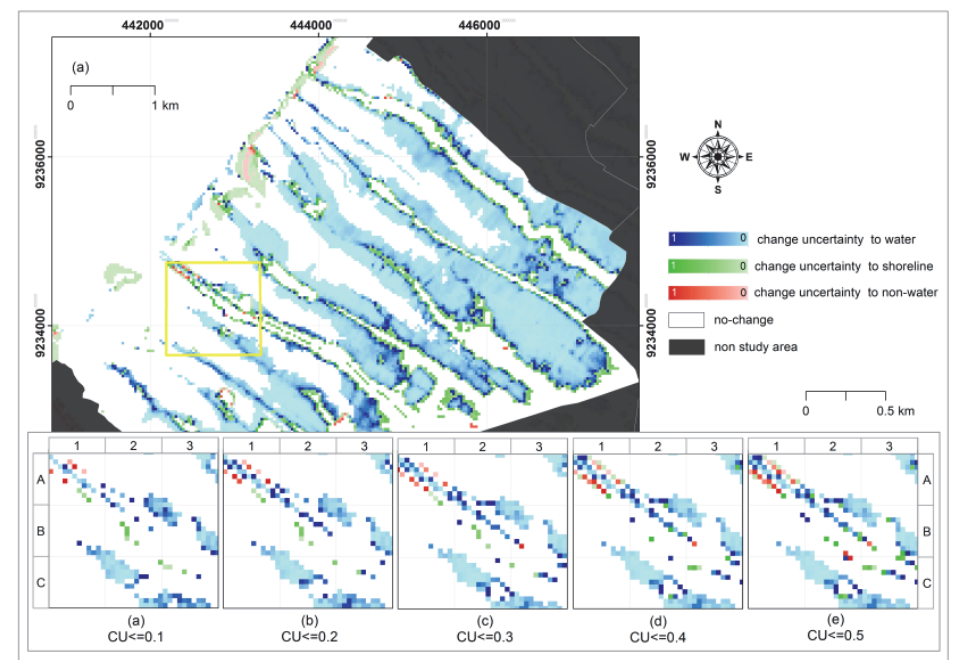

Figure 2.13 (a) Shoreline change uncertainty for the period 1994-2000; (bf) Change uncertainty was measured at different levels for yellow rectangle site. A number of pixels (red, green, and blue) increases with the increase in the level of uncertainty. Changes from non-water to shoreline and from water to shoreline were grouped under one label and are presented in shades of green, while changes from shoreline and water to non-water are presented in shades of red. Changes from non-water and shoreline to water are represented as shades of blue 
Table 2.6 Changed area (in the number of pixels) between shoreline margin, water and non-water at different uncertainty levels (see yellow rectangle site in Figure 2.13a). Obvious changes were observed for a level of uncertainty $\leq 0.1$

\begin{tabular}{lrrrrr}
\hline \multirow{2}{*}{ Change Area } & \multicolumn{5}{c}{$\boldsymbol{C U}$ Level } \\
\cline { 2 - 6 } & $\mathbf{0 . 1}$ & $\mathbf{0 . 2}$ & $\mathbf{0 . 3}$ & $\mathbf{0 . 4}$ & $\mathbf{0 . 5}$ \\
\hline Shoreline to non-water & +1 & +2 & +3 & +6 & +10 \\
Water to shoreline & +17 & +14 & +12 & +21 & +23 \\
Non-water to shoreline & -11 & -20 & -21 & -26 & -34 \\
Shoreline to water & -88 & -94 & -101 & -101 & -103 \\
Non-water to water & -149 & -175 & -189 & -189 & -190 \\
Water to non-water & +6 & +8 & +10 & +11 & +11 \\
\hline
\end{tabular}

Note: + gain of non-water, - loss of non-water

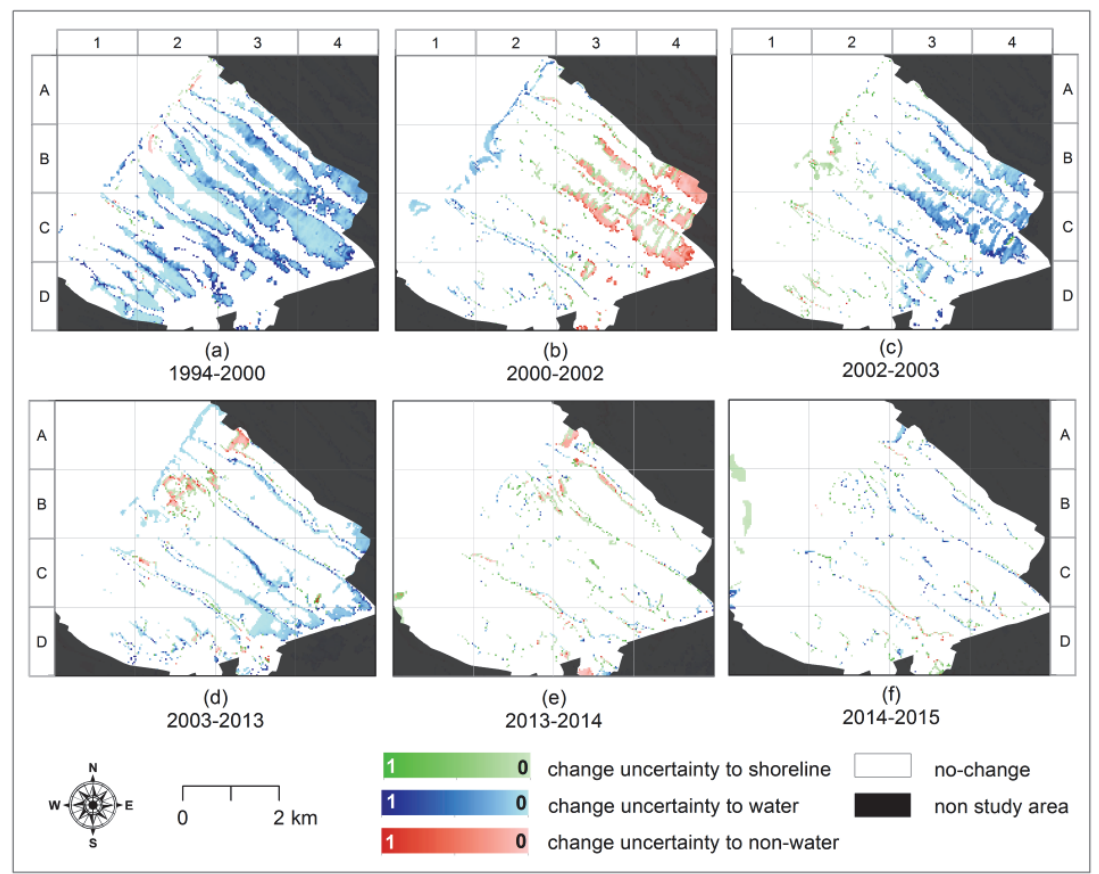

Figure 2.14 (a-f) Change uncertainty of shoreline margins and their associated sub-areas at $C U$ level $\leq 0.1$ in the period 1994-2015. (a) The largest coastal inundation occurred in the period 1994-2000. It was dominated by light blue pixels indicated low change uncertainty values to water. (b) The largest increase in non-water occurred in the period 20002002 represented by light red pixels indicated low change uncertainty to nonwater 
The changes of shoreline margin, water and non-water sub-area were analyzed over the period 1994-2015. Figure 2.14 and Table 2.7 present the results of shoreline change analysis at the uncertainty level $\leq 0.1$. Table 2.7 shows that the largest coastal inundations in terms of area occurred between 1994 and 2000, when 739.4 ha changed from non-water and shoreline to water (see Figure 2.14a, e.g., grid cells C3, and D3), and in 2003-2013 for 199.7 ha (see Figure 2.14d, e.g., grid cells B3 and C3). Between 2000 and 2002, 186.3 ha changed from water and shoreline to non-water (see Figure 2.14b, e.g., grid cells C3 and D3), and another 64.6 ha in 2013-2014 (Figure 2.14e, e.g., grid cell C1). In general, we can conclude that there was a considerable change of shoreline margin and its associated sub-areas over these two decades.

Table 2.7 Changed area (in ha) at $\boldsymbol{C U} \leq 0.1$ in the period 1994-2015. The largest change from non-water to water due to coastal inundation occurred in the period 1994-2000, and the largest change from water to non-water due to different planting periods in an agricultural area occurred in the period 2000-2002

\begin{tabular}{|c|c|c|c|c|c|c|}
\hline Change Area & $\begin{array}{l}1994- \\
2000\end{array}$ & $\begin{array}{l}2000- \\
2002\end{array}$ & $\begin{array}{l}2002- \\
2003\end{array}$ & $\begin{array}{l}2003- \\
2013\end{array}$ & $\begin{array}{l}2013- \\
2014\end{array}$ & $\begin{array}{l}2014- \\
2015\end{array}$ \\
\hline $\begin{array}{l}\text { Shoreline to } \\
\text { non-water }\end{array}$ & +0.3 & +2.4 & +3.4 & +4.1 & +5.6 & +10.4 \\
\hline $\begin{array}{l}\text { Water to } \\
\text { shoreline }\end{array}$ & +8.3 & +94.9 & +48.5 & +36.8 & +63.7 & +32.8 \\
\hline $\begin{array}{l}\text { Water to non- } \\
\text { water }\end{array}$ & +5.5 & +167.7 & +8.6 & +38.5 & +39.9 & +11.0 \\
\hline $\begin{array}{l}\text { Non-water to } \\
\text { shoreline }\end{array}$ & -3.0 & -4.1 & -6.2 & -7.3 & -7.5 & -3.1 \\
\hline $\begin{array}{l}\text { Shoreline to } \\
\text { water }\end{array}$ & -115.1 & -61.5 & -105.4 & -135.9 & -27.1 & -41.3 \\
\hline $\begin{array}{l}\text { Non-water to } \\
\text { water }\end{array}$ & -635.3 & -13.1 & -178.3 & -136.0 & -10.0 & -9.7 \\
\hline Net change & $\begin{array}{l}-739.4 \\
\end{array}$ & +186.3 & -229.3 & -199.7 & +64.6 & +0.1 \\
\hline
\end{tabular}

Note: + gain of non-water, - loss of non-water

\subsection{Discussion}

In this chapter, we have demonstrated two change detection methods for shoreline considering its complex and fuzzy nature including its uncertainty. Both methods were successful in identifying abrupt and gradual changes of shoreline at an object level and in estimating the spatial distribution of uncertainty at the pixel level. The first method derived the shoreline by applying a threshold $d=0.5$ 
on the water membership images. Shoreline was then considered as a single line; its position was influenced by the spatial extent of its associated sub-areas. The uncertainty in the shoreline position could be assessed by means of the uncertainty of its associated sub-areas. The second method derived shoreline margin as an area in which water moves to and fro as tides rise and fall. This margin was presented as a crisp object with a boundary determined by $d$ values resulting from parameter estimation. Comparing these showed that the second method allowed us to assess the spatial extent of the shoreline and measure its change in uncertainty at different levels. This method provided more insight into the spatial distribution of changes and their uncertainty and more spatial detail of the process of change from non-water via shoreline margin to water and vice versa. In estimating the net change category, both methods gave similar results. Net changes identified by the second method covered a larger area both for negative changes (1994-2000, 2002-2003 and 2003-2013) as well as for positive changes (2000-2002 and 20132014), with the exception of 2014-2015 (see Tables 2.5 and 2.7). The different results were mainly due to differences in threshold values when generating the shoreline. Shoreline and its changes have been presented as crisp sub-areas. The changed areas were thus associated with the distribution of change uncertainty.

In deriving shorelines as a fuzzy object, we used FCM to calculate the membership. Membership values obtained by applying FCM were used to deal with uncertain information on the position of objects, such as the location of fuzzy shorelines. In this research, we implemented FCM for two classes, since shoreline is the set of locations where water and non-water have physical interactions. In addition, the difference between water and non-water provided the largest spectral differences in images, as was confirmed in Bijker et al. (2011). For similar situations, a suitable number of clusters need to be specified either by users based on their a priori knowledge or estimated from the images. In the literature, several methods exist to measure the cluster validity index for finding a suitable number of clusters, as for example exponential cluster validity index, nonfuzziness index, fuzziness performance index, and entropy measure (Fisher and Pathirana, 1990; Roubens, 1982; Tso and Mather, 2009; Zarandi et al., 2010).

Reference data were collected in the field in 2015. In this research, images were selected based on the same low tide condition, and therefore, reference points were also selected under similar low tide conditions. Due to limited availability of high resolution images, 
however, the 2003 QuickBird image was used for accuracy assessment of images in 2000, 2002 and 2003, even though it was collected during rising tide. Differences in tides between images and these reference data have led to a low accuracy of classified images for 2000, 2002 and 2003, as compared to 2013 and 2015. Moreover, because of limited availability of Landsat images and severe cloud cover problems in the study area, other criteria such as availability of images with the same seasonal condition have not been applied yet. For images captured during rainy seasons, the rain increased the wetness of soil surfaces, which led to a false impression of more flooded conditions in the classified images, and increased the uncertainty in the shoreline position. Landsat images captured in 2000 and 2002 were recorded during the rainy seasons, while the 2003 QuickBird image, used as reference data, was captured during the dry season. Therefore, differences in seasons and tides could have contributed to the misclassification of water and non-water leading to lower classification accuracy. Considering the larger availability of new satellite images in the future, we recommend to select images recorded under similar, preferably dry, seasonal conditions to reduce the uncertainty due to seasonal influence.

The shoreline change detection methods developed and applied in this research involved the generation of a shoreline and its uncertainty using selected $m$ and $d$ values, and produced a hard classification by means of thresholding. A variation in $m$ values had little influence on the results of the classification. An important reason was the small changes in membership values obtained when $m$ values were set between 1.5 and 3.0. Within that range, the change in membership value was generally less than 0.1 . However, $d$ variation strongly influenced the results. Small variations in $d$ causing large variation in area indicate the presence of gradual boundaries, as for example in a muddy area. Meanwhile, sharp or sudden boundaries caused little change in area with varying $d$, such as at a steep coast or at the shoreline with embankment.

The change uncertainty value expresses how sure we are that a change really occurred. Therefore, the uncertainty addressed in this research corresponds to the existential uncertainty of the identified changes. A complete model of uncertainty, however, should also include an extensional uncertainty which considers the spatial extent of the change (Molenaar and Cheng, 2000). This would involve modelling shoreline as a fuzzy object as proposed by Cheng (1999). In fact, the membership and $d$ values of the water class in this work may be used to represent shoreline as a conditional boundary since 
spatial extents of water (and non-water) depend on the choice of $d$ value. In this case, points where $\mu=1$ are the interior of fuzzy subareas (cores), whereas points with $0<\mu<1$ would belong to transition zones and points with $\mu=0$ belong to non-water objects.

Analysis of shoreline changes in the study area in Sayung sub-district revealed an extensive change of shoreline with the largest change between 1994 and 2000. Land subsidence was indicated as one of the causes of this permanent submergence. Chaussard et al. (2013) mentioned that the rate of the land subsidence in this location reaches approximately $6.0 \mathrm{~cm} \cdot \mathrm{yr}^{-1}$. Subsidence was accelerated by an extreme ground water extraction for industrial purposes and as the consequence of a rapid population growth, classified as an anthropogenic subsidence. Putranto and Rüde (2011) cited the Directorate of Environmental Geology and Mining Regions of Indonesia, stating the number of registered deep wells in Semarang Demak in the early 1900s was only 16 . The number of deep wells increased significantly up to 1,194 in 2002. Besides, land subsidence was also triggered by a natural compaction of clayey sediment and settlement loading (Chaussard et al., 2013; Lubis et al., 2011; Marfai and King, 2007). Furthermore, the threat of flooding comes from sea level rise as well. As mentioned by Sofian (2010), the rise of sea level in Indonesia is approximately $0.2-1.0 \mathrm{~cm} \cdot \mathrm{yr}^{-1}$ with an average of 0.6 $\mathrm{cm} \cdot \mathrm{yr}^{-1}$.

Different planting periods in agricultural areas could be a major cause of the changes from water and shoreline to non-water in the period 2000-2002 followed by a large reverse change in the period 20022003 (see Table 2.5 and 2.7). In addition, we identified coastal land reclamation activities to install an industrial area and a settlement in Sriwulan village. After the period 2003-2013, more agricultural areas were converted into fishponds as a result of expanding saltwater infiltration. On the other hand, some changes from water to nonwater occurred as a result of a successful mangrove planting program which started in 2003.

The study area was located in a river delta formed from deposits carried by many rivers discharging into the Java Sea. The remarkable coastal inundation and erosion, which Sayung sub-district has faced for more than two decades, was probably also due to a change in sediment-carrying capacity of the longshore current (Anonymous, 2014; Astra et al., 2014). This longshore current, generated by waves, exceeded the quantity of sediment supplied to the beach. Further, land use change in upstream areas resulted in an increase of 
erosion and water discharge in particular during rainy seasons, yielding more sediment to the downstream area. In fact, not all of this sediment could be discharged into the sea; some was deposited along the river bottom, irrigation canals, estuaries and other water bodies in its path. This led not only to the narrowing and to silting up of the canals and rivers, but also to the reduction of sediment supply to the littoral zone inducing coastal erosion. Moreover, massive coastal reclamation in a neighbouring area such as Terboyo industrial complex extended seaward after 1994, and Tanjung Emas Harbour first developed in 1985 could have changed currents and material transport along the coast in the study area as well. To prove that there were some influences of harbour development and beach reclamation to the severe inundation impact, however, is beyond the scope of this study.

\subsection{Conclusions}

This research presents two methods to identify shoreline positions: as a line and as a margin, including a measure of change uncertainty at different epochs. Both methods used FCM classification to determine partial membership of water and non-water. While shoreline changes can be detected by both methods, the shoreline as a margin provides a more detailed estimation of change area than the shoreline as a line. Moreover, by having shoreline as a margin, we can assess its spatial extent and measure its change uncertainty at different levels. Abrupt and gradual changes of shoreline were identified at an object level and the spatial distribution of uncertainty estimated at a pixel level.

Some challenges for the improvement of the method consist of: (1) including an extensional uncertainty and represent shoreline as a conditional boundary; (2) including seasonal condition in the selection of images; and (3) integrating the results with a digital elevation model. In addition, the integration with other datasets such as land use and land cover pattern, hydrological data and other information associated with the study area is important as well to have a better understanding of processes which influence the shoreline change.

Both methods have been successfully implemented in a coastal area in the Sayung sub-district in Java using a series of Landsat images. The change area estimation and its change uncertainty may support local government and other stakeholders in monitoring shoreline 
changes. Integrating the results with the distribution of elements at risk such as settlements and other important facilities can help to analyze which location needs to be prioritized in disaster response. For example, priority could be given to a change area from shoreline to water which has low change uncertainty value as it was obvious that shoreline has changed due to inundation or erosion. Priority could also be given, however, to the area with higher change uncertainty, for example if the location is a densely populated area. Continuous monitoring of shoreline changes in order to understand risks and to anticipate the potential impacts is highly important. 


\section{Monitoring Shorelines with Change Vector Analysis}

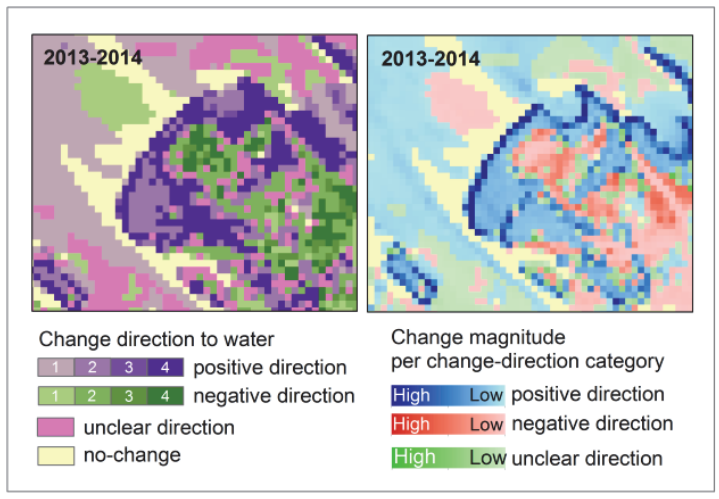

A method to identify shoreline positions and their changes as a fuzzy area is presented including a measure of change confusion. The method provided information regarding the change magnitude and the trend of water membership in each pixel. This information represents specific type of change processes showing multi-year patterns of water membership changes over time.

This chapter is based on the published paper: Dewi, R.S., Bijker, W., Stein, A. Change Vector Analysis to Monitor the Changes in Fuzzy Shorelines. Remote Sensing. 2017, 9, 147 
Abstract

Mapping of shorelines and monitoring of their changes is challenging due to the large variation in shoreline position related to seasonal and tidal patterns. This study focused on a flood-prone area in the north of Java. We show the possibility of using fuzzy-crisp objects to derive shoreline positions as the transition zone between the classes water and non-water. Fuzzy c-means classification was used to estimate the membership of pixels to these classes. A transition zone between the classes represents the shoreline, and its spatial extent was estimated using fuzzy-crisp objects. In change vector analysis (CVA) applied to water membership of successive shorelines, a change category was defined if the change magnitude between two years, $t_{1}$ and $t_{2}$, differed from zero, while zero magnitude corresponded to no-change category. Over several years, overall change magnitude and change directions of the shoreline allowed us to identify the trend of the fluctuating shoreline and the uncertainty distribution. The fuzzy error matrix (FERM) showed overall accuracies between 0.84 and 0.91 . Multi-year patterns of water membership changes could indicate coastal processes such as: (a) high change direction and high change magnitude with a consistent positive direction probably corresponding to land subsidence and coastal inundation, while a consistent negative direction probably indicates a success in a shoreline protection scheme; (b) low change direction and high change magnitude indicating an abrupt change which may result from spring tides, extreme waves and winds; (c) high change direction and low change magnitude which could be due to cyclical tides and coastal processes; and (d) low change direction and low change magnitude probably indicating an undisturbed environment, such as changes in water turbidity or changes in soil moisture. The proposed method provided a way to analyze changes of shorelines as fuzzy objects and could be well-suited to apply to coastal areas around the globe.

Keywords: shoreline change; change vector; confusion index; coastal inundation; Indonesia 


\subsection{Introduction}

The study of changing shorelines is essential to assist in the design of effective coastal protection (Jin et al., 2015; Zanuttigh et al., 2005), verifying numerical models (Baldassarre et al., 2009; Kaergaard and Fredsoe, 2013), developing hazard maps (Snoussi et al., 2009), formulating policies regarding coastal development (O'Connor et al., 2010), and for coastal research and monitoring (Tamassoki et al., 2014). A shoreline is defined as the intersection of coastal land and water surface indicating the water edge movements of which the position is changing through time due to different water levels during high tide and low tide (Bird, 1985; Boak and Turner, 2005; DavidsonArnott, 2010). Oertel (2005) referred to a shoreline as the line associated with sea level rather than with high and low tides. When considering only the tide, many shorelines are due to the shifting of water with tidal differences. Tidal differences vary and are influenced by the changes in the magnitude of gravitational attractions on the water body of the Earth, winds and waves. Furthermore, shorelines have changed their dynamics at varying rates as a response to coastal processes such as sediment erosion, transportation and deposition along the shore. Rapid changes occur during an extreme event such as storms, whereas gradual changes occur during an intervening period (Bird, 2000). Shoreline changes can be estimated over various time scales and result into long-term, cyclic and local random variation. Long-term variation includes variation due to the land subsidence, relative sea level rise and sediment storage. Cyclic variation is related to the tide cycles or seasons, whereas waves and storms cause random variation of a local character.

As the shoreline positions vary over time, shoreline indicators are used as proxies to represent shoreline positions, including: (a) distinguishable coastal features, for example, a previous high-tide line; (b) the intersection of coastal profile with specific vertical water elevation, e.g., the mean sea level; and (c) shoreline features observable from remote sensing images. An example of the latter is the boundary between water and non-water pixels (Dewi et al., 2016; Ghosh et al., 2015; Liu et al., 2014; Moore et al., 2006). The shoreline boundary between coastal land and water is fuzzy since there is a gradual transition from coastal land to water. Given the nature of the fuzzy shoreline and its changing position, detection of shoreline requires dealing with uncertainty. Fisher (1999) mentioned three types of uncertainty: (a) errors: if a shoreline is clearly identified, the uncertainty may arise from error, for example in data 
processing, spatial generalization, and measurement; (b) vagueness: if it is not possible to define the spatial extent of coastal land, water, and the transition zone (Williamson (1994) after Fisher (1999)); and (c) ambiguity: relating to the confusion of land and water definition considering a different classification system or a different perception.

Previous studies have proposed several ways of generating shoreline positions. Shoreline survey and photogrammetry have been primary technology for shoreline mapping, yet both methods are time consuming and expensive ( $\mathrm{Li}$ et al., 2002). Therefore, image classification is used widely nowadays to detect shoreline positions. Most studies regarding shoreline detection have used hard classification such as thresholding, water indices, iterative selforganizing data analysis (ISODATA), binary slicing, maximum likelihood classification (MLC) and manual digitizing (Ghosh et al., 2015; Marfai et al., 2008a; Senthilnatha et al., 2012; Shenbagaraj et al., 2014; Tamassoki et al., 2014), whereas only a few applied soft classifications (Dewi et al., 2016; Muslim et al., 2006; Taha and Elbeih, 2010).

Due to the fuzziness of shoreline positions, using hard classification for shoreline mapping could produce errors on the classification results, since hard classification assigns a single label to a pixel, based on its highest membership. To overcome this limitation, this chapter explores fuzzy classification to detect shoreline positions from a remote sensing image. In our previous work, we proposed two procedures to derive fuzzy shorelines: (a) we derived shorelines by applying a threshold equal to 0.5 to the membership and depicted shorelines as a single line; and (b) we derived shorelines as a margin determined by the choice of thresholds on the membership function (Dewi et al., 2016). In the current paper, we proposed a third procedure to distinguish shoreline proxies from digital images. A shoreline is represented as the transition zone between water and land. In this case, pixels at which the membership value $(\mu)$ exceed 0.99 are the core of a class, whereas pixels with $0.01<\mu<0.09$ belong to transition zones and pixels with $\mu<0.01$ do not belong to objects. In this way, we can account for the gradual transition between water and land (vagueness of the boundary). Moreover, in change detection, use of transition zones instead of crisp shorelines allows us to account for the influence of ambiguity resulting from comparing images recorded under different circumstances, such as weather, and have a more detailed description, of not only the magnitude and direction of the changes, but also of the related uncertainty. 
Various change detection techniques have been developed. They can be divided into two groups, namely bi-temporal change detection and temporal trajectory analysis (Jianya et al., 2008; Lambin and Strahler, 1994). The former measures changes based on two separate time periods, for example image differencing and post classification comparison. Image differencing does not provide a detailed change matrix while post classification comparison does not allow the detection of subtle changes within a class. The latter, temporal trajectory analysis is based on the temporal development curve or trajectory for successive times. It focuses both on what has changed between dates, as well as on the trend of the change over the period (Jianya et al., 2008; Lambin and Strahler, 1994; Lu et al., 2014; Singh, 1989). Change detection in this research utilizes the second method. To measure the change of the fuzzy shoreline, change vector analysis (CVA) based upon pixel-wise comparison was used to estimate the changes of successive shorelines. CVA identifies changes of features which were acquired at different times. In previous studies, CVA was applied to the brightness and greenness indices (Kauth and Thomas, 1976; Malila, 1980), normalized difference vegetation index (Lambin and Ehrlich, 1997; Lambin and Strahler, 1994), near infrared band and vegetation index (Landmann et al., 2013), wetness and bare soil index (Vorovencii, 2014), and spectral bands and textural images (He et al., 2011; Singh and Talwar, 2015). In this study, CVA was applied to the water membership values of shoreline images. Furthermore, in the earlier studies CVA has been applied in the multi-spectral space (Malila, 1980; Özyavuz et al., 2011), and then extended to be applied in multi-temporal observation vectors of an indicator variable measured at different times (Lambin and Strahler, 1994). CVA provides an overall change magnitude and change direction showing the trend of the fluctuating shoreline.

The objective of this study was to develop a method that is useful for monitoring the changes of a fuzzy shoreline. The method is based on fuzzy classification and CVA. A series of Landsat images is used to detect shoreline positions as a transition zone while taking tides into account. For this study, the uncertainty of shoreline positions was estimated by means of confusion indices. We focus on inherent uncertainty caused by continuous variation of a shoreline over time, and on uncertainty as it propagates from extraction and implementation of the shoreline change detection method. The method is applied to an area in Java, in the northern coastal area of the Central Java Province, Indonesia, where extensive shoreline 
changes associated with coastal inundation have increased in term of frequency and duration.

\subsection{Shoreline monitoring using fuzzy-crisp object model and CVA}

\subsubsection{Satellite images, data pre-processing and reference data generation}

\section{Satellite images and data pre-processing}

Multi-temporal images from the Landsat 8 OLI/TIRS (Operational Land Imager/Thermal Infrared Sensor) with $30 \mathrm{~m}$ spatial resolution were used to monitor the shoreline change between 2013 and 2015 (Table 3.1). We obtained terrain corrected Landsat images (L1T product) from USGS EarthExplorer (USGS, 2015). Those images were acquired at the low tide. Tidal data relating to the time of acquisition of the images were collected from the Indonesian Geospatial Information Agency.

Table 3.1 Landsat 8 OLI/TIRS images captured in the low tides supplemented by tide level and reference images used in the accuracy assessment purpose for each period

\begin{tabular}{ccc}
\hline Acquisition Date & Astronomical Tide Level (m) & Reference Data \\
\hline 23 May 2013 & -0.1 & \\
12 September 2013 & -0.1 & Pleiades \\
14 October 2013 & -0.3 & (27 February 2013) \\
1 December 2013 & -0.3 & \\
\hline 10 May 2014 & -0.01 & SPOT 6 \\
15 September 2014 & -0.2 & (5 October 2014) \\
1 October 2014 & -0.2 & Sentinel 2 \\
18 November 2014 & -0.3 & (26 December \\
\hline 29 May 2015 & +0.04 & \\
18 September 2015 & -0.1 & \\
20 October 2015 & -0.3 &
\end{tabular}

Pre-processing of Landsat 8 OLI/TIRS comprises two steps: (a) histogram minimum adjustment; it was applied to remove the influence of atmospheric path radiance (Hadjimitsis et al., 2010; Mather, 2004); and (b) geo-referencing; it was implemented using $>100$ ground control points (GCP) collected from road intersections, 
rivers and other prominent features. The root mean square error (RMSE) values were less than 0.1 pixels. Geo-registration of Landsat images was conducted using geometrically corrected reference images: (1) a Pleiades image at a $2 \mathrm{~m}$ spatial resolution; (2) a SPOT 6 (Satellite Pour l'Observation de la Terre) image at a $6 \mathrm{~m}$ spatial resolution; and (3) a Sentinel 2 image at a $10 \mathrm{~m}$ spatial resolution. The spectral band information for each reference image including Landsat 8 OLI/TIRS is available in Table 3.2.

Table 3.2 The spectral band information of Landsat 8 OLI/TIRS used in image classifications, Pleiades, SPOT 6 and Sentinel 2 used as reference images

\begin{tabular}{ccc}
\hline Satellite & Bands & Wavelength $(\boldsymbol{\mu} \mathbf{m})$ \\
\hline \multirow{3}{*}{ Landsat 8 OLI/TIRS } & Blue & $0.43-0.45$ \\
& Green & $0.45-0.51$ \\
& Red & $0.53-0.59$ \\
& NIR & $0.64-0.67$ \\
& SWIR 1 & $0.85-0.88$ \\
& SWIR 2 & $1.57-1.65$ \\
Pleiades & Blue & $2.11-2.29$ \\
& Green & $0.43-0.55$ \\
& Red & $0.50-0.62$ \\
& NIR & $0.59-0.71$ \\
SPOT 6 & Blue & $0.74-0.94$ \\
& Green & $0.45-0.52$ \\
& Red & $0.53-0.59$ \\
& NIR & $0.625-0.695$ \\
& Blue & $0.76-0.89$ \\
\hline \multirow{2}{*}{ Sentinel 2 } & Green & 0.49 \\
& Red & 0.56 \\
& SWIR & 0.665 \\
& & 0.842 \\
\hline
\end{tabular}

\section{Reference data generation}

To evaluate the accuracy of a fuzzy classification, it is necessary to use soft reference data (Congalton and Green, 2009; Lu and Weng, 2007). We generated soft reference data from available fine resolution datasets (Harikumar et al., 2015; Pontius and Cheuk, 2006). These datasets (Pleiades, SPOT 6 and Sentinel 2) were rectified using a 2015 orthoimage. To reduce the variance of the Pleiades image, smoothing was performed using the average filter applied to a $3 \times 3$ window size. Afterwards, we applied fuzzy c-means 
with the number of classes $c=2$ and the fuzzy weight $m=1.7$ (Dewi et al., 2016). Further, membership images generated using FCM classification from these high resolution datasets were used as reference images.

For accuracy assessment purpose, the pixel size of SPOT 6 image was resampled to $10 \mathrm{~m}$ using nearest neighbour resampling, so that the spatial resolution of Pleiades, SPOT 6, Sentinel 2 and Landsat images were in the ratio 15:3:3:1. Hence, 225 pixels $(15 \times 15)$ of Pleiades, 9 pixels $(3 \times 3)$ of SPOT 6 , and 9 pixels $(3 \times 3)$ of Sentinel 2 were combined (pixel values averaged) to achieve the pixel dimension of Landsat images. Furthermore, an effective comparison could be made between images of different resolutions.

For the alternative methods, MLC and hardened classification, we visually interpreted Pleiades and SPOT 6 images as hard reference data for the year 2013 and 2014 respectively, whereas ground data were used as the 2015 reference data.

\subsubsection{FCM classification}

To discriminate water classes from non-water, we applied a fuzzy cmeans classification (Bezdek et al., 1984). FCM iteratively separates data clusters with fuzzy means and fuzzy boundaries and the results assign each pixel to a partial membership of land cover classes. The membership values $(\mu)$ range from 0 to 1 , and add up to 1 for each pixel. In this work, the membership values of the classification follow the trapezoidal membership function. In the literature, there are two possible ways of generating the membership function: Similarity Relation Model (SRM) and Semantic Import Model (SIM) (Burrough, 1989; Cheng, 2002; Zhu et al., 2010). The former derives the membership function using classifiers like for example fuzzy $k$ means, fuzzy c-means, and neural networks (Chuang et al., 2006; Zhu et al., 2010). The first two are data driven, partitioning the observations based on multivariate attributes. The latter, SIM, generates membership based on expert knowledge (Burrough, 1989; Medasani et al., 1998).

The FCM results assign each pixel to membership of the two classes. The value of $m$ determines the level of fuzziness in FCM classification. If $m=1$, FCM is hard classifier. FCM was carried out by labeling two membership images resulting from each FCM classification as the water and non-water images. To do so, the combination of near infrared (NIR) and shortwave infrared (SWIR) of Landsat bands were 
used. The water label was given to the class which has the minimum value of the sum of the cluster means in the infrared bands. Detailed descriptions regarding the FCM algorithm are available in Bezdek et al. (1984), whereas detailed explanations regarding membership function, pixel labeling, and parameter estimation for FCM classification can be found in Dewi et al. (2016).

\subsubsection{Validation}

To quantify the accuracy of the FCM classifier, a conventional error matrix cannot be used. In this study, we used a fuzzy error matrix which has non-negative real numbers (Binaghi et al., 1999; Pontius and Cheuk, 2006; Silván-Cárdenas and Wang, 2008), since pixels have a partial membership to two classes.

For accuracy assessment, soft reference images were generated by applying an FCM classification to Pleiades, SPOT 6, and Sentinel 2 images which were all captured during low tides. Let the value of $\mu_{i k}$ and $\mu_{j l}$ represent membership values of the $k^{\text {th }}$ pixel for class $i$ in the classified image and $l^{\text {th }}$ pixel for class $j$ in the reference images. It was assumed that the rows of the matrix are classes of the classified image and the columns are classes of the reference image. The fuzzy error matrix (FERM) is obtained using minimum operator showing the maximum possible overlap between the classified and reference images and indicating the agreement between classes in both images (Harikumar et al., 2015; Pontius and Cheuk, 2006; Silván-Cárdenas and Wang, 2008):

$$
A_{i=j}=M I N\left(\mu_{i k}, \mu_{j l}\right)
$$

To calculate the agreement in FERM, a group of 225 Pleiades pixels $(15 \times 15)$, 9 SPOT 6 pixels $(3 \times 3)$ and 9 Sentinel 2 pixels $(3 \times 3)$ were averaged to achieve pixel dimension of Landsat images. Using this reference data, membership of 200 pixels randomly selected from both classified and reference images were computed to obtain the overall accuracies (OA) of the FCM classifications:

$$
O A=\frac{\sum_{i=1}^{c} A_{i=j}}{k_{s}}
$$

where $k_{s}$ represents the number of pixels used to generate the FERM. Moreover, we compared the quality of the FCM results with respect to alternative pixel-based classification methods. Firstly, we classified the multi-spectral bands of Landsat using the MLC classifier being the most commonly used supervised classification technique for remote sensing images (Richards, 2013). Secondly, we classified the multi- 
spectral bands of Landsat images using FCM and then labelled each pixel to the class to which it has the highest membership. It was assumed that hard output is the highest membership value which is actually computed from the soft output (Dutta, 2009; Tso and Mather, 2009; Wang, 1990; Zhang and Foody, 1998b). We called this the hardened classification. After classification, post classification comparisons were applied to detect the changes of the shorelines by superimposing the classification results in GIS.

\subsubsection{Deriving fuzzy shoreline}

FCM classification derives two raster layers, namely: water and nonwater membership images. Each layer consists of fuzzy regions with fuzzy boundaries. Estimation of the spatial extent of objects i.e., water, non-water and shoreline, and their representations is related to the interpretation of the fuzziness of objects (Cheng, 2002). To derive shorelines at the locations where water and non-water objects meet, we modified the fuzzy-crisp object model based upon Cheng (2002). The two classes (water and non-water) are spatially disjoint, but their boundary is vaguely defined, whereas their interiors are crisp. Given this concept, we consider the boundary between water and non-water as fuzzy and form a transition zone that we call shoreline. To determine the spatial extent of water, non-water and shoreline, it is necessary to combine class objects from different layers into a single layer. The decision function $d_{w k}$ assigns pixel $k$ with water membership value $\mu_{w k}$ to a sub-area of water class based upon the following conditions:

$$
\text { If }\left(\mu_{w k}>0.99\right) \text { then }\left(d_{w k}=1\right)
$$

which means that the pixels belong to sub-areas water. Threshold 0.99 was set to represent the highest water membership values indicating the core of water.

$$
\text { If }\left(0.01<\mu_{w k}<0.99\right) \text { then }\left(d_{w k}=\mu_{w k}\right)
$$

This equation classifies pixels as shoreline.

$$
\text { If }\left(\mu_{w k}<0.01\right) \text { then }\left(d_{w k}=0\right)
$$

Pixels not belonging to water or shoreline constitute non-water. A threshold of 0.01 represents the lowest water membership values. This indicates pixels with membership below that threshold not belong to water or shoreline areas. The results after deriving fuzzy shorelines by applying Equations (3.3)-(3.5) were called as shoreline images. 


\subsubsection{Uncertainty estimation}

The uncertainty in class assignment was estimated by a measure of the confusion index $C I$ for each pixel resulting from FCM classification as follows (Burrough et al., 1997; Cheng et al., 2001; Zhang and Kirby, 1999):

$$
C I=1-\left(\mu_{i k}^{1}-\mu_{i k}^{2}\right)
$$

If $C I$ approaches 1 then the difference in membership values between the first and the second highest membership values are small meaning that both membership values are almost equal. Thus, it is more likely that the pixel defines a fuzzy boundary and the uncertainty of the pixel to belong to the class with the largest membership is high. If $C I$ approaches 0 , however, then the difference in membership values between the first and the second highest membership values are high and the uncertainty of the pixel to belong to the class with the largest membership is low.

\subsubsection{Shoreline change detection}

For establishing the changes over time, shoreline images obtained using Equations (3.3)-(3.5) of the same year were stacked and compared with the stack of shoreline images of the next year with corresponding seasons. If membership values to water $\left(\mu_{w k}\right)$ of shoreline images within year $t_{1}$ and $t_{2}$ are given by $G=\left(g_{1}, g_{2}, \ldots, g_{z}\right)^{t_{1}}$ and $H=\left(h_{1}, h_{2}, \ldots . ., h_{z}\right)^{t_{2}}$, respectively, and $z$ is the number of shoreline images, a change vector is defined as:

$$
\Delta C V=H-G=\left(\begin{array}{c}
h_{1}-g_{1} \\
h_{2}-g_{2} \\
\cdots . . \\
h_{z}-g_{z}
\end{array}\right)
$$

Here, $\triangle C V$ includes all the change information between two years for a given pixel. The final result of CVA is an image of vector changes. The shoreline change is defined as the vector difference between successive time periods and is represented by a vector in a multidimensional space. The length of the change vector indicates the magnitude of change and its direction indicates the nature of the change (Lambin and Strahler, 1994; Lunetta and Elvidge, 1999).

\section{Change magnitude}

The change magnitude $\|\Delta C V\|$ was derived by determining the Euclidean distance between shoreline images as: 


$$
\|\Delta C V\|=\sqrt{\left(h_{1}-g_{1}\right)^{2}+\left(h_{2}-g_{2}\right)^{2}+\ldots \ldots+\left(h_{z}-g_{z}\right)^{2}}
$$

$\|\Delta C V\|$ represents the total membership differences between two years and measures the intensity of the shoreline change. Two categories of change were identified, namely change and no-change. A change category was defined when the water membership difference between $t_{1}$ and $t_{2}$ is larger than zero, whereas a no-change category is related to a magnitude equal to zero. A higher change magnitude corresponds with a large water membership difference between shoreline images in $t_{1}$ and $t_{2}$. When the change magnitude is low, the water membership difference between shoreline images in $t_{1}$ and $t_{2}$ is small.

\section{Change direction}

For all pixels classified as change, we estimated the change directions. Change direction was determined by evaluating the water membership difference between shoreline images in two successive years. It quantifies the variation of water membership in each pixel and shows how frequent the changes have occurred. Change direction estimation started by calculating the number of change combinations $(C C)$ as:

$$
C C=D^{p}
$$

where $D$ refers to the types of change direction which can be distinguished when comparing the stack of shoreline images from both years for corresponding seasons and $p$ refers to the number of shoreline image pairs. We identified three types of change direction to water: positive change direction (or in short positive direction), negative change direction (negative direction) and unclear change direction (unclear direction).

The change vector ( $\mathrm{CV}$ ) showing water membership difference between a pair of shoreline images in $t_{1}$ and $t_{2}$ from corresponding seasons needs to be estimated: (a) if the water membership difference between pair of shoreline images within years $t_{1}$ and $t_{2}$ is less than zero then $C V=-1$ showing a decrease of water membership in $t_{2} ;$ (b) if the water membership difference is larger than zero then $C V=+1$ showing an increase of water membership in $t_{2} ;$ (c) if the water membership difference is equal to zero then $C V=0$ showing that the water membership in $t_{1}$ and $t_{2}$ were the same. The total change vector $(T C V)$ values are defined as:

$$
T C V=C V 1+C V 2+\ldots \ldots+C V z
$$


CV1 refers to $\left(h_{1}-g_{1}\right), C V 2$ refers to $\left(h_{2}-g_{2}\right)$, and $C V z$ refers to $\left(h_{z}-\right.$ $g_{z}$ ). Finally, the change direction (Chg.dir) categories showing the degree of change direction to water membership were obtained by grouping the direction values: (a) TCV values from +1 up to $+z$ were grouped as positive direction; (b) TCV values from -1 up to $-z$ were grouped as negative direction; (c) TCV values equal to 0 showing unclear change directions were classified as unclear direction; and (d) $T C V$ values equal to 0 having water membership differences equal to 0 at all time periods were classified as no-change. Table 3.3 shows the procedure to determine the change direction categories by using four pairs of image used in this study.

Based upon these results, the change area of a specific change direction category (positive direction, negative direction, and unclear direction) and the no-change area were defined as:

$$
A(\mathrm{Chg})=P_{k}(\mathrm{Chg}) \times A(k)
$$

where $P_{k}(\mathrm{Chg})$ is the number of pixels belonging to the area of change and no-change, and $A(k)$ is area of pixel $k\left(30 \times 30 \mathrm{~m}^{2}\right)$.

\subsubsection{Change uncertainty}

Based upon the change detection results, the change uncertainty of related areas was estimated by the confusion index $C I$. If $C I$ of two images for $t_{1}$ and $t_{2}$ are given by $Q=\left(q_{1}, q_{2}, \ldots ., q_{z}\right)^{t_{1}}$ and $R=$ $\left(r_{1}, r_{2}, \ldots, r_{Z}\right)^{t_{2}}$, respectively, then the change confusion is derived as:

$$
\|\Delta C U\|=\sqrt{\left(q_{1}-r_{1}\right)^{2}+\left(q_{2}-r_{2}\right)^{2}+\ldots \ldots+\left(q_{z}-r_{z}\right)^{2}}
$$

A high $\|\Delta C U\|$ value is related to a large difference of confusion indices between images for $t_{1}$ and $t_{2}$, whereas a low change confusion corresponds to a small difference of confusion indices between images for $t_{1}$ and $t_{2}$. 
Table 3.3 The procedure to estimate change directions of shoreline. It quantifies the variation of water membership in each pixel and shows how frequent the changes have occurred

\begin{tabular}{|c|c|c|c|c|c|c|c|c|c|c|c|c|c|}
\hline \multirow[b]{2}{*}{$C C$} & \multicolumn{4}{|c|}{$C V$} & \multirow[b]{2}{*}{$T C V$} & \multirow[b]{2}{*}{ Chg.Dir } & \multirow[b]{2}{*}{$C C$} & \multicolumn{4}{|c|}{$C V$} & \multirow[b]{2}{*}{$T C V$} & \multirow[b]{2}{*}{ Chg.Dir } \\
\hline & $C V 1$ & $\mathrm{CV}_{2}$ & CV3 & CV4 & & & & $\begin{array}{c}C V \\
1\end{array}$ & $C V 2$ & $\mathrm{CV}_{3}$ & CV4 & & \\
\hline 1 & 0 & 0 & 0 & 0 & 0 & $\begin{array}{l}\text { No- } \\
\text { change }\end{array}$ & 21 & 0 & +1 & -1 & +1 & +1 & $\begin{array}{l}\text { Positive } \\
\text { direction }\end{array}$ \\
\hline 2 & +1 & +1 & +1 & +1 & +4 & $\begin{array}{l}\text { Positive } \\
\text { direction }\end{array}$ & 22 & 0 & -1 & +1 & +1 & +1 & $\begin{array}{l}\text { Positive } \\
\text { direction }\end{array}$ \\
\hline 3 & +1 & 0 & +1 & +1 & +3 & $\begin{array}{l}\text { Positive } \\
\text { direction }\end{array}$ & 23 & -1 & +1 & 0 & +1 & +1 & $\begin{array}{c}\text { Positive } \\
\text { direction }\end{array}$ \\
\hline 4 & 0 & +1 & +1 & +1 & +3 & $\begin{array}{l}\text { Positive } \\
\text { direction }\end{array}$ & 24 & -1 & 0 & +1 & +1 & +1 & $\begin{array}{l}\text { Positive } \\
\text { direction }\end{array}$ \\
\hline 5 & +1 & +1 & 0 & +1 & +3 & $\begin{array}{l}\text { Positive } \\
\text { direction }\end{array}$ & 25 & +1 & 0 & -1 & +1 & +1 & $\begin{array}{l}\text { Positive } \\
\text { direction }\end{array}$ \\
\hline 6 & +1 & +1 & +1 & 0 & +3 & $\begin{array}{l}\text { Positive } \\
\text { direction }\end{array}$ & 26 & +1 & -1 & 0 & +1 & +1 & $\begin{array}{l}\text { Positive } \\
\text { direction }\end{array}$ \\
\hline 7 & +1 & -1 & +1 & +1 & +2 & $\begin{array}{l}\text { Positive } \\
\text { direction }\end{array}$ & 27 & +1 & 0 & +1 & -1 & +1 & $\begin{array}{l}\text { Positive } \\
\text { direction }\end{array}$ \\
\hline 8 & -1 & +1 & +1 & +1 & +2 & $\begin{array}{l}\text { Positive } \\
\text { direction }\end{array}$ & 28 & +1 & -1 & +1 & 0 & +1 & $\begin{array}{l}\text { Positive } \\
\text { direction }\end{array}$ \\
\hline 9 & +1 & +1 & -1 & +1 & +2 & $\begin{array}{l}\text { Positive } \\
\text { direction }\end{array}$ & 29 & +1 & +1 & 0 & -1 & +1 & $\begin{array}{l}\text { Positive } \\
\text { direction }\end{array}$ \\
\hline 10 & +1 & +1 & +1 & -1 & +2 & $\begin{array}{l}\text { Positive } \\
\text { direction }\end{array}$ & 30 & +1 & +1 & -1 & 0 & +1 & $\begin{array}{l}\text { Positive } \\
\text { direction }\end{array}$ \\
\hline 11 & 0 & +1 & +1 & 0 & +2 & $\begin{array}{l}\text { Positive } \\
\text { direction }\end{array}$ & 31 & 0 & +1 & +1 & -1 & +1 & $\begin{array}{l}\text { Positive } \\
\text { direction }\end{array}$ \\
\hline 12 & +1 & 0 & +1 & 0 & +2 & $\begin{array}{l}\text { Positive } \\
\text { direction }\end{array}$ & 32 & -1 & +1 & +1 & 0 & +1 & $\begin{array}{l}\text { Positive } \\
\text { direction }\end{array}$ \\
\hline 13 & +1 & 0 & 0 & +1 & +2 & $\begin{array}{l}\text { Positive } \\
\text { direction }\end{array}$ & 33 & 0 & +1 & -1 & 0 & 0 & $\begin{array}{c}\text { Unclear } \\
\text { direction }\end{array}$ \\
\hline 14 & 0 & +1 & 0 & +1 & +2 & $\begin{array}{l}\text { Positive } \\
\text { direction }\end{array}$ & 34 & 0 & -1 & +1 & 0 & 0 & $\begin{array}{c}\text { Unclear } \\
\text { direction }\end{array}$ \\
\hline 15 & +1 & +1 & 0 & 0 & +2 & $\begin{array}{l}\text { Positive } \\
\text { direction }\end{array}$ & 35 & -1 & +1 & 0 & 0 & 0 & $\begin{array}{c}\text { Unclear } \\
\text { direction }\end{array}$ \\
\hline 16 & 0 & 0 & +1 & +1 & +2 & $\begin{array}{l}\text { Positive } \\
\text { direction }\end{array}$ & 36 & -1 & 0 & +1 & 0 & 0 & $\begin{array}{c}\text { Unclear } \\
\text { direction }\end{array}$ \\
\hline 17 & +1 & 0 & 0 & 0 & +1 & $\begin{array}{l}\text { Positive } \\
\text { direction }\end{array}$ & 37 & +1 & 0 & -1 & 0 & 0 & $\begin{array}{c}\text { Unclear } \\
\text { direction }\end{array}$ \\
\hline 18 & 0 & +1 & 0 & 0 & +1 & $\begin{array}{l}\text { Positive } \\
\text { direction }\end{array}$ & 38 & +1 & -1 & 0 & 0 & 0 & $\begin{array}{c}\text { Unclear } \\
\text { direction }\end{array}$ \\
\hline 19 & 0 & 0 & 0 & +1 & +1 & $\begin{array}{l}\text { Positive } \\
\text { direction }\end{array}$ & 39 & 0 & 0 & +1 & -1 & 0 & $\begin{array}{c}\text { Unclear } \\
\text { direction }\end{array}$ \\
\hline 20 & 0 & 0 & +1 & 0 & +1 & $\begin{array}{l}\text { Positive } \\
\text { direction }\end{array}$ & 40 & -1 & 0 & 0 & +1 & 0 & $\begin{array}{l}\text { Unclear } \\
\text { direction }\end{array}$ \\
\hline
\end{tabular}


Chapter 3

Table $\mathbf{3 . 3}$ (Continued)

\begin{tabular}{|c|c|c|c|c|c|c|c|c|c|c|c|c|c|}
\hline \multirow{2}{*}{$C C$} & \multicolumn{4}{|c|}{$C V$} & \multirow{2}{*}{$T C V$} & \multirow{2}{*}{ Chg.Dir } & \multirow{2}{*}{$C C$} & \multicolumn{4}{|c|}{$C V$} & \multirow{2}{*}{$T C V$} & \multirow{2}{*}{ Chg.Dir } \\
\hline & $C V 1$ & $\mathrm{CV} 2$ & $\mathrm{CV} 3$ & CV4 & & & & $C V 1$ & $C V 2$ & CV3 & CV4 & & \\
\hline 41 & 0 & +1 & 0 & -1 & 0 & $\begin{array}{l}\text { Unclear } \\
\text { direction }\end{array}$ & 61 & 0 & -1 & -1 & +1 & -1 & $\begin{array}{l}\text { Negative } \\
\text { direction }\end{array}$ \\
\hline 42 & +1 & 0 & 0 & -1 & 0 & $\begin{array}{l}\text { Unclear } \\
\text { direction }\end{array}$ & 62 & -1 & -1 & +1 & 0 & -1 & $\begin{array}{l}\text { Negative } \\
\text { direction }\end{array}$ \\
\hline 43 & 0 & 0 & -1 & +1 & 0 & $\begin{array}{l}\text { Unclear } \\
\text { direction }\end{array}$ & 63 & +1 & -1 & -1 & 0 & -1 & $\begin{array}{l}\text { Negative } \\
\text { direction }\end{array}$ \\
\hline 44 & 0 & -1 & 0 & +1 & 0 & $\begin{array}{l}\text { Unclear } \\
\text { direction }\end{array}$ & 64 & -1 & +1 & -1 & 0 & -1 & $\begin{array}{l}\text { Negative } \\
\text { direction }\end{array}$ \\
\hline 45 & -1 & +1 & +1 & -1 & 0 & $\begin{array}{l}\text { Unclear } \\
\text { direction }\end{array}$ & 65 & -1 & -1 & 0 & +1 & -1 & $\begin{array}{l}\text { Negative } \\
\text { direction }\end{array}$ \\
\hline 46 & +1 & -1 & +1 & -1 & 0 & $\begin{array}{l}\text { Unclear } \\
\text { direction }\end{array}$ & 66 & -1 & 0 & -1 & +1 & -1 & $\begin{array}{l}\text { Negative } \\
\text { direction }\end{array}$ \\
\hline 47 & +1 & -1 & -1 & +1 & 0 & $\begin{array}{l}\text { Unclear } \\
\text { direction }\end{array}$ & 67 & 0 & 0 & -1 & -1 & -2 & $\begin{array}{l}\text { Negative } \\
\text { direction }\end{array}$ \\
\hline 48 & -1 & +1 & -1 & +1 & 0 & $\begin{array}{l}\text { Unclear } \\
\text { direction }\end{array}$ & 68 & -1 & 0 & -1 & 0 & -2 & $\begin{array}{l}\text { Negative } \\
\text { direction }\end{array}$ \\
\hline 49 & +1 & +1 & -1 & -1 & 0 & $\begin{array}{l}\text { Unclear } \\
\text { direction }\end{array}$ & 69 & 0 & -1 & -1 & 0 & -2 & $\begin{array}{l}\text { Negative } \\
\text { direction }\end{array}$ \\
\hline 50 & -1 & -1 & +1 & +1 & 0 & $\begin{array}{l}\text { Unclear } \\
\text { direction }\end{array}$ & 70 & -1 & -1 & 0 & 0 & -2 & $\begin{array}{l}\text { Negative } \\
\text { direction }\end{array}$ \\
\hline 51 & 0 & -1 & 0 & 0 & -1 & $\begin{array}{l}\text { Negative } \\
\text { direction }\end{array}$ & 71 & 0 & -1 & 0 & -1 & -2 & $\begin{array}{l}\text { Negative } \\
\text { direction }\end{array}$ \\
\hline 52 & -1 & 0 & 0 & 0 & -1 & $\begin{array}{l}\text { Negative } \\
\text { direction }\end{array}$ & 72 & -1 & 0 & 0 & -1 & -2 & $\begin{array}{l}\text { Negative } \\
\text { direction }\end{array}$ \\
\hline 53 & 0 & 0 & -1 & 0 & -1 & $\begin{array}{l}\text { Negative } \\
\text { direction }\end{array}$ & 73 & +1 & -1 & -1 & -1 & -2 & $\begin{array}{l}\text { Negative } \\
\text { direction }\end{array}$ \\
\hline 54 & 0 & 0 & 0 & -1 & -1 & $\begin{array}{l}\text { Negative } \\
\text { direction }\end{array}$ & 74 & -1 & +1 & -1 & -1 & -2 & $\begin{array}{l}\text { Negative } \\
\text { direction }\end{array}$ \\
\hline 55 & 0 & +1 & -1 & -1 & -1 & $\begin{array}{l}\text { Negative } \\
\text { direction }\end{array}$ & 75 & -1 & -1 & -1 & +1 & -2 & $\begin{array}{l}\text { Negative } \\
\text { direction }\end{array}$ \\
\hline 56 & 0 & -1 & +1 & -1 & -1 & $\begin{array}{l}\text { Negative } \\
\text { direction }\end{array}$ & 76 & -1 & -1 & +1 & -1 & -2 & $\begin{array}{l}\text { Negative } \\
\text { direction }\end{array}$ \\
\hline 57 & -1 & +1 & 0 & -1 & -1 & $\begin{array}{l}\text { Negative } \\
\text { direction }\end{array}$ & 77 & 0 & -1 & -1 & -1 & -3 & $\begin{array}{l}\text { Negative } \\
\text { direction }\end{array}$ \\
\hline 58 & -1 & 0 & +1 & -1 & -1 & $\begin{array}{l}\text { Negative } \\
\text { direction }\end{array}$ & 78 & -1 & 0 & -1 & -1 & -3 & $\begin{array}{l}\text { Negative } \\
\text { direction }\end{array}$ \\
\hline 59 & +1 & 0 & -1 & -1 & -1 & $\begin{array}{l}\text { Negative } \\
\text { direction }\end{array}$ & 79 & -1 & -1 & -1 & 0 & -3 & $\begin{array}{l}\text { Negative } \\
\text { direction }\end{array}$ \\
\hline \multirow[t]{2}{*}{60} & +1 & -1 & 0 & -1 & -1 & $\begin{array}{l}\text { Negative } \\
\text { direction }\end{array}$ & 80 & -1 & -1 & 0 & -1 & -3 & $\begin{array}{l}\text { Negative } \\
\text { direction }\end{array}$ \\
\hline & & & & & & & 81 & -1 & -1 & -1 & -1 & -4 & $\begin{array}{l}\text { Negative } \\
\text { direction }\end{array}$ \\
\hline
\end{tabular}

Notes: $\boldsymbol{C V}$ : Change vector (based on Equation (3.7); $\boldsymbol{C C}$ : Change combinations number (based on Equation (3.9)); $\boldsymbol{T C V}$ : Total change vector (based on Equation (3.10)); and Chg.Dir: Change direction 


\subsection{Change detection results and the estimation of uncertainty}

\subsubsection{FCM classification and accuracy assessment}

Table 3.4 presents the accuracy assessment of classification results using FCM and alternative classification methods. The FCM classifier outperformed MLC and the accuracy values of FCM are generally higher than the hardened classification.

Table 3.4 Summary of the overall classification accuracy using FCM, MLC and hardened classification

\begin{tabular}{cccc}
\hline & \multicolumn{3}{c}{ Overall Accuracy } \\
\cline { 2 - 4 } Classified Images & FCM & MLC & $\begin{array}{c}\text { Hardened } \\
\text { Classification }\end{array}$ \\
\hline 23 May 2013 & 0.87 & 0.72 & 0.86 \\
12 September 2013 & 0.85 & 0.76 & 0.85 \\
14 October 2013 & 0.86 & 0.73 & 0.86 \\
1 December 2013 & 0.86 & 0.73 & 0.84 \\
\hline 10 May 2014 & 0.89 & 0.78 & 0.87 \\
15 September 2014 & 0.90 & 0.76 & 0.88 \\
1 October 2014 & 0.90 & 0.78 & 0.88 \\
18 November 2014 & 0.91 & 0.79 & 0.90 \\
\hline 29 May 2015 & 0.84 & 0.75 & 0.84 \\
18 September 2015 & 0.88 & 0.79 & 0.87 \\
20 October 2015 & 0.89 & 0.79 & 0.86 \\
21 November 2015 & 0.89 & 0.80 & 0.88 \\
\hline
\end{tabular}

Figure 3.1 presents an example of FCM outputs, together with MLC and hardened classification. In the image, MLC overestimated the non-water area shown by the larger area of non-water (see Figure 3.1d,e,f, e.g., grid cells B1 and B2), whereas the hardened classification underestimated the non-water area (see Figure 3.1g, h,i, e.g., grid cells B1 and B2). Both methods failed to distinguish the gradual transition between water and non-water.

The results of FCM classification are presented in Figure 3.2 with the values ranging from 0 to 1 for both membership images of water (Figure 3.2a,b,c) and non-water (Figure 3.2d,e,f). Areas with higher water membership values were located for example in marine areas, fishponds, and water-covered agricultural areas (Figure 3.2a, e.g., grid cell $\mathrm{A} 2$ ). In Figure 3.2d, higher non-water membership pixels are 
located near settlements adjacent to the shorelines, and mangrove forests (Figure 3.2d, e.g., grid cells B2 and C3).

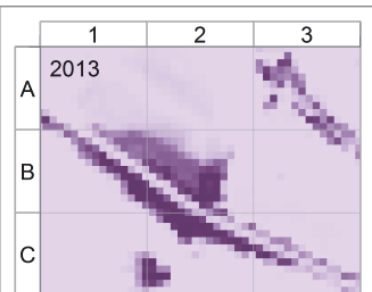

(a)

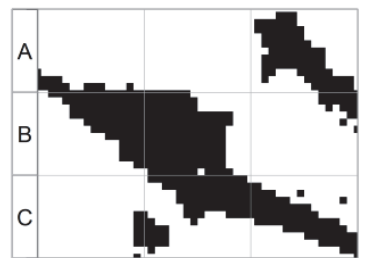

(d)

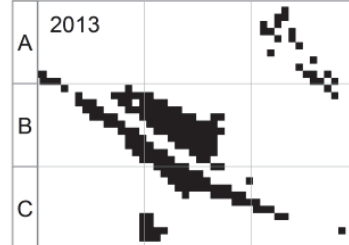

(g)

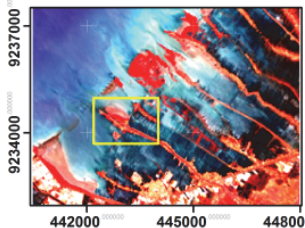

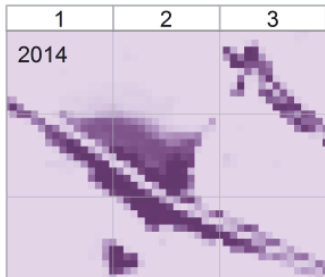

(b)

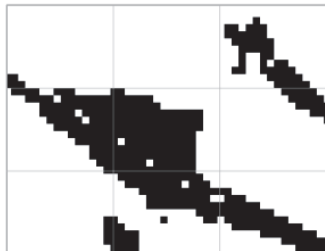

(e)

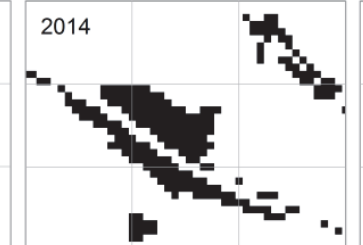

(h)
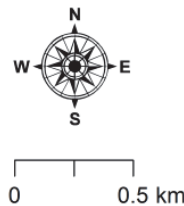

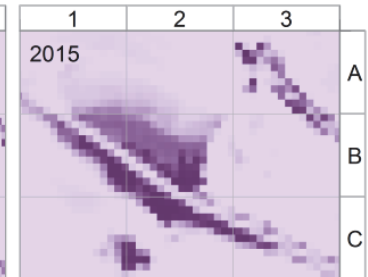

(c)

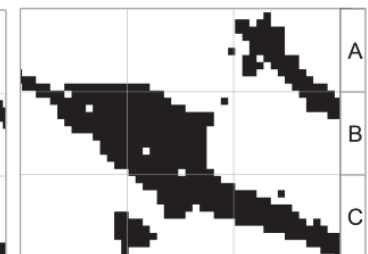

(f)

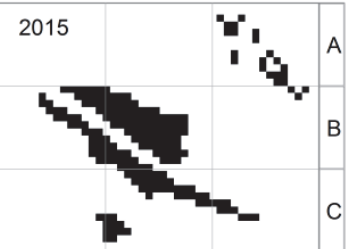

(i)

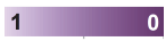

memberships

water

non-water

Figure 3.1 Example of classification results using: FCM $(a, b, c)$; MLC classifier $(d, e, f)$; and hardened classification $(g, h, i) .(a-i)$ are the detail presentations of yellow rectangle site in the insert map. Hard classification resulted from alternative methods are of limited use in identifying the transition zone between water and non-water, for example, see grid cells, e.g., B1 and B2.

\subsubsection{Fuzzy shoreline and uncertainty estimation}

Figures 3.2g-i and 3.3a, d show the results of the fuzzy-crisp objects model to derive shorelines. Figures $3.3 \mathrm{~b}$,e presents the $C I$. Dark pixels with $C I$ close to 0 indicate the areas classified as lower uncertainty (Figure 3.3e, e.g., grid cell A1), whereas brighter pixels with confusion index close to 1 indicate areas classified as the fuzzy boundary with higher uncertainty (Figure 3.3e, e.g., grid cell B2). 
Figures 3.3c, f shows shorelines images with fuzziness represented by $C I$ values. These ambiguous areas indicate shoreline positions represented by pixels in grey shades (Figure 3.3f, grid cells e.g., A2 and B2). The width of these shorelines is determined by natural conditions of the coastal areas, for example, a wider shoreline is more likely to be found in a muddy coastal area or at a gently sloping beach, whereas a narrow shoreline is usually found along a steeper slope beach and coastal area with embankment and other man-made structures.

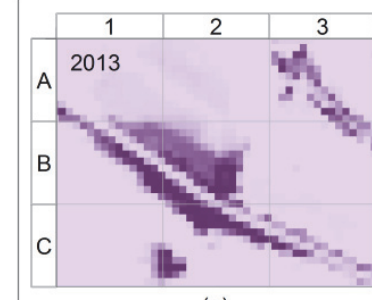

(a)

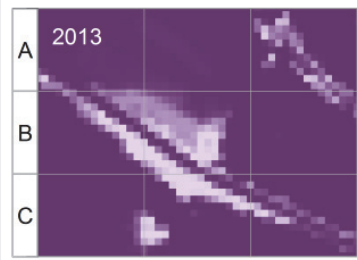

(d)

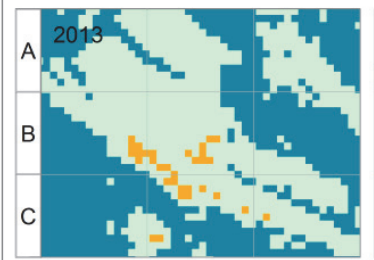

(g)

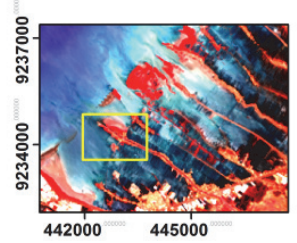

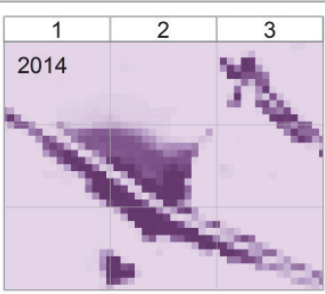

(b)

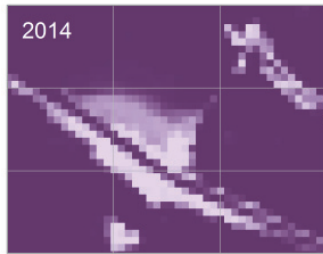

(e)

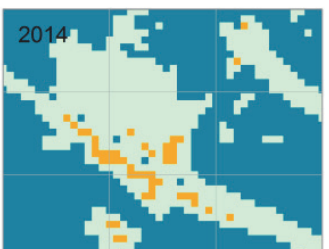

(h)

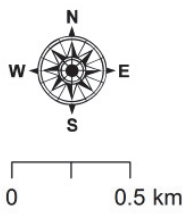

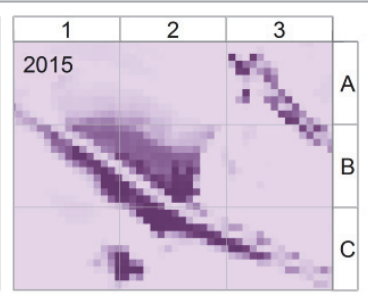

(c)

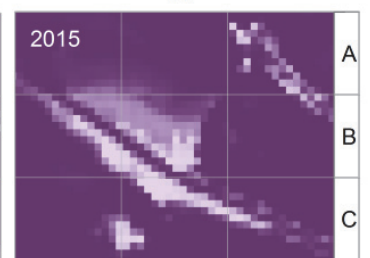

(f)

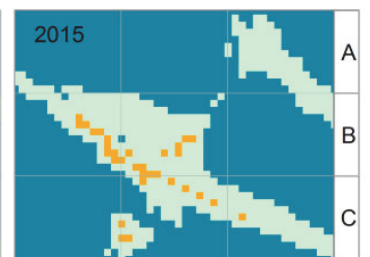

(i)

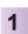

memberships

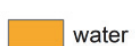

$\square$ non-water

Figure 3.2 FCM results show the membership of: water $(a, b, c)$; and nonwater $(d, e, f)$. To derive shoreline position, we combined both membership images using fuzzy-crisp object model $(g, h, i)$. Blue pixels indicate core of water, orange pixels represent the core of non-water and shoreline is represented by light green pixels. 


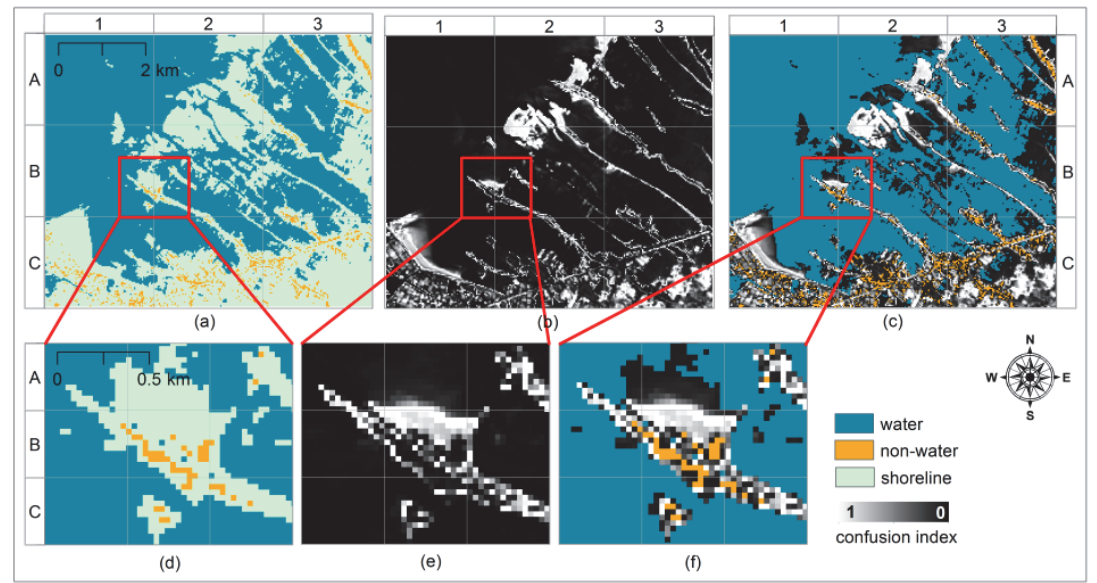

Figure 3.3 The representation of fuzzy-crisp object model: (a) the core of water and non-water objects, and shorelines; (b) confusion index values considered for the quantification of classification uncertainty; and (c) shoreline image with fuzziness represented by confusion index. Detailed presentation of shorelines in red rectangle sites are displayed in (d-f).

\subsubsection{Shoreline change detection}

\section{Change magnitude and change uncertainty}

The change magnitude and the change and no-change categories of shoreline are displayed in Figure 3.4. Low change magnitude values correspond to a small water membership difference between shoreline images at $t_{1}$ and $t_{2}$. They cover marine areas (Figure 3.4a, e.g., grid cells A2 and B3) and a relatively undisturbed coastal land (Figure 3.4c e.g., grid cells D1 and D2). In addition, high change magnitude values correspond to a large water membership difference. Those pixels cover muddy areas (Figures 3.4a,c, e.g., grid cells $C 1$ and D1) and coastal land which was highly-influenced by tidal floods (Figures 3.4b, d, e.g., grid cells B2 and B3).

The fuzziness of shoreline changes is presented in Figure 3.5. Low change confusion correspond to small $C I$ differences between images in $t_{1}$ and $t_{2}$. This indicates a low uncertainty that the changes have occurred as can be seen in Figures 3.5a,c, e.g., grid cells A1, A2 and B1. High values are associated with large $C I$ differences and indicate a high uncertainty that the changes have occurred (Figures $3.5 b, d$, e.g., grid cells B1, B2 and B3). 


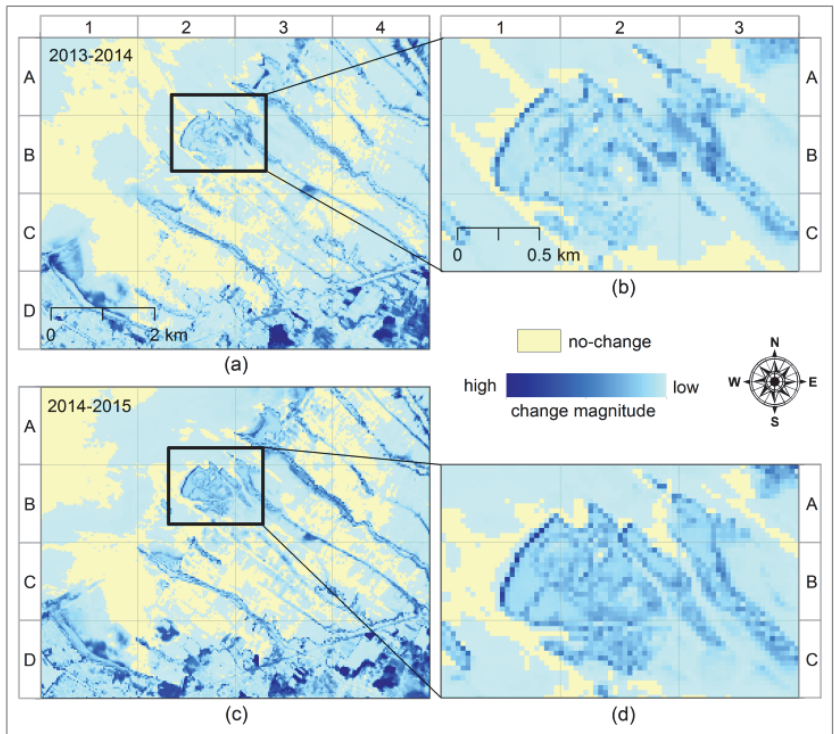

Figure 3.4 The magnitude of shoreline change during: 2013-2014 (a,b); and 2014-2015 (c,d). The magnitude values vary from high magnitude represented by dark blue pixels up to low magnitude represented by light blue pixels, whereas light yellow pixels show the no-change areas

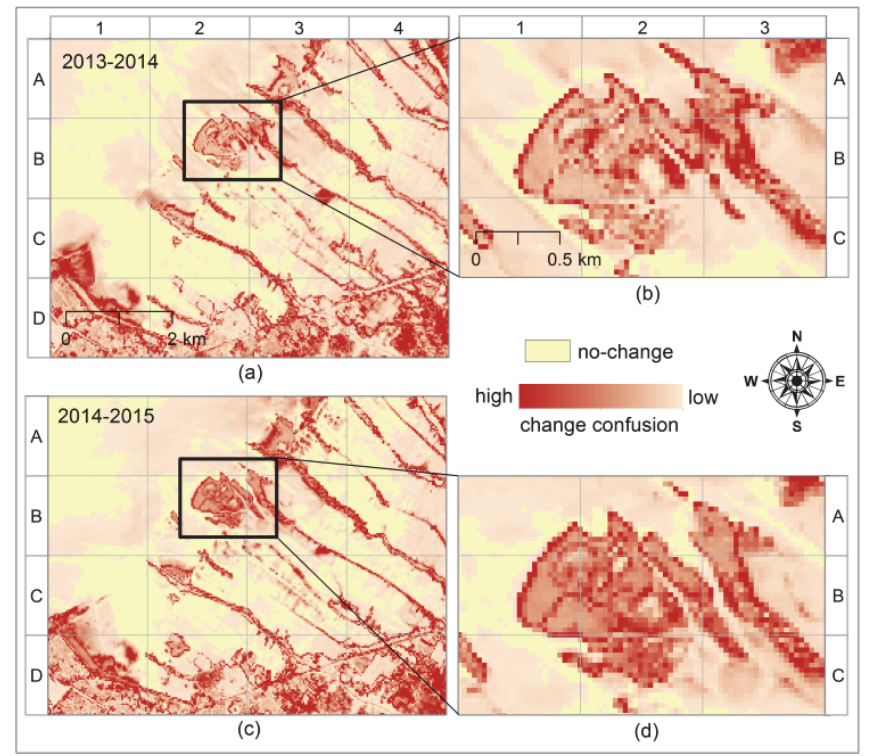

Figure 3.5 The fuzziness of the shoreline is represented by change confusion values in the periods: 2013-2014 (a,b); and 2014-2015 (c,d). The change confusion values vary from high values represented by dark orange pixels up to low values represented by light orange pixels, whereas light yellow pixels show the no-change areas 


\section{Change direction}

The representation of change direction of shoreline showing the variation of water membership in each pixel can be seen in Figure 3.6. Positive directions to water membership correspond to the increase of water membership at time $t_{2}$ (Figure 3.6a, e.g., grid cells $\mathrm{A} 2, \mathrm{~B} 1$, and $\mathrm{C} 1)$. On the contrary, negative directions to water membership were associated with the decrease of water membership values at time $t_{2}$ (see Figure $3.6 \mathrm{~d}$, e.g., grid cells A2 and B1). The no-change category indicates an undisturbed environment (see Figure 3.6a, e.g., grid cell B1), whereas the unclear direction category indicates an ambiguous condition since the changes occurred without an obvious trend (see Figure 3.6b, e.g., grid cells A2 and $\mathrm{C} 1$ ).

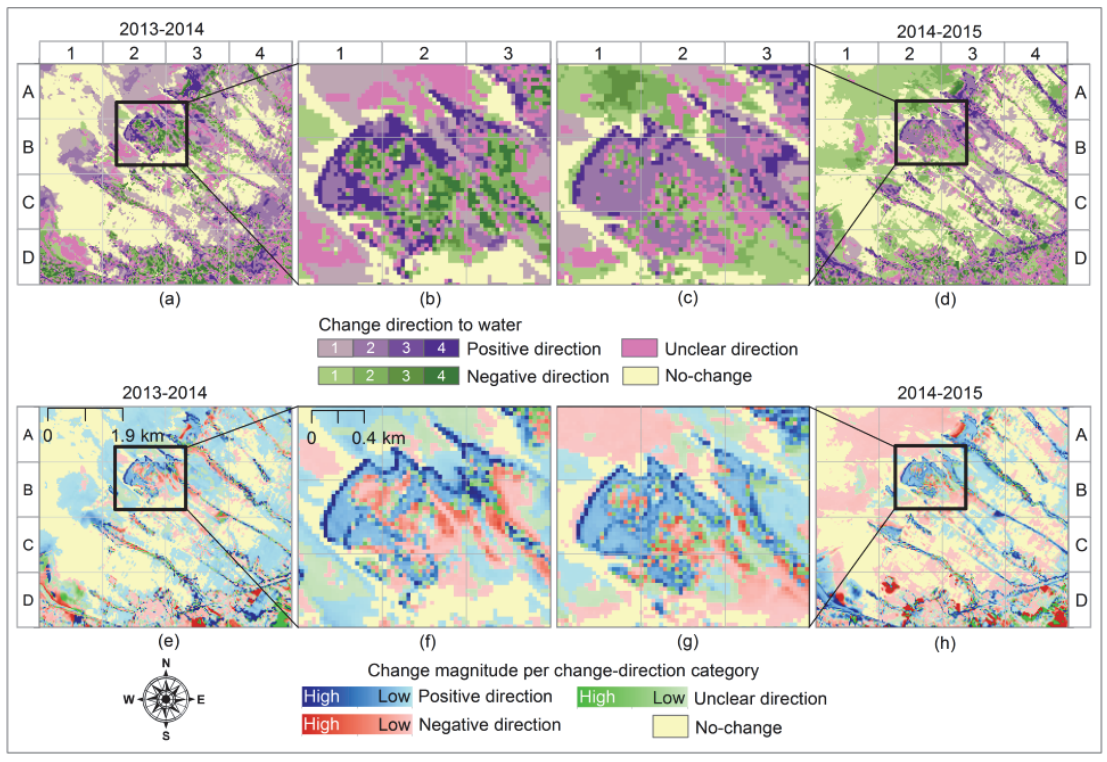

Figure 3.6 The representation of shoreline change direction: in the period 2013-2014 (a,b); and in the period 2014-2015 (c,d). Darker colour pixels show a higher frequency of change to a certain direction. Shades of violet pixels depict a positive direction to water membership while shades of green pixels illustrate a negative direction to water membership. Figures in the second row show the magnitude of each change direction category in the period 2013-2014 (e,f); and in the period 2014-2015 $(\mathrm{g}, \mathrm{h})$. Darker colour pixels represent a higher change magnitude while lighter colour pixels show a lower change magnitude

The change areas for each category are presented in Table 3.5. A positive direction to water covers an area of approximately 1828 ha 
in the period 2013-2014 and 1120 ha in the period 2014-2015. A negative direction has occurred for 920 ha and 1635 ha in the period 2013-2014 and in the period 2014-2015, respectively. Unclear direction category presented as pink pixels can be seen in Figure 3.6c, e.g., grid cells $A 2$ and $C 1$ covering an area of 616 and 528 ha in 2013-2014 and in 2014-2015, respectively. No-change direction shows a stable area which is mostly located at the sea or inundated fishponds represented by light yellow colour (see Figures 3.6a,d, e.g., grid cells A1 and B1) covering an area of 1319 and 1403 ha in the period 2013-2014 and in the period 2014-2015, respectively.

Table 3.5 Change area (in ha) for each change category in the period of 2013-2014 and 2014-2015.

\begin{tabular}{ccc}
\hline Change Category & $2013-2014$ & $2014-2015$ \\
\hline Positive direction & 1828 & 1120 \\
Negative direction & 920 & 1635 \\
Unclear direction & 616 & 528 \\
No-change & 1319 & 1403 \\
\hline
\end{tabular}

\section{Change confusion}

The intensity of the change confusion was identified for each change direction category in the period 2013-2014 and in the period 20142015, respectively (Figures $3.7 \mathrm{a}, \mathrm{c}$ ). Three change confusion values were identified including positive direction, negative direction and unclear direction.

\section{Comparison with alternative change detection methods}

Figures 3.8 and 3.9 show the change detection of shoreline using post classification comparison of MLC and hardened classification, respectively. Both MLC and hardened classification present shoreline as a single line. The changes of this single shoreline have occurred due to the changes of water and non-water area. Binary images from two dates $t_{1}$ and $t_{2}$ were superimposed in GIS and four types of change were identified, namely: non-water to water, water to nonwater, water to water and non-water to non-water. Figures 3.8a-c and $3.9 a-c$ show the changes of shoreline in three consecutive dates in 2013, whereas Figures 3.8d,e and 3.9d,e present two examples of shoreline changes from 2013 to 2014 (Figures 3.8d and 3.9d) and from 2014 to 2015 (Figures 3.8e and 3.9e). 


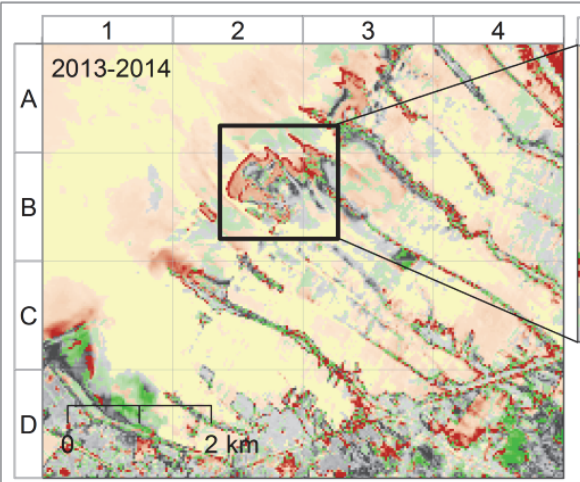

(a)

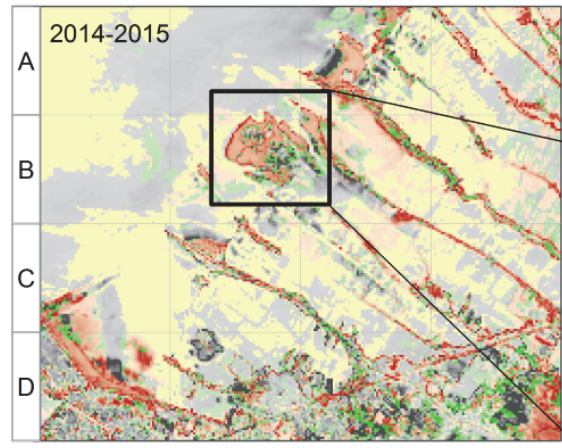

(c)

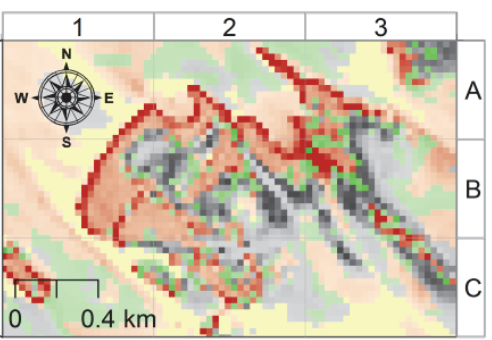

(b)

Change confusion per change direction category

High Low Positive direction High Low Negative direction High Low Unclear direction No-change

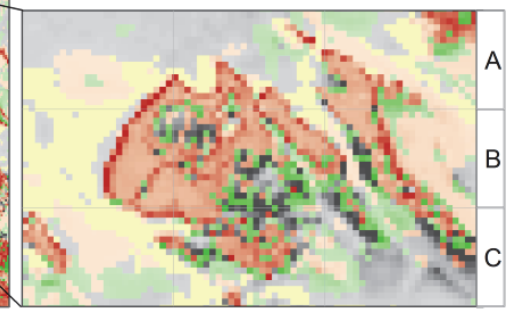

(d)

Figure 3.7 Total intensity of confusion indices for each change direction category: in the period 2013-2014 (a,b); and in the period 2014-2015 (c,d). Shades of orange pixels represent change confusion values for the area with positive direction, and shades of grey pixels show change confusion values for the area with negative direction. The change confusion values for the unclear direction category are represented by shades of green, whereas no-change category is depicted by light yellow colour

Figure 3.10 shows the comparison between the proposed method and the alternative method at the selected study area. In this example, both methods agree on the results of change detection as can be seen in Figure 3.10, e.g., grid cells B3 and C2. From CVA results (Figures $3.10 \mathrm{c}, \mathrm{d}$ ), the area in yellow polygons shows a negative change to water membership with high change magnitudes as shown in Figures 3.10e,f. The negative change to water membership means a change towards non-water. Similarly, post classification results also denote that these yellow polygon sites experienced a change from water to non-water without further information on the intensity of the change (Figures 3.10a,b). 


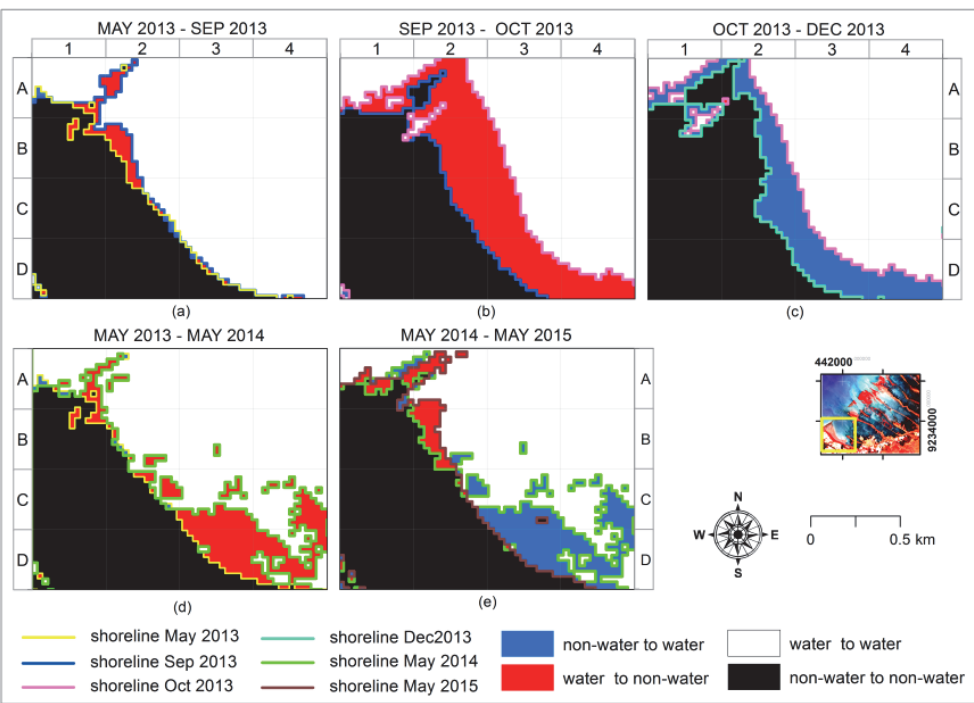

Figure 3.8 Change detection of shorelines using post classification comparison of MLC results; $(a-c)$ the change of shorelines in three consecutive dates in 2013; (d) shoreline changes from 2013 to 2014; and (e) shoreline changes from 2014 to 2015 . Blue polygons show the changes of non-water to water and red polygons display the changes from water to non-water. Nochange areas of water and non-water are represented by white and black polygons, respectively

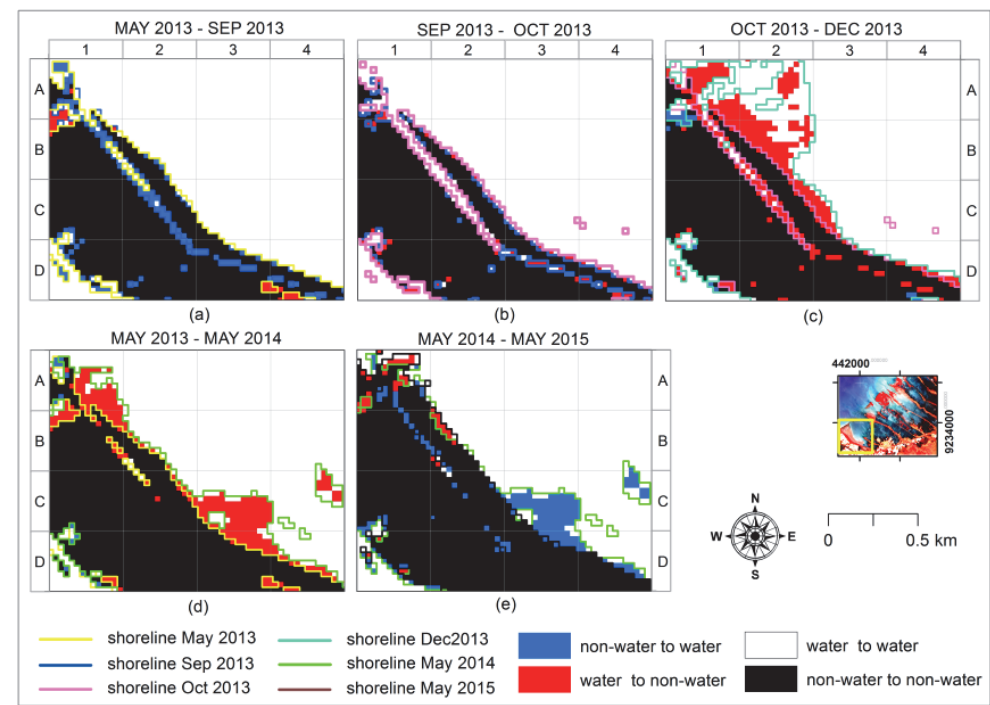

Figure 3.9 Post classification comparison of shoreline as the results of hardened classification: $(a-c)$ the changes of shoreline in three consecutive dates in 2013; (d) shoreline changes from 2013 to 2014; and (e) from 2014 to 2015 


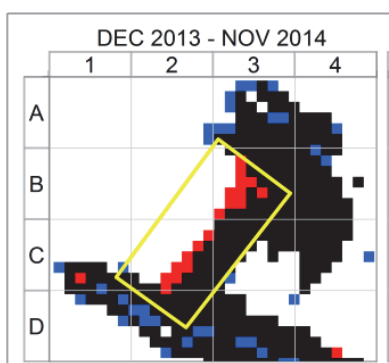

(a)

2013-2014

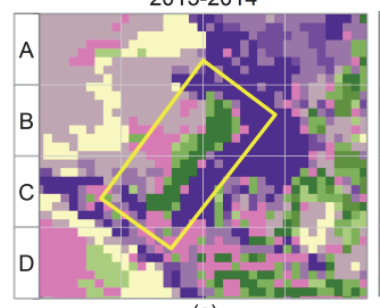

(c)

2013-2014

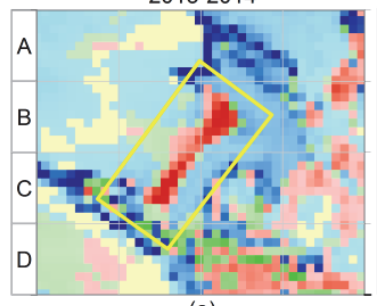

(e)

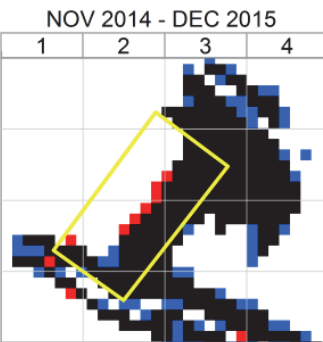

(b)

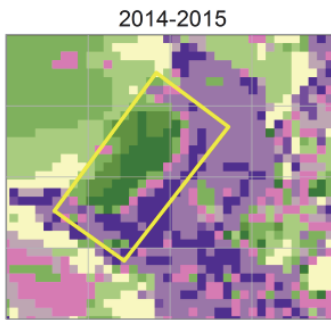

(d)

2014-2015

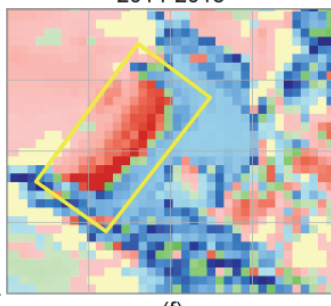

(f)

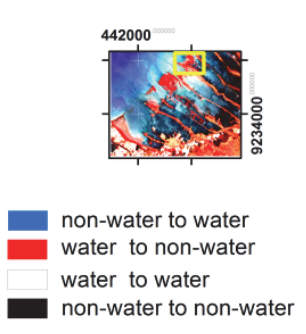

non-water to non-water

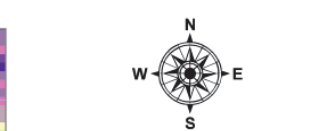

Change direction to water

\begin{tabular}{|l|lll|l}
1 & 2 & 3 & 4 & positive direction
\end{tabular}

\begin{tabular}{|l|l|l|l|l|l|}
\hline 1 & 2 & 3 & 4 & negative direction \\
\hline
\end{tabular}

unclear direction

no-change

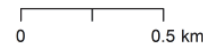

Change magnitude

per change-direction category

High Low positive direction

High Low negative direction

High Low unclear direction

$\square$ no-change

Figure 3.10 An example of comparison results between post classification comparison and CVA method. Both methods agree on change results of the area in yellow polygons that show a change from water to non-water $(a, b)$ which equal to negative direction $(c, d)$ with high change magnitude $(e, f)$

\section{Multi-year pattern of water membership changes}

Each pixel from the resulting change vectors provides information regarding its change direction and magnitude. Each combination represents specific types of change processes that may occur in the field and shows a multi-year pattern of water membership changes over the observation periods. Four combinations of change and their related processes are interpreted as follows:

\section{a) High change direction and high change magnitude}

The areas with high change direction and high change magnitude values are observed for both positive and negative directions. Both conditions indicate a continuous change of an area to a certain direction with a relatively large intensity. A consistency to positive 
direction indicates a persistence of enhanced water influence as those pixels show an increase of water membership in multi-temporal images (see Figures $3.11 \mathrm{a}-\mathrm{d}$ ). This probably corresponds to the land subsidence and coastal inundation. As the land subsides and the water level increases, some mangrove trees located closely to the sea are falling down. The RGB 542 of Landsat images in Figures 3.11e,g depict these changes indicated by the decrease of vegetation cover between 2013 and 2015.

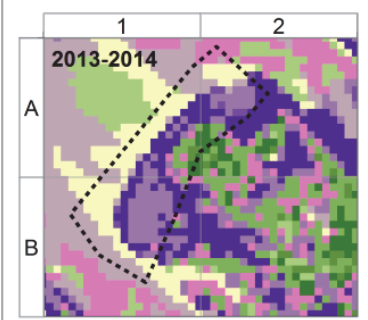

(a)

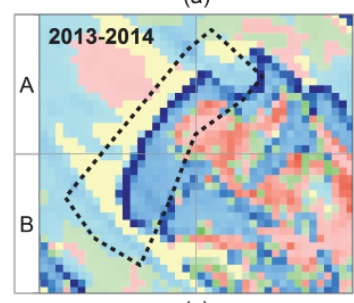

(c)

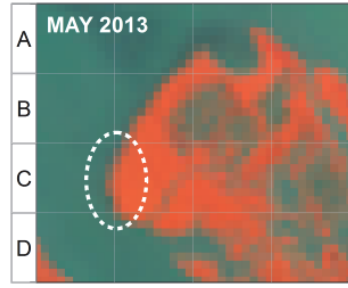

(e)

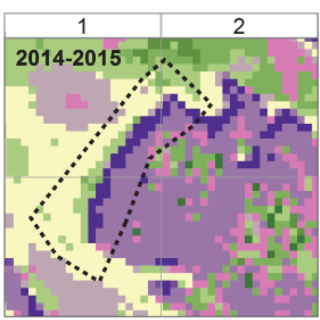

(b)

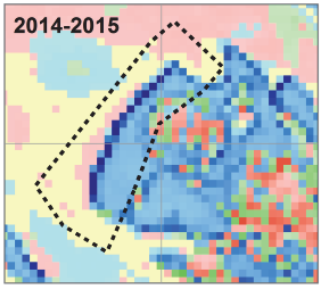

(d)

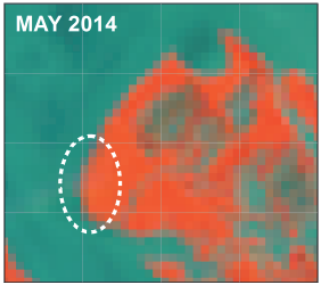

(f)

Change direction to water

\begin{tabular}{|l|l|l|l|l}
\hline & 2 & 3 & 4 & positive direction
\end{tabular}

\begin{tabular}{|l|l|l|l|l|}
\hline 1 & 2 & 3 & 4 & negative direction
\end{tabular}

unclear direction

$\square$ no-change

per change-direction category

High Low positive direction High Low negative direction

High Low unclear direction $\square$ no-change

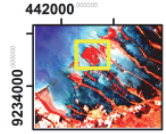

Landsat image RGB 532
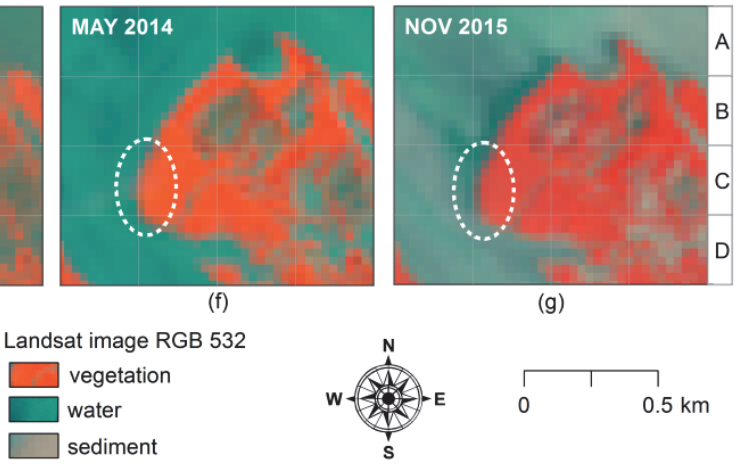

(g)

Figure 3.11 Multi-year pattern of water membership changes showing a high change direction to positive direction (see dark violet pixels in black-dashed polygons in $(a, b))$ and high change magnitude (see dark blue pixels in blackdashed polygons in $(c, d))$. RGB 542 of Landsat images show a decrease of vegetation coverage from 2013 to 2015 (see white-dashed ellipses in (e-g))

Figure 3.12 presents areas characterized by continuously decreasing water membership in multi-temporal images categorized as negative 
direction (Figures 3.12a,b) with high change magnitude (Figures $3.12 c, d)$. This may indicate a success in shoreline protection scheme that caused sediment accretion to occur allowing mangroves to grow as can be seen from the RGB 542 of Landsat images in white-dashed ellipses in Figures 3.12e-g.

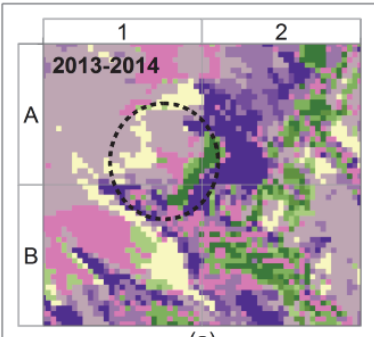

(a)

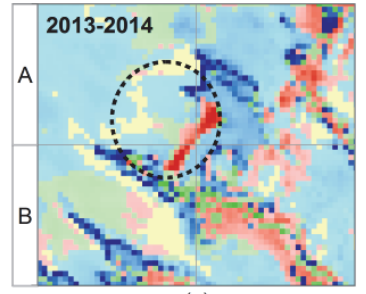

(c)

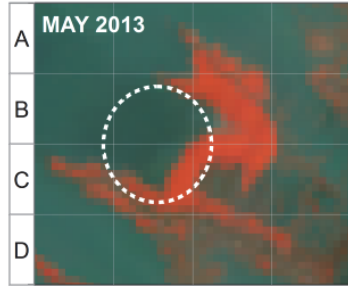

(e)

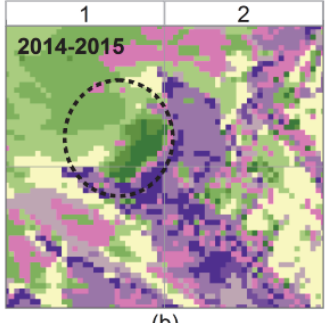

(b)

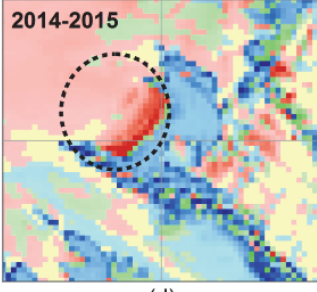

(d)

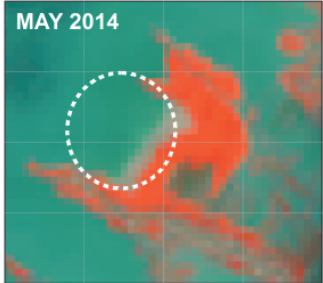

(f)

Change direction to water

$\begin{array}{llllll}1 & 2 & 3 & 4 & \text { positive direction }\end{array}$

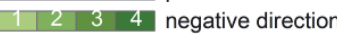

unclear direction

$\square$ no-change

Change magnitude

per change-direction category

High Low positive direction High Low negative direction High Low unclear direction no-change

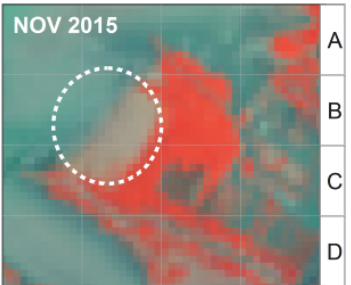

$(\mathrm{g})$

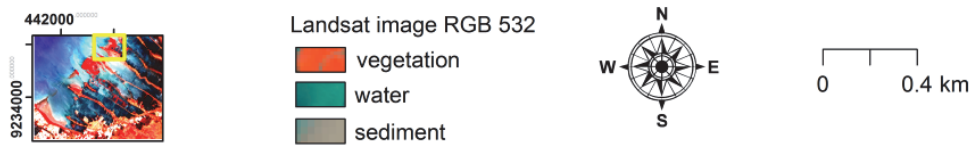

Figure 3.12 Water membership changes showing a continuous change to negative direction (see dark green pixels in black-dashed circles in $(a, b)$ ) with high change magnitude (see dark red pixels in black-dashed circle in $(c, d)$ ). RGB 542 of Landsat images show an increase of sediment and mangrove coverage from 2013 to 2015 (see white-dashed circle in $(e-g)$ ) 


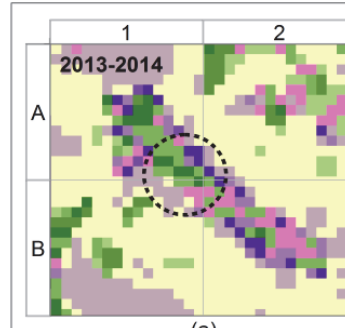

(a)
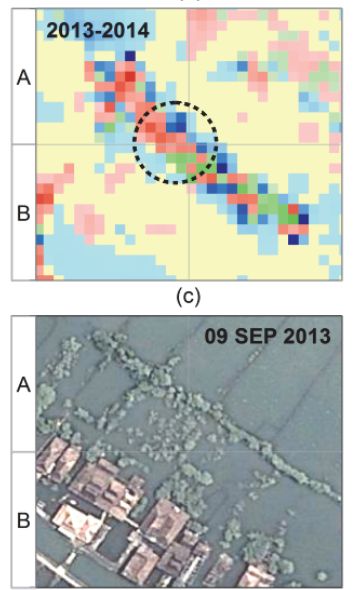

(e)

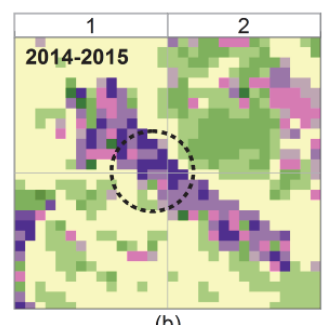

(b)
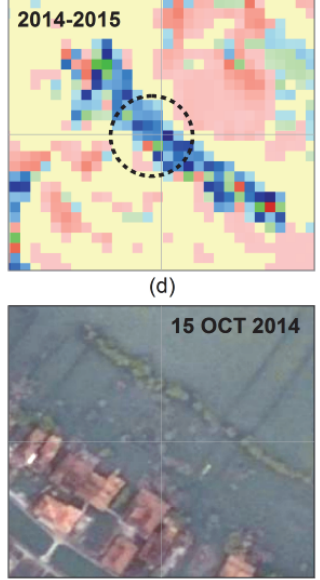

(f)

Change direction to water

\begin{tabular}{lllll}
\hline 1 & 2 & 3 & 4 & positive direction
\end{tabular} \begin{tabular}{|l|l|ll|}
\hline 1 & 2 & 3 & 4 \\
\end{tabular}

unclear direction

$\square$ no-change

Change magnitude
per change-direction category

High Low positive direction

High Low negative direction

High Low unclear direction

$\square$ no-change

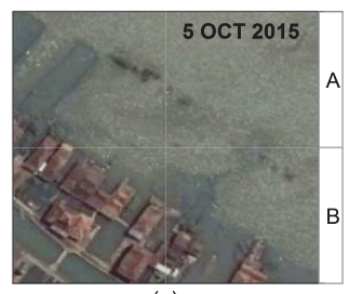

(g)
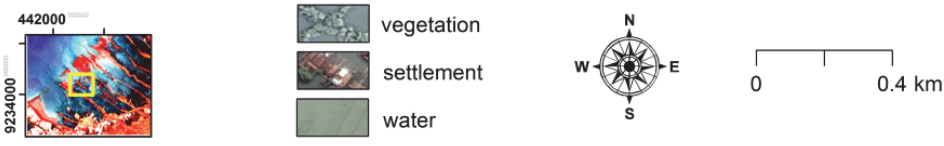

water

Figure 3.13 The location shows an unclear direction (see pink pixels in blackdashed circle in (a)), while in the period 2014-2015 the location shows a low change to positive direction (light violet pixels in black-dashed circle in (b)). The change magnitude values were low in the period 2013-2014 (c), while in the period of 2014-2015 the values were high (see dark blue pixels in blackdashed circle in (d)). Images made available by Google Earth (e-g) show the decrease of mangrove coverage

\section{b) Low change direction and high change magnitude}

This category indicates an abrupt change which may be influenced by random events. Figure 3.13b shows a low positive direction with high change magnitude (Figure 3.13d) which may result from coastal flooding triggered by spring tides, extreme waves and winds. Since the magnitude of the changes is high and the change is sudden, this type of change may indicate a higher risk. Images made available by Google Earth from 2013 to 2015 in Figures 3.13e-g show the decrease of mangrove coverage. In fact, mangroves can act as sediment trap and can reduce the energy of the high waves, 
therefore, when the mangroves disappear, the threat from tidal floods increases. Figures $3.14 \mathrm{a}, \mathrm{b}$ shows the embankment which protects settlements from high tide; however, during an extreme event for example when a higher tide combines with an extreme wind, the water level may increase and overflow this embankment.

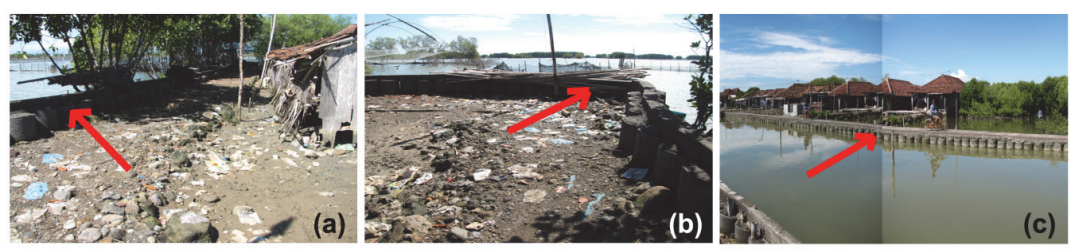

Figure 3.14 The embankment (shown by red arrows) for protecting the settlements $(a-c)$. (c) shows the river and settlements built on the river banks prone to high tides from both the sea and the river

\section{c) High change direction and low change magnitude}

A gradual, continuous increase of wet conditions was observed by an increase in water membership with low magnitude values. This type of change was categorized as positive direction which could be due to cyclical tides and coastal processes, for example flooded land (Figures $3.15 a, c$ ), and water turbidity (Figures 3.15b,d). Even though the magnitude of the change is low, the changes occur frequently. Hence, this type of change may give a higher risk. In a longer observation, if the areas persistently become wetter, this location may have a risk of coastal inundation as well.

\section{d) Low change direction and low change magnitude}

This type of change probably indicates an undisturbed environment with a low change magnitude (see black-dashed circle sites in Figures $3.16 \mathrm{c}, \mathrm{d})$. This category mainly occurs in water areas, probably due to the changes in water turbidity (see black-dashed circle sites in Figures $3.16 a, b)$. In addition, this type of change was observed in small patches of the coastal land probably resulting from changes in soil moisture (see black rectangle sites in Figures $3.16 \mathrm{~b}, \mathrm{~d}$ ). 


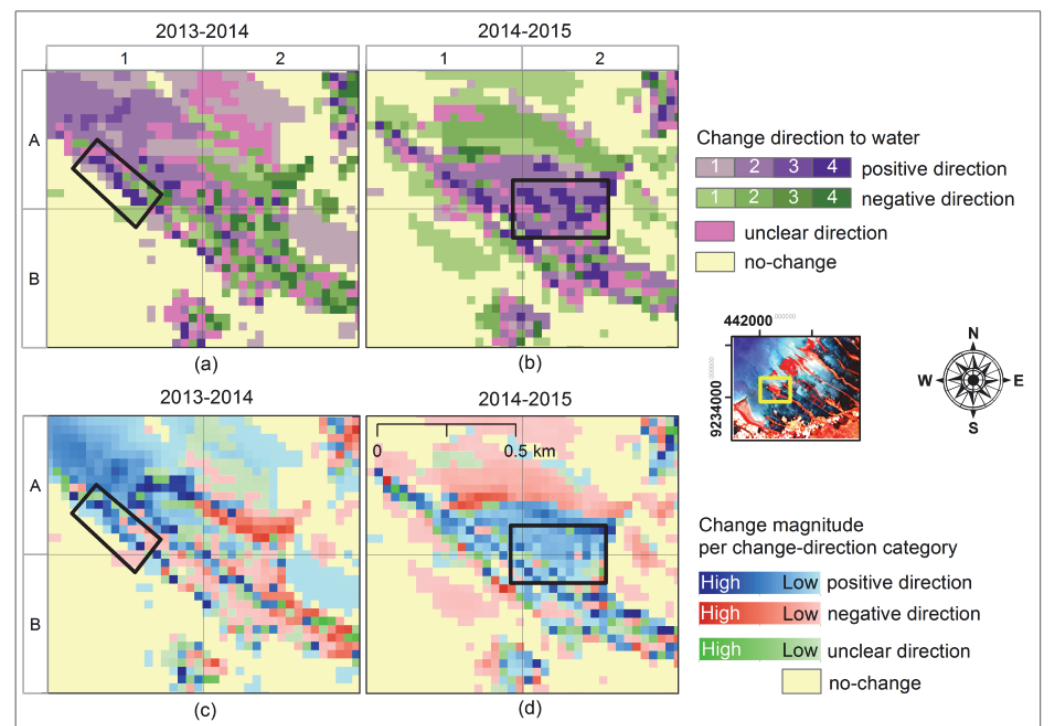

Figure 3.15 Water membership changes showing a higher change to positive direction (see dark violet pixels in black rectangle sites in $(a, b)$ ) with low change magnitude values (see dark blue pixels in black rectangle sites in $(c, d))$

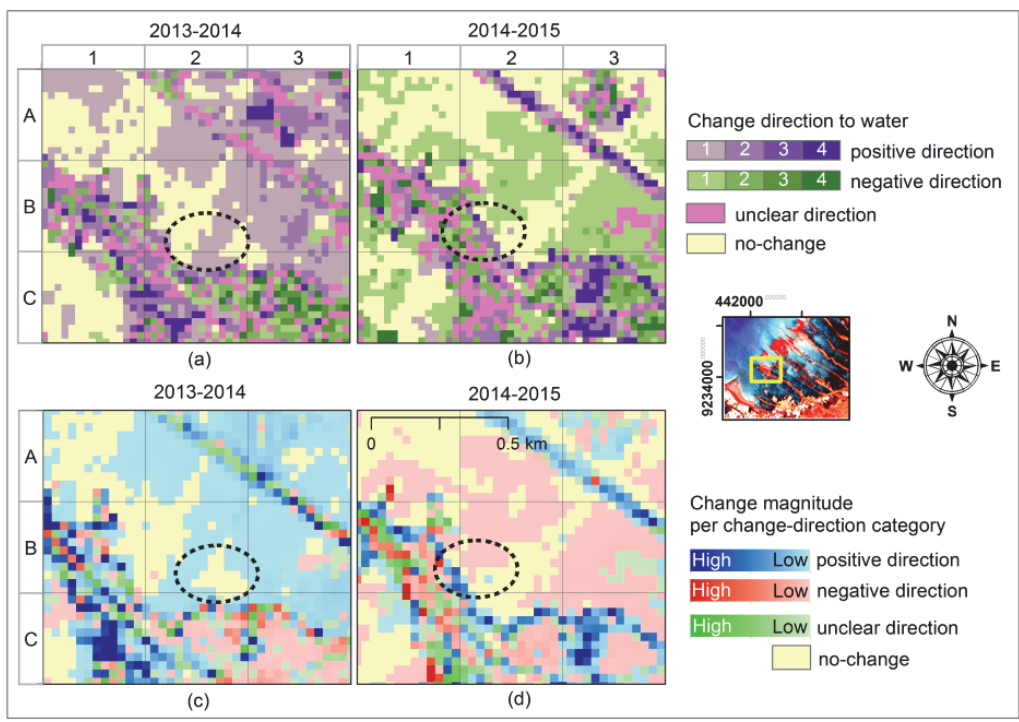

Figure 3.16 Water membership changes show a low change direction to positive direction in the period 2013-2014 (a); and to negative direction in the period 2014-2015 (b). The change magnitude values were low in both periods $(c, d)$. This type of change was also observed as small patches of the coastal land (see black rectangle sites in $(b, d)$ ) 


\subsection{Discussion}

In this study, the dynamics of fuzzy shorelines have been assessed using fuzzy classification and a raster-based change detection technique. FCM classification was used to discriminate the land and water classes and to estimate their memberships. FCM is a wellknown clustering method which is less dependent on the initial state of clustering (Tso and Mather, 2009) and capable of describing phenomena such as water and non-water which is changing gradually. Instead of FCM, there are various ways to derive a fuzzy classification for example from fuzzy maximum likelihood classification (Wang, 1990), and artificial neural network fuzzy classification (Zhang and Foody, 2001). Membership values obtained by applying FCM are used to deal with the uncertain information on the position of fuzzy shorelines. In FCM classification, we set $c=2$ since we were interested in identifying the boundary between water and non-water and because both classes give the largest spectral differences in image (Bijker et al., 2011; Dewi et al., 2016). Finding the suitable number of clusters in the beginning of the classification could be difficult. A priori knowledge regarding the study area, for example by observing an aerial photo, can be used to define the suitable number of clusters (Fisher and Pathirana, 1990; Wang and Shi, 2013). For other situations, by assessing the homogeneity measure using a posteriori indicators, the number of clusters could be determined using entropy and non-fuzziness index (Fisher and Pathirana, 1990), exponential cluster validity (Zarandi et al., 2010), and spatial fuzzy clustering (Delinom et al., 2008).

Shorelines and their changes were presented as fuzzy areas. The fuzzy-crisp object model in this study was successful in identifying the extent of shoreline positions as the transition zone between water and non-water. Setting the threshold to the highest (0.99) and the lowest (0.01) memberships are intended to find the core of water and non-water, respectively. The uncertainty addressed in this research corresponds to the existential and extensional uncertainty of shoreline objects as has been mentioned by Molenaar and Cheng (2000) and Cheng (2002). Existential uncertainty expresses the uncertainty of the existence of shoreline in reality. It refers to the possibility of existence of a shoreline to be detected on an image. Extensional uncertainty implies that the area indicated as shoreline can be determined with limited certainty, for example with boundaries that reflect the transition zone between water and nonwater. Moreover, when the values of an adjacent grid are very 
similar, the zones of confusion divide regions indicating the presence of gradual transitions. The extensional uncertainty in shoreline identification includes differences in applied threshold values when defining the core of water and non-water, the applied shoreline definition, tides condition during image acquisition, time series of observation, and the nature of the beaches (such as flat or steep slope beaches, and muddy or rocky beaches). In addition, the changed areas of the fuzzy shoreline are thus associated with the distribution of changed confusion indices. The change uncertainty represented by changed confusion indices shows the degree of uncertainty of the changes that have occurred. It can be seen from the results that a location having a higher change magnitude, has a higher change confusion value as well. It corresponds to the higher differences of both water memberships and confusion indices between corresponding images in $t_{1}$ and $t_{2}$. Explicit handling of uncertainty by addressing the shoreline as a transition zone allows decision makers and planners to include this uncertainty in spatial planning. Moreover, it visualizes not only the changes in shoreline, but also the uncertainty of these changes for every location, thereby providing a better base for a debate on the combined effects of land subsidence and sea level rise in this area.

The change of shoreline was explained in terms of change magnitude and change direction using CVA. Information provided by CVA allows us to see the trend of the fluctuating shoreline over time, whereas the change detection results of the alternative method could provide only "from-to" change information and the detail of subtle withinclass changes was lost because it only compared images from two dates (Jianya et al., 2008; Lambin and Strahler, 1994). In our previous study, we used post classification comparison because we were interested in observing the changes of shoreline over a longer period from 1994 up to 2015 (Dewi et al., 2016). Given different methods have been implemented in monitoring the change position of shoreline, both studies confirmed that shoreline changes associated with coastal inundation have occurred in this study area.

The analysis of information provided by the change magnitude and direction reveals that each change combination represents one specific change process type. The processes could vary depending on the characteristic of the coastal areas. For example, shorelines could change due to floods triggered by land subsidence, and floods caused by seasonal variation, abrupt shoreline changes due to extreme tides and waves, and the changes of water turbidity and soil moisture triggered by daily weather events. These specific type processes were 
explained on the basis of the analysis of four images for each observation period. In fact, the number of images could easily be extended to more than four images. The seasonal variation of shorelines and other information regarding whether the changes would lead to a permanent coastal inundation could not fully be assessed in this study because only four observations each year were compared. This shows that the change vector analysis is sensitive to the length of the stacked period and the number of images stacked over that period, as is also confirmed by Lambin and Strahler (1994).

To have images captured during similar tides and with corresponding seasons for each pair is important, hence shorelines can be compared equally. Images captured during wet seasons gave more uncertainty to the classification results since the rain affected the wetness of soil surfaces, thus the classified images produced false impression of higher flooding. Therefore, to reduce the uncertainty due to seasonal influence, images captured during dry season should be preferred. Furthermore, the uncertainty of the results was also influenced by tide differences. Images captured during high tides and low tides produced different positions of the boundary between water and nonwater. Hence, this increased the uncertainty of shoreline position as well, because shoreline by its definition is an intersection of coastal land and water surface. To have images acquired at exactly the same tide level is hardly possible. Therefore, all images were acquired at the low tides with negligible differences. We only considered astronomical tide level assuming it was more influential than meteorological factors, as confirmed by Pugh (1987). Astronomical and meteorological factors have different influences on different slope conditions and the magnitude of the influences may become larger if the slope is gentler. However, if there would be any remaining small influence of meteorological factors, it would be accounted for by the use of fuzzy classification in deriving fuzzy shoreline.

In the accuracy assessment, soft reference data were generated from various higher resolution images. To obtain the required image resolution, resampling and aggregating have been implemented. Resampling of image and aggregation of pixel values were potential sources of error but were ignored in this work since the error was likely to be very small (Chawla, 2010; Harikumar et al., 2015). Furthermore, using a soft classifier to generate soft reference data is more likely to reduce the uncertainty due to the vagueness in class definition and mixed pixel problems. Hence, the finer resolution dataset was not assumed to be pure and no information was lost due to the hardening of the soft classification (Dutta, 2009; Foody, 2002; 
Zhang and Foody, 1998b). This could be an explanation for the higher accuracies obtained by using the proposed classification in comparison with alternative methods, as confirmed by Zhang and Foody (Zhang and Foody, 1998b) and Chawla (Chawla, 2010). Furthermore, although the differences of the accuracy results were only small, the advantage of a fuzzy approach is not only in the improved accuracy of the shoreline, but also in the fact that it makes clear what the margins of uncertainty around the shoreline are, which provides a better basis for decision.

Analysis of the shoreline changes in the northern coastal area of Central Java shows the changes of shoreline positions from 2013 to 2015. This could be related to the processes that shape shorelines determined by the interaction of several factors, including: (a) the change of sea-level; (b) the amount of sediment supplied to the beach by rivers; (c) the movement of the sediment by marine processes; and (d) the role of waves, currents, tides and winds in moving the sediment (Dean and Dalrymple, 2002). Furthermore, sediment transport is not constant, and it is constantly subject to change. The alteration of sediment transport can come from changes in water flow, water level, weather events and human influence. In addition, previous studies have mentioned that this location has suffered from the changing of shorelines for more than 20 years due to coastal inundation accelerated by, for example, land subsidence, sea level rise, seaport development, and ground water extraction (Dewi et al., 2016; Harwitasari and van Ast, 2011; Marfai et al., 2008a). Many attempts have been made to combat coastal inundation and erosion along the $1.3 \mathrm{~km}$ coast in Demak. Elevated roads, raised floor of the houses, breakwater, and mangrove planting have been applied. In 2013, a Dutch-Indonesian consortium agreed to start a pilot project "Building with Nature" building a permeable dam of natural material called "hybrid engineering" (NetherlandsWater-Partnership, 2016; Winterwerp et al., 2014). This development could be one reason for the increase of negative changes to water membership in the period of 2014-2015. Hybrid engineering is one type of coastal protection combining technical and ecosystem-based solutions referred to as sediment traps (Winterwerp et al., 2014). Netherlands-Water-Partnership (2016) reported that after a year, new sediment layers were deposited at the surrounding areas. 


\subsection{Conclusions}

In this article, we present a method to identify shoreline positions and their changes as a fuzzy area including a measure of change confusion. Shoreline changes could be detected, and the method provided information regarding the change magnitude and the trend of water membership in each pixel. Our results reveal that this information represents specific type of change processes showing multi-year patterns of water membership changes over time. These include: (a) high change direction and high change magnitude with a consistent positive change direction, which probably corresponds to land subsidence and coastal inundation, while a consistent negative direction may indicate a success in shoreline protection scheme; (b) low change direction and high change magnitude indicates an abrupt change which may be influenced by random events, such as flooding triggered by spring tides, extreme waves and winds; (c) high change direction and low change magnitude, which, if in positive direction, could be due to cyclical tides and coastal processes, for example flooded land; and (d) low change direction and low change magnitude probably indicates an undisturbed environment, such as water areas with changes in water turbidity and coastal land with changes in soil moisture. Finally, we conclude that the proposed method can assess changes in a shoreline by taking into account that it is a fuzzy boundary.

The change area estimation, change magnitude and direction of the shorelines may support local government and stakeholders in monitoring the change of fuzzy shorelines. Combining information given by this research with other information such as distribution of population could help to determine priority locations prioritized in disaster preparedness and response. To include digital elevation model in the processing phase is important for further research, because it allows the change analysis to focus more on the area affected by tidal floods. We further realized that astronomical and meteorological factors have different influences on different slope conditions. Observation data regarding the wave run-up and other incident wave conditions in the study area were not available for each observation period. This information may be collected and used in a near-shore wave model. This might be included in future studies as well. 


\section{Modeling the Uncertainty of Fuzzy Shorelines}

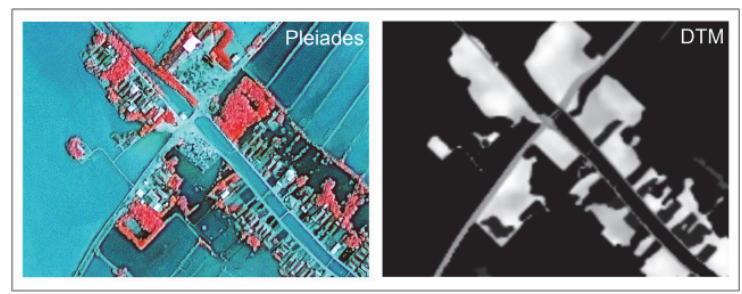

This chapter presents a comparison of two methods to model the uncertainty of fuzzy shorelines. Fuzzy sets and random sets performed well in modelling the uncertainty of shorelines and had similar results when using either Pleiades or Pleiades + DTM. The integration of DTM data improved classification accuracy. Considerable improvements were achieved for objects, e.g., roofs, inundated houses and yards.

This chapter is based on the published paper: Dewi, R.S., Bijker, W., Stein, A. Comparing Fuzzy Sets and Random Sets to Model the Uncertainty of Fuzzy Shorelines. Remote Sensing. 2017, 9, 885 


\section{Abstract}

This chapter addresses uncertainty modelling of shorelines by comparing fuzzy sets and random sets. Both methods quantify extensional uncertainty of shorelines extracted from remote sensing images. Two datasets were tested: pan-sharpened Pleiades with four bands (Pleiades) and pan-sharpened Pleiades stacked with elevation data as the fifth band (Pleiades + DTM). Both fuzzy sets and random sets model the spatial extent of shoreline including its uncertainty. Fuzzy sets represent shorelines as a margin determined by upper and lower thresholds and their uncertainty as confusion indices. They do not consider randomness. Random sets fit the mixed Gaussian model to the image histogram. It represents shorelines as a transition zone between water and non-water. Their extensional uncertainty is assessed by the covering function. The results show that fuzzy sets and random sets resulted in shorelines that were closely similar. $\mathrm{k}$ values were slightly different and McNemar's test showed high $\mathrm{p}$ values indicating a similar accuracy. Inclusion of the DTM (digital terrain model) improved the classification results, especially for roofs, inundated houses and inundated land. The shoreline model using Pleiades + DTM performed better than that of using Pleiades only, when using either fuzzy sets or random sets. It achieved $\kappa$ values above $80 \%$.

Keywords: fuzzy sets; random sets; possibility; probability; shorelines; uncertainty 


\subsection{Introduction}

Remote sensing offers a practical and economical means for coastal research. A series of remote sensing images can be used, for example, for mapping the dynamics of wet grassland and vegetation patches (Zhao et al., 2011a), mapping depth and water quality (Jay and Guillaume, 2014), coastal erosion (Hereher, 2011), and in particular shoreline mapping (Dewi et al., 2017a; Dewi et al., 2016; Sukcharoenpong et al., 2016). Instantaneous shoreline locations extracted from remote sensing images have become popular since mapping shorelines using ground survey and photogrammetry is costly. Several methods have been proposed, for example, using manual digitization (Dewan et al., 2017), spectral indices extraction such as water and vegetation indices (Ouma and Tateishi, 2007), active contour segmentation (Sukcharoenpong et al., 2016), band ratios (Kuleli, 2010), and image classification (García-Rubio et al., 2015; Taha and Elbeih, 2010). Most of these methods are based on hard classifications, and only a few considered soft classifications in the context of shoreline mapping (Dewi et al., 2017a; Dewi et al., 2016; Muslim et al., 2006). A hard classifier allocates a pixel to one class only based on the highest similarity. Therefore, applying hard classification for shoreline mapping could be misleading, since a shoreline is defined as the interface between land and water surfaces with its position changing over time. As images only capture a shoreline at a particular instant, they convey various kinds of uncertainties. Riesch (2013) mentioned that uncertainties may be inherent in the system or can arise from incomplete knowledge. This first type of uncertainty is classified as errors (Fisher, 1999) or as indeterminate boundaries (Burrough et al., 1997; Schneider, 1998). When a shoreline is clearly identified, the errors or the kind of indeterminate boundaries may arise, for example, during data processing and measurements. Meanwhile, the second type of uncertainty is divided into vagueness and ambiguity (Fisher, 1999). A vague boundary inherently belongs to the nature of the shorelines, i.e., it is hardly possible to define the extent of shoreline objects such as coast land, water and their gradual transition. The ambiguity may arise owing to the difference in classification system and perception of shorelines.

A common approach to model the uncertainty of objects is based upon probability theory (Goodman and Nguyen, 1985). For example, the epsilon band (Skidmore and Turner, 1992) is applied to model positional uncertainties of geographical objects. In addition, random 
sets theory is applied to handle the uncertainty in spatial information, for example for the definition of geographical areas, in mathematical morphology and in geostatistics (Couso et al., 2014). Fuzzy sets theory introduced by Zadeh provides a conceptual framework for solving representation and classification problems in an ambiguous environment by means of membership functions (Zadeh, 1965).

In this study, we focused on the similarity of fuzzy sets and random sets in modelling the uncertainty in shoreline locations. Fuzzy sets are sets or classes that allow partial memberships (Tso and Mather, 2009; Zadeh, 1978). A fuzzy set is characterized by a membership function which assigns to each object a grade of membership in the range $[0,1]$, with 0 representing the "non-membership" and 1 representing the "full-membership" of the set. Two ways are commonly distinguished to develop this membership function: the semantic import model (SIM) derived from expert knowledge, and the fuzzy c-means classifier. SIM is subjective in nature (Robinson, 2003) since it is based on subjective perceptions of vague categories rather than on data in the given problem, i.e., by extending the crisp boundaries into a transition zone (Cheng, 2002). In contrast, FCM is obtained from a set of attribute data and results in an objective approach. It is a commonly used method to estimate the membership values. FCM was developed by Dunn (Dunn, 1973) and generalized by Bezdek et al. (1984). Fuzzy sets theory has been widely used in remote sensing i.e., for image classification (Cheng et al., 2001; Dewi et al., 2016; Vlag and Stein, 2007; Zhang and Foody, 1998a). Fuzzy sets were applied also in GIS, e.g., for developing spatial data models for vague objects and their topological relation (Dilo et al., 2007; Liu et al., 2011b; Robinson, 2003; Schneider, 2001).

A random set is a generalization of a random variable taking subsets as values. Random sets theory is an inherent part of probability theory (Matheron, 1975; Molchanov, 2005; Nguyen, 2006). We can estimate the probabilities whether a random set is included in a given set, i.e., core, support and $\alpha$-level sets or not (Couso et al., 2014). Random sets theory has been employed to develop image segmentation methods (Epifanio and Soille, 2007), to characterize varying geometrical shapes (Stoyan and Stoyan, 1994) and to quantify the extensional uncertainty of spatial objects such as road polygons (Zhou and Stein, 2013) and wetlands (Zhao et al., 2011a).

The connection between fuzzy sets and random sets has been discussed in the past (Goodman et al., 1997; Nguyen and BerlinWu, 2006; Singpurwalla and Booker, 2004; Zadeh, 1995). Random sets 
theory is a methodology to deal with the uncertainty of outcomes of random phenomena. Fuzzy sets theory describes the uncertainty associated with classification or the placement of an outcome in a given class due to imprecision (Singpurwalla and Booker, 2004). Goodman and Nguyen (1985) stated that fuzzy sets are equivalent to a weak specification of random sets. Moreover, Zadeh argued that probability theory must be used together with fuzzy logic to enhance its effectiveness and both theories are complimentary rather than competitive (Zadeh, 1995). Fuzzy sets and random sets can be related via the one-point covering function of random sets, defined as the probability that an element is covered by a random set. The membership function of fuzzy sets is then considered as the probability of a random set covering a point (Goodman, 1984; Goodman and Nguyen, 1985; Mahler, 2007).

The objective of this research is to compare the performance of fuzzy sets and random sets in shoreline mapping. In this case, water and non-water pixels were used as proxies to determine the shoreline features extracted from remote sensing images. The comparison between both methods is implemented using two types of images: original Pleiades and the combination of Pleiades with an airborne LIDAR altimetry data.

\subsection{Modeling shoreline using fuzzy sets and random sets}

\subsubsection{Dataset}

We used a high resolution Pleiades image and elevation data. Water level observed from a nearby tide station at the time of image acquisition was also used. Those three data sources were provided by the Indonesia Geospatial Information Agency (BIG).

The image was acquired on 27 February 2013 at the lowest tides (the water level was $0.17 \mathrm{~m}$ below MSL). Table 4.1 shows the characteristics of the Pleiades image used. The image is a pansharpened ortho product obtained in standard processing level at which pan-sharpening, radiometric and geometric corrections were applied by the image provider. 
Table 4.1 The characteristics of Pleiades image used

\begin{tabular}{ll}
\hline Acquisition date & 27th February 2013 \\
Acquisition time & $03: 04$ UTC \\
Incidence angle (deg) & 13.66 \\
Sun elevation (deg) & 62.51 \\
Resolution (m) & 0.5 (pan-sharpened product) \\
Bands ( $\boldsymbol{\mu m )}$ & blue $(0.43-0.55)$, green $(0.50-0.62)$, \\
& red $(0.59-0.71)$, NIR $(0.74-0.94)$ \\
Map projection & UTM WGS84 \\
\hline
\end{tabular}

The DTM was created from LIDAR data recorded in August 2014. The data are in UTM projection and elevations are in meters referenced to the Earth Gravitational Model 2008 (EGM 2008). The mission report (Anonymous, 2014) states that the DTM data have a pixel size of 1.0 $\mathrm{m}$, a vertical accuracy of $\pm 0.17 \mathrm{~m}$ (linear error at $90 \%$ confidence, LE90), and a horizontal accuracy of $\pm 0.22 \mathrm{~m}$ (circular error at $90 \%$ confidence, CE90).

\subsubsection{Pre-processing}

The DTM was combined with the Pleiades imagery to improve the quality of the classification. The DTM data and Pleiades image must be pre-processed before they can be combined. First, the Geoidbased DTM data needed to be adjusted, so that it coincided with local MSL. In the study area, the Geoid and MSL differ as much as $1.34 \mathrm{~m}$ (Pangastuti and Sofian, 2015). Second, the DTM data were linearly stretched to map its original elevation range $(-1.34$ to $4.0 \mathrm{~m})$ to the 16-bit range of Pleiades image. Third, the histogram minimum method (Hadjimitsis et al., 2010) was applied to the image and the average filter was applied in $3 \times 3$ window size to reduce the image variance. Fourth, the Pleiades image was co-registered and resampled to match the DTM data.

For comparison of the methods, we prepared two types of datasets: (a) pan-sharpened Pleiades with four bands (referred to as Pleiades); and (b) pan-sharpened Pleiades with four bands that were stacked with the DTM as the fifth band (referred to as Pleiades + DTM). We created 13 subsets and grouped them into four groups (Figure 4.1), denoted as $S_{a-b}$ as the name of subsets; $a$ is the group number $(a=1, \ldots, 4)$, and $b$ is the subset number $(b=1, \ldots 13)$. Each subset consists of $423 \times 282$ pixels, except $S_{2-3}$, which consists of $374 \times 381$ pixels and $S_{2-13}$, which has $317 \times 478$ pixels. We grouped the subsets based on land cover similarities; 
a) $S_{1}$ is a mix of settlements and vegetation. This group consists of six subsets. They have a similar land orientation, stretching from northwest to southeast direction indicating rural settlements with a strip land surrounded by inundated fishponds. Rivers with various widths divide each island into two sides and small roads are found on either sides of the river. Rural settlements are mostly concentrated alongside the roads with sparse vegetation coverage.

b) $S_{2}$ is a mix of settlement and vegetation with more complex composition. Small rivers are clearly seen in $S_{2-3}$ and $S_{2-12}$. Fishponds with irregular shapes are visible at the northern part of $S_{2-12}$ and $\mathrm{S}_{2-13}$.

c) $S_{3}$ is dominated by vegetation coverage. Rural settlements are visible in $\mathrm{S}_{3-5}$ along the river side and a wide muddy area can be found in the northern part of the subset close to the mangrove area.

d) $S_{4}$ shows rural settlements surrounded by inundated fishponds. The settlements are protected by concrete embankment.

\subsubsection{Modelling shoreline using fuzzy sets FCM classification}

Unsupervised FCM was applied as the clustering algorithm (Bezdek et al., 1984) to estimate membership values. It separates the datasets into two classes allowing each pixel to have a membership value to multiple classes. The membership values $(\mu)$ range from 0 to 1 , and add up to 1 for each pixel. In this work, the membership values of the classification follow the trapezoidal membership function (Dewi et al., 2016).

FCM classification has a parameter $c$ specifying the number of classes, and $m$ specifying fuzziness. Bezdek et al. (1984) stated that values of $m$ between 1.5 and 3.0 produced good results while Deer and Eklund (2003) used $m=1.6$. In our previous study using Landsat images, we found that $m=1.7$ produced an accurate fuzzy classification. In this study, we investigated values of $m$ from 1.1 to 3.0 in steps of 0.1 in to identify the optimal value. We also investigated a $c$ value from 2 to 4 in order to find the optimal number of classes. In addition, we determined the cluster validity index from Xie and Beni (1991) as:

$$
C V I=\frac{\sum_{i=1}^{c} \sum_{k=1}^{N} \mu_{i k}^{m}\left\|V_{i}-X_{k}\right\|^{2}}{N \min _{i, k}\left\|V_{i}-V_{k}\right\|^{2}}
$$




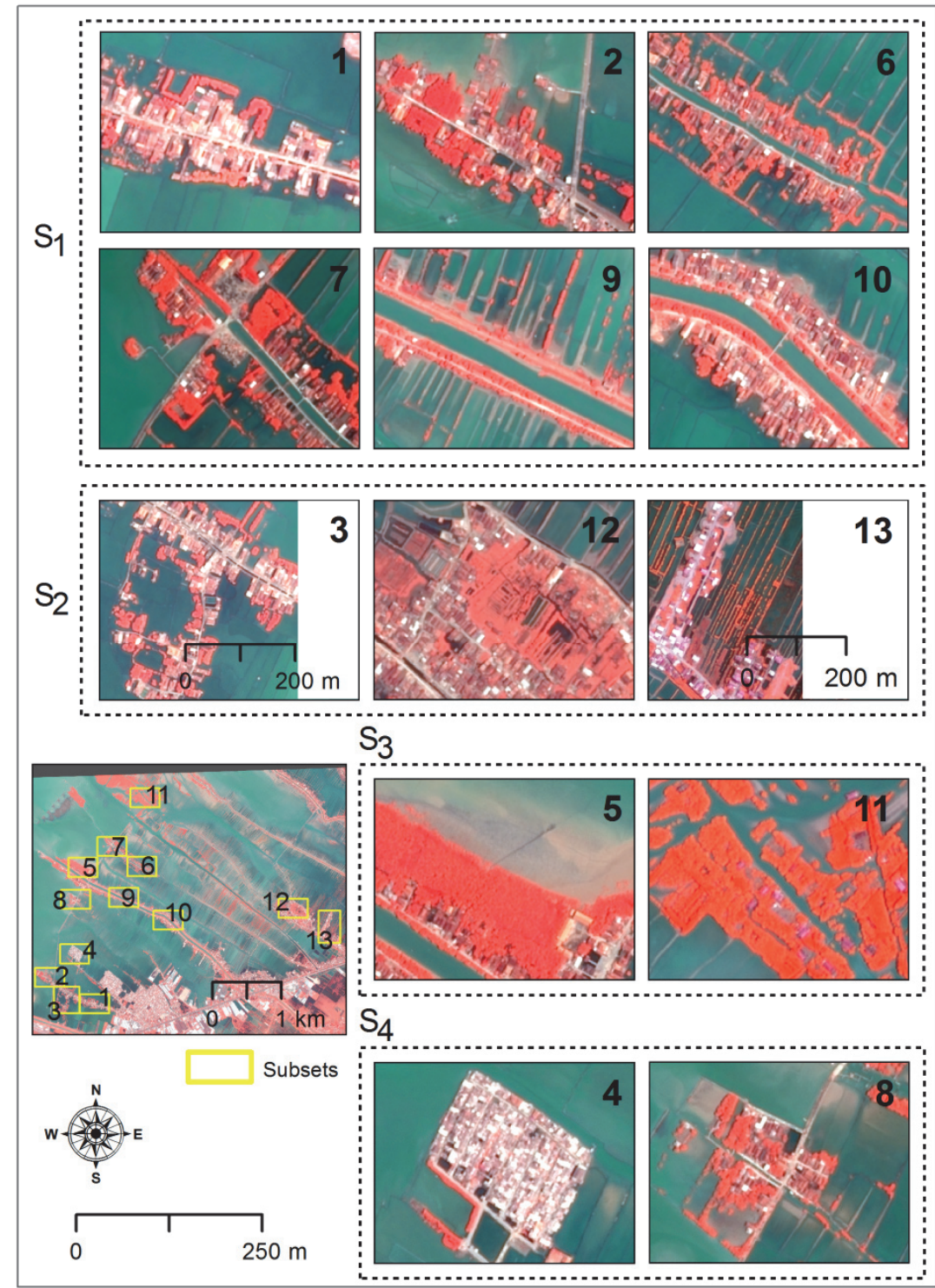

Figure 4.1 Study area is presented here as a false colour composite of a Pleiades image with red colour representing the vegetation, bluish green showing water area, and greyish and white pixels showing the built-up area. Yellow rectangles represent several the selected sites for this work, and blackdashed rectangles show four groups of subsets.

CVI refers to the compactness and separation validity function of fuzzy partition of the set of digital number $X=\left\{X_{k} ; k=1,2, \ldots, N\right\}$, where $V_{i}(i=1,2, \ldots, c)$ is the mean of class $i, N$ is the number of pixels, $\mu_{i k}$ is 
the membership of pixel $k$ to class $i$, and $\min _{i, k}\left\|V_{i}-V_{k}\right\|$ is the minimum distance between the mean of the classes.

After clustering, membership images were compiled for each class. We labelled one of the two membership images as belonging to the water class by using the near infrared (NIR) band of Pleiades. The water label was given to the class which has the minimum value of the class mean in the near infrared band (Dewi et al., 2016).

\section{Image segmentation}

The possible shoreline location was determined by generating a margin or transition zone between classes water and non-water. We applied a similar approach (Dewi et al., 2016), by defining a threshold range obtained from parameter estimation in the subsets. We applied thresholding to create crisp boundaries of the transition zone determined by lower $\left(d_{1}\right)$ and upper thresholds $\left(d_{2}\right)$. The class water $C_{w}$ was defined as:

$$
C_{w}=\left\{\begin{array}{c}
1 \text { if } \mu_{w k} \geq d \\
0 \text { otherwise }
\end{array}\right.
$$

where $\mu_{w k}$ is the membership to water, and $d$ is threshold value. We investigated values of $d$ from 0.1 to 0.9 in steps of 0.1 to estimate the optimal threshold value.

\section{Uncertainty estimation}

The uncertainty of deriving fuzzy shoreline was estimated by a measure of confusion index $C I$ for each pixel as follows (Burrough et al., 1997):

$$
C I=1-\left(\mu_{i k}^{1}-\mu_{i k}^{2}\right)
$$

where $\mu_{i k}^{1}$ refers to the first highest membership and $\mu_{i k}^{2}$ denotes the second highest membership. The $C I$ values range from 0 to 1 . If the value approaches 1 , it means the difference in membership value between the first and the second highest membership is small. The uncertainty of the pixel to belong to the class with the largest membership is high.

\subsubsection{Modelling shoreline by random sets}

Parameter estimation of random sets

Let the intensity of an image $I$ within a window $W$ be denoted as $f: W \rightarrow[0,1]$. Each pixel $k \in W$ has an intensity value $f(k) \in[0,1]$. The intensity function $f$ can be interpreted as a collection of sets $=\{k \in$ 
$W, \mathcal{R} \in[0,1]: f(k) \geq \mathcal{R}\} . F$ becomes a random set when $\mathcal{R}$ is a random variable. The distribution of a random set is determined by $f$ and the random variable $\mathcal{R}$ (Zhao et al., 2011a).

The thresholding was chosen to model the shoreline from the water membership image. Thresholding is a process to separate pixels from an image into regions (or clusters) based on their intensity. Usually this segmentation process is based on the image histogram (Tobias and Seara, 2002). If the image is composed of regions with clear separation in its histogram, the histogram is usually bimodal with a deep valley. In that case, the bottom of the valley is taken as the threshold for foreground and background separation. However, the choice of threshold is not an easy task due to the existence of uncertain area in between the two peaks of the histogram. There are various methods to find the optimal threshold between the foreground and the background (Shi et al., 2010; Zhao et al., 2011a). In this study, we consider the uncertain area, the transition zone between the foreground and background as the third class, shoreline, with intensity values in the interval $\left[d_{1}, d_{2}\right]$, where $0 \leq d_{1} \leq$ $d_{2} \leq 1$ (Figure 4.2). We consider shoreline as the transition zone between water as the foreground and the coastal land as the background. We aim to extract the extent of shoreline and model it as a random set to quantify its extensional uncertainty.

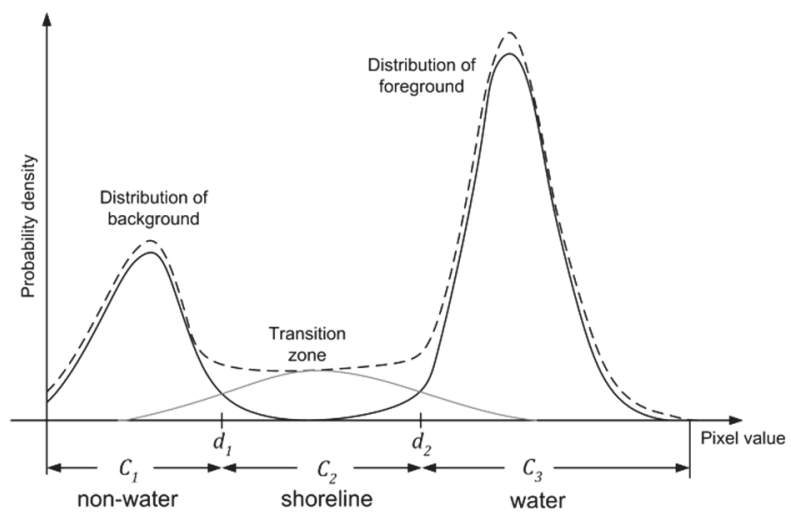

Figure 4.2 Density functions of shoreline object and related mixed Gaussian model

The critical part of creating the random sets model is to generate realizations that characterize its distribution. To obtain these realizations, the probability distribution of $\mathcal{R}$ was determined and random numbers in the transition zone $\left[d_{1}, d_{2}\right]$ were generated as multiple thresholds. We chose the Gaussian distribution (Shi et al., 2010; Zhao et al., 2011a), based on the assumption that pixel values 
close to the object boundary have a higher probability to be labelled as the boundary than pixels at a distance.

A mixed Gaussian model was used to fit a density distribution to the image histogram and to determine the transition zone $\left[d_{1}, d_{2}\right]$ (Figure 4.2). When using multi-temporal images for shoreline mapping, each image has a different histogram reflecting a different proportion of transition zones. An image recorded during a low tide has a broader transition zone than an image recorded at a high tide. Hence, we chose the mixed Gaussian model with three components: the distributions of water, non-water, and shoreline as the transition zone.

Let the three classes be denoted as non-water $\left(C_{1}\right)$, shoreline $\left(C_{2}\right)$ and water $\left(C_{3}\right)$. We assumed that the intensity of pixels which belong to class $C_{i}, i \in\{1,2,3\}$ follows the Gaussian distribution. $C_{i}$ has the Gaussian distribution $C_{i} \sim \mathrm{N}\left(M_{i}, \Sigma_{i}\right)$ with mean $M_{i}$, standard deviation $\Sigma_{i}$ and density function $\left(\sqrt{2 \pi \Sigma_{i}}\right)^{-1} \exp \left[-\frac{1}{2}\left(z-M_{i}\right)^{2} / \Sigma_{i}^{2}\right]$ in a onedimensional model. The density function of $I$ is the mixed density distribution of $C_{i}$ :

$$
d(Z)=d\left(Z ; \Theta_{\mathrm{i}}, M_{i}, \Sigma_{i}\right)=\sum_{i=1}^{3} \Theta_{i} \mathrm{~N}\left(M_{i}, \Sigma_{i}\right)(Z)
$$

where $Z=f(k), \Theta_{\mathrm{i}}$ is the weight coefficient for $C_{i}$ and $\sum_{i=1}^{3} \Theta_{\mathrm{i}}=1$. It is assumed that $M_{1}<M_{2}<M_{3}$. The lower limit of the shoreline is to be determined at $d_{1}$ where $\Theta_{1} \mathrm{~N}\left(M_{1}, \Sigma_{1}\right)\left(d_{1}\right)=\Theta_{2} \mathrm{~N}\left(M_{2}, \Sigma_{2}\right)\left(d_{1}\right)$, and the upper limit at $d_{2}$ where $\Theta_{2} \mathrm{~N}\left(M_{2}, \Sigma_{2}\right)\left(d_{2}\right)=\Theta_{3} \mathrm{~N}\left(M_{3}, \Sigma_{3}\right)\left(d_{2}\right)$. In this way, we identify three classes as presented in Figure 4.2: non-water $\left(C_{1}\right): f(k)<d_{1}$, shoreline $\left(C_{2}\right): d_{1} \leq f(k) \leq d_{2}$, and water $\left(C_{3}\right): f(k)>d_{2}$. The transition interval $\left[d_{1}, d_{2}\right]$ is determined by tuning the weight of the shoreline component. For example, suppose that the thresholds $0.4,0.5$, and 0.6 were adopted for shoreline hard classification, and then we investigated an interval around these values, to find the optimal threshold interval for random sets.

\section{Modelling the extent of shoreline by random sets}

We generated $\varphi$ random numbers from the distribution $\mathcal{R} \sim \mathrm{N}\left(M_{2}, \Sigma_{2}\right)$ in $\left[d_{1}, d_{2}\right]$. This results into different realizations of a random set $O_{i}, \ldots, O_{\varphi}$ by thresholding the water membership image using $\mathcal{R}_{i}, \ldots, \mathcal{R}_{\varphi}$ as the multiple thresholds: $O_{i}=\left\{k \in W, i \in\{1, \ldots, \varphi\}, \mathcal{R}_{i} \in\left[d_{1}, d_{2}\right]: f(k) \geq\right.$ $\left.\mathcal{R}_{i}\right\}$. We investigated the optimal value of $\varphi(\varphi=10, \ldots, 300)$ in steps of 10. Intuitively, a value closer to the optimal $\varphi$ should be more 
reliable and the variance of random sets $\Gamma$ becomes stable as $\varphi$ increases. For each $\varphi$, the covering function $\operatorname{Pr}_{\Gamma}(k)$ can then be determined including the core, median, support and level sets. We provided a curve for the core area as a function of $\varphi$ values. If the difference of two standardized core area between two successive $\varphi$ (denoted as $\delta_{i}$ ) is small (e.g., in the range -1 to +1 ), we accepted this $\varphi$ as the optimal $\varphi$.

The idea of the generation of random sets is that the extent of segmented shoreline objects should be sensitive to the variance of the parameter in the threshold when we extracted objects with a large extensional uncertainty. By slightly changing the threshold values $\mathcal{R}_{i}, \ldots, \mathcal{R}_{\varphi}$, we obtained a set of objects $O_{i}, \ldots, O_{\varphi}$ and construct a random set $\Gamma$. For example, for $\varphi=100$ and threshold interval [0.3, 0.7], this means that we generate 100 thresholds to slice the membership image and make samples as binary maps. Each sample is a realization of focal element $O_{i}$ of random sets $\Gamma$. The focal elements are regions which are subsets of $W: O_{i} \in \mathcal{P}(W)$. If the random set is constructed by $\varphi$ focal elements with equal probability, then $u_{i}=1 / \varphi$. We need to estimate the covering function $\operatorname{Pr}_{\Gamma}(k)$ to measure the probability of pixel $k$ being covered by random sets. The covering function characterizes the distribution of random sets $\Gamma$. The covering function $\operatorname{Pr}_{\Gamma}(k)$ at point $k$ equals $P(\Gamma \cap\{k\} \neq 0)=P(k \in \Gamma)$. It can be described by focal elements $O_{i}$ with corresponding uncertainty assignments $u_{i}$, indicated as a collection of pairs $\left\{O_{i}, u_{i}\right\}, i \in(1, \ldots, \varphi)$ (Zhou and Stein, 2013). The covering function of random sets can be estimated by (Zhao et al., 2011a; Zhou and Stein, 2013):

$$
\operatorname{Pr}_{\Gamma}(k)=\frac{1}{\varphi} \sum_{i=1}^{\varphi} I_{O_{i}}(k), k \in W
$$

where $I_{O_{i}}$ is the indicator function of $O_{i}, i \in(1, \ldots, \varphi): I_{O_{i}}=\left\{\begin{array}{cc}1, k \in O_{i} \\ 0, k \notin O_{i}\end{array}\right.$.

Figure 4.3a illustrates a simple example for covering function estimations of random sets with equal uncertainty assignments reflected by equal interval $u_{i}$. Figure $4.3 \mathrm{~b}$ shows the covering function values at six pixels derived by Equation (4.5). Table 4.2 provides the statistical parameters of random sets (Zhao et al., 2010). 


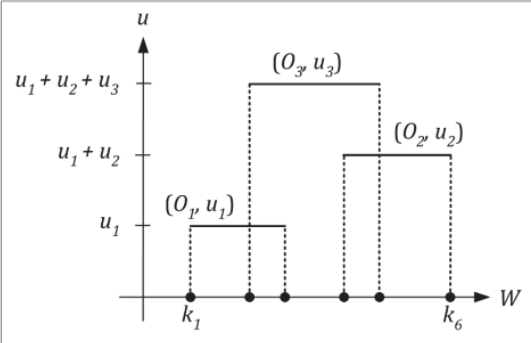

(a)

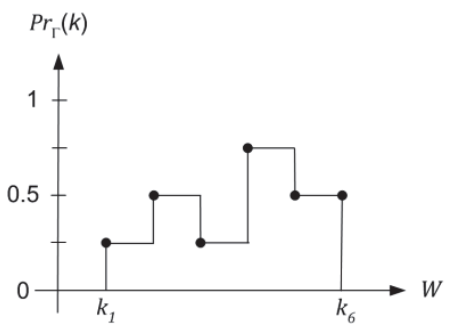

(b)

Figure 4.3 Focal elements with their equal uncertainty assignments $u_{1}=$ $u_{2}=u_{3}$ to construct a realization of random sets (a); and covering function of the random sets (b). These figures are adapted from Zhao et al. (2010).

Table 4.2 The statistical parameter of random sets

\begin{tabular}{ll}
\hline Definition & Equation \\
\hline $\begin{array}{l}\text { The } \alpha \text {-level set: to describe the } \\
\text { spatial distribution of the varying } \\
\text { sizes of } \Gamma\end{array}$ & $\Gamma_{\alpha}=\left\{k \in \mathcal{R}^{2}, 0 \leq \alpha \leq 1: \operatorname{Pr}_{\Gamma}(k) \geq \alpha\right\}$ \\
\hline $\begin{array}{l}\text { The core set: to describe the certain } \\
\text { part of } \Gamma\end{array}$ & $\Gamma_{1}=\left\{k \in \mathcal{R}^{2}: \operatorname{Pr}_{\Gamma}(k)=1\right\}$ \\
\hline $\begin{array}{l}\text { The median set: to describe the } \\
\text { 0.5-level set }\end{array}$ & $\Gamma_{0.5}=\left\{k \in \mathcal{R}^{2}: \operatorname{Pr}_{\Gamma}(k)=0.5\right\}$ \\
\hline $\begin{array}{l}\text { The support set: to describe the } \\
\text { possible part of } \Gamma\end{array}$ & $\Gamma_{0}=\left\{k \in \mathcal{R}^{2}: \operatorname{Pr}_{\Gamma}(k)>0\right\}$ \\
\hline The mean area of $\Gamma$ & $E A(\Gamma)=\int_{\mathcal{R}^{2}} \operatorname{Pr}_{\Gamma}(k) d k$ \\
\hline The mean set of $\Gamma$ & $\Gamma_{m}=\left\{k \in \mathcal{R}^{2}, 0 \leq \alpha_{m} \leq 1: \operatorname{Pr}_{\Gamma}(k) \geq \alpha_{m}\right\}$ \\
\hline The set-theoretic variance & $\Gamma_{v}(k)=\frac{1}{\varphi} \sum_{i=1}^{\varphi}\left(I_{O_{i}}(k)-\operatorname{Pr}_{\Gamma}(k)\right)^{2}$ \\
\hline The sum of variance $S V$ & $S V=\int_{\Gamma_{0}} \Gamma_{v}(k) d k$ \\
\hline The coefficient of variation $\mathrm{CV}$ & $C V=\frac{\int_{\Gamma_{0}} \sqrt{\Gamma_{v}(k) d k}}{\int_{\Gamma_{0}} \operatorname{Pr}_{\Gamma}(k) d k}$ \\
\hline
\end{tabular}

\subsubsection{Validation and comparing classification performance}

To quantify the accuracy of each model, we used the error matrix to estimate the $\mathrm{k}$ values. In this case, we produced a hardened FCM using $d=0.5$ and the median set $\Gamma_{0.5}$. We compared the performance 
of both approaches using two input images (Pleiades and Pleiades + DTM).

Reference data were derived from the $0.5 \mathrm{~m}$ Pleiades image acquired in 2013. Using stratified random sampling, approximately 138 points were randomly selected for each subset. A visual interpretation approach was performed to distinguish a land cover class for each selected point.

To test the significance of the difference between: a) fuzzy sets and random sets; b) Pleiades and Pleiades + DTM, we performed McNemar's test (Foody, 2004; Leeuw et al., 2006; Manandhar et al., 2009). McNemar's test is based on confusion matrices that are 2 by 2 in dimension. The null hypothesis stated that both input images produced similar accuracy. The test is based on chi-square statistics at the $95 \%$ level of confidence, and computed as follows:

$$
\chi^{2}=\frac{\left(f_{12}-f_{21}\right)^{2}}{\left(f_{12}+f_{21}\right)}
$$

where $f_{12}$ denotes number of samples that are incorrectly classified by the first method or the first image but correctly classified by the second method or the second image, and $f_{21}$ denotes number of samples that are correctly classified by the first method or the first image but incorrectly classified by the second method or the second image.

\subsection{Results and classification comparison}

\subsubsection{Modelling shoreline using fuzzy sets Parameter estimation of FCM classification}

Figure 4A.1 shows the $\kappa$ values when we estimated $c$ and $m$ values for all subsets of the Pleiades + DTM image. For low $m$ (e.g., $m=1.1$ 1.6), classifications show a comparable $\kappa$ for all thresholds, and the highest $\mathrm{k}$ was obtained for $c=2$, while by setting a high $m(m=2.0$ $3.0)$, high $\kappa$ values were obtained only for certain $d$ values. For example, when we set $m=1.5$ and $c=2$, high $\kappa$ were obtained for $d=0.2-0.8$ while for $m=3$ and $c=3$, high $\kappa$ were only obtained for $d=0.2$. In this case, for a high $m$ value, the choice of $d$ becomes more sensitive. In addition, Table 4A.1 shows the cluster validity measures as an alternative approach to determine the number of classes for FCM classification. From the results, $c=2$ obtained the minimum 
values for all $m$ which indicates a partition in which all clusters are overall compact, and separate from each other. Based on both approaches in estimating the suitable number of classes for FCM classification, we decided $c=2$ was the optimal number of classes for further image processing steps.

Figure 4A.2 shows the results of threshold range estimation when we set a constant $c(c=2)$ for various $m$. We can see that $d=0.5$ gave a highest $\kappa$ value for all subsets while the threshold range 0.3-0.7 provided high $\kappa$ values. High values of $m$ resulted in a low $\kappa$ value, especially at a low $d(d<0.3)$ and a high $d$ value $(d>0.6)$. Given the fact that the threshold range 0.3-0.7 produced high $\kappa$ values, we selected those values as the threshold range at which the boundary between water and land can probably be distinguished.

In Figure 4A.2, we can also see that $m=1.5$ and $m=1.6$ are comparable as indicated by the stability of $k$ value, whereas, for $m>1.6$, the choice of $d$ becomes more sensitive. Given the results, we chose $m=1.6$ as the optimal $m$ value for FCM.

\section{Hardened FCM and Accuracy Comparison}

Figures 4.4 and 4.5 show the comparison of thresholding results for hardened FCM at $d=0.5$ for both input images. The inclusion of DTM data has improved the classification results. In Figure 4.4 , an example is presented at which roofs (non-water) were correctly classified by Pleiades + DTM, but were classified incorrectly by Pleiades. The classification improvement also can be seen from Figure 4.5 provides an example in which inundated land was clearly identified by Pleiades + DTM.

Table 4.3 shows the comparison of the accuracy between Pleiades and Pleiades + DTM. For all subsets, Pleiades + DTM outperformed Pleiades. Table 4A.2 presents the significance of the different accuracies given by both images. Seven of the tests show significant improvement of the Pleiades + DTM over the Pleiades, as shown by very low $p$-values, whereas, few results have similar accuracies, as shown by $p$-values $\geq 0.05$. 


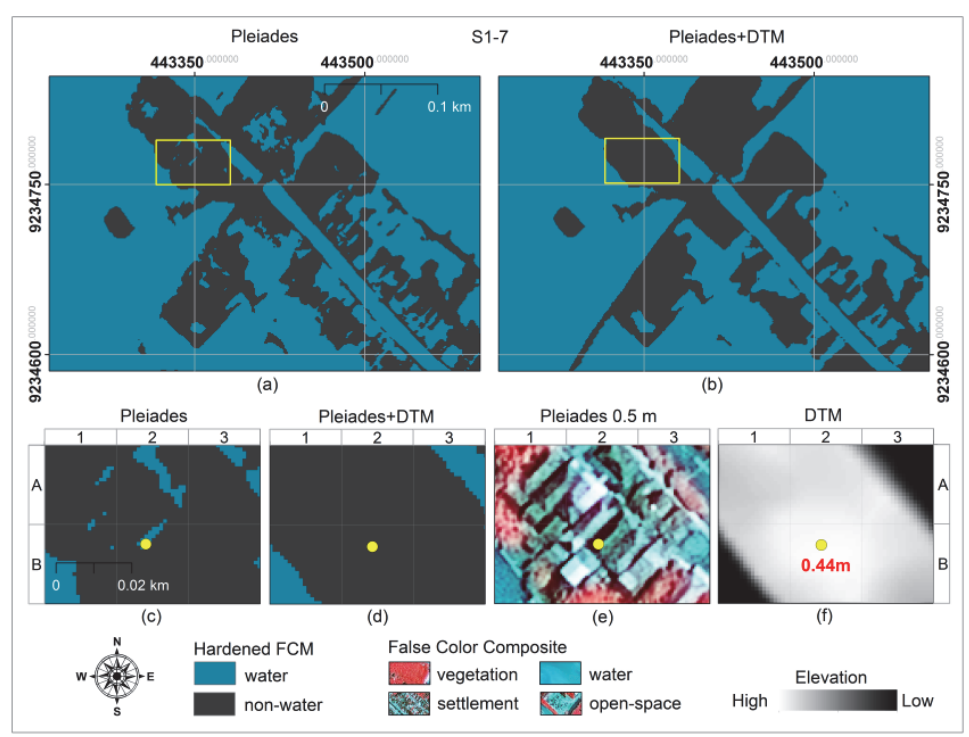

Figure 4.4 Comparison of the fuzzy classification results between: Pleiades $(\mathrm{a}, \mathrm{c})$; and Pleiades + DTM $(\mathrm{b}, \mathrm{d})$. Pleiades $0.5 \mathrm{~m}(\mathrm{e})$; and elevation data ( $\mathrm{f}$ ) are displayed to interpret the attribute of yellow points. In $(c, d)$, we can see that Pleiades misclassified pixels as water instead of roofs (non-water), as can be seen in (e)

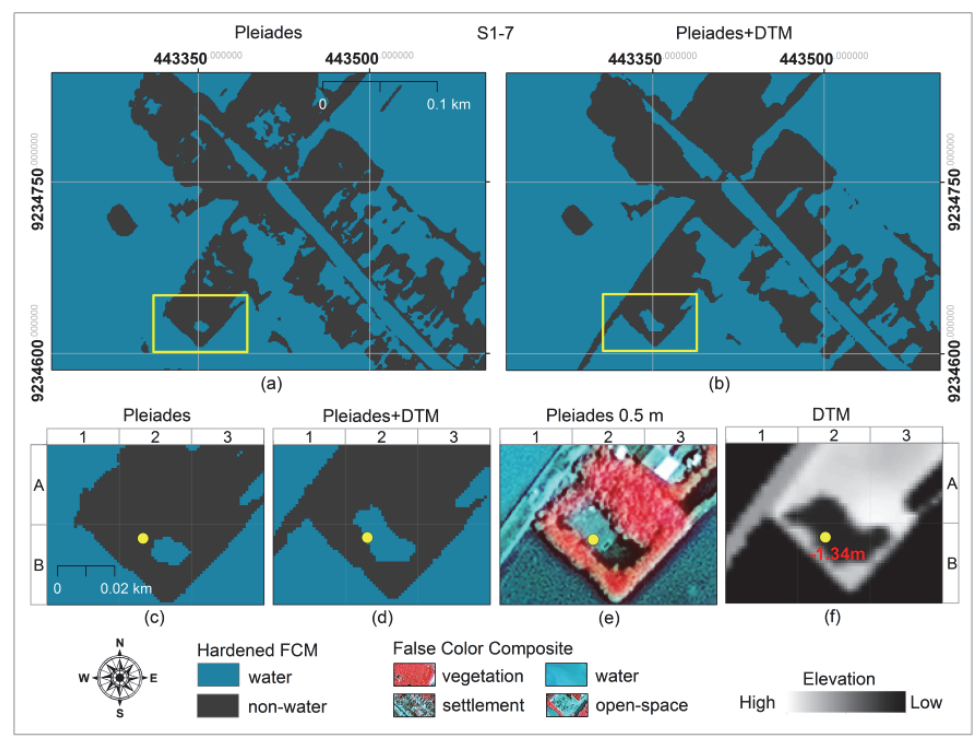

Figure 4.5 An example of inundated land that was: incorrectly classified by Pleiades $(a, c)$; and classified successfully by Pleiades + DTM $(b, d)$. Pleiades $0.5 \mathrm{~m} \mathrm{(e)}$; and elevation data (f) are presented to interpret the yellow points 
Table 4.3 The accuracy comparison between Pleiades and Pleiades + DTM using FCM classification with thresholding $(\boldsymbol{c}=2, \boldsymbol{m}=1.6, \boldsymbol{d}=0.5)$. The inclusion of DTM in classifications clearly improved the classification results. $\boldsymbol{S}_{\boldsymbol{a}-\boldsymbol{b}}$ : the name of subsets, $\boldsymbol{a}$ is the group number $(\boldsymbol{a}=1, \ldots, 4)$ and $\boldsymbol{b}$ is the subset number $(\boldsymbol{b}=1, \ldots, 13)$

\begin{tabular}{ccc}
\hline Subset & Pleiades & Pleaides + DTM \\
\hline$S_{1-1}$ & 0.77 & 0.86 \\
$S_{1-2}$ & 0.62 & 0.86 \\
$S_{1-6}$ & 0.76 & 0.88 \\
$S_{1-7}$ & 0.48 & 0.84 \\
$S_{1-9}$ & 0.56 & 0.87 \\
$S_{1-10}$ & 0.74 & 0.88 \\
$S_{2-3}$ & 0.74 & 0.91 \\
$S_{2-12}$ & 0.74 & 0.87 \\
$S_{2-13}$ & 0.78 & 0.87 \\
$S_{3-5}$ & 0.50 & 0.82 \\
$S_{3-11}$ & 0.74 & 0.89 \\
$S_{4-4}$ & 0.65 & 0.88 \\
$S_{4-8}$ & 0.67 & 0.81 \\
\hline
\end{tabular}

\section{Fuzzy Shoreline and Uncertainty Estimation}

Figure 4.6 shows an illustration of shoreline margin with fuzziness generated by setting $d=0.3$ as the lower $d$ and $d=0.7$ as the upper $d$ by using Pleiades + DTM (for other results, see Figure 4A.3). In this figure, the shoreline (in light green colour) represents the transition zone between water (in blue colour) and non-water (in black colour). The combination of the shoreline image and the confusion index is provided in Figure 4.6d. In this figure, a wider shoreline indicates a wider gradual transition between water and non-water representing a more gently sloping beach or muddy coastal area, while a narrow shoreline indicates a steeper sloping beach.

\subsubsection{Modelling Shoreline by Random Sets Parameter Estimation Results}

Table 4A.3 show the results of parameter $\varphi$ and threshold interval estimation of random sets with the related $\kappa$ values estimated from the $\Gamma_{0.5}$. In Table 4A.3 and Figure 4.7, it can be seen that threshold interval $=0.3-0.7$ generally produced the highest $\kappa$ value. We plotted the curves of the $\Gamma_{1}$ area for four subsets by setting the selected threshold interval $=0.3-0.7$ (see Figures 4.8 and 4A.4). From these curves, we can assess the optimal $\varphi$ at which we obtained a stabile $\Gamma_{1}$ 
area. Each subset has a different $\varphi$ to reach a stabile $\Gamma_{1}$ area, which might be influenced by the land cover characteristics of the study area. In Figure 4.8, the curve of $S_{4-4}$ reached the highest $\varphi$ value to achieve the stability of the $\Gamma_{1}$ area, whereas $S_{2-12}$ reached the lowest $\varphi$.

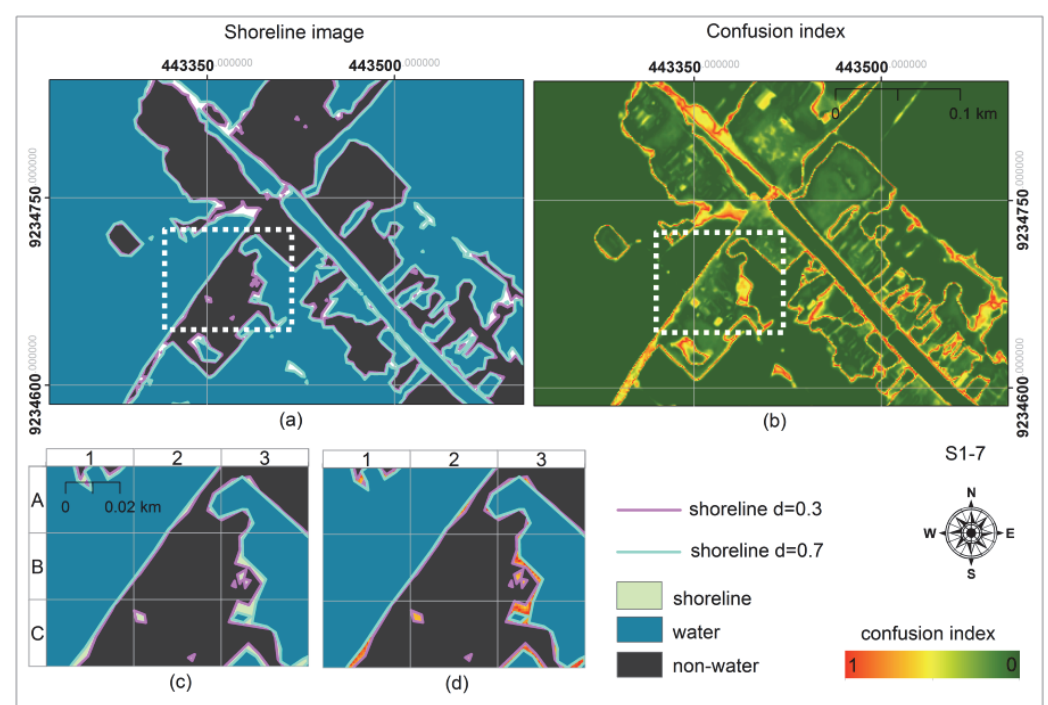

Figure 4.6 The shoreline as the transition zone between water and non-water (a); the fuzziness of the shoreline is represented by the confusion index denoting the uncertainty of pixels to be classified to the largest membership (b); zooming into the white-dashed rectangle sites (c); and shoreline image with fuzziness represented by the confusion index (d).

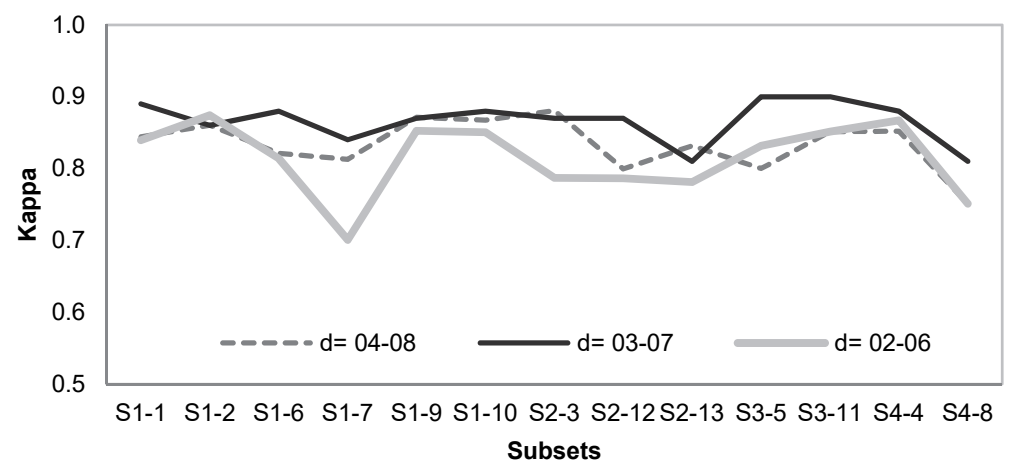

Figure 4.7 Estimation of threshold interval for random sets based on the optimal $n$ selected for each subset. Threshold interval $=0.3-0.7$ generally produced the highest $\mathrm{k}$ value. $S_{a-b}$ : the name of subsets, $a$ is the group number $(a=1, \ldots, 4)$ and $b$ is the subset number $(b=1, \ldots, 13)$ 


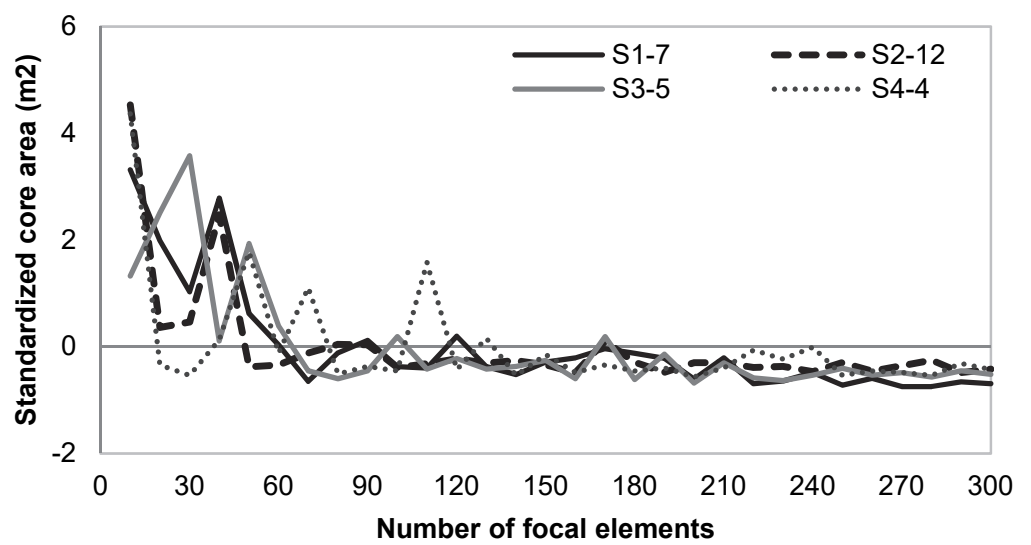

Figure 4.8 The curve of differences between two successive standardized core sets $\delta_{i}$. When $\delta_{i}$ is in the range -1 to +1 , we determined this $\varphi$ value for performing random sets (see notations in Figure 4.7 for the name of subsets).

\section{Uncertainty modelling of shoreline objects}

Figure 4.9 shows some examples of binary images and the related covering functions that resulted from slicing water membership images determined by the optimal $\varphi$ (the other results can be seen in Figure 4A.5). By slightly changing the threshold for $\mu_{w k^{\prime}}$, we obtained binary maps as a realization of focal element $O_{i}$ with various extents. From these focal elements, we constructed random sets by estimating the covering function, as can be seen in Figure 4.9f.

We plotted the area of focal elements to explore information on the extent of random sets (see Figure 4.10). From the plot in Figure 4.10, we can see that $S_{2-12}, S_{2-13}$, and $S_{3-5}$ have the largest variance, whereas $S_{4-4}, S_{1-10}$ and $S_{1-9}$ have the smallest variance. 


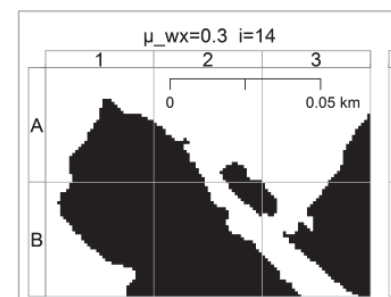

(a)

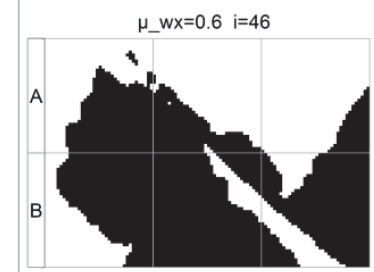

(d)

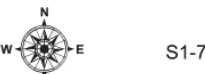

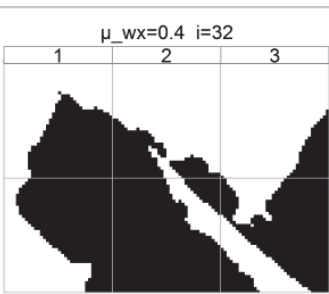

(b)

$\mu \_w x=0.7 \quad i=21$

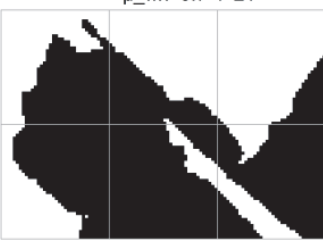

(e)

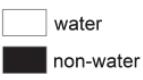

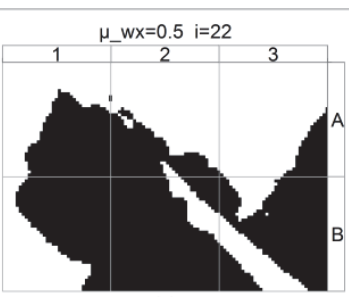

(c)

covering function

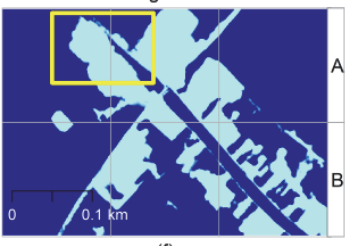

(f)

covering function

1

Figure 4.9 Samples of the random sets with various extents and their covering function. (a-e) Samples are at $\mu_{w k}=0.3-0.7$. Pixels in white indicate the water area and pixels in black indicate the non-water area. (f) The related covering functions, where 0 indicates a low probability and 1 indicates a high probability to be covered by the random sets. Various extents of focal elements at each binary map can be seen when zooming into the yellow rectangle site.

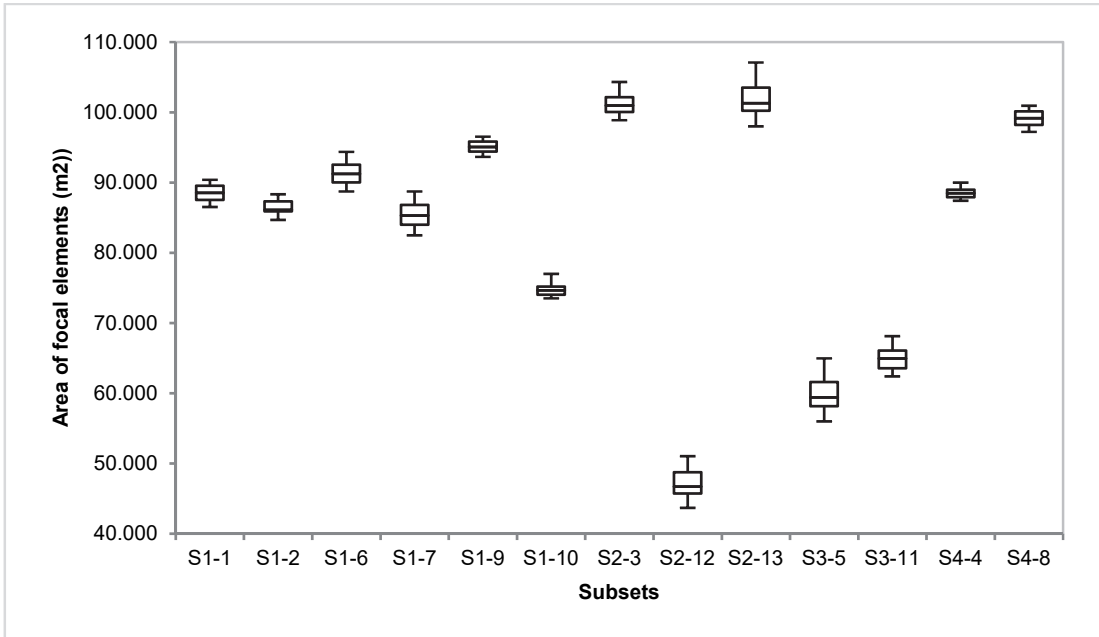

Figure 4.10 Statistical distribution of area of focal elements sampled from 13 random sets (see notations in Figure 4.7 for the name of subsets) 
In Table 4.4, we can see that subset $S_{4-4}$ has the lowest $C V$ value. A lower $C V$ indicates that the random sets have small $\Gamma_{v}$, reflecting a lower uncertainty. By checking the Pleiades image in Figure 4.1, it is obvious that $S_{4-4}$ comprises a rural settlement with concrete roads. The settlement was protected by embankment from its surrounding open water. For an object with little uncertainty, the membership values are homogenous. Therefore, the resulting samples $O_{1}, \ldots, O_{\varphi}$ have similar extents (see Figure 4.10 subset $S_{4-4}$ ). On the contrary, $S_{2-12}$ has the highest $C V$ value, which obviously indicates the highest uncertainty. For an object with a high uncertainty, the membership values are heterogeneous. Hence, the resulting samples $O_{1}, \ldots, O_{\varphi}$ have various extents and are very sensitive to small variations in $d$ value (see Figure 4.10 subset $S_{2-12}$ ).

In Figure 4.11a, the set-theoretic variance $\Gamma_{v}$ is presented in grey scale values with light colour denoting high variations in uncertain transition zones and dark colour denoting low variations of water and non-water (the other results can be seen in Figure 4A.6). For pixels inside $\Gamma_{1}$ or outside $\Gamma_{0}, \Gamma_{v}$ equals 0 , whereas pixels close to the contours of $\Gamma_{1}$ or $\Gamma_{0}$ have $\Gamma_{v}$ values in the range $[0,1]$. Figure $4.11 \mathrm{~b}$ shows the contours of $\Gamma_{1}, \Gamma_{m}$ and $\Gamma_{0}$ of random sets. The yellow rectangle sites (1) in Figures 4.11a,b have a different extent implying that these sites have a wider, more gradual transition (see Figure $4.11 c)$, mainly caused by the location close to the mangrove forest in a muddy area. For the yellow sites (2), however, the contours of $\Gamma_{1}$, $\Gamma_{m}$ and $\Gamma_{0}$ are similar and the segmentation boundaries show small variation (see Figure 4.11d).

Table 4.4 The quantification of the extensional uncertainty of the all subsets (the $\boldsymbol{S V}$ is the sum of variance, and $\boldsymbol{C V}$ denotes the coefficient of variance). See notations in Table 4.3 for the name of subsets

\begin{tabular}{ccc|ccc}
\hline Subset & $\boldsymbol{S V}$ & $\boldsymbol{C V}$ & Subset & $\boldsymbol{S V}$ & $\boldsymbol{C V}$ \\
\hline$S_{1-1}$ & 657 & 0.007 & $S_{2-12}$ & 1525 & 0.032 \\
$S_{1-2}$ & 811 & 0.009 & $S_{2-13}$ & 1710 & 0.017 \\
$S_{1-6}$ & 915 & 0.010 & $S_{3-5}$ & 1490 & 0.025 \\
$S_{1-7}$ & 901 & 0.010 & $S_{3-11}$ & 883 & 0.014 \\
$S_{1-9}$ & 466 & 0.005 & $S_{4-4}$ & 441 & 0.005 \\
$S_{1-10}$ & 574 & 0.008 & $S_{4-8}$ & 580 & 0.006 \\
$S_{2-3}$ & 953 & 0.009 & & & \\
\hline
\end{tabular}




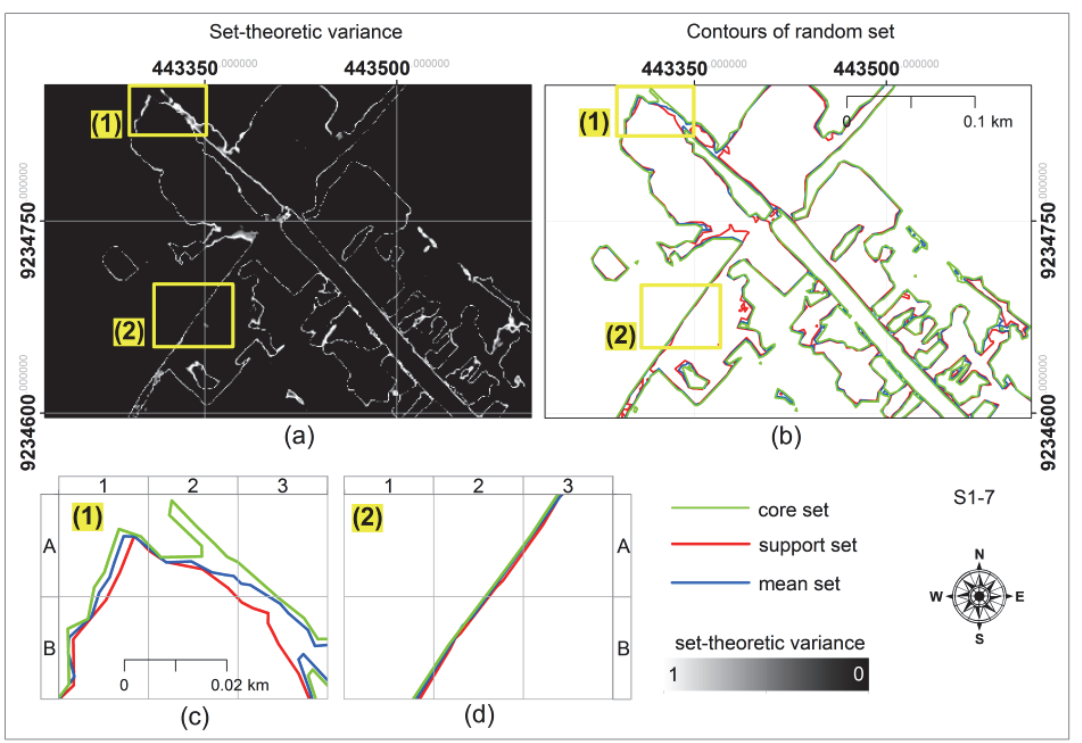

Figure 4.11 The set-theoretic variance (a); some examples of the contour of $\Gamma_{1}, \Gamma_{0.5}$ and $\Gamma_{0}(\mathrm{~b})$; and a detail representing the yellow rectangle sites as an example of contours with a broad variation (c); and contours with a small variation indicating a narrow shoreline $(d)$.

More pixels with a non-zero $\Gamma_{v}$ in the objects indicate a large uncertainty area. $S V$ values are the largest for $S_{2-12}, S_{2-13}$, and $S_{3-5}$ (see Table 4.4) because the number of pixels with non-zero $\Gamma_{v}$ values in those subsets are the largest (see Figure 4A.6). Subsets $S_{1-9}, S_{4-4}$ and $S_{4-8}$ have the smallest $C V$, which can be observed well in Figure 4A.6 indicating a small number of pixels with a non-zero $\Gamma_{v}$.

The extent of the shoreline is represented by a random sets model in Figure 4.12 as an example of the representations of the core set $\Gamma_{1}$, the support set $\Gamma_{0}$, and the covering function $\operatorname{Pr}_{\Gamma}(k)$ of random sets (see Figure 4A.7 for other results). Figure $4.12 \mathrm{a}$ shows the $\Gamma_{1}$ (in blue pixels) representing the area that obviously belongs to water. Figures $4.12 \mathrm{~b}$ displays the $\Gamma_{0}$ (in blue colour) indicating the possible part of the area that belongs to water, whereas the area outside this $\Gamma_{0}$ belongs to non-water (see black pixels in Figure 4.12d). The gradual changes in the transition zone representing the shoreline are represented by the set-theoretic variance $\Gamma_{v}$. Pixels with value close to 1 have a high variation indicating a high uncertainty, whereas, pixels with value close to 0 have a low variation indicating a low uncertainty (Figures $4.12 \mathrm{~d}, \mathrm{e}$ ). A clear distinction exists between a narrow transition zone, for example, which separates settlements and 
open water (Figure 4.12e, e.g., grid cells A2 and B2), and broad transition zones between open water and vegetation (Figure $4.12 \mathrm{e}$, e.g., grid cells B3).

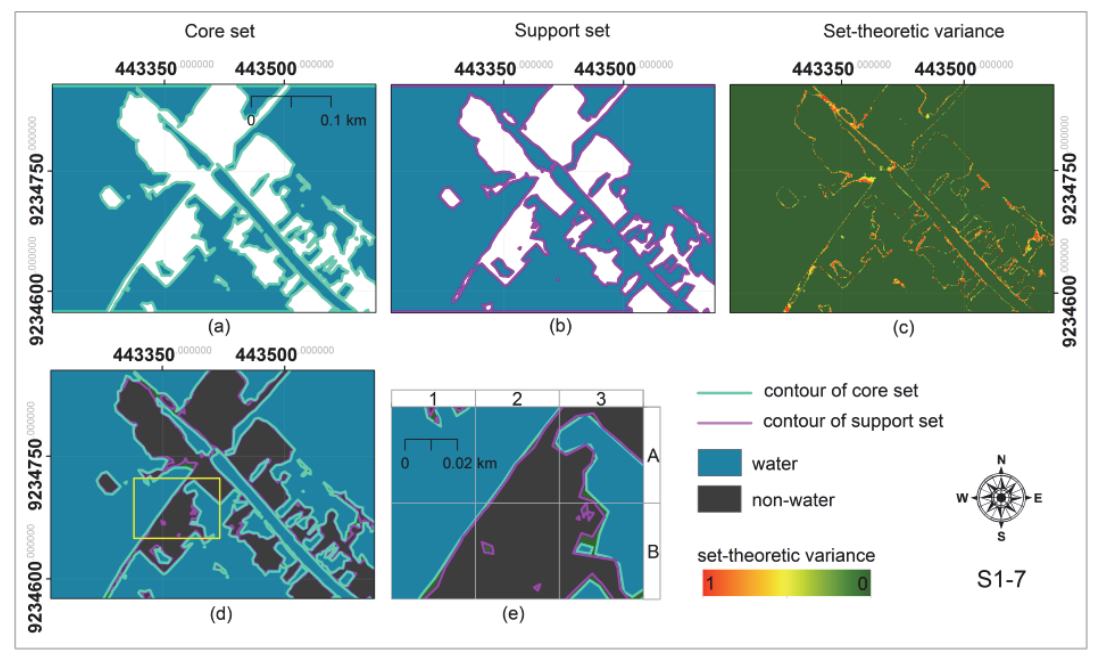

Figure 4.12 An example of a random set: the core set $\Gamma_{1}$ and its contour (a); the support set $\Gamma_{0}$ and its contour (b); the set-theoretic variance image (c); the transition zone between water and non-water represented by the settheoretic variance values (d); and zoom-in to the yellow rectangle site (e).

\section{Accuracy assessment of random sets results}

Table 4.5 shows the comparison of accuracy between Pleiades and Pleiades $+D T M$ by using random sets. Similar to fuzzy sets, using random sets, Pleiades + DTM outperformed Pleiades. McNemar's test results of random sets using Pleiades and Pleiades + DTM are shown in Table 4A.4. Seven of the subsets show significant improvement of the Pleiades + DTM over the Pleiades image, as shown by their very low $p$-values (see Table 4 A. 4 subsets $S_{1-1}, S_{1-2}, S_{1-7}, S_{1-9}, S_{1-10}, S_{3-5}$, and $\left.S_{4-4}\right)$, whereas the rest of the results show that similar accuracies were obtained from both of them. 
Table 4.5 The accuracy comparison between Pleiades and Pleiades + DTM by random sets (see notations in Table 4.3 for the name of subsets)

\begin{tabular}{ccc|ccc}
\hline Subset & Pleiades & $\begin{array}{c}\text { Pleiades } \\
+\boldsymbol{D T M}\end{array}$ & Subset & Pleiades & $\begin{array}{c}\text { Pleiades } \\
+\boldsymbol{D T M}\end{array}$ \\
\hline$S_{1-1}$ & 0.76 & 0.89 & $S_{2-12}$ & 0.74 & 0.87 \\
$S_{1-2}$ & 0.58 & 0.86 & $S_{2-13}$ & 0.79 & 0.81 \\
$S_{1-6}$ & 0.76 & 0.88 & $S_{3-5}$ & 0.56 & 0.90 \\
$S_{1-7}$ & 0.48 & 0.84 & $S_{3-11}$ & 0.77 & 0.90 \\
$S_{1-9}$ & 0.56 & 0.87 & $S_{4-4}$ & 0.66 & 0.88 \\
$S_{1-10}$ & 0.74 & 0.88 & $S_{4-8}$ & 0.67 & 0.81 \\
$S_{2-3}$ & 0.75 & 0.87 & & & \\
\hline
\end{tabular}

\subsubsection{Comparing Classification Performance}

Table 4A.5 presents the McNemar's test results by fuzzy sets and random sets using Pleiades image. The table indicates that the methods agree on $f_{22}$ and $f_{11}$ but disagree on $f_{12}$ and $f_{21}$ samples. From the test results, we can see that $p$-values are relatively high $(\geq 0.05)$ implying that both methods obtained a similar accuracy when using Pleiades.

Table 4A.6 presents the McNemar's test results by fuzzy sets and random sets using Pleiades + DTM image as input data. From the test results, we can see that $p$-values are relatively high $(\geq 0.05)$ implying that both methods obtained a similar accuracy when using Pleiades + DTM.

\subsection{Discussion}

This research compared two methods for handling the uncertainty of shorelines: fuzzy sets and random sets. Shoreline is a spatial object with inherent uncertainty that cannot be extracted effectively from satellite images by means of a crisp-based classification, since these methods ignore uncertain areas or gradual transition zones. This chapter demonstrates that fuzzy sets and random sets produced comparable results for modelling the uncertainty of fuzzy shorelines. When using fuzzy sets, the same results can be achieved without taking randomness into account, as confirmed by Zadeh (1995).

The $\kappa$ accuracies from both fuzzy sets and random sets are slightly different (see Tables 4.3 and 4.5). In addition, the McNemar's test 
failed to reject the null hypothesis of equal performance of both methods by using either Pleiades or Pleiades + DTM (see Tables 4A.5 and 4A.6). Although fuzzy sets and random sets were not identical, shorelines resulted from both methods were close to each other (see Figures $4.6 \mathrm{~d}$ and $4.12 \mathrm{e}$ ) and neither could be considered more accurate, as confirmed by the literature (Goodman, 1984; Mahler, 2007). This is probably related to the fact that each segmentation of random sets can be interpreted as a different interpretation of a fuzzy concept, since the multiple thresholds to generate the segments are selected among the possible interpretations (Mahler, 2007). Furthermore, Goodman (1984) argued that any given fuzzy sets is equal to one nested random set.

Both methods were successful in identifying the spatial extent of shorelines including their extensional uncertainties. Fuzzy sets present a shoreline as a margin derived from a crisp boundary determined by $d$ values. Here, the extensional uncertainty of shoreline represented by a confusion index values implies that the shoreline can be detected with limited certainty. Through the confusion index, the presence of a gradual transition was distinguished when the values of an adjacent grid are very similar. When using random sets, a shoreline is presented as the third class, the transition zone between water and non-water. The extensional uncertainty of a shoreline was assessed by using the covering function of random sets and its statistical parameters $\left(\Gamma_{1}, \Gamma_{m}, \Gamma_{0}\right.$ and $\left.\Gamma_{v}\right)$. By using these parameters, we demonstrated that the randomness of segmentation parameters, i.e., multiple thresholds, has a different effect on extracted features when objects have different extensional uncertainties (see Figure 4.9). Moreover, there are other indicators such as $S V$ and $C V$ to summarize the size of extensional uncertainties. A high $S V$ and $C V$ indicate a high extensional uncertainty.

Fuzzy sets were applied by first estimating the membership function. In this study, we computed the membership value by performing FCM classification. On the one hand, this method is less subjective as compared to the semantic import model (Burrough, 1996; Cheng, 2002), while, on the other hand, the choice of values for $c$ and $m$ influence the results of the classification. In contrast, random sets as a probabilistic approach avoid user interference (Nguyen, 2006; Zhao et al., 2011b) in generating random sets.

The random sets model was combined with thresholding to model shorelines from water membership images. Here, the choice of $\varphi$ as 
the number of focal elements was critical. Improper threshold values $\mathcal{R}_{i}, \ldots, \mathcal{R}_{\varphi}$, from the worst $\varphi$ values in segmentation will result in errant segments. At low $\varphi$, the $\Gamma_{1}$ area changed abruptly, and by the increasing of $\varphi$ values, the $\Gamma_{1}$ area reached its stability. In fact, by increasing $\varphi$, we increase the chance to have optimal threshold values for segmentation of random sets. Performing random sets modelling with such large $\varphi$ values was computationally expensive. Comparing random sets to fuzzy sets, fuzzy sets were relatively computationally less expensive. However, the choice of optimal $c, m$, and $d$ values for classification influences the results and requires a thorough investigation.

To model a shoreline using fuzzy sets, we need to adopt other concepts to quantify the extensional uncertainty of the shoreline, such as $\alpha$-cut, shoreline as a margin, and fuzzy-crisp object (Cheng et al., 2001; Dewi et al., 2017a; Dewi et al., 2016), whereas a random sets approach through its covering function and statistical parameters directly quantifies the extensional uncertainty of shoreline without resorting to other concepts.

The integration of DTM data improved the results of both fuzzy sets and random sets. The integration of Pleiades and elevation has higher accuracy than Pleiades only. The additional DTM band leads to an improvement in the classification accuracy for roofs, inundated houses and inundated land. After this integration, roofs were clearly distinguished and separated from their surroundings (i.e., water and inundated soil). Usually, the ground close to the building location is slightly higher than its surroundings while water area or an inundated land clearly has a lower elevation. By using only Pleiades, it was difficult to discriminate dark roofs and water or inundated soil, since they are often have similar spectral characteristics. The ability to discriminate two similar characteristics is influenced by the number of spectral bands available. The other objects that were successfully classified from the addition of DTM were inundated houses and land. In this case, the elevation data help to identify the water area. In addition to the benefit given by addition of the DTM in the classification, a downside could be found as well, especially for tree objects. This is due to the time difference between Pleiades and DTM data of one and half years. In several locations, trees were submerged and finally no longer exist in newer data and these changes caused loss of accuracy. In this case, the use of DTM data that have the same date of acquisition as the remote sensing image is preferable. 


\subsection{Conclusions}

In this chapter, fuzzy sets and random sets are compared for shoreline detection. Both methods performed well in modelling the uncertainty of shorelines and had similar results when using either Pleiades or Pleiades + DTM.

Application of fuzzy sets produced higher classification accuracy for Pleiades + DTM than for Pleiades. Similarly, for random sets, Pleiades + DTM gained a significant improvement over Pleiades. Considerable improvements were achieved for objects, e.g., roofs, inundated houses and yards. Pleiades + DTM achieved accuracy above $80 \%$, demonstrating that it provides a valuable data source for shoreline mapping. In the absence of elevation data, we may overestimate in particular the water area. The research further confirmed the need of DTM integration to remote sensing images to provide reliable and accurate shoreline mapping that may give benefit to coastal planners and managers. The proposed methods are to be further applied in other areas for future study. This will help to better understand how different condition of the area can influence the results and to upscale the methods to larger areas of land. 


\section{Transferability and Upscaling of Fuzzy Classification}

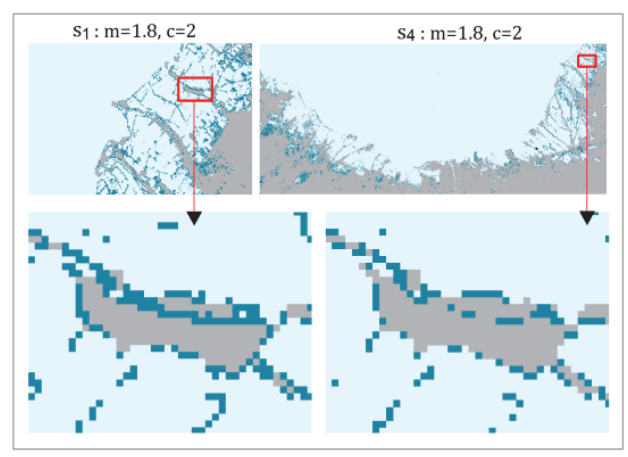

This chapter provides methods to test the transferability and upscaling potential of fuzzy classification to other areas and towards larger area. FCM parameters (level of fuzziness, $m$ and number of classes, $c$ ) are optimized based on predominant land use/cover. The value of the class means and number of classes of the reference subset are be used to initialize target subsets. The optimal level of fuzziness $(m=1.8)$ provided in this research can be adopted for similar coastal areas.

This chapter is based on the published paper: Dewi, R.S., Bijker, W., Stein, A., Marfai, M.A., 2018. Transferability and Upscaling of Fuzzy Classification for Shoreline Change over 30 years. Remote Sensing. 2018. 10, 1377 
Abstract

Local authorities require information on shoreline change for land use decision making. This study investigated the transferability of a fuzzy classification of shoreline changes and to upscale towards a larger area. Using six sub areas, we conducted three strategies: (i) optimizing two FCM parameters based on the predominant land use/cover of the reference subset; (ii) adopting the class mean and number of classes resulting from the classification of reference subset to perform FCM on target subsets; and iii) estimating the optimal level of fuzziness of target subsets. This approach is applied on a series of images to identify shoreline positions in a part of the northern Central Java Province, Indonesia which experienced a severe change of shoreline position in three decades. From the experimental results, we obtained $\mathrm{m}$ values in the range from 1.3 to 1.9 for seven land use/cover classes that have been analysed. Furthermore, for ten images used in this research, we obtained the optimal $\mathrm{m}=1.8$. For a similar coastal characteristic, this $\mathrm{m}$ value can be adopted and the relation between land use/cover and two FCM parameters can help to shorten the time needed to optimize the parameters. The proposed method for upscaling and transferring the classification method to a larger and to different areas is promising showing $\kappa$ values $>0.80$ and agreement of water membership values $>0.82$ between the reference and target subsets. We conclude that the method is applicable to the current study area. The relation between land use/cover classes and the value of FCM parameters produced in this study can be adopted.

Keywords: fuzzy classification, transferability, upscaling, shoreline change 


\subsection{Introduction}

A shoreline represents the boundary where the land meets the sea. It does not form a permanent line, but is a dynamic environment as the land and sea are changing in response to both natural and anthropogenic factors (French, 2001). Natural factors include erosion, accretion, storm, wave, tide, whereas anthropogenic factors include coastal development. The position of the shorelines can change due to: (i) variation in sea level that is influenced by either meteorological or astronomical factors (Pugh, 1987); and (ii) alteration in the shape and volume of sediments along the shore (Pardo-Pascual et al., 2012).

Previous methods to extract shorelines can be divided into two broad categories (Sukcharoenpong et al., 2016). In the first category are model-based methods which generate shoreline by intersecting a digital elevation model (DEM) with a water level at a desired tidal datum, for example shoreline mapping from LiDAR-based DEM and ground survey (Kim et al., 2017; White et al., 2011). The second category consist of image-based methods which extract instantaneous shoreline as it appears on images of which its acquisition time is correlated with tidal data, for instance shoreline mapping from digital photogrammetry (Yao et al., 2015a) and remote sensing imagery (Choung and Jo, 2016).

Since remotely sensed images record a shoreline at a particular instant, modelling shoreline with remote sensing images should include estimation of its uncertainty (Dewi et al., 2017b; Zhao et al., 2011b). The uncertainty in shoreline modelling can arise due to an inherent variability in nature, for example due to a variation of a shoreline over time and the presence of gradual transition between land and water (Fisher, 1999; Riesch, 2013). When a shoreline is clearly identified, however, the uncertainty in shoreline modelling can originate from errors during image processing and taking measurements (Fisher, 1999). Given that the shoreline is imprecise (Atkinson and Foody, 2002), it is best handled by soft classification (Foody, 1996). Few studies exist on modelling shoreline using soft classification e.g. fuzzy c-means classification and the linear spectral mixture model (Dewi et al., 2016; Huang et al., 2017; Muslim et al., 2006; Taha and Elbeih, 2010). In our previous study, we used FCM classification to estimate the water memberships and then generate shoreline margin by using a choice of thresholds (Dewi et al., 2016). To estimate membership values by using FCM, we need to specify 
parameters $c$ as the number of classes, and $m$ as the level of fuzziness. The choice of these parameters is not always an easy task, especially when the user does not have any knowledge about the number of information classes. As an alternative, we can estimate specific indices to measure clustering performance with a range of cluster numbers and a range of fuzziness values. The transferability and the upscaling potential of the shoreline model to larger areas than those where it has been developed have only rarely been checked. Better knowledge about the transferability and the upscaling potential would lead to the development of more robust shoreline models which eventually would advance our understanding of changes in the coastal environment.

In this study, we aim to test the transferability of the method developed in Dewi et al. (2016) to another area and to upscale it towards a larger area. Both transferability and upscaling were assessed by the optimization of the $m$ and $c$ parameters. The method was implemented on a series of images in the northern part of Central Java.

\subsection{Transferability and upscaling methods}

\subsubsection{Satellite images, reference data and pre-processing}

Landsat and ASTER images available from USGS EarthExplorer (USGS, 2017) were used in this study (Table 5.1). In total, we used 10 images dating from 1988 to 2017 denoted as $I_{\beta}$, where $\beta$ is the image number $(\beta=1, \ldots, 10)$. These images were recorded at the low tide. Tidal data relating to the time of image acquisition were collected from Indonesia Geospatial Information Agency (BIG, 2017).

All images were transformed to the Universal Transverse Mercator (UTM), World Geodetic System (WGS 84) projection. Landsat 8 OLI/TIRS were rescaled to the same 8-bit format as Landsat TM, Landsat ETM+ and ASTER images. Histogram minimum adjustment was applied to all images (Hadjimitsis et al., 2010) to reduce the effect of atmospheric path radiance. Landsat 8 OLI/TIRS of 19 June 2017 was rectified using a 2015 orthoimage. This Landsat image was then used as the base image to which all other images were georectified using ground control points (GCPs) of permanent features in the images. The root mean square error (RMSE) values were less than 0.5 pixel. Reference data from several images including 
Sentinel-2, ASTER, Landsat TM (USGS, 2017) and images obtained via Google Earth were used for accuracy assessment purposes.

Table 5.1 Images used in this study and their related reference data

\begin{tabular}{|c|c|c|c|c|c|}
\hline Images & $\begin{array}{l}\text { Acquisition } \\
\text { Date }\end{array}$ & Sensors & $\begin{array}{l}\text { Astronomic } \\
\text { al Tide } \\
\text { Level }(\mathrm{m})\end{array}$ & $\begin{array}{c}\text { Reference } \\
\text { Data }\end{array}$ & $\begin{array}{c}\text { Acquisition } \\
\text { Date }\end{array}$ \\
\hline$I_{1}$ & 23 Sep 1988 & TM & -0.03 & Landsat TM & 23 Sep 1988 \\
\hline$I_{2}$ & 31 Aug 1991 & TM & 0.01 & Landsat TM & 31 Aug 1991 \\
\hline$I_{3}$ & 08 Sep 1994 & TM & 0.19 & Landsat TM & 08 Sep 1994 \\
\hline$I_{4}$ & 15 Aug 1997 & TM & 0.05 & Landsat TM & 15 Aug 1997 \\
\hline$I_{5}$ & 06 Jul 2000 & TM & 0.19 & ASTER & 16 Feb 2001 \\
\hline$I_{6}$ & 20 May 2003 & ETM+ & 0.01 & ASTER & 26 Feb 2002 \\
\hline$I_{7}$ & 12 May 2006 & ASTER & 0.08 & ASTER & 12 May 2006 \\
\hline$I_{8}$ & 07 Jul 2009 & ASTER & 0.3 & ASTER & 07 Jul 2009 \\
\hline$I_{9}$ & 27 Aug 2013 & OLI/TIRS & -0.09 & $\begin{array}{l}\text { Image via } \\
\text { Google }\end{array}$ & 31 Dec 2013 \\
\hline$I_{10}$ & 19 Jun 2017 & OLI/TIRS & 0.04 & Sentinel-2 & 28 Jun 2017 \\
\hline
\end{tabular}

\subsubsection{FCM parameter estimation for land use/cover types}

Optimization of parameters $m$ and $c$ was performed for various land use/cover types in order to see the relation between land use/cover composition and the value of $m$ and $c$. For this purpose, we estimated the cluster validity index (CVI) based on Xie and Beni (1991) by using a range of combinations of $m$ and $c$. We tested values 1.1 to 3.0 in the steps of 0.1 for $m$ and values 2 to 7 in the steps of 1 for $c$. This CVI has been used to evaluate the validity of partitions produced by FCM clustering algorithm (Pal and Bezdek, 1995; Wu and Yang, 2005). The lowest values produced by the CVI indicate a partition in which all the clusters are overall compact and separate from each other (Xie and Beni, 1991). The CVI is estimated as:

$$
C V I=\frac{\sum_{i=1}^{c} \sum_{k=1}^{N} \mu_{i k}^{m}\left\|V_{i}-X_{k}\right\|^{2}}{N \min _{i, k}\left\|V_{i}-V_{k}\right\|^{2}}
$$

where $X=\left\{X_{k} ; k=1,2, \ldots, N\right\}$ is the set of digital number; $V_{i}(i=1,2, \ldots, c)$ is the mean of the classes; $N$ is the number of pixels; $c$ is the number of classes; $\mu_{i k}$ is the membership of pixel $k$ belonging to class $i ; m$ is the level of fuzziness, and $\min _{i, k}\left\|V_{i}-V_{k}\right\|$ is the minimum distance between the mean of the classes. 


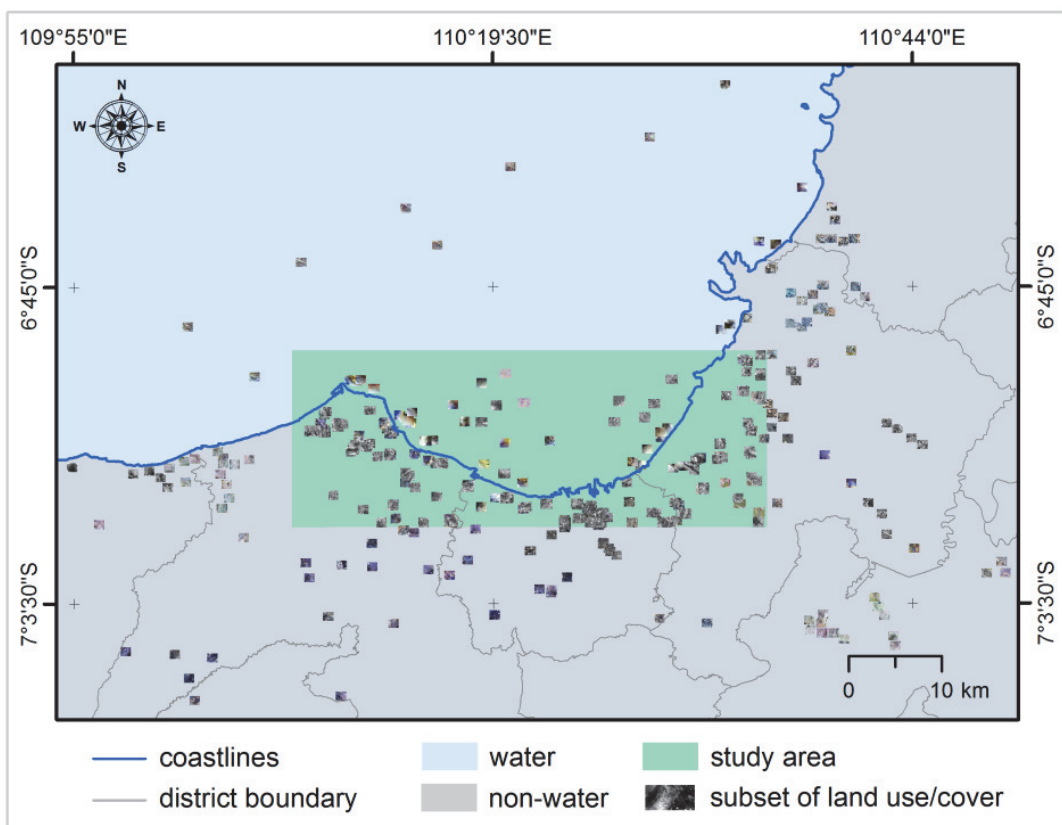

Figure 5.1 Location of subsets for each land use/cover class in the city of Semarang, Kendal and Demak

We created small subsets consisting of approximately $30 \times 30$ pixels for seven land use/cover classes (i.e., water, fishpond, wet paddy, dry paddy, other crops, built-up, and bare soil) that can be identified in the study area. We collected 55 subsets over the full extent of images based on the dominated land use/cover of the subset area. We considered these 55 subsets sufficient to describe the relation between land use/cover and the $m$ and $c$ values required for classification. It is unlikely that increasing the number of subsets for the estimation will achieve different results. Figure 5.1 shows the spatial distribution of the collected subsets over the city of Semarang, Kendal and Demak.

\subsubsection{Shoreline model}

The shoreline model as developed in Dewi et al. (2016) was applied by performing FCM classification and deriving shoreline margins by the choice of threshold interval $(d)$. To assess the transferability of the shoreline model and to upscale it towards a larger area, we conducted three strategies: (i) optimizing $m$ and $c$ based on the predominant land use/cover of the reference subset by utilizing information provided in Section 5.2.2; (ii) adopting the values of $V_{i}$ and $c$ which resulted from the classification of the reference subset to 
perform FCM on the target subset; and (iii) estimating the optimal $m$ of the target subsets.

FCM classification was performed to estimate the membership value that separates the data cluster into sets so that each pixel has a membership value to multiple classes. The clustering used in the FCM is based on minimizing the within-groups sum of squared error function $J_{m}$ (Bezdek et al., 1984):

$$
J_{m}=\sum_{k=1}^{N} \sum_{i=1}^{c}\left(\mu_{i k}\right)^{m}\left\|X_{k}-V_{i}\right\|^{2}, 1 \leq m \leq \infty
$$

After choosing the number of classes $c$ and the level of fuzziness $m$, FCM adds initial value to $V_{i}$ of each class in order to initialize clustering membership matrix. Instead of taking random values as the initial $V_{i}$, we used the value of $V_{i}$ of the reference subset. The FCM classification is thus performed by iteratively estimating and updating the membership value $\mu_{i k}$ and the mean cluster $V_{i}$ (Bezdek et al., 1984; Tso and Mather, 2009). After completing the clustering, membership images were compiled for each class. One of the membership images was labelled as belonging to water class by using the infrared bands of the images. The water label was given to the class which has the minimum value of $V_{i}$ in the infrared bands (Dewi et al., 2016). The final $V_{i}$ and the optimal $m$ values were then evaluated by assuming that a large deviation of $m$ and $V_{i}$ from the reference subset indicates that a new choice of $c$ is required.

Afterwards, the possible shoreline location was determined by generating a margin or transition zone between classes water and non-water. We defined a threshold interval based on $\mathrm{k}$ estimation to create hard boundaries of the transition zone determined by lower $\left(d_{1}\right)$ and upper thresholds $\left(d_{2}\right)$. We tested threshold values from 0.1 to 0.9 in steps of 0.05 to estimate the optimal threshold value and then decided a threshold interval $d_{1}$ and $d_{2}$ to generate a shoreline margin.

\subsubsection{Subsetting}

We created subsets for upscaling towards a larger area and to test the transferability to a different area. Subsets were denoted as $s_{b}$, where $b$ is the subset numbers $(b=1, \ldots, 6)$. We selected subset $s_{1}$ as a reference subset. The reference subset is a subset whose parameters are used to initialize other subsets (target subsets). We considered $s_{1}$ at the corner of the study area (Figure 5.2a), thus obtaining a 
maximum distance between reference and target subsets for the purpose of upscaling.

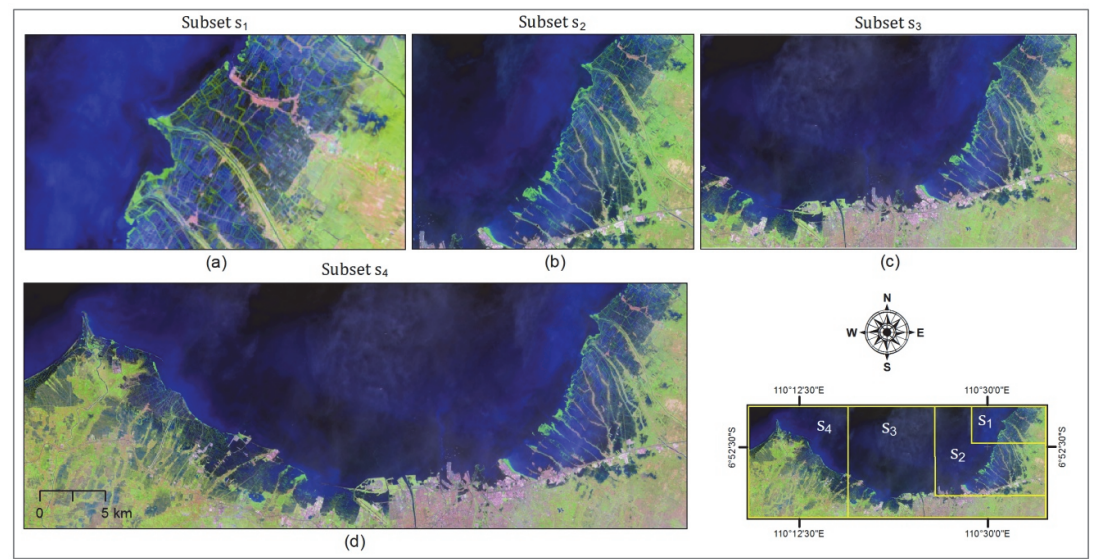

Figure 5.2 Four subsets with various sizes were used to upscale the method to a larger study area. Subset $\boldsymbol{s}_{\mathbf{1}}(\mathrm{a})$ is a reference subset while the others are target subsets (b-d). False natural colour composite of 2017 Landsat image is used for visualisation. Dark blue represents water area, green refers to vegetation, and shades of pink refer to built-up.

Subset $s_{1}$ is dominated by water and fishponds with mangroves planted along their dykes. In addition, it can be seen that bare soil was a dominant land cover in older images $\left(I_{1}\right.$ up to $\left.I_{4}\right)$. Meanwhile, in more recent images, this area was dominated by dry paddy ( $I_{5}$ up to $\left.I_{10}\right)$. From all images, this area has shown very little environmental changes reflected in a relatively steady shoreline position. For upscaling, we created three target subsets (Figures 5.2b-d). We gradually increased the size to see how various land use/cover influences the values of $m$ and $V_{i}$. In general, water was a dominant land use/cover in the area, while other types of land use/cover are described as follows:

a) Subset $s_{2}$ : the presence of agricultural area (paddy and other crops) was mainly influenced by the seasonal condition when the images were recorded. Bare soil was a dominant land use/cover in image $I_{1}$ up to $I_{4}$, while image $I_{5}$ up to $I_{10}$ were dominated by vegetation e.g., paddy and other crops. In addition, in the later subsets, we found an increase of built-up as the city has expanded to the north-east direction.

b) Subsets $s_{3}$ and $s_{4}$ obviously have a large coverage of water, especially clear water which contributes to a low spectral reflectance of water class. The city of Semarang was also located 
in these subsets. Therefore, these subsets have more built-up contributing to a high spectral reflectance of non-water class.

To test the transferability of FCM to a different area, we created two more subsets (i.e., $s_{5}$ and $s_{6}$ ) with similar size as $s_{1}$ (see Figure 5.4). Subset $s_{5}$ is similar to $s_{1}$, however $s_{5}$ has more built-up. Meanwhile, $s_{6}$ is dominated by urban area located close to the sea side. In the earlier images, fishponds were visible in the north-eastern and western part of the site. Agriculture areas could be identified at the south-eastern part of the city. In the later images, the city has been expanding and transformed fishponds and agriculture areas into settlements and commercial areas. A national sea-port and airport were built extending sea-ward and the concrete embankment was made as a protection along the shore.

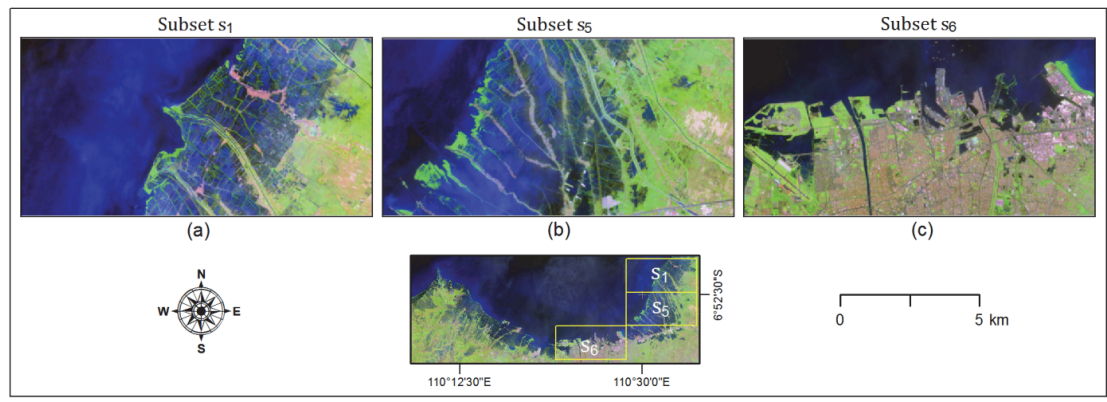

Figure 5.3 Three subsets to test the transferability of the method to different areas. $\boldsymbol{s}_{\mathbf{1}}$ and $\boldsymbol{s}_{\mathbf{5}}$ are dominated by water and agriculture area while $\boldsymbol{s}_{\mathbf{6}}$ is dominated by water and urban area.

We estimated the optimal FCM parameter at the reference subsets by utilizing knowledge provided in Section 5.2.2. Afterwards, we applied the values of $c$ and $V_{i}$ of the reference subsets for FCM classification of the target subsets. For upscaling, we used parameters of smaller subsets to be applied to larger subsets. For example, first, we estimated the optimal parameters for $s_{1}$. Second, we used the value of $V_{i}$ and the same $c$ from classification to estimate $s_{2}$. Likewise, we used the resulting class means of $s_{2}$ as the initial $V_{i}$ to estimate $s_{3}$. Finally, we compared the initial $V_{i}$ and $m$ values with the final $V_{i}$ and the final $m$ values. For the transferability, we similarly used the values of $c$ and $V_{i}$ resulting from classification on the reference subset i.e., $s_{1}$ to estimate the target subsets $s_{5}$ and $s_{6}$. To evaluate the classification performance, we performed classifications on two different reference subsets and compared the results. As a result, we 
have six shoreline images consisting of two reference subsets and four target subsets.

Each time we applied the method to either a larger area or another area with different land use/cover composition, FCM updated the initial $V_{i}$ by considering the existing land use/cover composition. Large deviation of both $V_{i}$ and $m$ from their initial values indicates that the target subset requires a new choice of $c$ for FCM. To check the variation of $V_{i}$ from their initial values, we used the infrared bands of the remote sensing images because the infrared bands exhibit a strong contrast between water and land features. In these infrared bands, the vegetation and soil show a high reflectance, but water has a low reflectance.

\subsubsection{Analyzing shoreline changes}

For the shoreline changes analysis, we used shoreline images developed for the whole study area (subset $s_{4}$ ). We performed post classification change detection by comparing information extracted from independently-produced classifications (Jianya et al., 2008; Lambin and Strahler, 1994). 'From-to' change information is provided, as well as the area and type of changes. Six types of changes are identified, namely shoreline to water, non-water to water, water to shoreline, non-water to shoreline, shoreline to nonwater and water to non-water. These changes were identified both as: i) abrupt changes when an area emerges at date $t_{2}$ without a corresponding area at date $t_{1}$ or vice versa; and ii) gradual changes when there is an expansion or shrinking of areas that were both exist at two dates $t_{1}$ and $t_{2}$.

Based on the results of shoreline change detection, the area of a specific change category was estimated by multiplying the number of pixels belonging to that specific change category and the area of a pixel. Three sections of the coastal area were selected for analysing the change of shoreline margin at time $t_{1}$ and $t_{2}$, namely east, middle, and west sections. The first two sections experienced an extensive change of shoreline while the third section can be considered as a moderate shoreline change.

\subsubsection{Change uncertainty estimation}

By considering the vagueness of the shoreline position and the uncertainty inherent in image processing, the confidence of the changed area is then estimated. The area change is associated with a value that reflects the change certainty of the shorelines. In this 
study, we modified the method proposed by Ardila et al. (2012), and we used differences in membership values estimated at $t_{1}$ and $t_{2}$ as proxy to the certainty in shoreline change. Six types of change certainties were identified namely change certainty of: shoreline to water, non-water to water, water to shoreline, non-water to shoreline, shoreline to non-water and water to non-water. Further for visualisation, we regrouped them into three types of change certainties namely change certainty to water, change certainty to shoreline and change certainty to non-water. For these change certainties, a high value corresponds to a high certainty of the change of the associated class in the shoreline image.

\subsubsection{Accuracy assessment}

For accuracy assessment purposes, we generated two error matrices: the conventional and the fuzzy error matrices. The conventional error matrix was used to assess the accuracy of shoreline models in the reference subset $\left(s_{1}\right)$, the accuracy of the transferability model $\left(s_{5}\right.$ and $\left.s_{6}\right)$, and the accuracy of the upscaling model $\left(s_{4}\right)$. For this purpose, we produced a hardened FCM at the selected threshold $d=0.5$. We collected randomly 150 points (for $s_{1}, s_{5}$ and $s_{6}$ ) and 400 points (for $s_{4}$ ) from each reference image. Subsequently, a visual interpretation approach was performed for a binary classification into water or non-water for each selected point. Afterwards, we estimated kappa ( $\kappa$ ) values by generating the confusion error matrix (Congalton and Green, 2009).

The fuzzy error matrix was developed to asses the agreement in water membership values between classes in both reference $\left(s_{1}\right)$ and target subsets when we upscaled the method to a larger area $\left(s_{2}, s_{3}\right.$ and $s_{4}$ ). For this purpose, we collected 150 points randomly from water membership images of both reference and target subsets. These points were collected over the extent of subset $s_{1}$ by assuming that the agreement obtained can represent the accuracy of the classification for the entire target subset with respect to the reference subset. The fuzzy error matrix is obtained by finding the maximum possible overlap between the target and the reference subsets (Dewi et al., 2017a; Pontius and Cheuk, 2006). Then, we estimated the overall accuracy of the classifications. 


\subsection{Results and assessment of accuracy}

\subsubsection{FCM parameter and threshold values estimation}

From FCM parameter estimation on seven land use/cover types, we found that bare soil and wet paddy have a similar optimal value of $c=2$ over the range between 2 and 7 for $c$, while the $m$ value varied between 1.5 and 1.9. Water, fishpond, dry paddy and built-up obtained optimal values of $c$ between 2 and 3 with $m$ values range from 1.3 to 1.9 . Other crops produced $m$ values between 1.5 and 1.7 and this class selects an optimal $m$ if $c$ lies in between 2 and 6 . Figure 5A. 1 shows histograms of the optimal $m$ and $c$ chosen by each CVI for seven land use/cover types in the study area.

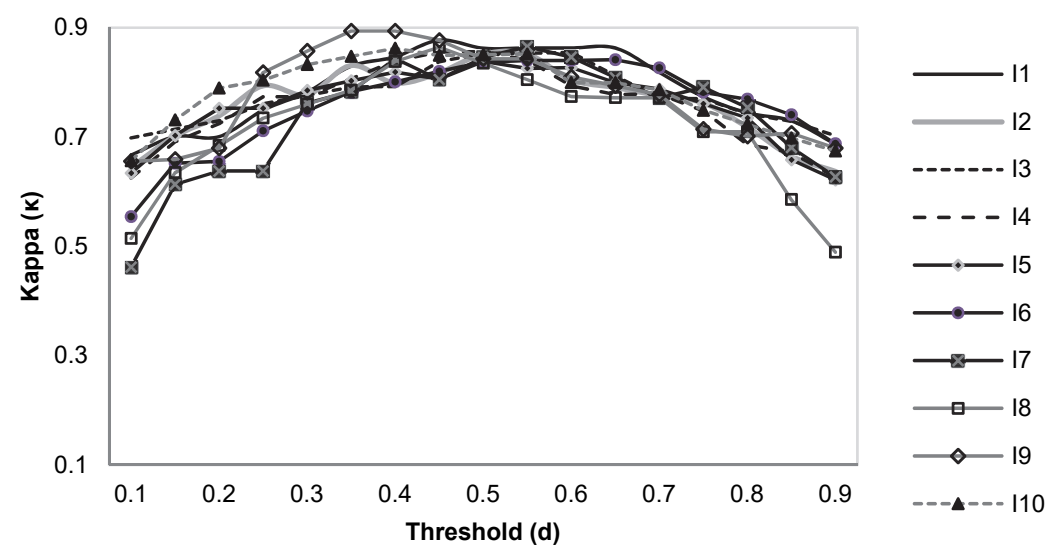

Figure $5.4 \kappa$ values to estimate threshold interval for generating the shoreline margin. The curves show that values of $\boldsymbol{d}$ larger than 0.7 and lower than 0.3 produced more erratic curves indicating low $\boldsymbol{\kappa}$ values. Threshold interval [0.3, 0.7] generally provides high $\boldsymbol{\kappa}$ values. Similar curves were obtained when estimated the $\boldsymbol{\kappa}$ for all images ( $\boldsymbol{I}_{\mathbf{1}}$ up to $\left.\boldsymbol{I}_{\mathbf{1 0}}\right)$

Figure 5.4 shows $\kappa$ values that were used to estimate an optimal threshold interval when generating shoreline margin. The highest $k$ values are given when setting $d$ values between 0.3 and 0.7 , whereas $d=0.25$ and $d=0.75$ also produced good results with $\mathrm{\kappa}$ values larger than 0.7 except for $I_{7}$. It can be clearly seen that $d$ values lower than 0.25 and larger than 0.75 obtained an erratic curve. The selected threshold interval produced similar curves when we estimated $\mathrm{k}$ values over time from 1988 up to 2017 (image $I_{1}$ up to $I_{10}$ ). Further, before proceeding to generate shoreline margins for the whole 
images, we visually evaluated shoreline margins by varying thresholds around the selected values. In this case, we set values 0.25 and 0.35 as $d_{1}$ and values 0.65 and 0.75 as $d_{2}$. We kept one threshold value (e.g., $d_{1}$ ) and varied the other threshold value $\left(d_{2}\right)$ to check whether extending the interval would give a large variation of margins. Changing $d_{1}$ and $d_{2}$ produced differences in the area of the shoreline margin. Based on the $\kappa$ values and visual analysis when varying thresholds around the selected interval, we decided to choose interval 0.3 to 0.7 as a suitable interval to generate the shoreline margins.

\subsubsection{Upscaling the shoreline model}

Optimization of the $m$ and $c$ value was performed for $s_{1}$ as the reference subset for all images (see Figure 5A.2). We applied FCM by setting $m=1.3$ to 1.9 and $c=2$ to 3 based on information provided in Figure 5A.1. For all these images, we obtained $m=1.8$ as the median value of the optimal $m$ and $c=2$ as the optimal $c$ chosen by each CVI.

Figure 5.5 shows the results of upscaling towards a larger area for $I_{10}$ and their related $m$ and $c$ values. For this image, the reference and target subsets required similar $m$ and $c$ values $(m=1.8$ and $c=2)$. Meanwhile, a complete result of optimization of target subsets is available in Figure 5A.3. In Figure 5.5, we compare shoreline images and zoom in at red rectangle sites to see the detailed visualisation of the area (see Figures $5.5 \mathrm{e}-\mathrm{h}$ ). The shoreline margin of target subset differed little from its reference when we upscaled the method to larger areas. This is also supported by information provided in Figure 5.6. The class means of water decreased when we compared smaller subsets to the larger subsets both in NIR and SWIR bands. This may be related to the increase of water area especially clear water which has a low spectral reflectance value (see Figure 5.2). On the contrary, an increase of the class mean of non-water can be identified from subset $s_{1}$ up to $s_{3}$. This may be due to the increase of built-up in both images as a result of city expansion. The small variation of shoreline margin (in Figures $5.5 \mathrm{e}-\mathrm{h}$ ) and small shift of $V_{i}$ value (in Figure 5.6) indicates that the differences between the smaller and the larger area were small. However, we notice that the more we upscaled the method to a larger area, the larger the deviation of shoreline margin from subset $s_{1}$.

Table 5.2 shows the overall accuracy values when we upscaled the method towards larger areas for images $I_{1}, I_{6}$ and $I_{10}$. The overall accuracies were larger than 0.82 for all subsets showing a high 
agreement in water memberships between the reference subset and the target subsets. However, the overall accuracy is slightly decreasing by the increase of the area of the subsets. A complete accuracy assessment result can be seen in Table 5A.1.

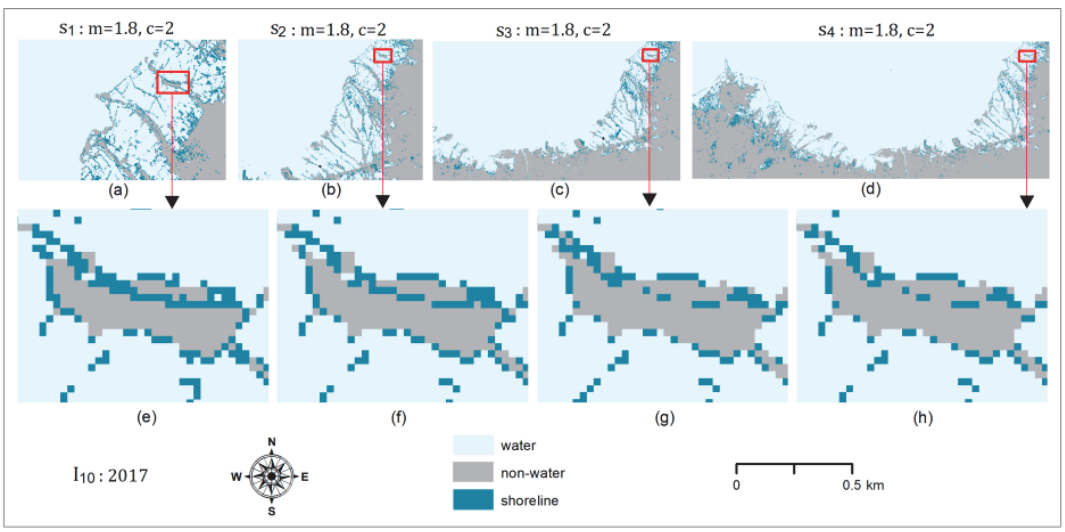

Figure 5.5 Image $\boldsymbol{I}_{\mathbf{1 0}}$ is used to show the comparison of shoreline images developed at the reference subset (a) and the target subsets (b-d). We zoom into an area in the red rectangle site $(e-h)$ to see a variation of shoreline margins (in turquoise) each time we upscaled the method to a larger area. The larger the area, the larger the deviation of shoreline margin from its reference subset
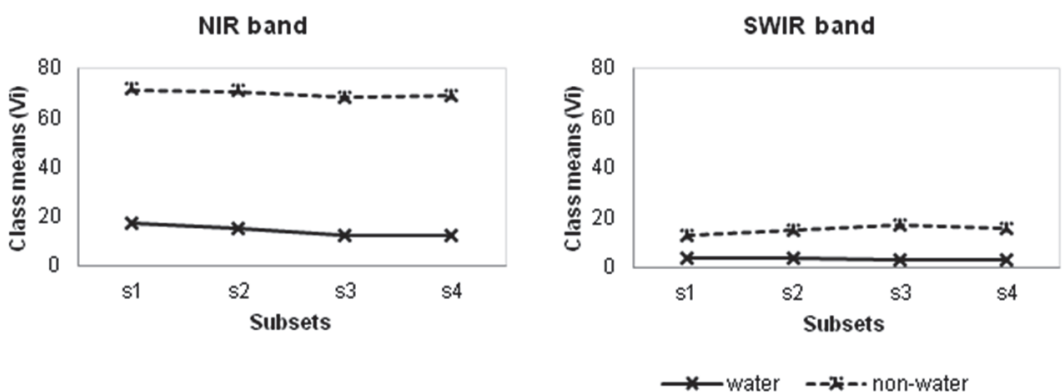

Figure 5.6 The comparison of the resulting class means of subsets $\boldsymbol{s}_{\mathbf{1}}$ up $\boldsymbol{s}_{\mathbf{4}}$ to for image $\boldsymbol{I}_{\mathbf{1 0}}$. The mean values of water class are slightly decreasing when we upscaled the method to larger areas both in NIR and SWIR bands. Whereas, mean values of non-water class are decreasing in NIR band and increasing in SWIR band for subsets $s_{1}$ up to $s_{3}$ 
Table 5.2 The overall accuracy indicating the water membership agreement between the reference subset $\boldsymbol{s}_{\mathbf{1}}$ and the target subsets $\left(\boldsymbol{s}_{2}\right.$ up to $\boldsymbol{s}_{\mathbf{4}}$ ) estimated using fuzzy error matrix for images $\boldsymbol{I}_{\mathbf{1}}, \boldsymbol{I}_{\mathbf{6}}$, and $\boldsymbol{I}_{\mathbf{1 0}}$

\begin{tabular}{cccc}
\hline Classified & \multicolumn{3}{c}{ Overall accuracy } \\
\cline { 2 - 4 } images & $\boldsymbol{s}_{\mathbf{2}}$ & $\boldsymbol{s}_{\mathbf{3}}$ & $\boldsymbol{s}_{\mathbf{4}}$ \\
\hline$I_{1}$ & 0.97 & 0.91 & 0.88 \\
$I_{6}$ & 0.92 & 0.83 & 0.82 \\
$I_{10}$ & 0.97 & 0.92 & 0.91 \\
\hline
\end{tabular}

\subsubsection{Transferability of the method to other areas}

Figure 5.7 shows the results when we transfer the method to a different area with different land use/cover composition. In Figure 5.7 , we used $s_{1}$ as the reference subset and the resulting $c$ and $V_{i}$ were used to estimate two target subsets $s_{5}$ and $s_{6}$. The reference and target subsets of image $I_{10}$ required similar $m$ and $c$ values $(m=1.8$ and $c=2$ ). A complete result of optimization of target subsets for other images is available in Figure 5A.4.

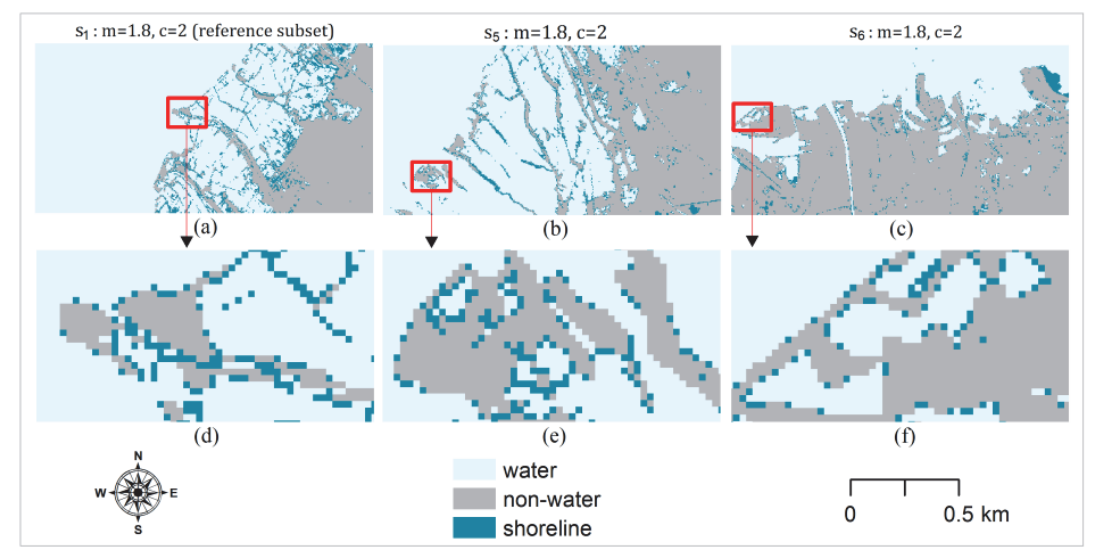

Figure 5.7 Shoreline margin generated by transferring the shoreline model to target subsets for image $\boldsymbol{I}_{\mathbf{1 0}}$. Subset $\boldsymbol{s}_{\mathbf{1}}$ (a) as the reference subset is used to estimate FCM parameter at target subsets (b-c). We zoom into an area in the red rectangle site $(d-f)$ to see a variation of shoreline margin

The comparison of the initial and final $V_{i}$ is provided in Figure 5.8. The mean of the water class is increasing from subset $s_{1}$ to $s_{5}$ in NIR band which is influenced by the increase of turbid water. The mean of the non-water class is increasing from subset $s_{5}$ to $s_{6}$ in SWIR band due to the increase of built-up area. 

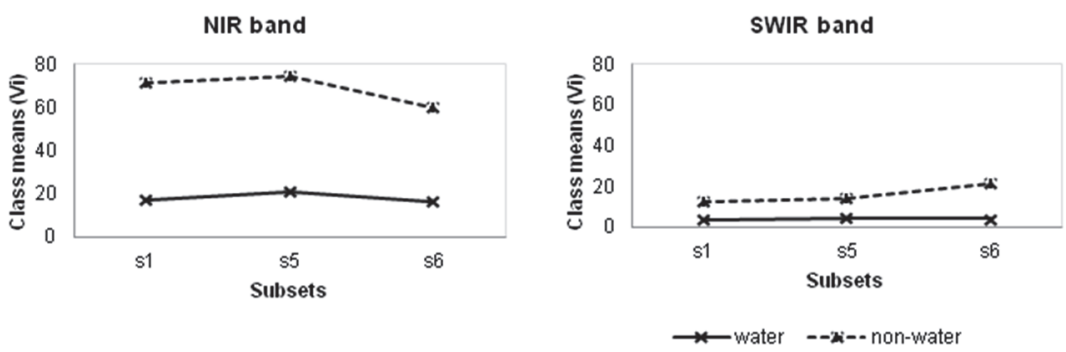

Figure 5.8 The comparison of the initial and final $V_{i}$ when we transfer the method from subset $\boldsymbol{s}_{\mathbf{1}}$ to subsets $\boldsymbol{s}_{\mathbf{5}}$ and $\boldsymbol{s}_{\mathbf{6}}$. FCM update the initial $\boldsymbol{V}_{\boldsymbol{i}}$ considering the existing land use/cover of the area. The decrease of $\boldsymbol{V}_{\boldsymbol{i}}$ of water class in NIR band is related to the increase of clear water and the increase of $\boldsymbol{V}_{i}$ of non-water class in SWIR band might be due to the increase of built-up area in subset $\boldsymbol{s}_{\mathbf{6}}$

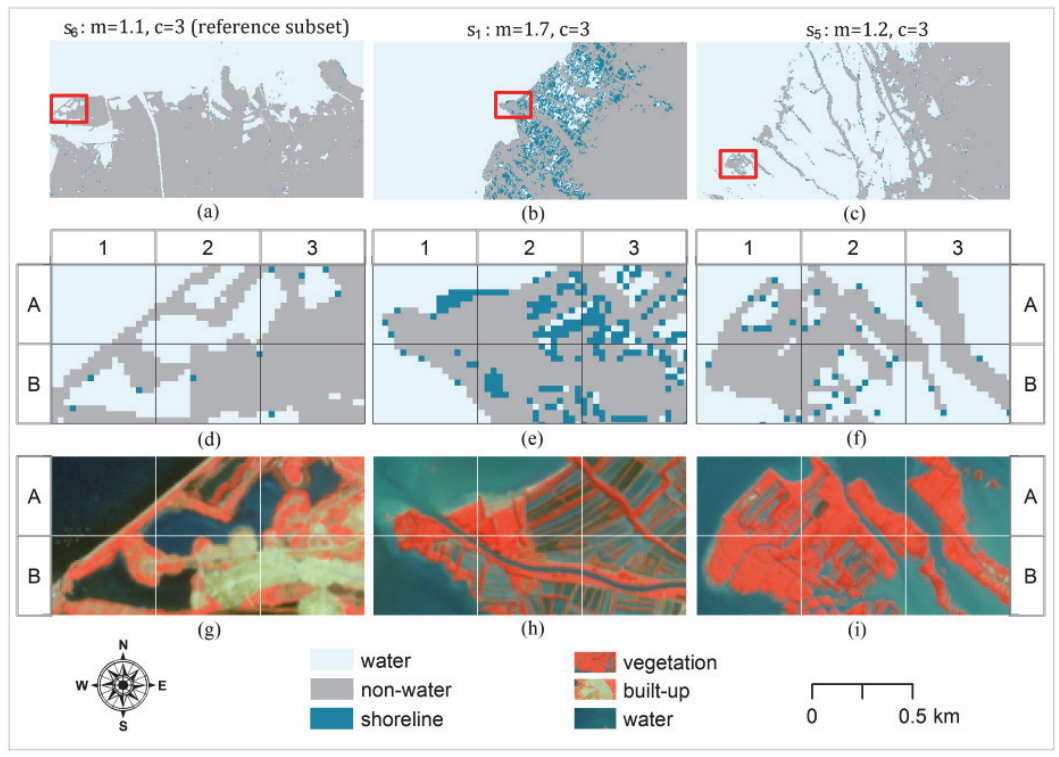

Figure 5.9 Subset $\boldsymbol{s}_{6}(a)$ is used as the reference subset to estimate FCM parameter of subsets $\boldsymbol{s}_{\mathbf{1}}$ and $\boldsymbol{s}_{\mathbf{5}}(\mathrm{b}-\mathrm{c})$. We zoom into red rectangle sites to see detailed representation of the area ( $d-f)$. The applied method failed to identify water area in subset $\boldsymbol{s}_{\mathbf{1}}$ (e) for e.g., grid cells A2, A3, and B2 and also failed to identify shoreline margin in subset $\boldsymbol{s}_{\mathbf{5}}$ (f) near vegetation areas for e.g., grid cells $\mathrm{A} 1$ and $\mathrm{B} 1$

As comparison, Figure 5.9 shows the results of shoreline images when we used subset $s_{6}$ as reference subset to estimate FCM parameters of subset $s_{1}$ and $s_{5}$. We obtained different shoreline 
images compared to those in Figure 5.7. The applied method overestimated the non-water area in subset $s_{1}$ (see Figure $5.9 \mathrm{e}$ grid cells $A 2$ and A3). Furthermore, there is a large deviation of $m$ from its initial value (from 1.1 to 1.7 ) and also a large shift of the non-water class mean as can be seen in Figure 5.10, indicating that we need a new choice of $c$ when applying the method.
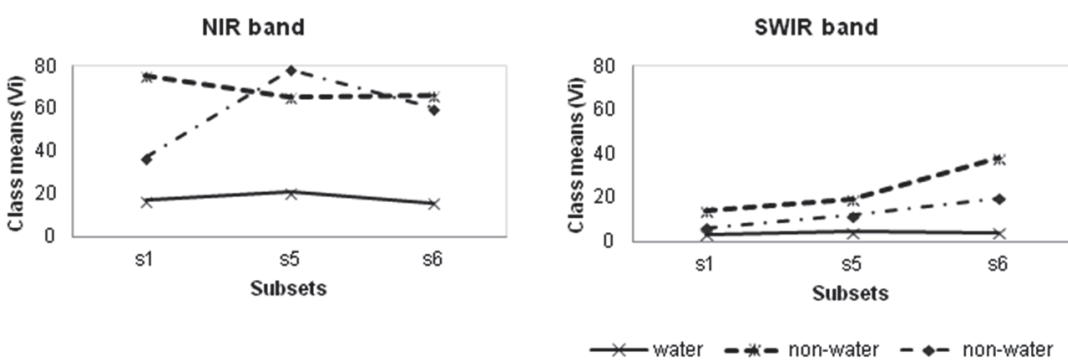

Figure 5.10 The comparison of the initial and final $\boldsymbol{V}_{\boldsymbol{i}}$ when we transfer the method from subset $\boldsymbol{s}_{\mathbf{6}}$ to subsets $\boldsymbol{s}_{\mathbf{1}}$ and $\boldsymbol{s}_{\mathbf{5}}$. There is a small variation of the water class means both in NIR and SWIR band from the reference subset to both target subsets. Meanwhile, there is a large variation of the non-water class specifically the non-water 2 in NIR band from subset $\boldsymbol{s}_{\mathbf{6}}$ to subsets $\boldsymbol{s}_{\mathbf{1}}$

Table 5.3 shows the $\mathrm{k}$ values when we performed thresholding at $d=0.5$ to the six shoreline images provided in Figures 5.7 and 5.9. The value of $\kappa$ was in the range of 0.80 to 0.85 except for subset $s_{1}$ which obtained $\mathrm{k}$ value of 0.51 . This low $\mathrm{k}$ value reflects the low quality of shoreline images produced by using $s_{6}$ as the reference subset. Considering this low $\mathrm{k}$ value, a large shift of $m$ from its initial value and a large deviation of $V_{i}$, we conclude that using subset $\mathrm{s}_{6}$ to estimate subset $s_{1}$ may not be a good option. However, we may use $s_{6}$ to estimate $s_{5}$ considering a good $k$ value and low variation in the value of $m$ and $V_{i}$.

Table 5.3 The accuracy assessment results of shoreline images at threshold $\boldsymbol{d}=0.5$ generated from two reference subsets $\left(\boldsymbol{s}_{\mathbf{1}}\right.$ and $\left.\boldsymbol{s}_{\mathbf{6}}\right)$

\begin{tabular}{lcc|lcc}
\hline \multicolumn{2}{l}{ Classified Images } & к value & \multicolumn{2}{l}{ Classified Images } & к value \\
\hline Reference & $\mathrm{s}_{1}$ & 0.85 & Reference & $s_{6}$ & 0.85 \\
\multirow{2}{*}{ Target } & $s_{5}$ & 0.80 & Target & $\mathrm{s}_{1}$ & 0.51 \\
& $\mathrm{~s}_{6}$ & 0.83 & & $s_{5}$ & 0.81 \\
\hline
\end{tabular}




\subsubsection{Shoreline change analysis and its uncertainty}

For the purpose of shoreline change analysis, we used ten shoreline images as a result of upscaling the shoreline model for the entire study area (see Figures 5A.5-7). Table 5.4 shows the $\mathrm{k}$ values generated from a conventional error matrix when we performed thresholding at $d=0.5$. We obtained $\kappa$ values larger than 0.80 .

Table 5.4 The accuracy assessment results after thresholding at thresholds $\boldsymbol{d}=0.5$ for the whole study area

\begin{tabular}{cc|cc}
\hline $\begin{array}{c}\text { Classified } \\
\text { Images }\end{array}$ & K value & $\begin{array}{c}\text { Classified } \\
\text { Images }\end{array}$ & K value \\
\hline$I_{1}$ & 0.83 & $I_{6}$ & 0.85 \\
$I_{2}$ & 0.80 & $I_{7}$ & 0.83 \\
$I_{3}$ & 0.82 & $I_{8}$ & 0.85 \\
$I_{4}$ & 0.83 & $I_{9}$ & 0.83 \\
$I_{5}$ & 0.80 & $I_{10}$ & 0.83 \\
\hline
\end{tabular}

The spatial distribution of shoreline changes in the east section for each consecutive date is provided in Figure 5.11. We can see that large changes into water were clearly seen from the periods 19972000 and 2009-2013 and large changes into shoreline margin occurred in the periods 2000-2003 and 2003-2006. Meanwhile for the middle section (see Figure 5A.8), a small gain of non-water areas occurred in the periods 1988-1991 and 1994-1997, in particular in the west part of the site, while a subtle change into water was shown in the periods 1997-2000 and 2009-2013. Compared to the east and middle sections, the west section (see Figure 5A.9) showed a relatively constant condition, indicated by a small change of shoreline positions over three decades. A small change into water occurred over the periods 1997-2000 and 2009-2013 which indicates erosion. While a small gain of non-water can be seen in the periods 19881991 and 2013-2017 at the eastern part of the site indicating land reclamation projects. 


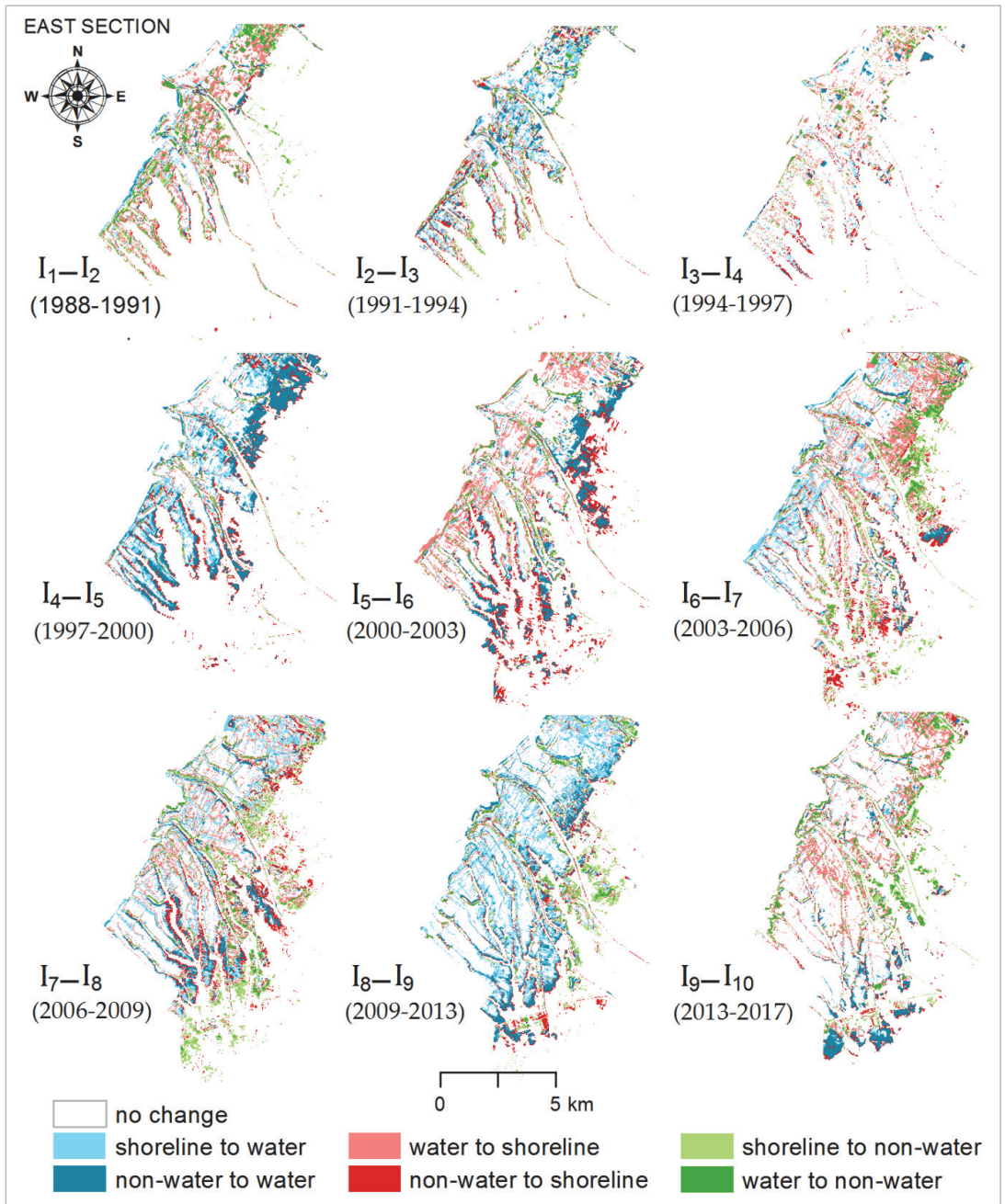

Figure 5.11 The spatial distribution of shoreline changes in the east section of the study area for consecutive dates. The changed area was getting larger in the recent images from 2000 up to 2017 reflecting the severity of inundation in the area.

Overall change certainty of shoreline margin, water and non-water are presented in Figure 5.12. We provide the change certainty in different levels of certainty for the black-dashed rectangle site. The area of each class is changing with the change in the certainty level. Table 5.5 shows the changed area in different levels of certainty for the period of 1988 up to 2017. 
Table 5.5 Changed area (in number of pixels) between shoreline margin, water and non-water at different levels of certainty for the east section

\begin{tabular}{|c|c|c|c|c|c|}
\hline \multirow{2}{*}{ Changed area } & \multicolumn{5}{|c|}{ Certainty level } \\
\hline & $\geq 0.5$ & $\geq 0.6$ & $\geq 0.7$ & $\geq 0.8$ & $\geq 0.9$ \\
\hline $\begin{array}{c}\text { Change certainty to } \\
\text { non-water }\end{array}$ & 2,174 & 1,740 & 1,185 & 602 & 69 \\
\hline $\begin{array}{l}\text { Change certainty to } \\
\text { shoreline }\end{array}$ & 4,178 & 1,564 & 46 & 15 & 1 \\
\hline $\begin{array}{c}\text { Change certainty to } \\
\text { water }\end{array}$ & 26,052 & 25,008 & 22,449 & 16,405 & 7,222 \\
\hline
\end{tabular}

Figure 5.13 shows an example of shoreline change analysis and its associated change certainty for the period of 1988 up to 2017 in the east section. Changes from non-water to water (in turquoise) are mostly related to high certainty of change into water (in dark green) (in Figures 5.13b and 5.13d e.g. grid cells B2 and C2). This indicates the area which was inundated permanently. Changes from water to non-water (in dark green) are mostly related to high certainty of change into non-water (in black) and indicated a reclamation area or the area at which mangroves were planted as protection (see Figures $5.13 \mathrm{~b}$ and $5.13 \mathrm{~d}$ grid cells A1). Meanwhile, changes of non-water to shoreline (in dark red) are mostly with high certainty of change into shoreline (in dark purple) and indicating an inundation influenced by tides (as in Figure 5.13b and 5.13d for e.g. grid cells A3 and B3). In addition, changes of water to shoreline (in light red) are mostly with low certainty of change into shoreline (in light purple) which might indicate sedimentation near mangrove areas (Figures $5.13 \mathrm{~b}$ and 5.13d e.g., grid cell A1).

Table 5.6 shows the overall changes of the three sections in 30 years. The largest shoreline changes occurred in the east section followed by the middle section, both showing large changes from non-water to water for 22.7 and $17.9 \mathrm{~km} 2$, respectively. Furthermore, the second largest changes were the change from non-water to shoreline which on the long term indicates a coastal inundation. This occurred for 8.5, 6.3 and $5.4 \mathrm{~km} 2$ in the east, west and middle sections, respectively. 


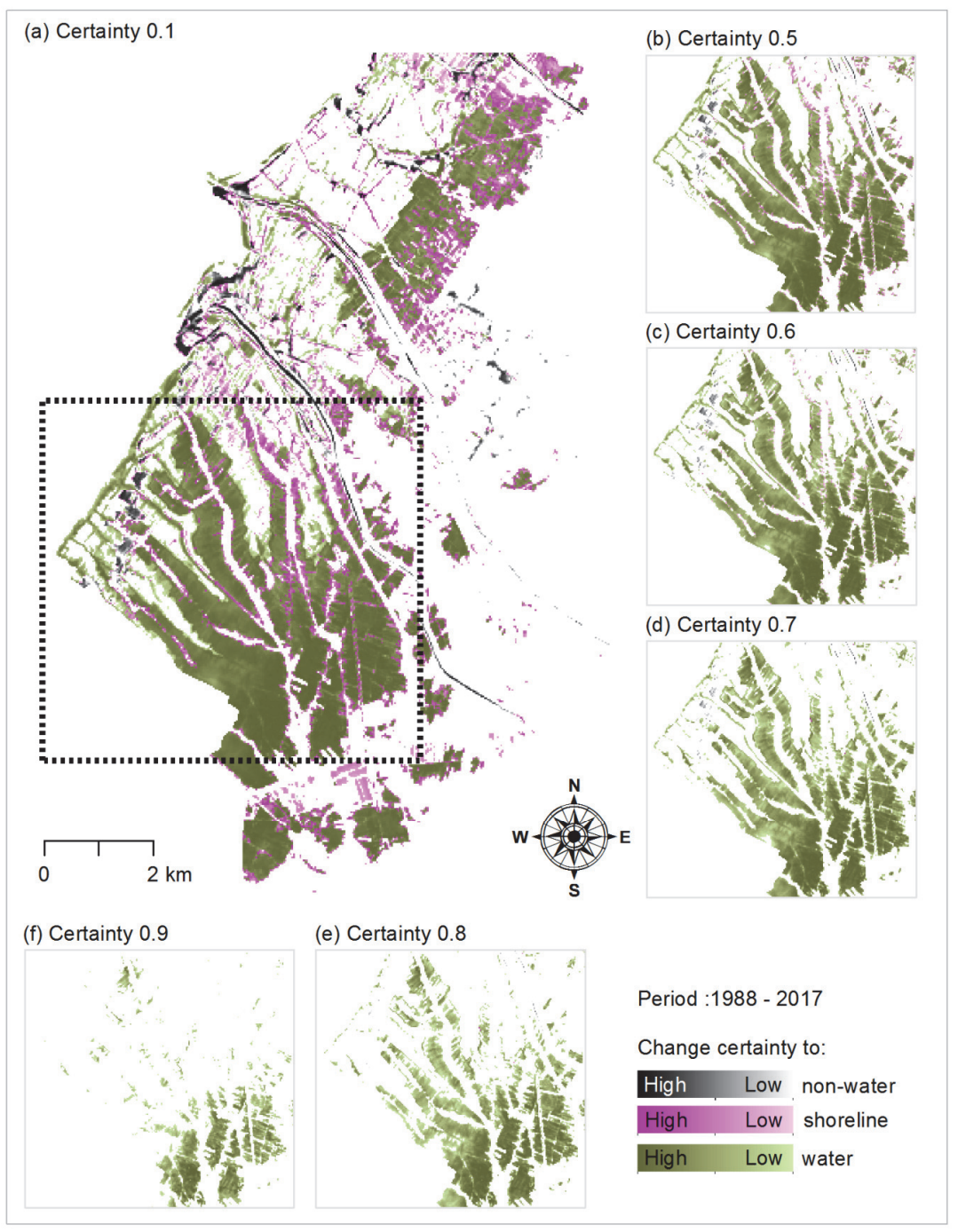

Figure 5.12 Change certainty of non-water, shoreline margin and water for the period 1988 up to 2017 in east section. The change area is decreasing by the increase of certainty level. 
Table 5.6 Change area in $\mathrm{km}^{2}$ in the period 1988 up to 2017 with change certainty level $\geq 0.1$. Changes to water indicate erosion and changes to nonwater show accumulation. The coastal area in the east section experienced the largest lost of land in three decades

\begin{tabular}{lccc}
\hline \multirow{2}{*}{ Change type } & \multicolumn{3}{c}{ Change area $\left.\mathbf{( k m}^{\mathbf{2}}\right)$} \\
\cline { 2 - 4 } & East & Middle & West \\
\hline Shoreline to non-water & 1.3 & 0.53 & 0.5 \\
Water to non-water & 1.6 & 4.2 & 6.4 \\
Non-water to shoreline & 8.5 & 5.4 & 6.3 \\
Water to shoreline & 2.6 & 0.9 & 1.4 \\
Shoreline to water & 4.1 & 1.7 & 0.8 \\
Non-water to water & 22.7 & 17.9 & 10.6 \\
\hline
\end{tabular}

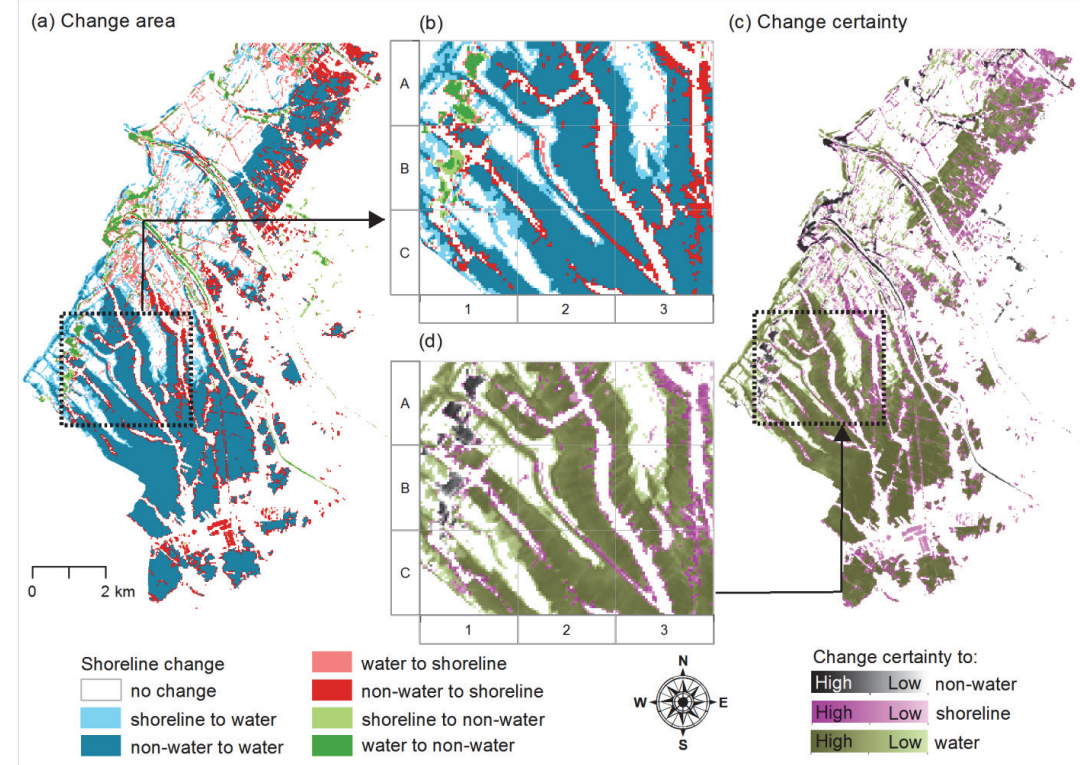

Figure 5.13 Shoreline change (a-b) and its related change certainty (c-d) between 1988 and 2017. Large changes from non-water into water (turquoise) indicating a permanent inundation of the area are mostly related to the high certainty of change into water (dark green), whereas large changes of non-water into shoreline (red) might indicate the area which was inundated gradually.

\subsection{Discussion}

In this chapter, we explored the possibility of both transferability and upscaling of fuzzy classification adopting the method that we 
developed in Dewi et al. (2016). To derive fuzzy shorelines, we used FCM to calculate the membership of water. To perform FCM, a suitable number of classes and level of fuzziness need to be specified either by users based on their a priori knowledge or estimated from images. This research provides information that can be used as the a priori knowledge to specify FCM parameters. Our results revealed that there is a relation between land use/cover composition and the values of $m$ and $c$. Seven land use/cover classes have been analysed in this study and they required $m$ values in the range of 1.3 to 1.9. Wet paddy and bare soil require $c=2$ as the optimal $c$, whereas water, fishpond, dry paddy and built-up require $c=2$ to 3 . The number of classes can vary up to 6 for other crops. When performing FCM for all images ( $I_{1}$ up to $I_{10}$ ) used in this study, we obtained $m=1.8$ as the median value of the optimal $m$. This value is close to the $m$ value that we used in our previous study $m=1.7$ (Dewi et al., 2016).

We proposed to use $V_{i}$ and $c$ values of the reference subset as the initial $V_{i}$ and $c$ values of the target subsets to upscale towards a larger area and to test the transferability of the method to another area with different land use/cover composition. From the results, it can be seen that the variation in spectral reflectance of the input image has a large influence on the number of classes needed for the FCM. The presence of water and moisture content on objects such as wet vegetation and wet soil decreases the reflectance in the infrared bands, thus it requires a lower number of classes in FCM. On the contrary, dry vegetation, dry soil and concrete such as in urban area have a higher variation in spectral reflectance in the infrared bands. Therefore, they require a larger number of classes for the classification.

Adopting the same $c$ value to transfer and to upscale the model may cause a generalization of the classification that reduces the detail of land use/cover pattern of the initial data. Thereby, we might miss specific detailed, but relevant information. On the contrary, it is also possible that we set an unnecessary high number of classes that causes a longer time for parameter estimation yet a poor quality of shoreline images (see Figure 5.9e). In fact, for shoreline estimation, further detail in non-water and water classes is not needed while non-water and water show the largest spectral differences, especially in a natural coastal area with less urban area, embankment or other coastal structures. Having only two classes in a coastal area will usually result in a split between water-related and land-related pixels. However, if the differences in area between sea and land are very large, having two classes for classification may not be a good 
choice since the available classes will be distributed for e.g., in the land area. In this work, we evaluated the resulting $V_{i}$ of the target subsets. FCM updated the initial $V_{i}$ by considering the land use/cover condition of the target subset. The small differences of the resulting $m$ and $V_{i}$ indicate that the selected subsets differ little and tend to have a similar land use/cover. On the other hand, if there is a large shift of the two $V_{i}$ values, it could indicate that the two subsets have large differences, and thus may require a new choice of $c$ value.

The proposed method was successful in performing FCM to estimate the water membership proven by high $\kappa$ values larger than 0.80 . However, due to limited availability of high resolution images, we performed the conventional error matrix for the accuracy assessment purposes after performing thresholding. In other situations, when high resolution images are available, we would suggest to use soft reference data and generate a fuzzy error matrix. Using a soft classifier to generate soft reference data is more likely to reduce the uncertainty due to the vagueness of shoreline positions (Dewi et al., 2017a; Harikumar et al., 2015). In addition, no information was lost due to the hardening of the soft classification (Foody, 2002). However, a thorough investigation is needed to estimate the FCM parameters of the higher resolution images.

To choose FCM parameters based on information provided in subsection 5.3.1, we considered the predominant land use/cover classes present in the area. The optimal $\mathrm{m}$ values $(m=1.8)$ when performing FCM for all images can be adopted, especially for similar coastal area characteristics which helps to shorten the time needed to optimize the parameters. However, the task is still difficult for the coastal area with a completely different characteristic, for example a rocky cliff coast, a coast with sand and gravel, and a swampy coast with mangroves. An urban coastal area with more buildings, impervious surfaces and coastal structures requires a higher $c$ value because those features have a higher variation in spectral reflectance. Whereas, a natural coastal area with less hard structures requires a lower $c$ value since water bodies, wet soils, and dark building roofs have a low spectral reflectance. Meanwhile, for upscaling, gradually enlarge the area of target subsets results in small shifts in $V_{i}$, thus FCM is able to keep up with the changes. However, there is a limitation to upscale towards a larger area as the larger the area, the larger the shift of shoreline margin from its reference subset (see Figure 5.5). 
In this study, we assessed shoreline changes and estimated change uncertainty for pixel locations. Two perspectives of changes were addressed: i) the spectral and spatial uncertainty inherent to shoreline in remote sensing image arising from their spatial characteristics and vagueness, and ii) the uncertainty in the changes propagating from the implementation of the developed change detection method. The first was addressed by applying a fuzzy classification to estimate the water membership, and the second was obtained by independent comparison of the changes with the variation of water memberships for the consecutive periods. An abrupt change produces strong variations of water memberships while a gradual change produces smaller water membership differences.

Our analysis of shoreline in the northern coastal area of Central Java reveals a general trend of continuous shoreline changes as a result of extensive coastal inundation. This process takes place as a progressive change from non-water to water. From the results, the change of shoreline was indicated by coastal land reclamation in the middle section (Semarang city) in the period 1988-1991. In fact, the land reclamation started already in the 1980s (Miladan, 2016). Coastal reclamation occurred on a large scale due to a high demand for space for housing and economic activity. Fishpond and marshes turned into urban areas including settlements, commercial and business areas, recreational areas and industrial zones, thereby anticipating urban growth. Despite the fact that land reclamation expands the space available for economic purposes, this activity comes at a price in terms of its negative impact on environment. The construction of urban areas increases the surface runoff and reduces the ability of the ground to absorb rainfall. Furthermore, when there are major land use changes in the coastal area, for example fishponds, swamps and paddy fields turned into built-up areas, as a consequence floods (Miladan, 2016; Pratiwi, 2012), land subsidence (Chaussard et al., 2013), and erosion (Damaywanti, 2013) leading to coastal inundation occur not only in the urban zones that were developed on the marsh areas but also in adjacent areas.

The land subsidence is believed to be caused by the combination of natural consolidation of alluvium soil, ground water extraction and load of buildings (Abidin et al., 2013; Marfai and King, 2007). Ground water extraction occurs for industrial purposes and for the household's needs as the consequences of the population growth. Furthermore, an excessive ground water extraction not only triggers land subsidence but also salt water intrusion. Even though the 
inundation as a result of subsidence is much larger than that caused by sea level rise, a combination of land subsidence and sea level rise makes the shoreline also more vulnerable to erosion by increasing wave height, in particular in a muddy coastal environment (Wesenbeeck et al., 2015). Once erosion is initiated, the water and salinity levels start to rise in remaining fishponds and further affect the agricultural area (Marfai, 2011). Furthermore, the inundated fishpond not only causes a decline in fish productivity but also leads to the abandonment of the fishpond area as mentioned by Wesenbeeck et al. (2015), who stated that when fishponds get inundated, people revert to small-scale off-shore fishery practises. Despite the fact that the substantial erosion which occurred in the study area leads to a massive retreat of the shoreline position, a gradual accretion leading to a seaward advancing of the shoreline can also be identified in a few places. Replanting mangroves trees as a response to coastal erosion is one of the causes of this accretion, starting from the period 2003-2006 up till 2013-2017 (see Figure E1 in the east site of the images), for example in Bedono (Fikriyani and Mussadun, 2014) and Timbulsloko villages (Astra et al., 2014), in the middle section.

\subsection{Conclusion}

This study investigates transferability of shoreline classification to other areas and upscaling to a larger study area. The experimental results concluded that: i) Parameters $m$ and $c$ can be optimized based on predominant land use/cover and the optimal $\mathrm{m}$ value $(m=1.8)$ provided in this research can be adopted for similar coastal areas; and ii) the value of $V_{i}$ and $c$ of the reference subset can be used to initialize target subsets. We conclude that the classification method in this study can be transferred to other areas and can be upscaled towards a larger study area. 


\section{Synthesis}

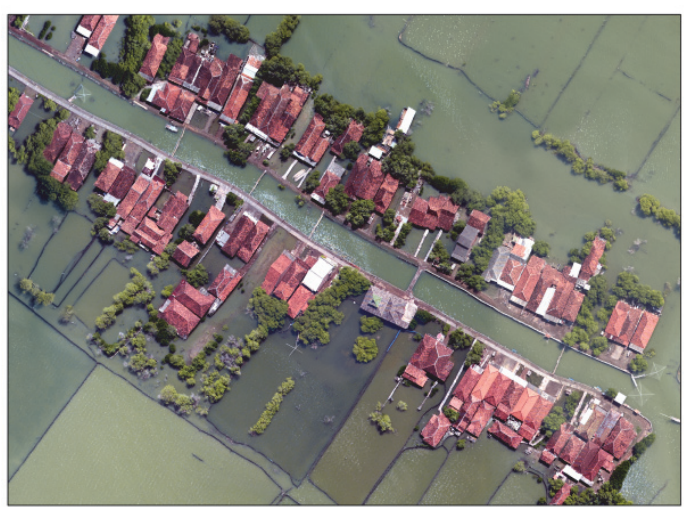

This chapter provides the conclusions to the objectives and research questions outlined in Chapter 1 based on findings of Chapters 2 to 5 . It also provides a reflection on the contribution of this thesis to sustainable development goals, disaster risk reduction, shoreline monitoring and estimation of data quality and uncertainty. It finishes with recommendations for further research. 


\subsection{Research findings and conclusions}

In this thesis, shoreline was modelled as an object with vague boundaries using multi-temporal remote sensing images in an area in Java which experienced a severe change of shoreline position. The thesis focuses on three components: 1 ) how to develop a model that considers the uncertainty in shoreline positions; 2) how to assess the changes of the fuzzy shoreline; 3 ) how to estimate the uncertainty of spatial and temporal information on shorelines derived from image analysis methods; and 4) how to transfer and upscale the model developed in objective 1 and 2 to a different area and to a larger area. The remainder of this chapter describes how the objectives and research questions of the thesis were achieved and answered. Detailed conclusions and the key findings for the individual objective are presented.

a) Objective 1: Develop a method for detecting shorelines by taking the gradual transition between water and land into account

Research question 1: Can fuzzy sets-based theory be applied effectively to extract a fuzzy shoreline?

In Chapter 2, FCM classification to estimate water membership was applied. The FCM is a clustering method that separates data clusters with class means and fuzzy boundaries allowing for partial membership. Two methods to generate shorelines were proposed. The first method derived the shoreline as a single line by applying a threshold of 0.5 on the water membership images. The second method derived shorelines as an area or margin presented as a crisp object with a boundary determined by threshold values resulting from parameter estimation. While shorelines can be detected by both methods, the shoreline as a margin provides more insight into the spatial distribution of changes and their uncertainty and more spatial detail of the process of change from non-water via shoreline margin to water and vice versa. Moreover, by having shoreline as a margin, we can assess its spatial extent and measure its change uncertainty at different levels of uncertainty. The proposed methods provided an effective way to present shoreline as a line and as a margin with fuzzy boundary and its associated change uncertainty.

In Chapter 3, a third approach by using fuzzy-crisp objects to derive a shoreline as the transition zone between water and non- 
water classes was proposed. In this case, pixels at which the membership value $(\mu)$ exceeds 0.99 are the core of a class, for example water class, whereas pixels with $0.01<\mu<0.99$ belong to transition zones or shoreline class, and pixels with $\mu<0.01$ do not belong to objects (water or shoreline). Setting the threshold to the highest (0.99) and the lowest (0.01) memberships intended to find the core of water and non-water, respectively. Deriving shoreline margin by using a fuzzy-crisp object allowed us to address the uncertainty corresponding to the existential and extensional uncertainty of shorelines. Moreover, the overall change magnitude and change directions, when change vector analysis was applied, provide information with respect to the trend of the fluctuating shoreline, e.g. the multi-year patterns of water membership changes that indicate coastal processes related to coastal inundation, erosion and accretion.

Research question 2: Can random sets be applied effectively to extract a fuzzy shoreline?

In Chapter 4, a shoreline model derived from a fuzzy classification was compared with one derived from random sets. Random sets theory is a methodology to deal with the uncertainty of outcomes of random phenomena. Meanwhile, fuzzy sets theory describes the uncertainty associated with classification due to imprecision and does not consider randomness. Random sets fit the mixed Gaussian model to the image histogram. When using random sets, a shoreline is presented as the third class, the transition zone between water and non-water. The extensional uncertainty of a shoreline was assessed by using the covering function of random sets and its statistical parameters. From the results, it was proven that random sets performed well in modelling the uncertainty of shorelines. Furthermore, the shoreline model derived from fuzzy sets and random sets were closely similar.

Research question 3: Can a digital elevation model be used effectively to improve shoreline extraction?

In Chapter 4, a digital elevation model (DTM) was combined with the Pleiades imagery to improve the quality of the shoreline extraction. The pan-sharpened Pleiades with four bands were stacked with the DTM as the fifth band. The integration of DTM data improved the results of both fuzzy sets and random sets. Considerable improvements were achieved for objects, e.g. roofs, 
inundated houses and yards. Pleiades + DTM achieved accuracy above $80 \%$, demonstrating that it provides a valuable data source for shoreline mapping. In the absence of elevation data, the classification may overestimate in particular the water area. By using only Pleiades data, it is difficult to discriminate dark roofs and water or inundated land since those features have similar spectral characteristics. The research further confirmed the need of DTM integration to remote sensing images to provide reliable and accurate shoreline mapping.

b) Objective 2: Develop a method for spatio-temporal change detection and monitoring of fuzzy shorelines

Research question: How can fuzzy approaches be used for spatio-temporal change detection and monitoring fuzzy shorelines?

In Chapters 2 and 5, crisp and fuzzy methods were combined for change detection. The post-classification comparison method was implemented to distinguish abrupt and gradual changes at the object level and provide the change uncertainty at the pixel level. Shoreline and its changes have been presented as crisp subareas. The changed areas were thus associated with the spatial distribution of change uncertainty. The method was successfully implemented for monitoring the change of shoreline associated with inundations from 1994 to 2015 in the northern coastal area of Java, Indonesia.

In Chapter 3, a change detection method for shorelines which account for their fuzzy character in remote sensing images was proposed and implemented. The change of shoreline was explained in terms of change magnitude and change direction using change vector analysis (CVA). Information provided by CVA allows us to see the trend of the fluctuating shoreline over time, whereas the change detection resulting from the postclassification comparison method could provide only "from-to" change information and could not provide information regarding the detail of subtle within-class changes. The analysis of information provided by the change magnitude and direction reveals that each change combination represents one specific change process type that may occur in the field and shows a multi-year pattern of water membership changes over the observation periods. Based on these results, it can be concluded 
that the proposed method can assess changes in a shoreline by taking into account that it is a fuzzy boundary.

c) Objective 3: Determine the uncertainty of spatial and temporal information on shoreline positions in objectives 1 and 2

Research question 1: How can the uncertainty of the developed and implemented methods be estimated?

This study focuses on uncertainty concerning the fuzziness character of shorelines and the uncertainty arising from image classification and change detection methods. In this work, attribute, existential and extensional uncertainties of shoreline objects were considered.

In Chapter 2, the imprecise position of the shoreline in remote sensing images and the uncertainty propagated through the change detection method were associated with values reflecting the uncertainty of pixels belonging to any of the classes. For this purpose, the possibility and necessity measures were quantified. The possibility measure corresponds to the element that has the highest possibility according to the degree of membership. The uncertainty values represent the uncertainty that a pixel belongs to the water class. Pixels which are spectrally closer to water have a higher membership to the water class. Consequently, these pixels may have a higher certainty to be classified as water. The change uncertainty value expresses how sure we are that a change really occurred. The change uncertainty was estimated by using the MIN operator which measures the maximum possible overlap between the uncertainty values of images at two different time $\left(t_{1}\right.$ and $\left.t_{2}\right)$. A high value of change uncertainty indicates a high uncertainty that change has occurred. Change uncertainty for the observed objects was measured at the pixel level.

In Chapter 3, the uncertainty in class assignment was estimated by a measure of the confusion index for each pixel resulting from FCM classification. In this case, shoreline can be determined with limited certainty, for example with boundaries that reflect the transition zone between water and non-water. Moreover, when the values of an adjacent grid are very similar, the zones of confusion divide regions indicating the presence of gradual transitions. In addition, the changed areas of the fuzzy shoreline are thus associated with the spatial distribution of differences 
between the confusion indices calculated by the Euclidean distance between the pixel positions. This change confusion value shows the degree of uncertainty of the changes that have occurred. A high value of change confusion indicates a large difference between confusion indices. It can be seen from the results that a location having a higher change magnitude, has a higher change confusion value as well. It corresponds to the larger differences of both water memberships and confusion indices between corresponding images in $t_{1}$ and $t_{2}$.

In Chapter 4, when shoreline using random set was generated, the extensional uncertainty of a shoreline was assessed by using the covering function of random sets and the statistical parameters (support, core, and mean sets). By using these parameters, it was demonstrated that the randomness of segmentation parameters, i.e., multiple thresholds, has a different effect on extracted features when objects have different extensional uncertainties.

Research question 2: How can the spatial accuracy of the developed and implemented methods be assessed?

In Chapter 2, 4 and 5, the spatial accuracy of shorelines derived from a hardened FCM was presented at the selected threshold value, e.g. $t=0.3,0,5,0,7$. A conventional error matrix was generated and kappa values were estimated for each shoreline images. In Chapter 3 and 5, a method that considered the vagueness of shoreline in satellite images was developed. The soft reference data were generated from a higher resolution image. The method integrated water membership values derived from FCM classification. A soft error matrix was then generated and overall accuracy of fuzzy shoreline was estimated. The use of soft reference data was more likely to reduce the uncertainty due to the vagueness in class definition and mixed pixel problems. In addition, by using soft reference data, no information was lost due to the hardening of the soft classification.

d) Objective 4: Test the transferability and upscaling of the methods developed in objective 1 and 2 to a different area and to a larger area of land

Research question: Can the method developed in objective 1 and 2 be transferred and upscaled to another area and towards a larger area? 
In Chapter 5, the application of a fuzzy classification to different areas and to upscale it towards a larger area was investigated. Three strategies were applied: (1) optimizing $m$ and $c$ based on the pre-dominant land use/cover of the reference subset; (2) adopting the class mean and the $c$ values resulting from the classification on the reference subset to perform FCM (fuzzy cmeans classification) on the target subset, and (3) estimating the optimal level of fuzziness of target subsets.

Each time the model was applied to either a larger area or another area with different land use/cover composition, FCM updated the initial class means by considering the existing land use/cover composition. Large deviation of both class means and $\mathrm{m}$ from their initial values indicates that the target subsets require a new choice of $c$ for FCM.

From the experimental results, $m$ values in the range 1.3 up to 1.9 were obtained for seven land use/cover classes which have been analysed. Meanwhile, from ten images used in the study, the optimal $m=1.8$ and $c=2$ were obtained. For a coast with similar characteristics, these values can be adopted for FCM classification, while for the area with slightly different land cover composition, the relation between land use/cover classes and the value of $m$ and $c$ for FCM used in this study can be adopted to shorten the time needed to optimize the parameters. Furthermore, the proposed method for upscaling and transferring the method to a larger area and to different areas is also promising, as shown by the high $\kappa$ values of more than 0.80 and a high agreement achieved between the reference and target subsets of more than 0.82 . From the results, it can be concluded that the method is applicable to the current study area. The relation between land use/cover classes and the values of $m$ and $c$ produced in this study can be used as initial values for more rapid optimisation.

\subsection{Reflections}

\subsubsection{On sustainable development goals (SDGs)}

Sustainable development is defined as "...development that meets the needs of the present without compromising the ability of future 
generations to meet their own needs" (WCED, 1987). The SDGs replaced the Millennium Development Goals (MDGs) which ended in 2015 and the SDGs became official since 2016. The SDGs seek to harmonize all three pillars of sustainable development: the economic, social and environmental (UN, 2015). The results presented in this dissertation support the environmental quality aspect of sustainable development in particular considering coastal area in two of its targets (targets 14.2 and 14.5) in SDG 14: conserve and sustainably use of the oceans, seas and marine resources for sustainable development (UN, 2015).

Economic development always brings risk of environmental damage. Environmental protection is thus inherent to the concept of sustainable development. In this context, there should be equilibrium between development and environmental protection. As shoreline position is one of the primary geoindicators for environmental change, monitoring the changes of shoreline plays an important role in achieving this equilibrium state. Shoreline changes can have a wide range of impacts on residential and commercial investment. Erosion of the beach damages settlements and business. Erosion and permanent inundation of agricultural areas result in destruction of crops. On the contrary, accretion in a shipping channel can prevent boats from reaching harbours. Therefore, knowledge of where and how much the coastal area changed and which part of the shoreline is more vulnerable to erosion and accretion are critical for local authorities or coastal planners to prioritize activities such as coastal protection, environmental restoration, and economic investment. This knowledge is also important for property owners and coastal communities to protect their properties and undertake strategies to mitigate the identified hazards, such as coastal erosion. Monitoring the changes of shoreline may contribute to make coastal cities and communities safer and more resilient, and in the same time, to protect and conserve the use of coastal and marine resources for a sustainable coastal development. In this case, the results of this dissertation aim to provide such information to measure and monitor the gains and losses in the land area through the development and the implementation of image analysis methods in monitoring the changes of the shoreline position.

\subsubsection{On disaster risk reduction (DRR)}

The shoreline position is an important indicator for coastal hazardand risk assessment, as most of the hazards i.e. beach erosion, landslides, tsunami and coastal inundation are related directly to the 
stability of the shore (Morton, 2002). Methods developed in this thesis support disaster risk reduction by addressing specific questions:

a) Which parts of the shoreline are more vulnerable to erosion and accretion?

b) Which areas of the shoreline need to be prioritized in disaster risk management?

c) How frequent have the changes occurred for instance due to seasonal influence?

d) What are the uncertainties of the identified shorelines and what is the change uncertainty of the shoreline changes?

Disaster risk reduction is a comprehensive approach to reduce disaster risk, covering several phases before, during and after a disaster and aiming to achieve the related sustainable development goal. The results of this dissertation support the prevention and preparedness phase of disaster risk reduction. Prevention and preparedness is a phase occurring before a disaster event (Greve, 2016). By knowing areas that are likely to be affected severely by the changes of shoreline positions, local authorities may adjust land use planning to move development away from prone areas including relocating exposed people and assets away from those hazard areas. Furthermore, local authorities can focus on constructing flood defences, and planting mangroves to stabilize shoreline areas. Assessing this coastal risk, such as that of coastal inundation and erosion, is challenging since it requires a long series of historical data for a comprehensive assessment. Methods proposed in this dissertation can contribute to fulfil this need.

\subsubsection{On the multi-temporal dimension of shoreline monitoring}

This thesis aims to contribute to monitoring of shoreline changes trough the development and the implementation of image analysis methods to quantify and monitor the changes of shoreline using remote sensing images. The spatial and temporal scale of analysis ranges from a fine scale to a medium scale at local government level. Shoreline position can be identified using a range of methods. An expensive method includes shoreline monitoring by using kinematic differential GPS and airborne LIDAR technology that define shoreline on the basis of an elevation and tidal datum (Morton et al., 2004). The availability of LIDAR data is limited especially for Asian countries 
such as Indonesia; however, there is an increasing demand for shoreline information. When these data are not available, other more low-cost methods would be helpful to understand an eroding or flooded beach. A low-cost method includes manual interpretation of shoreline indicator such as high water line (HWL) from aerial photography or through available imagery for instance via Google Earth. However, this method is a tedious, subjective and labour intensive process as it relies on the individual skills of the interpreter. As an alternative, deriving shoreline information from remote sensing images as suggested in this thesis is more objective and faster, compared to the manual interpretation of shoreline from the aerial photography. Furthermore, by using free satellite images, e.g. Landsat and Sentinel 2, the methods can be considered low-cost. Using long series of images in this study enable long-term monitoring of shoreline change to address questions such as:

a) Where and how far has the shoreline retreated or advanced?

b) Where and how much has the coastal area changed?

Shoreline monitoring is performed on a variety of spatial and temporal levels. The frequency of observation can be determined using a risk-based approach by which those areas with a greater threat from coastal erosion or inundation are monitored more frequently than those areas with a smaller threat. The frequency of observation can also depend on the context of investigation and the need to update information and technology advances that allow rapid acquisition of shoreline positions.

In Chapter 5, shoreline monitoring is intended to compare the historical and current shoreline positions as the key information to understand coastal processes over almost three decades. The results reported in this study are expected to give an insight regarding the preliminary state of shorelines and their changes before conducting more detailed measurements for the areas that have a greater risk. In this case, identifying shoreline changes within a three-year interval was assumed to be sufficient. Meanwhile in Chapter 3, the primary interest was to see the seasonal-annual nature of the shorelines. For this purpose, four images of the same year were stacked and compared with the stack of shoreline images of subsequent years with corresponding seasons. It would be better if there are more images to be included in the classification for each year so that the seasonal variation of shorelines can be fully assessed.

In this study, both the spatial and the temporal dimension in the study of shoreline changes were considered. In Chapter 3, the multi- 
year patterns of water membership changes are the prime interest of the proposed monitoring methods. The multi-year pattern of water membership resulting from combination of change direction and magnitude indicate coastal processes that may occur in the field over the observation periods. A consistency to positive direction (change into water) reported in this work may correspond to costal inundation and land subsidence. On the other hand, a continuous decreasing of water membership categorized as negative direction (change into non-water) may indicate accretion or sedimentation. Abrupt changes reported in this work informed a higher risk of shoreline changes resulting from coastal flooding triggered by spring tides or extreme waves. In Chapter 2 and 5, 'from-to' change information reported in this study permitted us to inform on gains and losses of water, nonwater and shoreline margin. Changes of shoreline to non-water, water to shoreline, and water to non-water might indicate accretion or land reclamation. Whereas the changes of an area where coastal inundation or erosion has taken place resulted in changes of nonwater to shoreline, shoreline to water, and non-water to water.

\subsubsection{On data quality and the uncertainty in remote sensing}

Along with the identification of shoreline positions and the estimation of their changes, this dissertation focused on the importance of the quality and the associated uncertainty of obtained results. To deal with uncertainty by addressing the shoreline as a transition zone allows decision makers and planners to include this uncertainty in spatial planning. Moreover, it visualizes not only the changes in shoreline, but also the uncertainty of these changes for every location, thereby providing a better base for a debate on the combined effects of land subsidence and sea level rise in this area.

To characterize the uncertainty derived from remote sensing imagery, the methods that were adopted in this dissertation consider the uncertainty on shoreline positions arising from attribute, existential and extensional uncertainties. In Chapter 2, the uncertainty of shoreline margin area was explored by means of possibility and necessity measures. The water membership value was used to estimate the uncertainty of pixels to be classified as water. Pixels close to water may have a higher certainty to be classified as water. In Chapter 3, the confusion index was used. The uncertainty of shoreline positions and their changes were explored and visualized at different levels of uncertainty. If the confusion value approaches 1 then the differences in membership between the first and the second highest membership values are small indicating that both 
membership values are almost equal. Therefore, it is more likely that the pixel defines a fuzzy boundary and the uncertainty of the pixel to belong to the class with the largest membership is high. Whereas, if CI approaches 0, however, then the difference in membership values between the first and the second highest membership values are high and the uncertainty of the pixel to belong to the class with the largest membership is low. Meanwhile, for change uncertainty estimation, three types of change uncertainty measures were introduced based on:

a) Maximum possible overlap of the uncertainty values (the intersection of two fuzzy sets); a high value of change uncertainty indicates a high uncertainty that change has occurred.

b) Euclidean distance of confusion indices of pixel position; a high value of change uncertainty corresponds to a large difference of confusion indices between images at different dates.

c) Differences in water membership values of different dates; a high value corresponds to a high certainty of the change of the associated class in the shoreline image.

\subsection{Recommendations}

This dissertation has explored the use of remote sensing images for shoreline monitoring; the following recommendations are made for future research:

a) The relation between land use/cover classes and values of $m$ and $c$ in this study can be adopted to estimate FCM parameters. For the purpose of automation, one may explore the use of CVI with range of $m$ and $c$ values to find the optimal parameters, or one may explore for instance histogram quantization to estimate the possible number of classes.

b) The clustering in the FCM is implemented by calculating the distance between a pixel and a cluster centre by using the Euclidean distance measures. The use of other distance measures such as the Mahalanobis distance could be explored.

c) Threshold interval estimation for generating shorelines is critical. Images from different sensors may produce shoreline margins by setting different thresholds. Therefore, threshold interval should 
be further investigated, for example by using grey-level histograms that extract objects from their background.

d) The automation of the methods proposed in this dissertation should be sought in order to enable the shoreline monitoring to be more effective. This can be done by exploring more different study areas and various images from different sensors. 


\section{Bibliography}

Abidin, H.Z., Andreas, H., Gumilar, I., Sidiq, T.P., \& Fukuda, Y. (2013). Land subsidence in coastal city of Semarang (Indonesia): characteristics, impacts and causes. Natural Hazards and Risk, 4, 226-240

Ali, T.A. (2010). Analysis of shoreline-changes based on the geometric representation of the shorelines in the GIS database. Journal of Geography and Geospatial Information Science, 1, 1-16

Andrieu, J. (2018). Land cover changes on the West-African coastline from the Saloum Delta (Senegal) to Rio Geba (Guinea-Bissau) between 1979 and 2015. European Journal of Remote Sensing, 51, 314-325

Anonymous (2006a). Integrating the Shoreline into Spatial Policy. In, Practical Guide: Messina Project

Anonymous (2006b). Monitoring and Modelling the Shoreline. In, Practical Guide: Messina Project

Anonymous (2014). The master plan of drainage system of Semarang. In O.o.t.M.o.S. City (Ed.), 7 (p. 45). City of Semarang: Office of the Mayor of Semarang City

Ardila, J.P., Bijker, W., Tolpekin, V.A., \& Stein, A. (2012). Quantification of crown changes and change uncertainty of trees in an urban environment. ISPRS J. Photogramm., 74, 41-55

Astra, A.S., Sabarini, E.K., Harjo, A.M., \& Maulana, M.B. (2014). Mangrovebased and community-based coastal protection in Timbulsloko village, Demak. In, Wetland Conservation Magazine (pp. 4-5). Bogor, Indonesia: Wetland International Indonesia

Atkinson, P.M., \& Foody, G.M. (2002). Uncertainty in remote sensing and GIS : fundamentals. In G.M. Foody, \& P.M. Atkinson (Eds.), Uncertainty in Remote Sensing and GIS (pp. 1-18). England: John Wiley \& Sons Ltd

Baldassarre, G.D., Schumann, G., \& Bates, P.D. (2009). A technique for the calibration of hydraulic models using uncertain satellite observations of flood extent. J Hydrol, 367, 276-282

Bezdek, J.C., Ehrlich, R., \& Full, W. (1984). FCM: the fuzzy c-means clustering algorithm. Comput. Geosci., 10, 191-203

BIG (2017). Online Tidal Prediction. In. Cibinong, Indonesia: BIG (Indonesia Geospatial Information Agency)

Bijker, W., Hamm, N.A., Ijumulana, J., \& Wole, M.K. (2011). Monitoring a fuzzy object : the case of Lake Naivasha. In, 6th International Workshop on the Analysis of Multi-temporal Remote Sensing Images (Multi-Temp). Trento, Italy 
Binaghi, E., Brivio, P.A., Ghezzi, P., \& Rampini, A. (1999). A fuzzy set-based accuracy assessment of soft classification. Pattern Recogn. Lett., 20, 935948

Bird, E.C.F. (1985). Coastline changes : a global review. John Wiley and Sons

Bird, E.C.F. (2000). Coastal Geomorphology : An Introduction. Chicester, England: John Wiley and Sons

Boak, E.H., \& Turner, I.L. (2005). Shoreline definition and detection: a review. J. Coastal Res, 21, 688-703

Bogaert, P., Waldner, F.o., \& Defourny, P. (2017). An information-based criterion to measure pixel-level thematic uncertainty in land cover classifications. Stoch Environ Res Risk Assess, 31, 2297-2312

Bracs, M.A., Turner, I.L., Splinter, K.D., Short, A.D., Lane, C., Davidson, M.A., Goodwin, I.D., Pritchard, T., \& Cameron, D. (2016). Evaluation of Opportunistic Shoreline Monitoring Capability Utilizing Existing "Surfcam" Infrastructure. J. Coastal Res, 32, 542-554

Brown, K.M., Foody, G.M., \& Atkinson, P.M. (2009). Estimating per-pixel thematic uncertainty in remote sensing classifications. International Journal of Remote Sensing, 30, 209-229

Burrough, P.A. (1989). Fuzzy mathematical methods for soil survey and land evaluation. J Soil Sci, 40, 477-492

Burrough, P.A. (1996). Natural Object with Indeterminate Boundaries. In P.A. Burrough, \& A.U. Frank (Eds.), Geographic Object with Indeterminate Boundaries (p. 345). Abingdon, UK: Taylor \& Francis

Burrough, P.A., Gaans, P.F.M.v., \& Hootsmans, R. (1997). Continuous classification in soil survey: spatial correlation, confusion and boundaries. Geoderma, 77, 115-135

Chaussard, E., Amelung, F., Abidin, H., \& Hong, S.-H. (2013). Sinking cities in Indonesia: ALOS PALSAR detects rapid subsidence due to groundwater and gas extraction. REMOTE SENS. ENVIRON., 128, 150-161

Chawla, S. (2010). Possibilistic c-means - spatial contextual information based sub-pixel classification approach for multi-spectral data. In, University of Twente Faculty of Geo-Information and Earth Observation (ITC) (p. 103). Enschede: University of Twente

Chen, W.W., \& Chang, H.K. (2009). Estimation of shoreline position and change from satellite images considering tidal variation. Estuar. Coast. and Shelf Science, 84, 54-60

Cheng, T. (1999). A process-oriented data model for fuzzy spatial objects. In, Department of Geoinformatics (p. 163). Wageningen: ITC-Wageningen University

Cheng, T. (2002). Fuzzy Objects: Their Changes and Uncertainties. Photogramm. Eng. Rem. S., 68, 41-49

Cheng, T., Molenaar, M., \& Lin, H. (2001). Formalizing fuzzy objects from uncertain classication results. Int. J. Geogr. Inf. Sci., 15, 27-42 
Choung, Y.-J., \& Jo, M.-H. (2016). Shoreline change assessment for various types of coasts using multi-temporal Landsat imagery of the east coast of South Korea. REMOTE SENS LETT, 7, 91-100

Chuang, K.-S., Tzeng, H.-L., Chen, S., Wu, J., \& Chen, T.-J. (2006). Fuzzy cmeans clustering with spatial information for image segmentation. Comput, Med. Imag. Grap., 30, 9-15

Congalton, R.G., \& Green, K. (2009). Assessing the Accuracy of Remotely Sensed Data : Principles and Practices. (Second Edition ed.). Boca Raton: CRC Press

Couso, I., Dubois, D., \& Sánchez, L. (2014). Random Sets and Random Fuzzy Sets as Ill-Perceived Random Variables. New York, NY, USA: Springer

Crowell, M., Leatherman, S.P., \& Buckley, M.K. (1991). Historical Shoreline Change: Error Analysis and Mapping Accuracy. J. Coastal Res, 7, 839-852

Damaywanti, K. (2013). Dampak Abrasi Pantai terhadap Lingkungan Sosial (Studi Kasus di Desa Bedono, Sayung Demak). In, Seminar Nasional Pengelolaan Sumberdaya Alam dan Lingkungan. Semarang: University of Diponegoro

Davidson-Arnott, R. (2010). An introduction to coastal processes and geomorphology. Cambridge University Press

Dean, R.G., \& Dalrymple, R.A. (2002). Coastal processes : with engineering applications. Cambridge: Cambridge University Press

Deer, P.J., \& Eklund, P. (2003). A study of parameter values for a Mahalanobis Distance fuzzy classifier. Fuzzy Sets Syst., 137 191-213

Delinom, R.M., Assegaf, A., Abidin, H.Z., Taniguchi, M., Suherman, D., Lubis, R.F., \& Yulianto, E. (2008). The contribution of human activities to subsurface environment degradation in Greater Jakarta Area, Indonesia. Scientific of the Total Environment, Science Direct, Vol 407, Pages 3129 3141

Demir, B., Minello, L., \& Bruzzone, L. (2014). Definition of Effective Training Sets for Supervised Classification of Remote Sensing Images by a Novel Cost-Sensitive Active Learning Method. IEEE T. Geosci. Remote, 52

Dewan, A., Corner, R., Saleem, A., Rahman, M.M., Haider, M.R., Rahman, M.M., \& Sarker, M.H. (2017). Assessing channel changes of the GangesPadma River system in Bangladesh using Landsat and hydrological data. Geomorphology, 276, 257-279

Dewan, A.M., \& Yamaguchi, Y. (2008). Effect of land cover changes on flooding : example from greater Dhaka of Bangladesh. Int. J. Geoinformatics, 4, 11 - 19

Dewi, R.S., Bijker, W., \& Stein, A. (2017a). Change Vector Analysis to Monitor the Changes in Fuzzy Shorelines. Remote Sens., 9, 147

Dewi, R.S., Bijker, W., \& Stein, A. (2017b). Comparing Fuzzy Sets and Random Sets to Model the Uncertainty of Fuzzy Shorelines. Remote Sens., 9 
Dewi, R.S., Bijker, W., Stein, A., \& Marfai, M.A. (2016). Fuzzy Classification for Shoreline Change Monitoring in a Part of the Northern Coastal Area of Java, Indonesia. Remote Sens., 8, 1-25

Dilo, A., By, R.A.d., \& Stein, A. (2007). A system of types and operators for handling vague spatial objects. Int. J. Geogr. Inf. Sci., 21, 397-426

Dolan, R., Fenster, M.S., \& Holme, S.J. (1991). Temporal analysis of shoreline recession and accretion. J Coastal Res., 7, 723-744

Dubois, D., Esteva, F., Godo, L., \& Prade, H. (2007). Fuzzy-set based logics an history-oriented presentation of their main developments. In D.M. Gabbay, \& J. Woods (Eds.), Handbook of the History of Logic (pp. 325449): Elsevier

Dunn, J.C. (1973). A Fuzzy Relative of the ISODATA Process and Its Use in Detecting Compact Well-Separated Clusters. Cybern. Sys., 3, 32-57

Duru, U. (2017). Shoreline change assessment using multi-temporal satellite images: a case study of Lake Sapanca, NW Turkey. Environ Monit Assess, 185

Dutta, A. (2009). Fuzzy c-means classification of multispectral data incorporating spatial contextual information by using markov random field. In. Enschede: International Institute for Geo-Information Science and Earth Observation (ITC)

Egenhofer, M.J., \& Al-Taha, K.K. (1992). Reasoning about gradual changes of topological relationships. In A.U. Frank, Campari, Irene, Formentini, Ubaldo (Ed.), Theories and Methods of Spatio-Temporal Reasoning in Geographic Space

Epifanio, I., \& Soille, P. (2007). Morphological Texture Features for Unsupervised and Supervised Segmentations of Natural Landscapes. IEEE Trans. Geosci. Remote Sens., 45, 1074-1083

Ervita, K., \& Marfai, M.A. (2017). Shoreline Change Analysis in Demak, Indonesia. Journal of Environmental Protection, 8, 940-955

Feyisa, G.L., Meilby, H., Fensholt, R., \& Proud, S.R. (2014). Automated Water Extraction Index: A new technique for surface water mapping using Landsat imagery. REMOTE SENS. ENVIRON, 140, 23-35

Fikriyani, M., \& Mussadun (2014). The evaluation of mangrove rehabilitation program in the coastal area of Bedono village Sayung sub-district Demak regency. Ruang, 2, 381-390

Fisher, J.S., \& Overton, M.F. (1994). Interpretation of Shoreline Position from Aerial Photographs. Shoreline from Aerial Photographs (pp. 1998-2003)

Fisher, P.F. (1999). Models of uncertainty in spatial data. Geogr.Inf.Sys., 1, 191-205

Fisher, P.F., \& Pathirana, S. (1990). The evaluation of fuzzy membership of land cover classes in the suburban zone. REMOTE SENS. ENVIRON., 34, 121-132

Foody, G. (1996). Approaches for the production and evaluation of fuzzy land cover classifications from remotely-sensed data. Int. J. Remote Sens., 17, $1317-1340$ 
Foody, G.M. (2002). Status of land cover classification accuracy assessment. REMOTE SENS. ENVIRON., Vol. 80, pp. 185-201

Foody, G.M. (2004). Thematic Map Comparison: Evaluating the Statistical Significance of Differences in Classification Accuracy. Photogramm. Eng. Remote Sens., Vol. 70, pp. 627-633

Ford, M. (2013). Shoreline changes interpreted from multi-temporal aerial photographs and high resolution satellite images: Wotje Atoll, Marshall Islands. REMOTE SENS. ENVIRON., 135 130-140

French, P.W. (2001). Coastal Defences : Processes, problems and solutions. London: Taylor and Francis

García-Rubio, G., Huntley, D., \& Russell, P. (2015). Evaluating shoreline identification using optical satellite images. Mar. Geol., 359, 96-105

Gens, R. (2010). Remote sensing of coastlines detection, extraction and monitoring. Int. J. Remote. Sens., 31, 1819-1836

Genz, A.S., Fletcher, C.H., Dunn, R.A., Frazer, L.N., \& Rooney, J.J. (2007). The predictive accuracy of shoreline change rate methods and alongshore beach variation on Maui, Hawaii. J. Coastal Res., 23, 87-105

Ghosh, M.K., Kumar, L., \& Roy, C. (2015). Monitoring the coastline change of Hatiya Island in Bangladesh using remote sensing techniques. ISPRS J. Photogramm., 101, 137-144

Goodman, I.R. (1984). Some New Results Concerning Random Sets and Fuzzy Sets. Inf. Sci., 34, 93-113

Goodman, I.R., Mahler, R.P.S., \& Nguyen, H.T. (1997). Mathematics of data fusion. Dordrecht, The Netherlands: Springer

Goodman, I.R., \& Nguyen, H.T. (1985). Uncertainty models for Knowledgebased systems. Amsterdam, The Netherlands: North Holland

Gorman, L., Morang, A., \& Larson, R. ( 1998). Monitoring the coastal environment; part IV: mapping, shoreline changes, and bathymetric analysis. J. Coastal. Res., 14, 61-92

Graham, D., Sault, M., \& Bailey, C.J. (2003). National Ocean Service Shoreline-Past, Present, and Future. J Coastal Res, SI, 14-32

Greve, A.I. (2016). Sustainable Development, Climate Change Adaptation and Disaster Management. In J.I. Uitto, \& R. Shaw (Eds.), Sustainable Development and Disaster Risk Reduction (p. 287). Japan: Springer

Hadjimitsis, D.G., Papadavid, G., Agapiou, A., Themistocleous, K., Hadjimitsis, M.G., Retalis, A., Michaelides, S., Chrysoulakis, N., Toulios, L., \& Clayton, C.R.I. (2010). Atmospheric correction for satellite remotely sensed data intended for agricultural applications: impact on vegetation indices. Nat. Hazards Earth. Syst. Sci., 10, 89-95

Hannv, Z., Qigang, J., \& jiang, X. (2013). Coastline Extraction Using Support Vector Machine from Remote Sensing Image. Journal of Multimedia, 8, 175-182

Harikumar, A., Kumar, A., Stein, A., Raju, P.L.N., \& Murthy, Y.V.N.K. (2015). An effective hybrid approach to remote-sensing image classification. Int. $J$. Remote Sens., 36, 2767-2785 
Hartini, S. (2015). Flood risk modelling on agricultural area in the North coastal area of Central Java. In, Geography Faculty (p. 164). Yogyakarta, Indonesia: Gadjah Mada University

Harwitasari, D., \& van Ast, J.A. (2011). Climate change adaptation in practice: people's responses to tidal flooding in Semarang, Indonesia. $J$. Flood Risk Manag., 4, 216-233

Hayden, B., Dolan, R., \& Felder, W. (1979). Spatial and temporal analyses of shoreline variations. Coastal Engineering, 2, 351-361

He, C., Wei, A., Shi, P., Zhang, Q., \& Zhao, Y. (2011). Detecting landuse/land-cover change in rural-urban fringe areas using extended changevector analysis. Int. J Appl. Earth Obs. Geoinf., 13, 572-585

Hereher, M.E. (2011). Mapping coastal erosion at the Nile Delta western promontory using Landsat imagery. Environ. Earth Sci., 64, 1117-1125

Heuvelink, G. (1998). Error Propagation in Environmental Modelling with GIS. London, UK: Taylor \& Francis Ltd

Huang, C., Chen, Y., Zhang, S., Li, L., Shi, K., \& Liu, R. (2017). Spatial Downscaling of Suomi NPP-VIIRS Image for Lake Mapping. Water, 9, 834

Jay, S., \& Guillaume, M. (2014). A novel maximum likelihood based method for mapping depth and water quality from hyperspectral remote-sensing data. REMOTE SENS. ENVIRON., 147, 121-132

Jianya, G., Haigang, S., Guorui, M., \& Qiming, Z. (2008). A review of multitemporal remote sensing data change detection algorithms. In, The International Archives of the Photogrammetry, Remote Sensing and Spatial Information Sciences. Beijing

Jin, D., Hoagland, P., Au, D.K., \& Qiu, J. (2015). Shoreline change, seawalls, and coastal property values. Ocean Coast Manage, 114, 185-193

Kaergaard, K., \& Fredsoe, J. (2013). A numerical shoreline model for shorelines with large curvature. Coast Eng, 74, 19-32

Kalkana, K., Bayramb, B., Maktava, D., \& Sunara, F. (2013). Comparison of support vector machine and object based Classification methods for coastline detection. In, International Archives of the Photogrammetry, Remote Sensing and Spatial Information Sciences. Antalya, Turkey: ISPRS

Kauth, R.J., \& Thomas, G.S. (1976). The Tasselled Cap -- A Graphic Description of the Spectral-Temporal Development of Agricultural Crops as seen by Landsat. In, LARS Symposia (pp. 41-51). Indiana, USA: Purdue University

Kim, H., Lee, S.B., \& Min, K.S. (2017). Shoreline Change Analysis using Airborne LiDAR Bathymetry for Coastal Monitoring. J Coastal Res, 79

Klemas, V. (2011). Beach profiling and LIDAR bathymetry: an overview with case studies. J. Coastal Res., 27, 1019-1028

Klir, G.J., \& Wiennan, M.J. (1999). Uncertainty -Based information: elements of generalized information theory: Berlin, Germany: Springer-Verlag Berlin Heidelberg GmbH

Kuleli, T. (2010). Quantitative analysis of shoreline changes at the Mediterranean Coast in Turkey. Environ. Monit. Assess., 167, 387-397 
Kurniawan, L. (2003). Tidal flood assessment in Semarang (case : Dadapsari). Alami, 8

Lambin, E.F., \& Ehrlich, D. (1997). Land-cover Changes in Sub-Saharan Africa (1982-1991): Application of a Change Index Based on Remotely Sensed Surface Temperature and Vegetation Indices at a Continental Scale. REMOTE SENS. ENVIRON., 64, 181-200

Lambin, E.F., \& Strahler, A.H. (1994). Change-Vector Analysis in Multitemporal Space: A Tool To Detect and Categorize Land-Cover Change Processes Using High Temporal-Resolution Satellite Data REMOTE SENS. ENVIRON., 48, 231-244

Landmann, T., Schramm, M., Huettich, C., \& Dech, S. (2013). MODIS-based change vector analysis for assessing wetland dynamics in Southern Africa. Remote Sens. Lett., 42, 104-113

Leatherman, S.P., \& Eskandary, L.S. (1999). Evaluation of coastal erosion hazards along Delaware's atlantic coast. J. Coastal Res., 43-49

Leeuw, J.d., Jia, H., Yang, L., Liu, X., Schmidt, K., \& Skidmore, A.K. (2006). Comparing accuracy assessments to infer superiority of image classification methods. Int. J. Remote Sens., 27, 223-232

Li, M., Stein, A., Bijker, W., \& Zhan, Q. (2015). Region-based urban road extraction from VHR satellite images using binary partition tree. Int. J. Appl. Earth Observation and Geoinformation, 44, 217-225

Li, R., Di, K., \& Ma, R. (2004). A Comparative Study of Shoreline Mapping Techniques. In D. Bartlett, \& J. Smith (Eds.), GIS for Coastal Zone Management. Florida, U.S.: CRC Press

Li, R., Ma, R., \& Di, K. (2002). Digital tide-coordinated shoreline. Mar. Geod., $25,27-36$

Li, X., \& Damen, M.C.J. (2010). Coastline change detection with satellite remote sensing for environmental management of the Pearl River Estuary, China. J. Marine Syst., 82, S54-S61

Liu, H. (2009). Shoreline Mapping and Coastal Change Studies Using Remote Sensing Imagery and LIDAR Data. In X. Yang (Ed.), Remote Sensing and Geospatial Technologies for Coastal Ecosystem Assessment and Management. Berlin Heidelberg: Springer-Verlag

Liu, H., Wang, L., Sherman, D.J., Wu, Q., \& Su, H. (2011a). Algorithmic Foundation and Software Tools for Extracting Shoreline Features from Remote Sensing Imagery and LiDAR Data. Journal of Geographic Information System, 3, 99-119

Liu, K., Shi, W., \& Zhanga, H. (2011b). A fuzzy topology-based maximum likelihood classification. ISPRS J. Photogramm. Remote Sens., Vol. 66, pp. 103-114

Liu, X., Xia, J.C., Blenkinsopp, C., Arnold, L., \& Wright, G. (2014). High Water Mark Determination Based on the Principle of Spatial Continuity of the Swash Probability. J. Coastal Res, 30, 487-499

Liu, Y., Wang, X., Ling, F., Xu, S., \& Wang, C. (2017). Analysis of Coastline Extraction from Landsat-8 OLI Imagery. Water, 9 
Lu, D., Li, G., \& Moran, E. (2014). Current situation and needs of change detection techniques. International Journal of Image and Data Fusion, 5, 13-38

Lu, D., \& Weng, Q. (2007). A survey of image classification methods and techniques for improving classification performance. International Journal of Remote Sensing, Vol. 28, pp. 823-870

Lubis, A.M., Sato, T., Tomiyama, N., Isezaki, N., \& Yamanokuchi, T. (2011). Ground subsidence in Semarang-Indonesia investigated by ALOS-PALSAR satellite SAR interferometry. J. Asian Earth Sci., 40, 1079-1088

Lunetta, R.S., \& Elvidge, C.D. (1999). Remote Sensing Change Detection : Environmental Monitoring Methods and Applications. UK: Taylor \& Francis

Mahler, R.P.S. (2007). Statistical Multisource-Multitarget Information Fusion. Norwood, MA, USA: Artech House

Maiti, S., \& Bhattacharya, A.K. (2009). Shoreline change analysis and its application to prediction: a remote sensing and statistics based approach. Mar. Geol., 257, 11-23

Malila, W.A. (1980). Change Vector Analysis: An Approach for Detecting Forest Changes with Landsat. In, LARS Symposia. Indiana, USA: Purdue University

Manandhar, R., Odeh, I.O.A., \& Ancev, T. (2009). Improving the Accuracy of Land Use and Land Cover Classification of Landsat Data Using PostClassification Enhancement. Remote Sens., 1, 330-344

Marfai, M.A. (2011). Impact of Coastal Inundation on Ecology and Agricultural Land Use Case Study in Central Java, Indonesia. Quaestiones Geographicae, 30, 19 - 32

Marfai, M.A., Almohammad, H., Dey, S., Susanto, B., \& King, L. (2008a). Coastal dynamic and shoreline mapping: multi-sources spatial data analysis in Semarang Indonesia. Environ. Monit. Assess., 142, 297-308

Marfai, M.A., \& King, L. (2007). Tidal inundation mapping under enhanced land subsidence in Semarang, Central Java Indonesia. Nat. Hazards

Marfai, M.A., King, L., Sartohadi, J., Sudrajat, S., Budiani, S.R., \& Yulianto, F. (2008b). The impact of tidal flooding on a coastal community in Semarang, Indonesia. Environmentalist, 28, 237 - 248

Martinis, S., Twele, A., Strobl, C., Kersten, J., \& Stein, E. (2013). A multiscale flood monitoring system based on fully automatic MODIS and TerraSAR-X processing chains. Remote Sensing, 5, 5598-5619

Masria, A., Nadaoka, K., Negm, A., \& Iskander, M. (2015). Detection of Shoreline and Land Cover Changes around Rosetta Promontory, Egypt, Based on Remote Sensing Analysis. Land, 4, 216-230

Mather, P.M. (2004). Computer processing of remotely-sensed images: an introduction. (Third Edition ed.). Chicester, England: John Wiley \& Sons

Matheron, G. (1975). Random sets and Integral Geometry. New York, NY, USA: John Wiley and Sons 
McFeeters, S.K. (1996). The use of the Normalized Difference Water Index (NDWI) in the delineation of open water features. Int J Remote Sens, 17, 1425-1432

Medasani, S., Kim, J., \& Krishnapuram, R. (1998). An overview of membership function generation techniques for pattern recognition. Int. J. Approx. Reason., 19, 391-417

Miladan, N. (2016). Communities' contributions to urban resilience process : a case study of Semarang city (Indonesia) toward coastal hydrological risk. In, Architecture, space management (p. 547). France: Universit le Paris-Est

Molchanov, I. (2005). Theory of Random Sets. London, UK: Springer-Verlag

Molenaar, M. (1998). An Introduction to the Theory of Spatial Object Modelling for GIS. London, UK: Taylor \& Francis Ltd

Molenaar, M. (2000). Three Conceptual Uncertainty Levels for Spatial Objects. In, International Archives of Photogrammetry and Remote Sensing. Amsterdam

Molenaar, M., \& Cheng, T. (2000). Fuzzy spatial objects and their dynamics. ISPRS J. Photogramm., 55, 164-175

Moore, L.J. (2000). Shoreline Mapping Techniques. J. Coastal Res, 16, 111 124

Moore, L.J., Ruggiero, P., \& List, J.H. (2006). Comparing Mean High Water and High Water Line Shorelines: Should Proxy-Datum Offsets be Incorporated into Shoreline Change Analysis? J. Coastal Res, 22, 894-905

Morton, R.A. (2002). Coastal geoindicators of environmental change in the humid tropics. Environmental Geology, 42, 711-724

Morton, R.A., Leach, M.P., Paine, J.G., \& Cardoza, M.A. (1993). Monitoring Beach Changes Using GPS Surveying Techniques. J. Coastal Res, 9, 702720

Morton, R.A., Miller, T.L., \& Moore, L.J. (2004). National Assessment of Shoreline Change: Part 1 Historical Shoreline Changes and Associated Coastal Land Loss Along The U.S. Gulf of Mexico. In (p. 45): U.S. Geological Survey, Center for Coastal and Watershed Studies

Muslim, A.M., Foody, G.M., \& Atkinson, P.M. (2006). Localized soft classification for super-resolution mapping of the shoreline. Int. J. Remote Sens., 27, 2271-2285

Netherlands-Water-Partnership (2016). Indonesia - the Netherlands integrated approach of future water challenges. In B.t. Braak (Ed.), Water for Food and Ecosystems : Using the Power of Nature (pp. 26-30). Netherlands: Netherlands Water Partnership (NWP)

Nguyen, H.T. (2006). An Introduction to Random Sets. Boca Raton, FL, USA: Chapman \& Hall/CRC

Nguyen, H.T., \& BerlinWu (2006). Random and fuzzy sets in coarse data analysis. Comput. Stat. Data Anal., 51, 70-85

NOAA (2014). Aerial Photography and Shoreline Mapping. In: NOAA 
NOAA (2018). Mapping and Charting. In, Tides and Currents. U.S.: Center for Operational Oceanographic Products and Services

O'Connor, M.C., Cooper, J.A.G., McKenna, J., \& Jackson, D.W.T. (2010). Shoreline management in a policy vacuum: A local authority perspective. Ocean \& Coast Manage, 53, 769-778

Oertel, G.F. (2005). Coasts, coastlines, shores, and shorelines. In M.L. Schwartz (Ed.), Encyclopedia of Coastal Science (pp. 323-327): (c) Springer

Ongkosongo, O. (2010). Indonesia. In E.C.F. Bird (Ed.), Encyclopedia of the World's Coastal Landforms. Dordrecht: Springer

Oort, P.v. (2005). Spatial data quality: from description to application. In. The Netherlands: Wageningen University

Ouma, Y.O., \& Tateishi, R. (2007). A water index for rapid mapping of shoreline changes of five East African Rift Valley Lakes: an empirical analysis using Landsat TM and ETM+ Data. Int. J. Remote Sens., 27, 3153-3181

Ozturk, D., Beyazit, I., \& Kilic, F. (2015). Spatiotemporal Analysis of Shoreline Changes of the Kizilirmak Delta. J. Coastal Res, 31, 1389-1402

Özyavuz, M., Şatır, O., \& Bilgili, B.C. (2011). A Change Vector Analysis Technique to Monitor Land-Use/Land-Cover in the Yildiz Mountains, Turkey. Fresenius Environmental Bulletin, 20, 1190-1199

Pajak, M.J., \& Leatherman, S. (2002). The High Water Line as Shoreline Indicator. J Coastal Res, 18, 329-337

Pal, N.R., \& Bezdek, J.C. (1995). On Cluster Validity for the Fuzzy c-Means Model. IEEE Trans. Fuzzy Syst., 3

Pangastuti, D., \& Sofian, I. (2015). Validation of Geoid EGM2008 in Java and Sumatra by the Parameter Mean Dynamic Topography (MDT) on Geometric Geoid. In, Maj. IIm. Globe. Cibinong: Geospatial Information Agency

Pardo-Pascual, J.E., Almonacid-Caballer, J., Ruiz, L.A., \& Palomar-Vázquez, J. (2012). Automatic extraction of shorelines from Landsat TM and ETM+ multi-temporal images with subpixel precision. REMOTE SENS. ENVIRON., $123,1-11$

Pontius, R.G., \& Cheuk, M.L. (2006). A generalized cross-tabulation matrix to compare soft-classified maps at multiple resolutions. Int. J. Geogr. Inf. Sci., 20, 1-30

Pratiwi, M.R.I. (2012). Impact of the Tidal Floods Dynamics to Social Ecological System of Semarang City (Case Study in Tanjung Mas District). In, Sekolah Pascasarjana (p. 95). Bogor, Indonesia: Institut Pertanian Bogor

Pugh, D.T. (1987). Tides, Surges and Mean Sea-Level. UK: John Wiley and Sons

Putranto, T.T., \& Rüde, T.R. (2011). Groundwater problem in Semarang Demak urban area, Java/Indonesia. In: Geostats-course.org 
RI'o, L.D., \& Gracia, F.J. (2013). Error determination in the photogrammetric assessment of shoreline changes. Nat. Hazards, 65, 2385-2397

Richards, J.A. (2013). Remote sensing digital image analysis. (Fifth Edition ed.). Springer

Riesch, H. (2013). Levels of Uncertainty. In S. Roeser, R. Hillerbrand, P. Sandin, \& M. Peterson (Eds.), Essentials of Risk Theory. Dordrecht, The Netherlands: Springer Netherlands

Robertson, W., Whitman, D., Zhang, K., \& Leatherman, S.P. (2004). Mapping Shoreline Position Using Airborne Laser Altimetry. J. Coastal Res, 20, 884892

Robinson, V.B. (2003). A Perspective on the Fundamentals of Fuzzy Sets and their Use in Geographic Information Systems. Trans. GIS, 7

Roubens, M. (1982). Fuzzy clustering algorithms and their cluster validity. Eur. J. Oper. Res., 10, 294-301

Sarbidi (2001). Rob influence on coastal settlements (case study : Semarang city). In, Losses in Buildings and Areas Due Sea-level Rise on Coastal Cities in Indonesia. Bandung: Research Center for Settlements, Ministry of Public Works - Indonesia

Sarwar, M.G.M., \& Woodroffe, C.D. (2013). Rates of shoreline change along the coast of Bangladesh. J Coast Conserv, 17, 515-526

Schneider, M. (1998). Modeling Spatial Objects with Undetermined Boundaries Using the Realm/ROSE Approach. In P.A. Burrough, \& A.U. Frank (Eds.), Geographic objects with indeterminate boundaries (pp. 112). London, UK: Taylor \& Francis

Schneider, M. (2001). Fuzzy Topological Predicates, Their Properties, and Their Integration into Query Languages. In, 9th ACM international symposium on Advances in geographic information systems ( $\mathrm{pp}$. 9-14). Atlanta, GA, USA: ACM Digital Library

Sebari, I., \& He, D.-C. (2013). Automatic fuzzy object-based analysis of VHSR images for urban objects extraction. ISPRS J. Photogramm., 79, 171-184

Sekovski, I., Stecchi, F., Mancini, F., \& Rio, L.D. (2014). Image classification methods applied to shoreline extraction on very high-resolution multispectral imagery. Int J Remote Sens, 35, 3556-3578

Senthilnatha, J., H, V.S., Omkar, S.N., \& Mani, V. (2012). Spectral-spatial MODIS image analysis using swarm intelligence algorithms and region based segmentation for flood assessment. In J.C. Bansal, P.K. Singh, K. Deep, M. Pant, \& A.K. Nagar (Eds.), Seventh International Conference on Bio-Inspired Computing: Theories and Applications: Springer

Shenbagaraj, N., Mani, N.D., \& Muthukumar, M. (2014). Isodata classification technique to assess the shoreline changes of Kolachel to Kayalpattanam coast. International Journal of Engineering Research \& Technology, 3

Shi, W. (2010). Principles of Modeling Uncertainties in Spatial Data and Spatial Analyses. United States of America: Taylor and Francis Group 
Shi, W., Liu, K., \& Huang, C. (2010). A Fuzzy-Topology-Based Area Object Extraction Method. IEEE Trans. Geosci. Remote Sens., 48, 147-154

Silván-Cárdenas, J.L., \& Wang, L. (2008). Sub-pixel confusion-uncertainty matrix for assessing soft classifications. REMOTE SENS. ENVIRON., 112, 1081-1095

Singh, A. (1989). Digital Change Detection Techniques using RemotelySensed Data. International Journal of Remote Sensing, 10, 989 - 1003

Singh, S., \& Talwar, R. (2015). Performance Analysis of Different Threshold Determination Techniques for Change Vector Analysis. J. Geol. Soc. India, $86,52-58$

Singpurwalla, N.D., \& Booker, J.M. (2004). Membership Functions and Probability Measures of Fuzzy Sets. J. Am. Stat. Assoc., 99, 867-877

Skidmore, A.K., \& Turner, B.f. (1992). Map Accuracy Assessment Using Line Intersect Sampling. Photogramm. Eng. Remote Sens., 58, 1453-1457

Snoussi, M., Ouchani, T., Khouakhi, A., \& Niang-Diop, I. (2009). Impacts of sea-level rise on the Moroccan coastal zone: Quantifying coastal erosion and flooding in the Tangier Bay. Geomorphology, 107, 32-40

Sofian, I. (2010). Scientific basis: analysis and projection of sea level rise and extreme event. In BAPPENAS (Ed.) (p. 70). Indonesia: National Development Planning Agency

Stive, M.J.F., Aarninkhof, S.G.J., Hamm, L., Hanson, H., Larson, M., Wijnberg, K.M., Nicholls, R.J., \& Capobianco, M. (2002a). Variability of shore and shoreline evolution. Coastal Engineering, 47, 211-235

Stive, M.J.F., Aarninkhof, S.G.J., Hamm, L., Hanson, H., Larsonc, M., Wijnberg, K.M., Nicholls, R.J., \& Capobianco, M. (2002b). Variability of shore and shoreline evolution. Coastal Engineering, 47, 211-235

Stockdon, H.F., Asbury H. Sallenger, J., List, J.H., \& Holrnan, R.A. (2002). Estimation of Shoreline Position and Change using Airborne Topographic Lidar Data. J. Coastal Res, 18, 502-513

Stoyan, D., \& Stoyan, H. (1994). Fractals, Random Shapes and Point Fields: Methods of Geometrical Statistics. Chichester, UK: John Wiley and Sons

Sukcharoenpong, A., Yilmaz, A., \& Li, R. (2016). An Integrated Active Contour Approach to Shoreline Mapping Using HSI and DEM. IEEE Trans. Geosci. Remote Sens., 54

Sunder, S., Ramsankaran, R., \& Ramakrishnan, B. (2017). Inter-comparison of remote sensing sensing-based shoreline mapping techniques at different coastal stretches of India. Environ Monit Assess, 189

Taha, L.G.E.-d., \& Elbeih, S.F. (2010). Investigation of fusion of SAR and Landsat data for shoreline super resolution mapping: the Northeastern Mediterranean sea coast in Egypt. Appl. Geomat., 2, 177-186

Tamassoki, E., Amiri, H., \& Soleymani, Z. (2014). Monitoring of shoreline changes using remote sensing (case study: coastal city of Bandar Abbas). In, 7th IGRSM International Remote Sensing \& GIS Conference and Exhibition IOP Publishing 
Taylor, J.R. (1982). An Introduction to Error Analysis : The Study of Uncertainties in Physical Measurements Sausalito, California: University Science Books

Thieler, E.R., \& Danforth, W.W. (1994). Historical Shoreline Mapping (I): Improving Techniques and Reducing Positioning Errors. J. Coastal Res, 10, 549-563

Tobias, O.J., \& Seara, R. (2002). Image Segmentation by Histogram Thresholding Using Fuzzy Sets. IEEE Trans. Image Process., 11, 14571465

Tso, B., \& Mather, P. (2009). Classification methods for remotely sensed data. Boca Raton, FL, USA: CRC Press

UN (2015). Transforming our world: the 2030 Agenda for Sustainable Development. In, Resolution adopted by the General Assembly on 25 September 2015: United Nation General Assembly

USGS (2015). United States Geological Survey. In

USGS (2017). EarthExplorer. In. USA: U.S. Geological Survey

Vaidya, A.M., Kori, S.K., \& Kudale, M.D. (2015). Shoreline response to coastal structures. Aquatic Procedia, 4, 333-340

Vlag, D.E.v.d., \& Stein, A. (2007). Incorporating Uncertainty via Hierarchical Classification Using Fuzzy Decision Trees. IEEE Trans. Geosci. Remote Sens., 45, 9

Vorovencii, I. (2014). A change vector analysis technique for monitoring land cover changes in Copsa Mica, Romania, in the period 1985-2011. Environ Monit Assess, 186, 5951-5968

Wang, F. (1990). Fuzzy Supervised Classification of Remote Sensing Images. IEEE T. Geosci. Remote, 28, 194-201

Wang, Q., \& Shi, W. (2013). Unsupervised classification based on fuzzy cmeans with uncertainty analysis. Remote Sens. Lett., 4

Wang, Y. (2004). Using Landsat 7 TM data acquired days after a flood event to delineate the maximum flood extent on a coastal floodplain. Int. J. Remote. Sens., 25, 959-974

Wang, Y., Hou, X., Jia, M., Shi, P., \& Yu, L. (2014). Remote Detection of Shoreline Changes in Eastern Bank of Laizhou Bay, North China. J Indian Soc Remote Sens, 42

WCED (1987). Our Common Future. In, Report of the World Commission on Environment and Development: United Nation

Wesenbeeck, B.K.v., Balke, T., Eijk, P.v., Tonneijck, Siry, H.Y., Rudianto, M.E., \& Winterwerp, J.C. (2015). Aquaculture induced erosion of tropical coastlines throws coastal communities back into poverty. Ocean \& Coastal Management, 116, 466-469

White, S.A., Parrish, C.E., Calder, B.R., Pe'eri, S., \& Rzhanov, Y. (2011). LIDAR-Derived National Shoreline: Empirical and Stochastic Uncertainty Analyses. J Coastal Res, 62, 62-74 
Winterwerp, H., Wesenbeeck, B.v., Dalfsen, J.v., Tonneijck, F., Astra, A., Verschure, S., \& Eijk, P.v. (2014). A sustainable solution for massive coastal erosion in Central Java. In, Discussion Paper (pp. 1-45). Delft, The Netherlands: Deltares - Wetland International

Woodcock, C.E. (2002). Uncertainty in Remote Sensing. In G.M. Foody, \& P.M. Atkinson (Eds.), Uncertainty in Remote Sensing and GIS (pp. 19-24): Wiley and Sons

Wu, K.-L., \& Yang, M.-S. (2005). A cluster validity index for fuzzy clustering. Pattern Recogn. Lett., 26, 1275-1291

Xie, X.L., \& Beni, G. (1991). A validity measure for fuzzy clustering. IEEE Trans. Pattern Anal. Mach. Intell., 13, 841 - 847

$\mathrm{Xu}, \mathrm{H}$. (2006). Modification of normalised difference water index (NDWI) to enhance open water features in remotely sensed imagery. Int $J$ Remote Sens, 27

Yao, F., Parrish, C.E., Pe'eri, S., Calder, B.R., \& Rzhanov, Y. (2015a). Modeling Uncertainty in Photogrammetry-Derived National Shoreline. Mar. Geod., 38, 128-145

Yao, F., Parrish, C.E., Pe'eri, S., Calder, B.R., \& Rzhanov, Y. (2015b). Modeling uncertainty in photogrammetry-derived national shoreline. Mar. Geod., 38, 128-145

Yin, J., \& He, F. (2011). Researching the Method of Coastline Extracted by Remote Sensing Image. In, International Conference on Geoscience and Remote Sensing (IITA-GRS). Qingdao, China: IEEE

Zadeh, L.A. (1965). Fuzzy Sets. Inf. Control, 8, 338-355

Zadeh, L.A. (1978). PRUF a meaning representation language for natural languages. Int. J. Mach. Stud., 10, 395-460

Zadeh, L.A. (1995). Discussion: Probability Theory and Fuzzy Logic Are Complementary Rather Than Competitive. Technometrics, 37

Zanuttigh, B., Martinelli, L., Lamberti, A., Moschella, P., Hawkins, S., Marzetti, S., \& Ceccherelli, V.U. (2005). Environmental design of coastal defence in Lido di Dante, Italy. Coast Eng, 52, 1089- 1125

Zarandi, M.H.F., Faraji, M.R., \& Karbasian, M. (2010). An exponential cluster validity index for fuzzy clustering with crisp and fuzzy data. Transaction $E$ : Industrial Engineering, 17, 95-110

Zhang, J., \& Foody, G.M. (1998a). A fuzzy classification of sub-urban land cover from remotely sensed imagery. Int. J. Remote Sens., 19, 27212738

Zhang, J., \& Foody, G.M. (1998b). A fuzzy classification of sub-urban land cover from remotely sensed imagery. International Journal of Remote Sensing, 19, 2721-2738

Zhang, J., \& Foody, G.M. (2001). Fully-fuzzy Supervised Classification of suburban Land Cover from Remotely Sensed Imagery: Statistical and Artificial Neural Network Approaches. Int. J. Remote Sens., 22, 615-628 
Zhang, J., \& Kirby, R.P. (1999). Alternative Criteria for Defining Fuzzy Boundaries Based on Fuzzy Classification of Aerial Photographs and Satellite Images. Photogramm. Eng. Rem. S., 65, 1379-1387

Zhao, X., Stein, A., \& Chen, X.-L. (2011a). Monitoring the dynamics of wetland inundation by random sets on multi-temporal images. REMOTE SENS. ENVIRON., 115 2390-2401

Zhao, X., Stein, A., \& Chen, X. (2010). Application of random sets to model uncertainties of natural entities extracted from remote sensing images. Stoch. Environ. Res. Risk Assess., 24, 713-723

Zhao, X., Stein, A., Chen, X., \& Zhang, X. (2011b). Quantification of Extensional Uncertainty of Segmented Image Objects by Random Sets. IEEE Trans. Geosci. Remote Sens., 49

Zhou, L., \& Stein, A. (2013). Application of random sets to model uncertainty of road polygons extracted from airborne laser points. Comp. Environ. Urban Syst., 41 289-298

Zhu, A.-X., Yang, L., Li, B., Qin, C., Pei, T., \& Liu, B. (2010). Construction of membership functions for predictive soil mapping under fuzzy logic. Geoderma, 155, 164-174 


\section{Appendices}
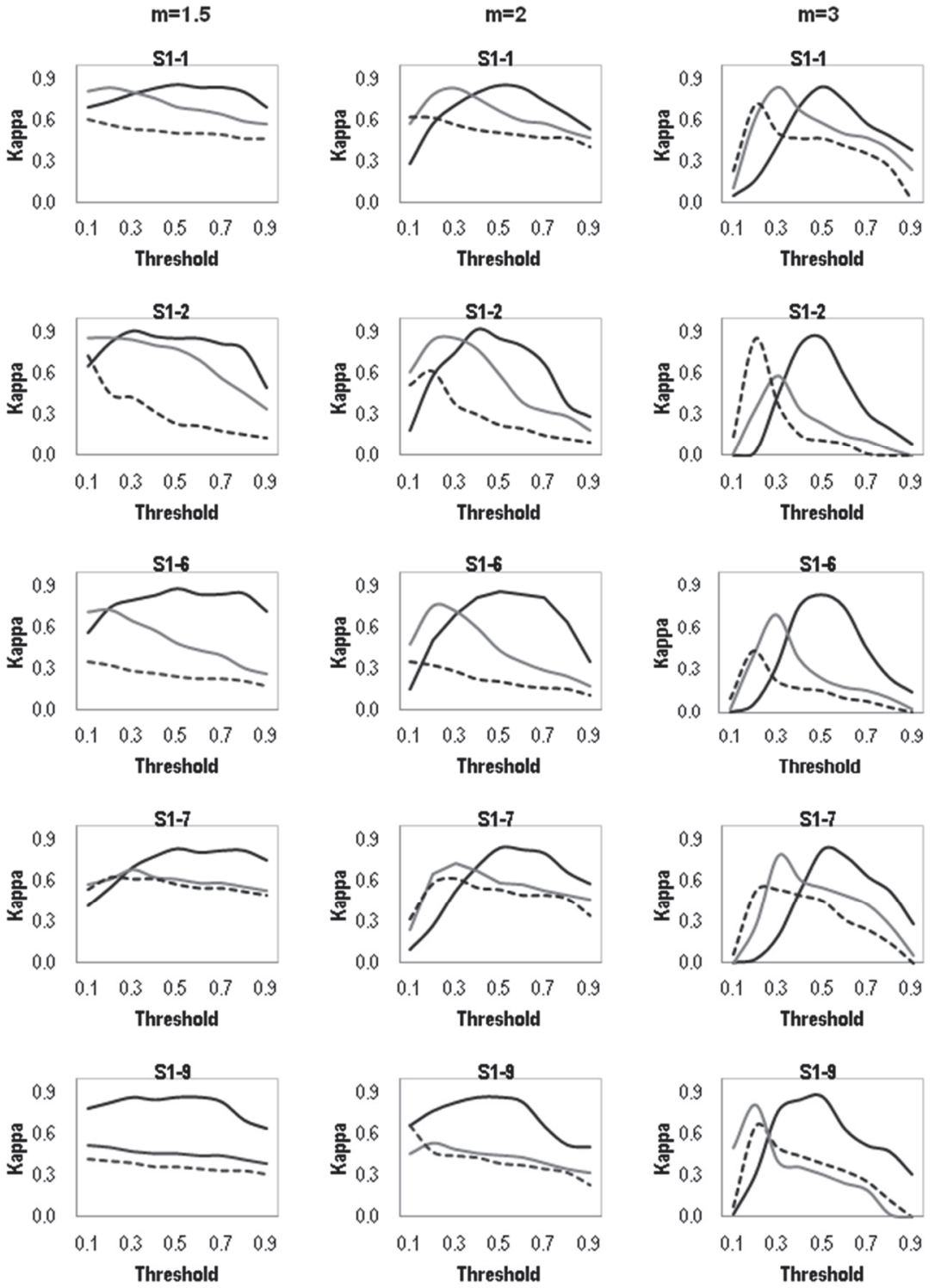

$-c=2-c=3 \quad-\cdots c=4$ 

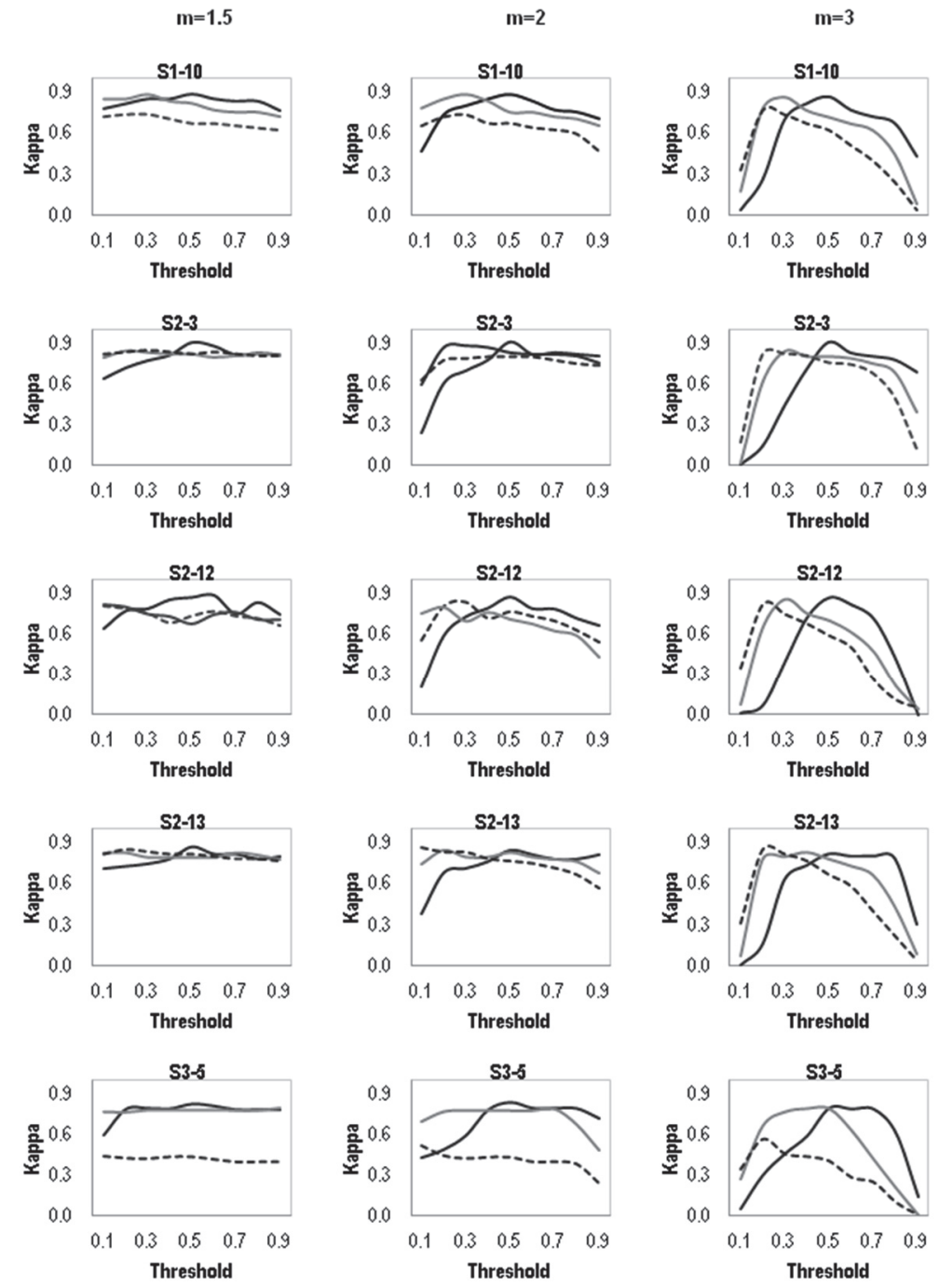

$-c=2-c=3 \quad \cdots \cdot c=4$ 

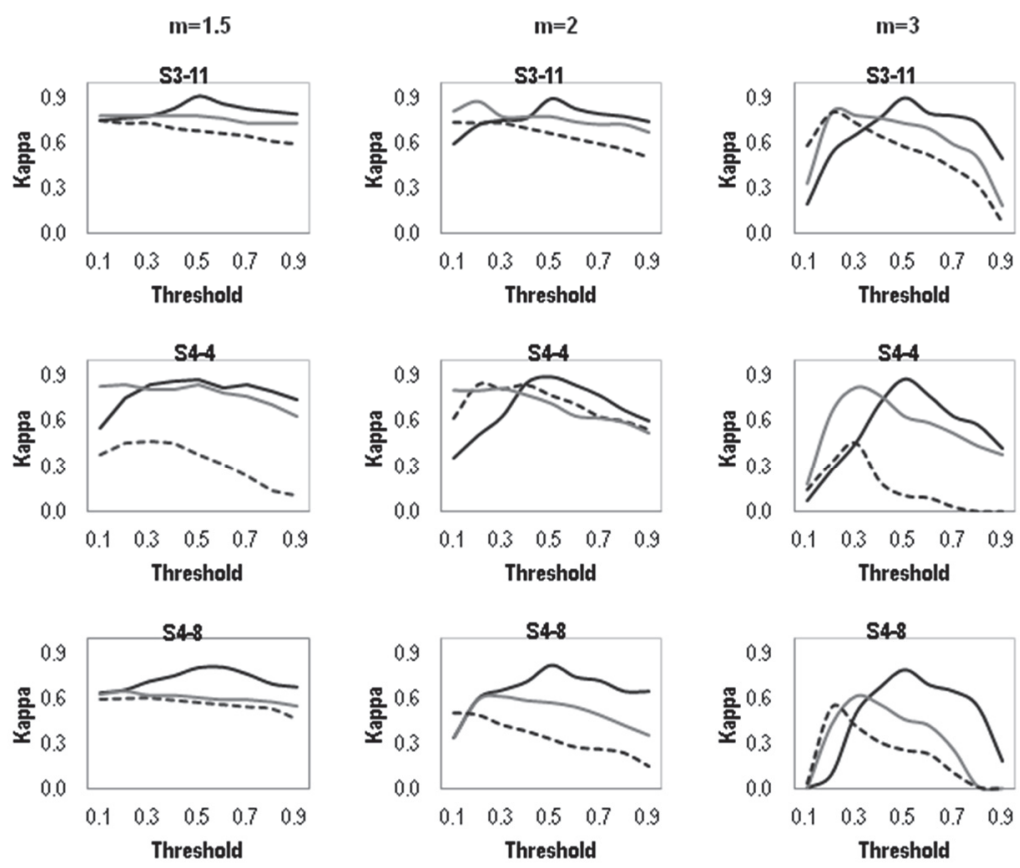

$c=2-c=3 \quad \cdots-\cdots c=4$

Figure 4A.1 The estimation results of $c$ and $m$ for FCM classification

Table 4A.1 The cluster validity index showing the compactness and the separateness among all clusters (applied using $\boldsymbol{m}=1.6$ )

\begin{tabular}{cccc}
\hline \multirow{2}{*}{ Subset } & \multicolumn{3}{c}{ Cluster validity index (CVI) } \\
\cline { 2 - 4 } & $\boldsymbol{c}=\mathbf{2}$ & $\boldsymbol{c}=\mathbf{3}$ & $\boldsymbol{c}=\mathbf{4}$ \\
\hline$S_{1-1}$ & 0.013 & 0.023 & 0.020 \\
$S_{1-2}$ & 0.019 & 0.030 & 0.044 \\
$S_{1-6}$ & 0.016 & 0.021 & 0.033 \\
$S_{1-7}$ & 0.016 & 0.027 & 0.026 \\
$S_{1-9}$ & 0.008 & 0.034 & 0.027 \\
$S_{1-10}$ & 0.015 & 0.039 & 0.033 \\
\hline$S_{2-3}$ & 0.017 & 0.028 & 0.027 \\
$S_{2-12}$ & 0.035 & 0.068 & 0.037 \\
$S_{2-13}$ & 0.023 & 0.027 & 0.031 \\
\hline$S_{3-5}$ & 0.019 & 0.038 & 0.052 \\
$S_{3-11}$ & 0.010 & 0.019 & 0.023 \\
\hline$S_{4-4}$ & 0.010 & 0.011 & 0.084 \\
$S_{4-8}$ & 0.013 & 0.039 & 0.040 \\
\hline
\end{tabular}



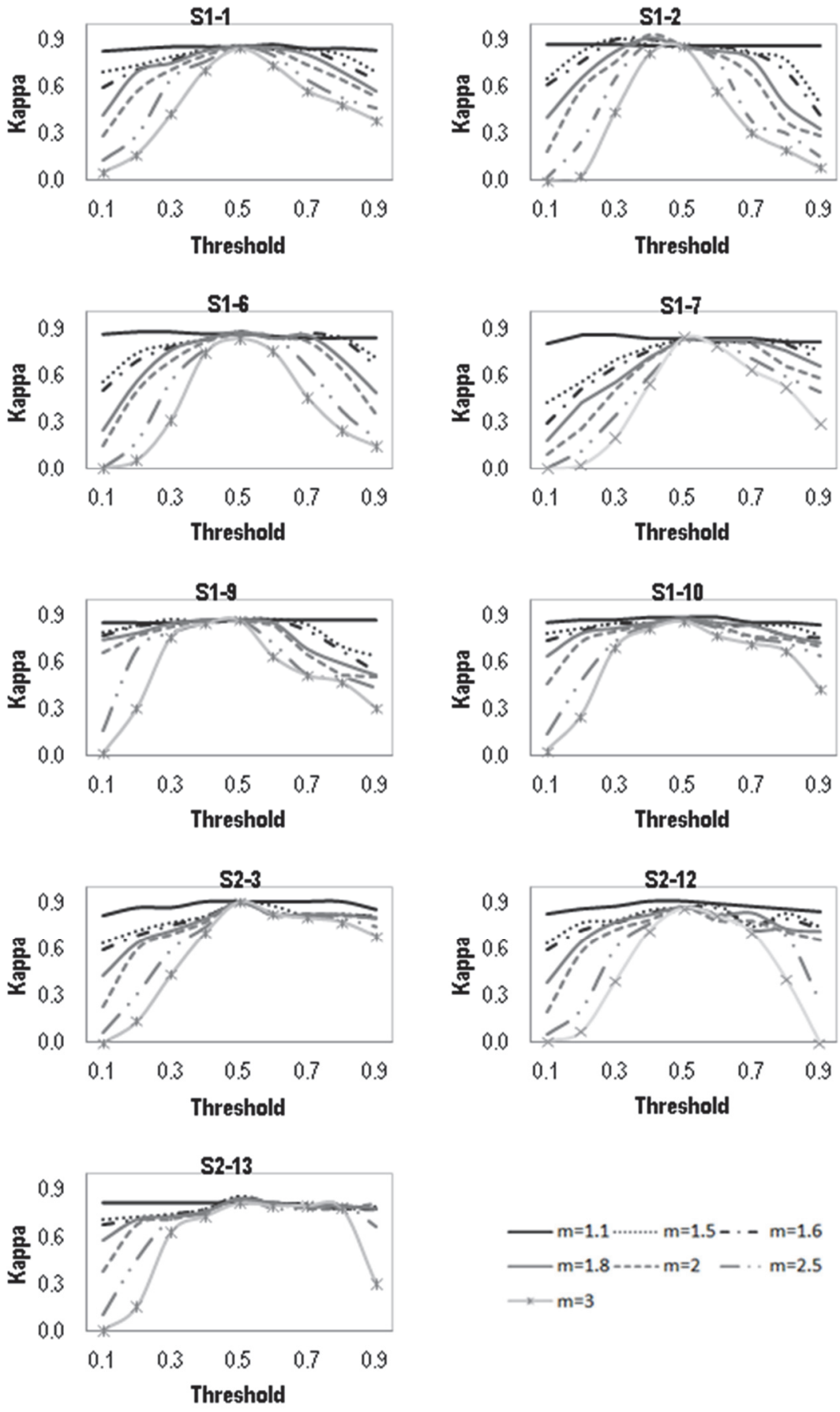

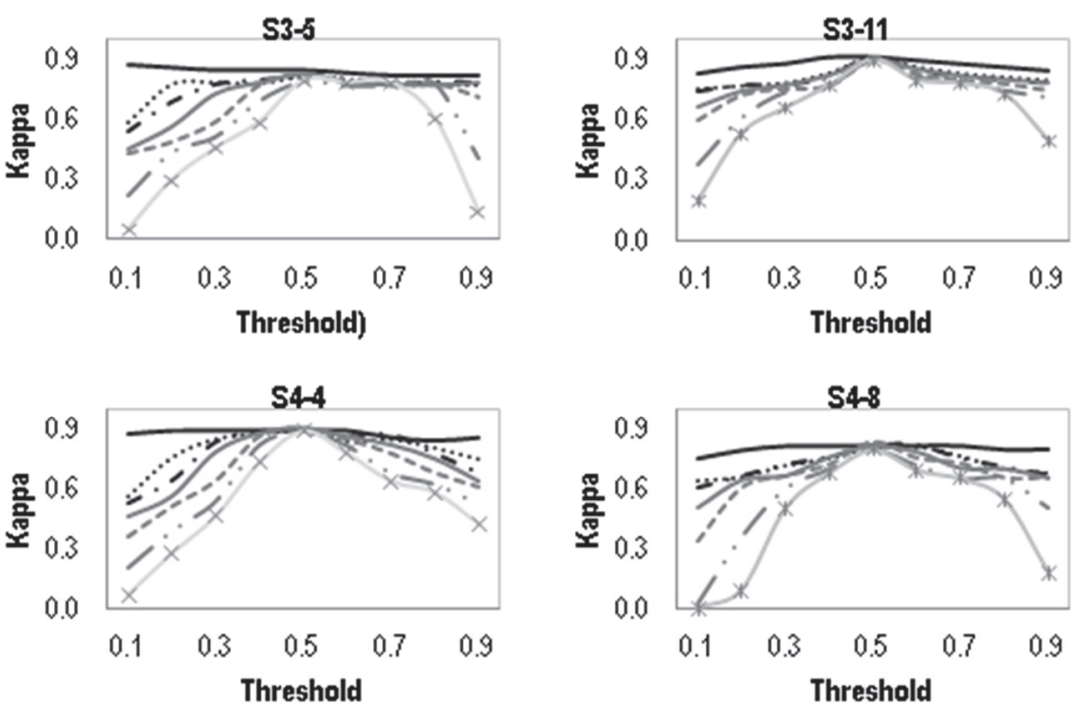

$\longrightarrow \mathrm{m}=1.1 \cdots \cdots \cdots \cdot \mathrm{m}=1.5-\cdots \mathrm{m}=1.6-\mathrm{m}=1.8-\cdots \mathrm{m}=2-\cdots \mathrm{m}=2.5 \longrightarrow \mathrm{m}=3$

Figure 4A.2 The estimation of threshold interval for $c=2$ and various $m$ values for FCM classification 
Table 4A.2 The results of McNemar's test showing the significance of the different accuracies given by Pleiades and Pleiades + DTM $(\boldsymbol{\alpha}=0.05)$ in FCM classification with thresholding

\begin{tabular}{|c|c|c|c|c|c|c|}
\hline \multirow[b]{2}{*}{ Subset } & \multicolumn{5}{|c|}{ McNemar's Test } & \multirow[b]{2}{*}{$p$-value } \\
\hline & $f_{11}$ & $f_{12}$ & $f_{21}$ & $f_{22}$ & $\begin{array}{c}\text { Chi-squared } \\
\left(X^{2}\right)\end{array}$ & \\
\hline$S_{1-1}$ & 10 & 9 & 0 & 156 & 7.1 & 0.01 \\
\hline$S_{1-2}$ & 3 & 24 & 7 & 109 & 8.3 & 0.00 \\
\hline$S_{1-6}$ & 6 & 23 & 4 & 119 & 12.0 & 0.00 \\
\hline$S_{1-7}$ & 4 & 34 & 8 & 101 & 14.9 & 0.00 \\
\hline$S_{1-9}$ & 3 & 23 & 9 & 78 & 5.3 & 0.02 \\
\hline$S_{1-10}$ & 3 & 13 & 4 & 101 & 3.8 & 0.05 \\
\hline$S_{2-3}$ & 7 & 15 & 2 & 128 & 8.5 & 0.00 \\
\hline$S_{2-12}$ & 1 & 15 & 5 & 100 & 4.1 & 0.04 \\
\hline$S_{2-13}$ & 7 & 4 & 0 & 107 & 2.3 & 0.13 \\
\hline$S_{3-5}$ & 2 & 38 & 8 & 116 & 18.3 & 0.00 \\
\hline$S_{3-11}$ & 3 & 11 & 3 & 104 & 3.5 & 0.06 \\
\hline$S_{4-4}$ & 4 & 23 & 5 & 116 & 10.3 & 0.00 \\
\hline$S_{4-8}$ & 1 & 19 & 10 & 91 & 2.2 & 0.14 \\
\hline
\end{tabular}

$\boldsymbol{f}_{11}$ : number of samples with incorrect classification using both images;

$\boldsymbol{f}_{22}$ : number of samples with correct classification using both images;

$f_{12}$ : number of samples that are incorrectly classified by Pleiades but correctly classified by Pleiades + DTM;

$\boldsymbol{f}_{21}$ : number of samples that are correctly classified by Pleiades but incorrectly classified by Pleiades + DTM 


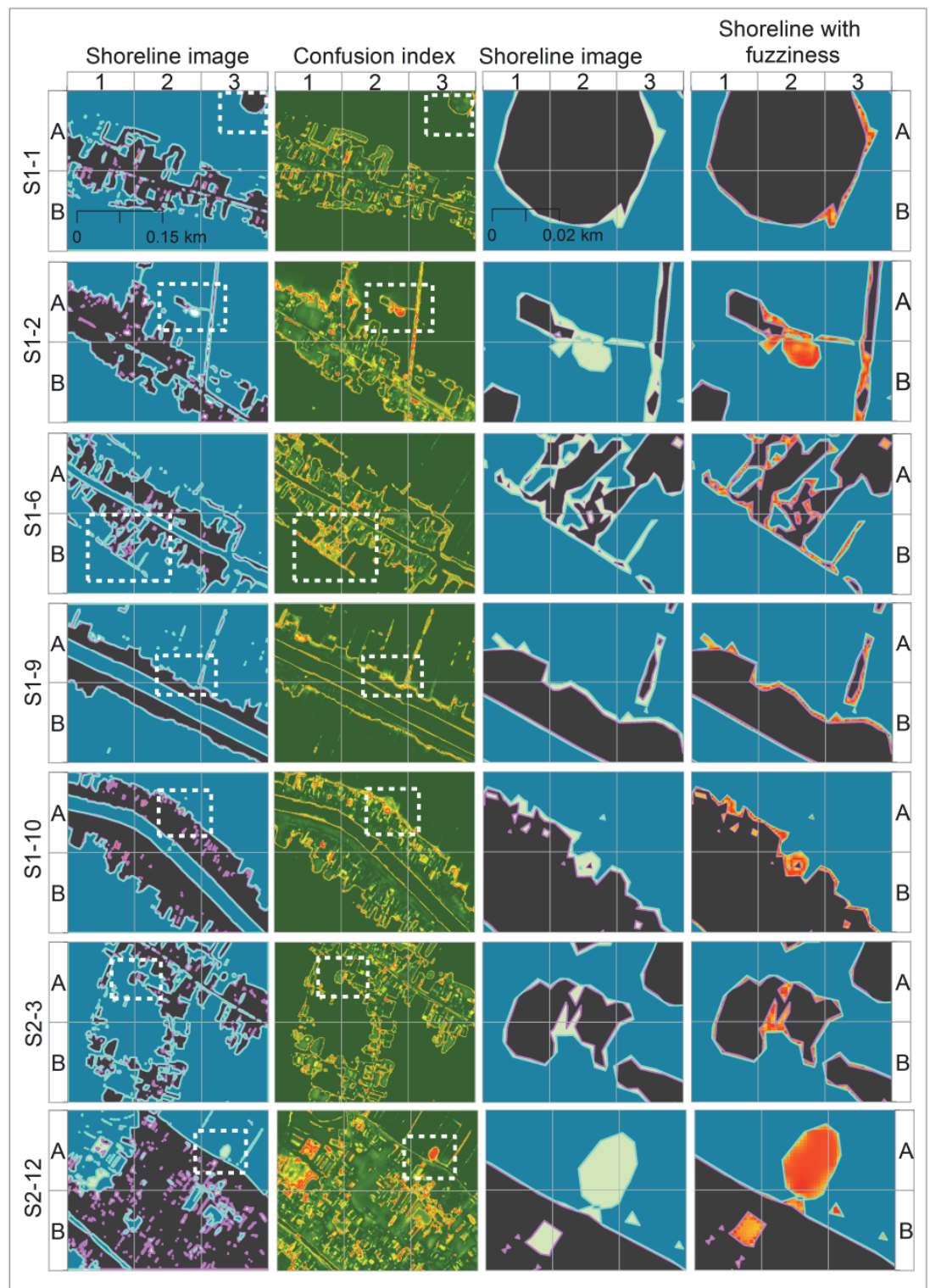




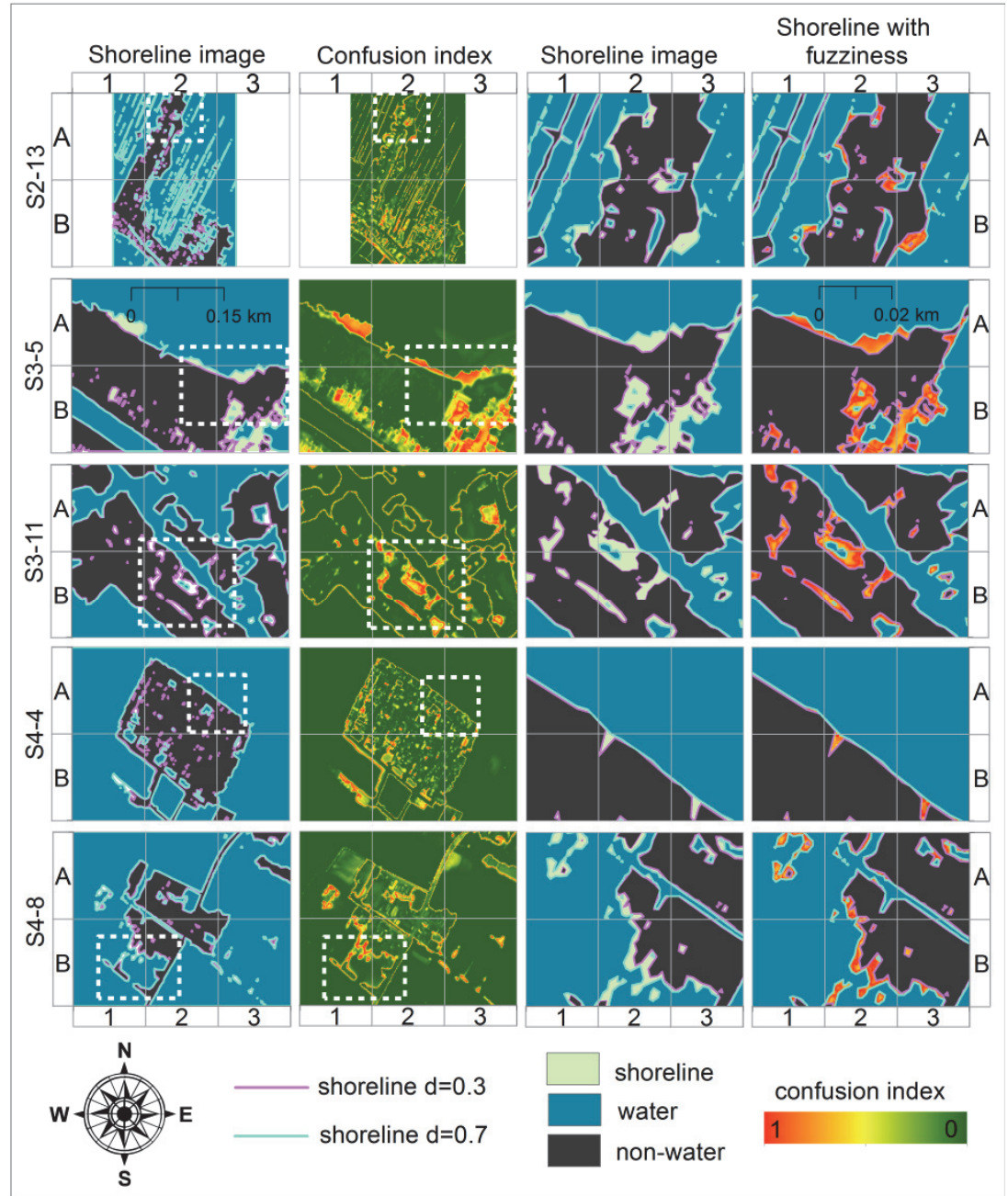

Figure 4A.3 The shoreline as the transition zone between water and nonwater (Column 1); confusion index images (Column 2); zooming into the white-dashed rectangle sites (Column 3); shoreline images with fuzziness represented by the confusion index (Column 4) 
Table 4A.3 The optimal $\varphi$ selected for each threshold interval and the related $\boldsymbol{\kappa}$ values for generation of random sets

\begin{tabular}{|c|c|c|c|c|c|c|}
\hline \multirow{2}{*}{ Subset } & \multicolumn{3}{|c|}{$\begin{array}{l}\text { Number of focal elements }(\varphi) \\
\text { for each threshold interval }\end{array}$} & \multicolumn{3}{|c|}{$\begin{array}{c}\text { K value for each threshold } \\
\text { interval }\end{array}$} \\
\hline & $0.2-0.6$ & $0.3-0.7$ & $0.4-0.8$ & $0.2-0.6$ & $0.3-0.7$ & $\begin{array}{c}0.4- \\
0.8\end{array}$ \\
\hline$S_{1-1}$ & 40 & 80 & 130 & 0.84 & 0.89 & 0.84 \\
\hline$S_{1-2}$ & 40 & 20 & 80 & 0.87 & 0.86 & 0.86 \\
\hline$S_{1-6}$ & 40 & 90 & 30 & 0.81 & 0.88 & 0.82 \\
\hline$S_{1-7}$ & 40 & 60 & 70 & 0.70 & 0.84 & 0.81 \\
\hline$S_{1-9}$ & 40 & 140 & 20 & 0.85 & 0.87 & 0.87 \\
\hline$S_{1-10}$ & 60 & 60 & 30 & 0.85 & 0.88 & 0.87 \\
\hline$S_{2-3}$ & 70 & 80 & 100 & 0.79 & 0.87 & 0.88 \\
\hline$S_{2-12}$ & 20 & 50 & 40 & 0.79 & 0.87 & 0.80 \\
\hline$S_{2-13}$ & 180 & 30 & 60 & 0.78 & 0.81 & 0.83 \\
\hline$S_{3-5}$ & 30 & 60 & 100 & 0.83 & 0.90 & 0.80 \\
\hline$S_{3-11}$ & 70 & 60 & 80 & 0.85 & 0.90 & 0.85 \\
\hline$S_{4-4}$ & 140 & 120 & 30 & 0.87 & 0.88 & 0.85 \\
\hline$S_{4-8}$ & 150 & 40 & 20 & 0.75 & 0.81 & 0.75 \\
\hline
\end{tabular}

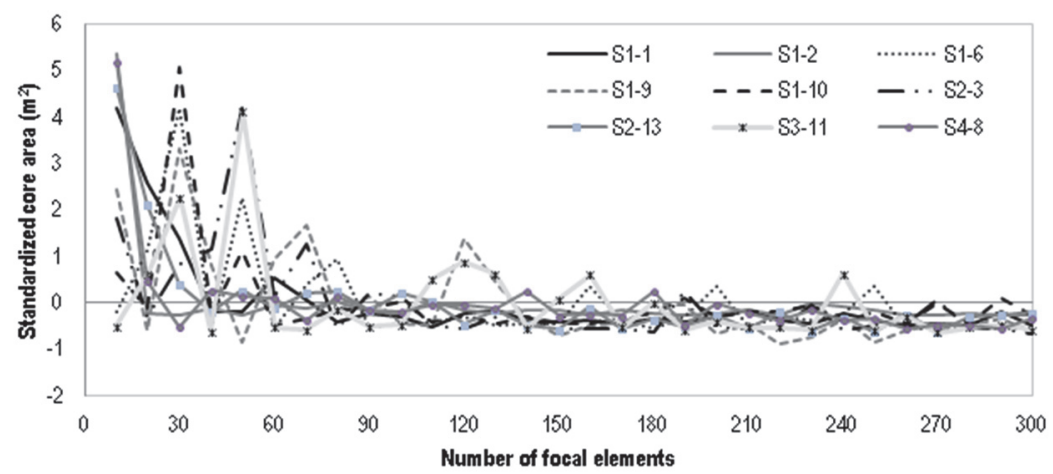

Figure 4A.4 The curve of differences between two successive standardized core sets $\delta_{i}$ 


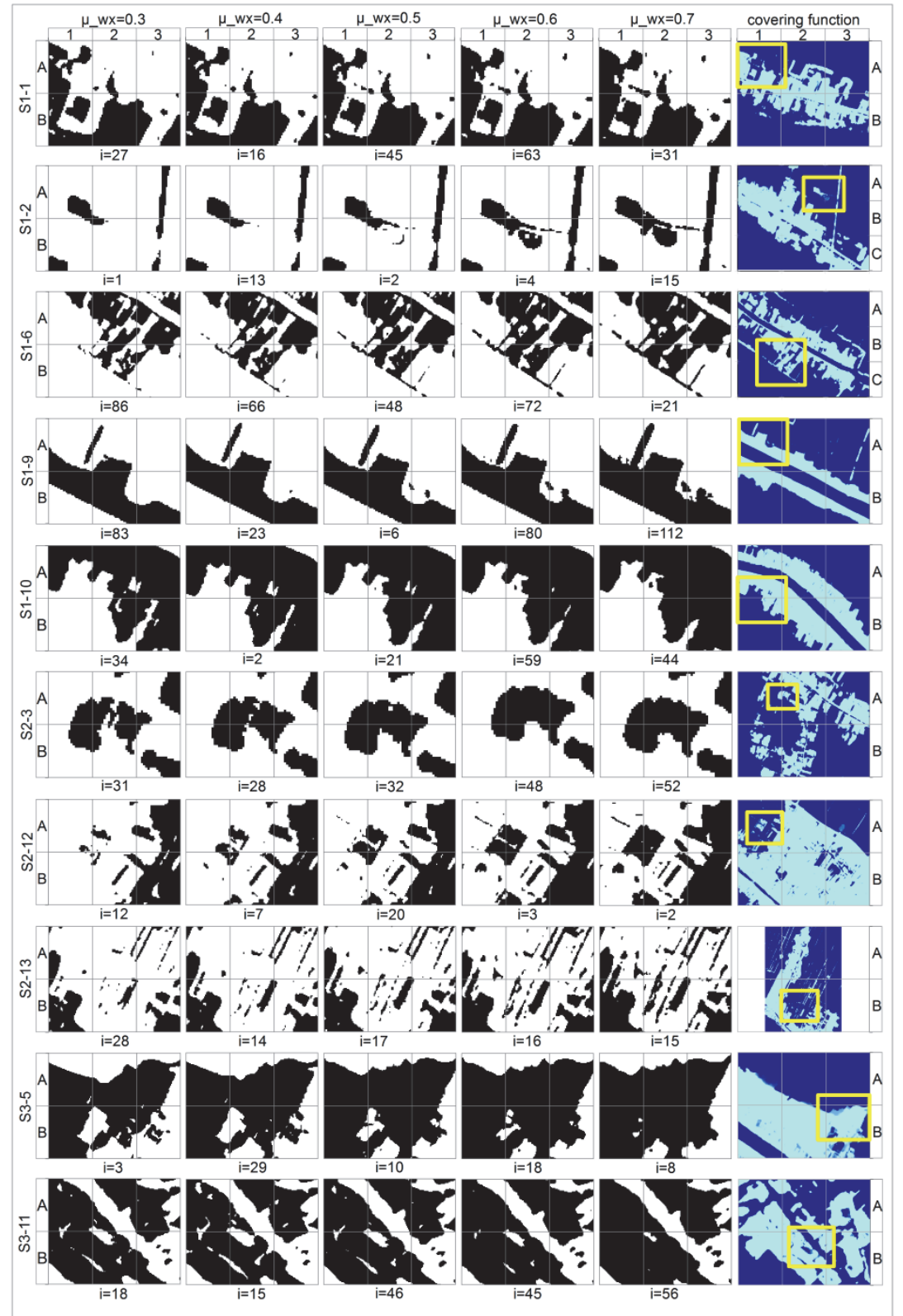




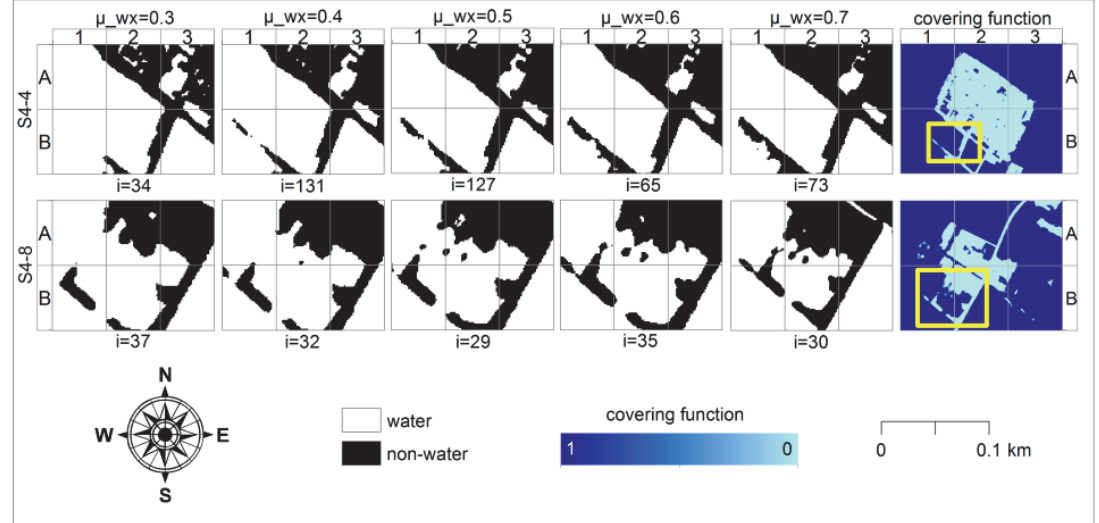

Figure 4A.5 Samples of the random sets with various extents and their covering functions 


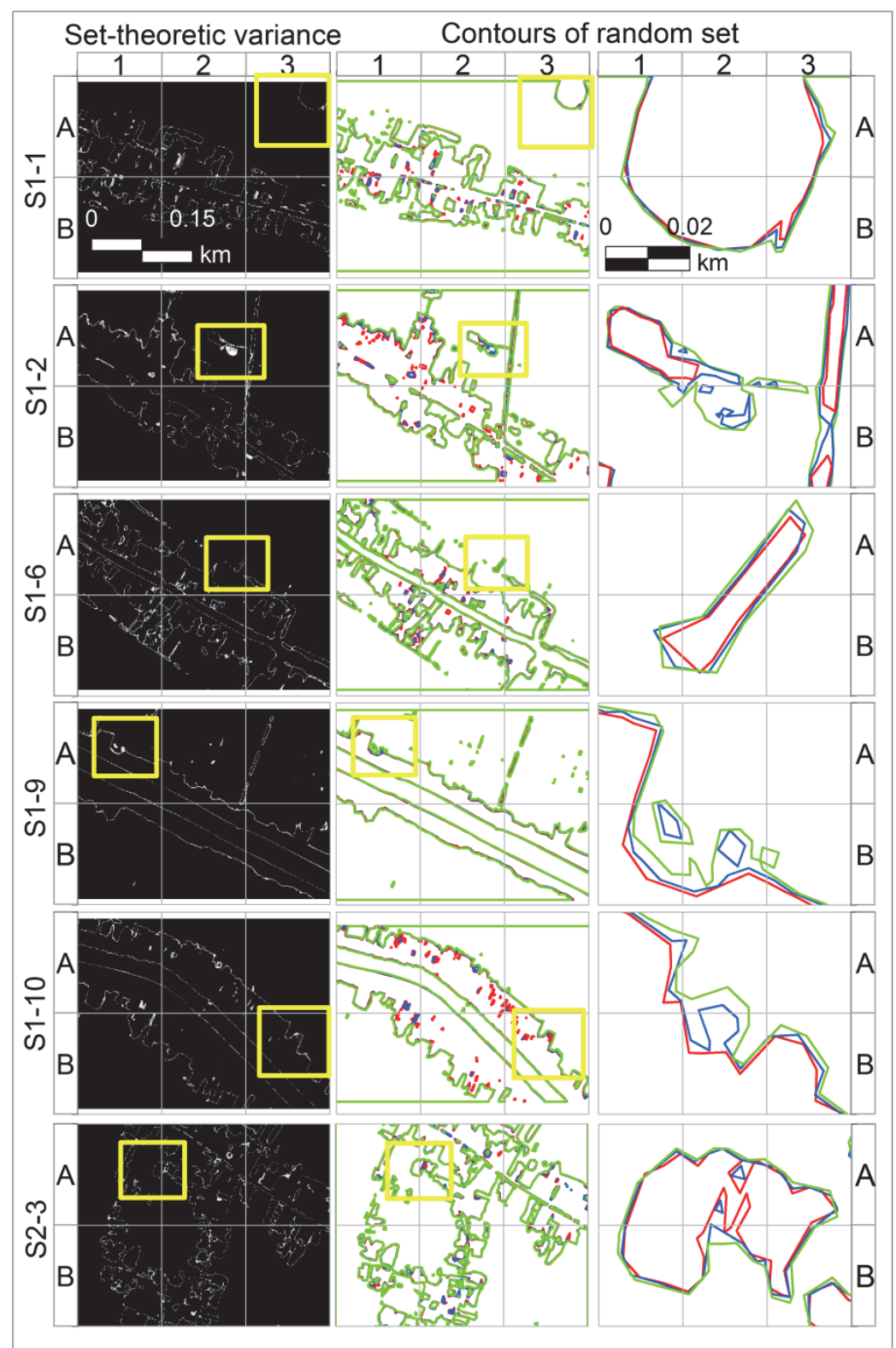




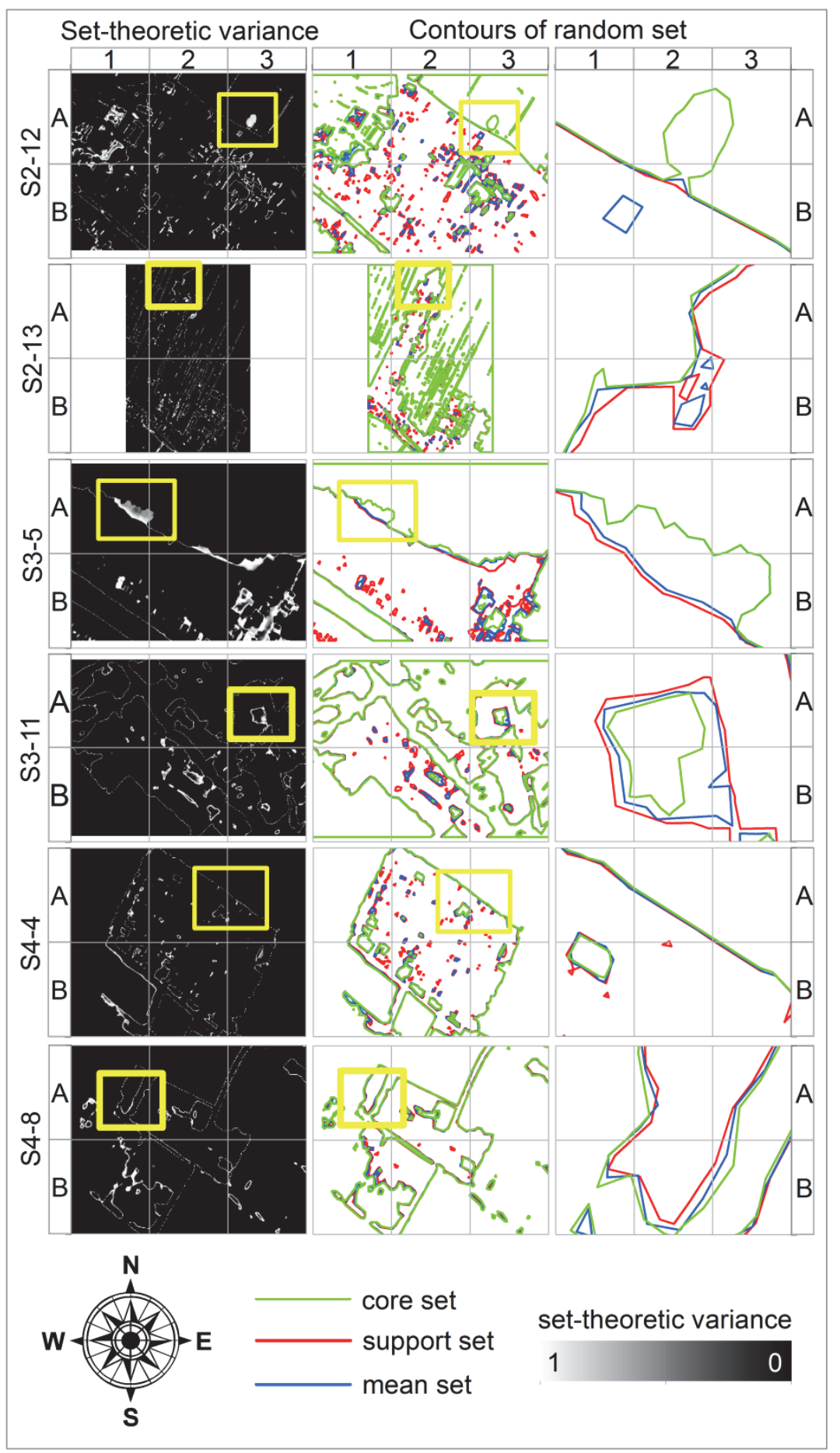

Figure 4A.6 The set-theoretic variance and the contour of random sets 


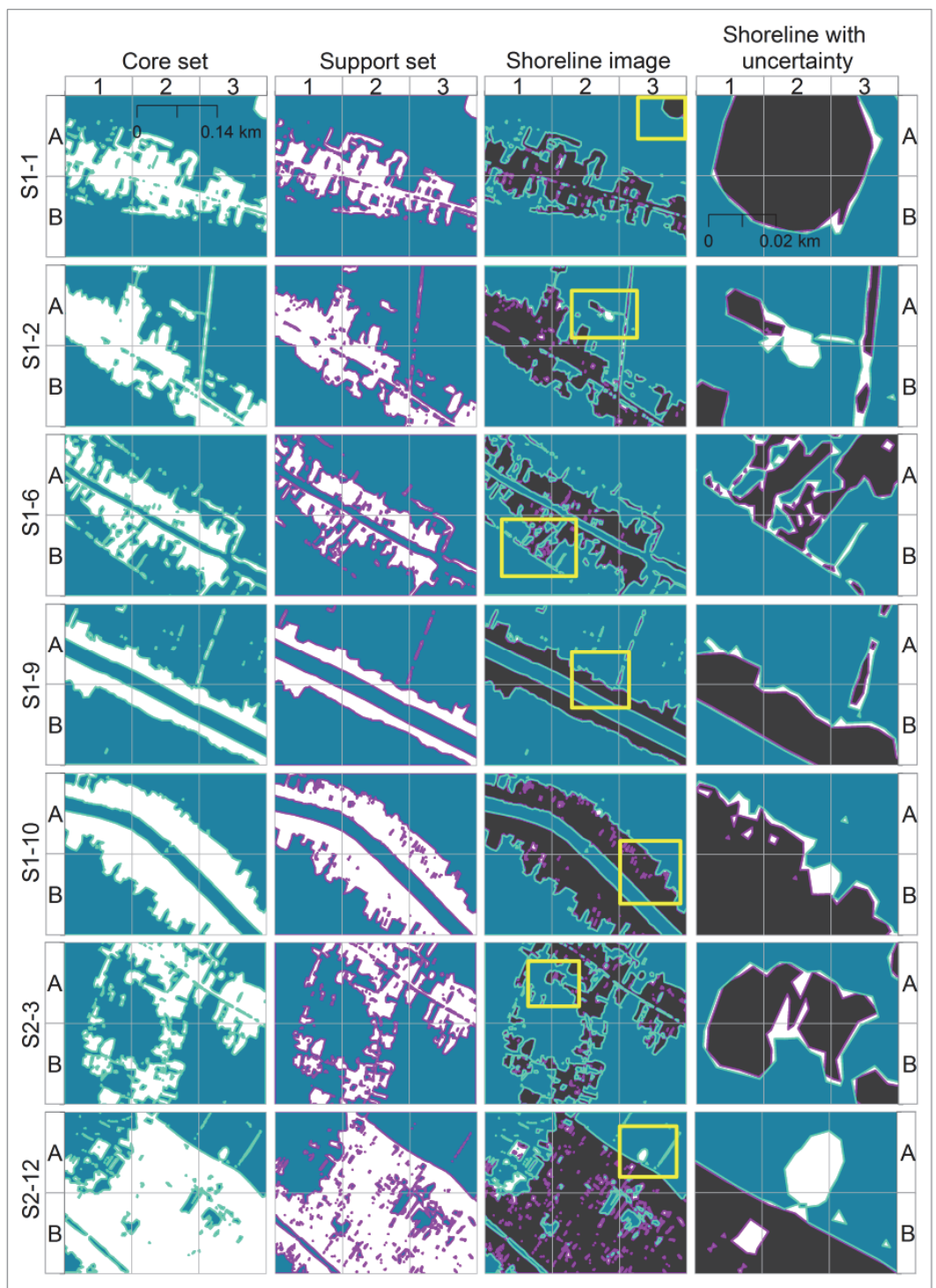




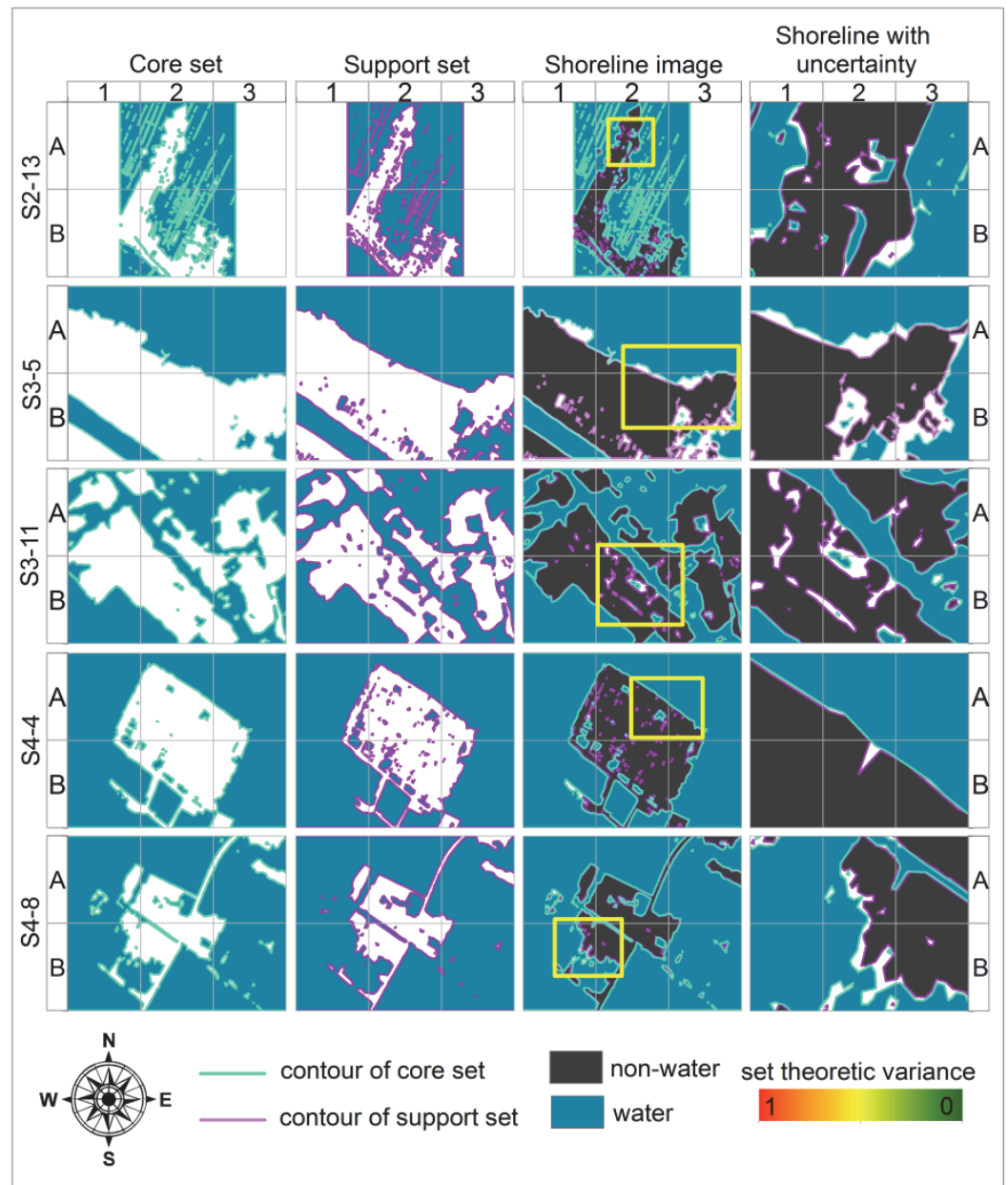

Figure 4A.7 An example of random sets; the core set $\Gamma_{1}$ and its contour (column 1); the support set $\Gamma_{0}$ and its contour (column 2); the transition zone between water and non-water represented by the set-theoretic variance (column 3); zooming into the yellow rectangle sites (column 4) 
Table 4A.4 The results of McNemar's test showing the significance of the different accuracies given by Pleiades and Pleiades +DTM $(\alpha=0.05)$ in random sets (see notations in Table 4A.2 for $\boldsymbol{f}_{11}, \boldsymbol{f}_{\mathbf{2 2}}, \boldsymbol{f}_{12}$, and $\boldsymbol{f}_{21}$ )

\begin{tabular}{ccccccc}
\hline & \multicolumn{5}{c}{ McNemar's Test } & \\
\cline { 2 - 6 } Subset & $\boldsymbol{f}_{\mathbf{1 1}}$ & $\boldsymbol{f}_{\mathbf{1 2}}$ & $\boldsymbol{f}_{\mathbf{2 1}}$ & $\boldsymbol{f}_{\mathbf{2 2}}$ & $\begin{array}{c}\text { Chi-squared } \\
\left(\boldsymbol{X}^{\mathbf{2}}\right)\end{array}$ & $\boldsymbol{p}$-value \\
\hline$S_{1-1}$ & 13 & 8 & 0 & 154 & 6.1 & 0.013 \\
$S_{1-2}$ & 2 & 26 & 7 & 108 & 9.8 & 0.002 \\
$S_{1-6}$ & 0 & 17 & 8 & 127 & 2.6 & 0.110 \\
$S_{1-7}$ & 4 & 34 & 8 & 101 & 14.9 & 0.000 \\
$S_{1-9}$ & 4 & 22 & 3 & 84 & 13.0 & 0.000 \\
$S_{1-10}$ & 1 & 12 & 2 & 82 & 5.8 & 0.016 \\
\hline$S_{2-3}$ & 7 & 11 & 4 & 130 & 2.4 & 0.121 \\
$S_{2-12}$ & 1 & 15 & 5 & 100 & 4.05 & 0.044 \\
$S_{2-13}$ & 13 & 3 & 3 & 100 & 0.0 & 1.000 \\
\hline$S_{3-5}$ & 2 & 37 & 6 & 119 & 20.9 & 0.000 \\
$S_{3-11}$ & 3 & 11 & 3 & 104 & 3.5 & 0.061 \\
\hline$S_{4-4}$ & 4 & 22 & 4 & 121 & 11.1 & 0.001 \\
$S_{4-8}$ & 2 & 18 & 10 & 91 & 1.8 & 0.186 \\
\hline
\end{tabular}


Table 4A.5 The results of McNemar's test showing the significance of the difference given by fuzzy sets and random sets $(\alpha=0.05)$ by using Pleiades

\begin{tabular}{ccccccc}
\hline & & \multicolumn{5}{c}{ McNemar Test } \\
\cline { 2 - 7 } Subset & $\boldsymbol{f}_{\mathbf{1 1}}$ & $\boldsymbol{f}_{\mathbf{1 2}}$ & $\boldsymbol{f}_{\mathbf{2 1}}$ & $\boldsymbol{f}_{\mathbf{2 2}}$ & $\begin{array}{c}\text { Chi-squared } \\
\left(\boldsymbol{X}^{\mathbf{2}}\right)\end{array}$ & $\boldsymbol{p}$-value \\
\hline$S_{1-1}$ & 18 & 1 & 2 & 154 & 0.0 & 1.000 \\
$S_{1-2}$ & 25 & 2 & 5 & 111 & 0.6 & 0.450 \\
$S_{1-6}$ & 11 & 18 & 6 & 117 & 5.0 & 0.025 \\
$S_{1-7}$ & 37 & 0 & 1 & 109 & 0.0 & 1.000 \\
$S_{1-9}$ & 26 & 1 & 0 & 86 & 0.0 & 1.000 \\
$S_{1-10}$ & 15 & 0 & 1 & 105 & 0.0 & 1.000 \\
\hline$S_{2-3}$ & 19 & 3 & 0 & 130 & 1.3 & 0.248 \\
$S_{2-12}$ & 16 & 1 & 0 & 104 & 0.0 & 1.000 \\
$S_{2-13}$ & 12 & 1 & 0 & 106 & 0.0 & 1.000 \\
\hline$S_{3-5}$ & 39 & 1 & 0 & 124 & 0.0 & 1.000 \\
$S_{3-11}$ & 13 & 0 & 1 & 107 & 0.0 & 1.000 \\
\hline$S_{4-4}$ & 26 & 1 & 0 & 124 & 0.5 & 0.480 \\
$S_{4-8}$ & 19 & 0 & 1 & 101 & 0.0 & 1.000 \\
\hline
\end{tabular}

$\boldsymbol{f}_{11}$ : number of samples with incorrect classification using both methods;

$\boldsymbol{f}_{\mathbf{2 2}}$ : number of samples with correct classification using both methods;

$f_{12}$ : number of samples that are incorrectly classified by fuzzy sets but correctly classified by random sets;

$\boldsymbol{f}_{21}$ : number of samples that are correctly classified by fuzzy sets but incorrectly classified by random sets; 
Table 4A.6 The results of McNemar's test showing the significance of the difference given by fuzzy sets and random sets $(\alpha=0.05)$ using Pleiades + DTM data (see notations in Table 4A.5 for $\boldsymbol{f}_{11}, \boldsymbol{f}_{\mathbf{2 2}}, \boldsymbol{f}_{\mathbf{1 2}}$, and $\boldsymbol{f}_{21}$ )

\begin{tabular}{ccccccc}
\hline & \multicolumn{6}{c}{ McNemar Test } \\
\cline { 2 - 7 } Subset & $\boldsymbol{f}_{\mathbf{1 1}}$ & $\boldsymbol{f}_{\mathbf{1 2}}$ & $\boldsymbol{f}_{\mathbf{2 1}}$ & $\boldsymbol{f}_{\mathbf{2 2}}$ & $\begin{array}{c}\text { Chi-squared } \\
\left(\boldsymbol{X}^{\mathbf{2}}\right)\end{array}$ & $\boldsymbol{p}$-value \\
\hline$S_{1-1}$ & 11 & 0 & 2 & 162 & 0.5 & 0.480 \\
$S_{1-2}$ & 9 & 0 & 1 & 133 & 0.0 & 1.000 \\
$S_{1-6}$ & 4 & 6 & 4 & 138 & 0.1 & 0.752 \\
$S_{1-7}$ & 12 & 0 & 1 & 134 & 0.0 & 1.000 \\
$S_{1-9}$ & 5 & 7 & 3 & 98 & 0.9 & 0.343 \\
$S_{1-10}$ & 7 & 1 & 0 & 113 & 0.0 & 1.000 \\
\hline$S_{2-3}$ & 8 & 2 & 2 & 140 & 0.0 & 1.000 \\
$S_{2-12}$ & 8 & 0 & 1 & 112 & 0.0 & 1.000 \\
$S_{2-13}$ & 8 & 0 & 3 & 108 & 1.3 & 0.248 \\
\hline$S_{3-5}$ & 6 & 2 & 1 & 155 & 0.0 & 1.000 \\
$S_{3-11}$ & 5 & 0 & 1 & 115 & 0.0 & 1.000 \\
\hline$S_{4-4}$ & 9 & 0 & 1 & 141 & 0.0 & 1.000 \\
$S_{4-8}$ & 11 & 1 & 0 & 109 & 0.0 & 1.000 \\
\hline
\end{tabular}



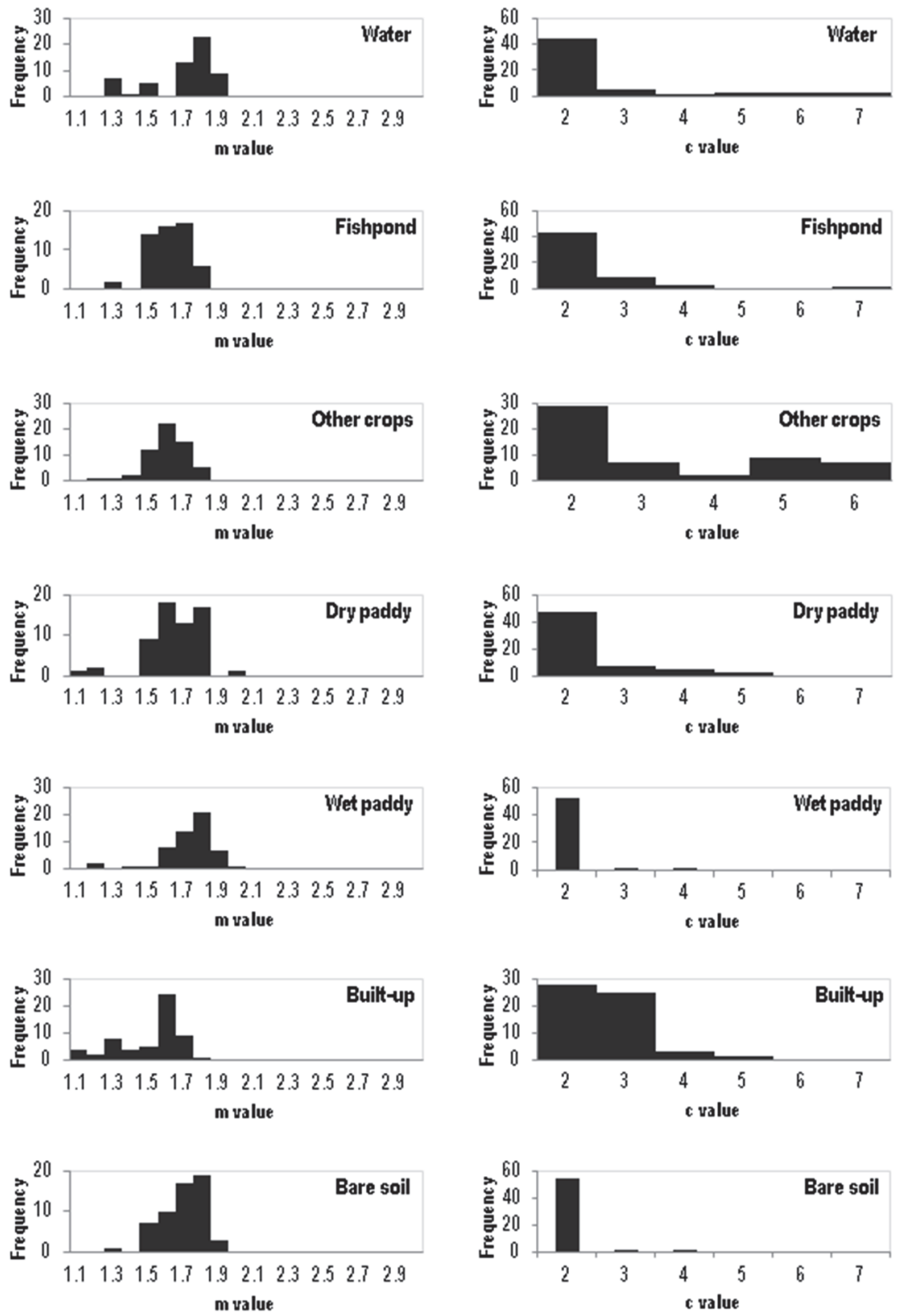

Figure 5A.1 Histograms of optimal values of $\boldsymbol{m}$ (left) and $\boldsymbol{c}$ (right) obtained after performing cluster validity measures on seven land use/cover classes 


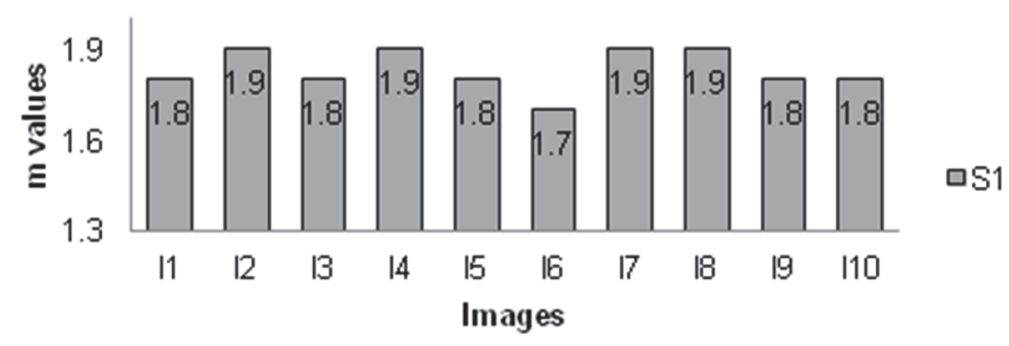

Figure 5A.2 The optimal $\boldsymbol{m}$ values of the reference subset $\left(\boldsymbol{s}_{1}\right)$ with $\boldsymbol{c}=2$ as the optimal $\boldsymbol{c}$ chosen by CVI for all images
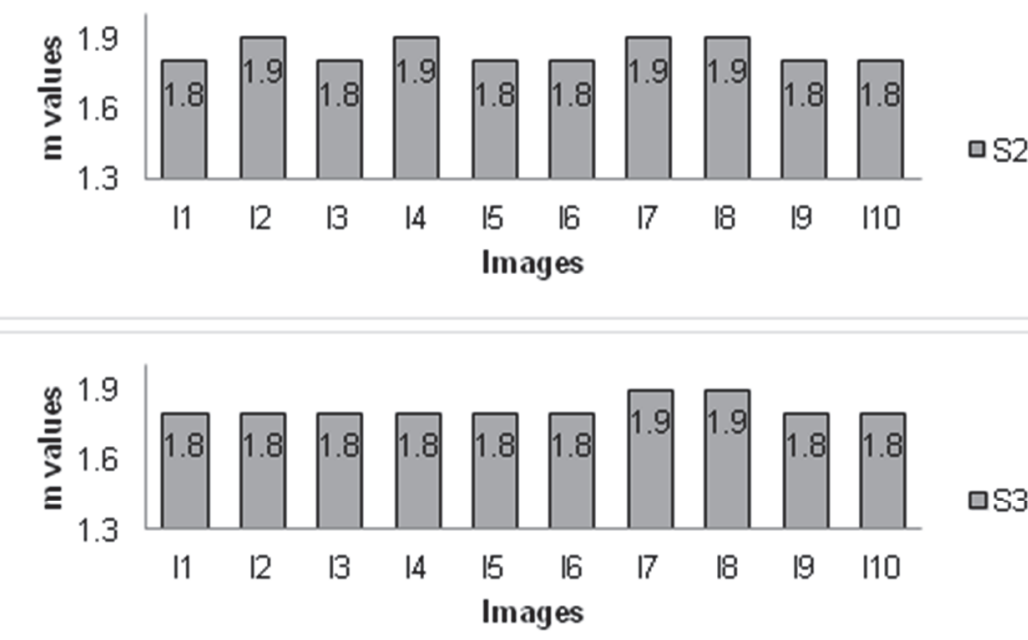

口S3

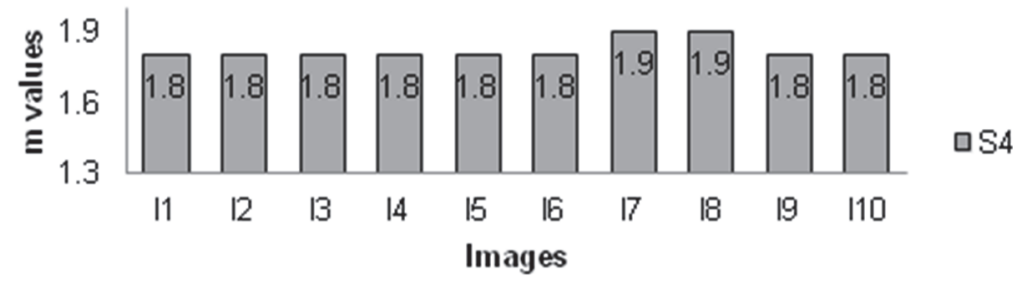

Figure 5A.3 The optimal $\boldsymbol{m}$ values as a result of upscaling towards larger areas by using $\boldsymbol{s}_{\mathbf{1}}$ as the reference subset and the optimal $\boldsymbol{c}=2$ was obtained for all these target subsets 

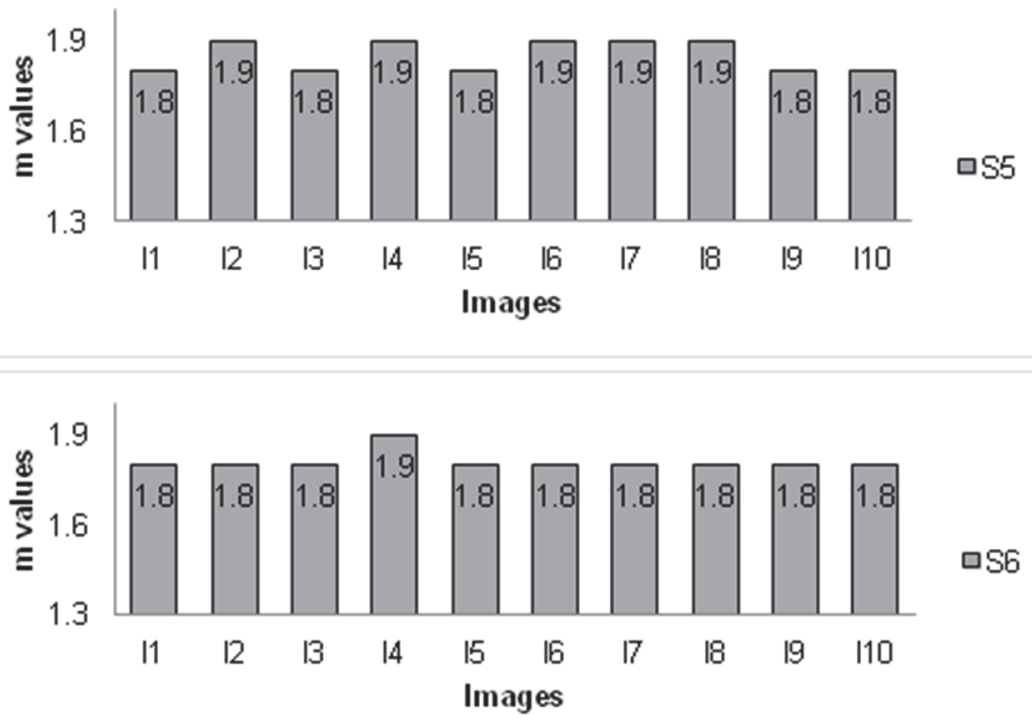

Figure 5A.4 The optimal $\boldsymbol{m}$ values as a result of transferability to other areas by using $s_{1}$ as the reference subset. We obtained $\boldsymbol{c}=2$ as the optimal $\boldsymbol{c}$ value for all images

Table 5A.1 The overall accuracy indicating water membership agreement between the reference $\left(\boldsymbol{s}_{1}\right)$ and target subsets $\left(\boldsymbol{s}_{2}\right.$ up to $\left.\boldsymbol{s}_{\mathbf{4}}\right)$ estimated using the fuzzy error matrix

\begin{tabular}{cccc}
\hline Classified & \multicolumn{3}{c}{ Overall accuracy } \\
\cline { 2 - 4 } images & $\mathbf{s}_{\mathbf{2}}$ & $\mathbf{s}_{\mathbf{3}}$ & $\mathbf{s}_{\mathbf{4}}$ \\
\hline$I_{1}$ & 0.97 & 0.91 & 0.88 \\
$I_{2}$ & 0.96 & 0.90 & 0.86 \\
$I_{3}$ & 0.97 & 0.93 & 0.92 \\
$I_{4}$ & 0.94 & 0.90 & 0.88 \\
$I_{5}$ & 0.94 & 0.91 & 0.90 \\
$I_{6}$ & 0.92 & 0.83 & 0.82 \\
$I_{7}$ & 0.94 & 0.90 & 0.90 \\
$I_{8}$ & 0.94 & 0.89 & 0.85 \\
$I_{9}$ & 0.96 & 0.96 & 0.97 \\
$I_{10}$ & 0.97 & 0.92 & 0.91
\end{tabular}




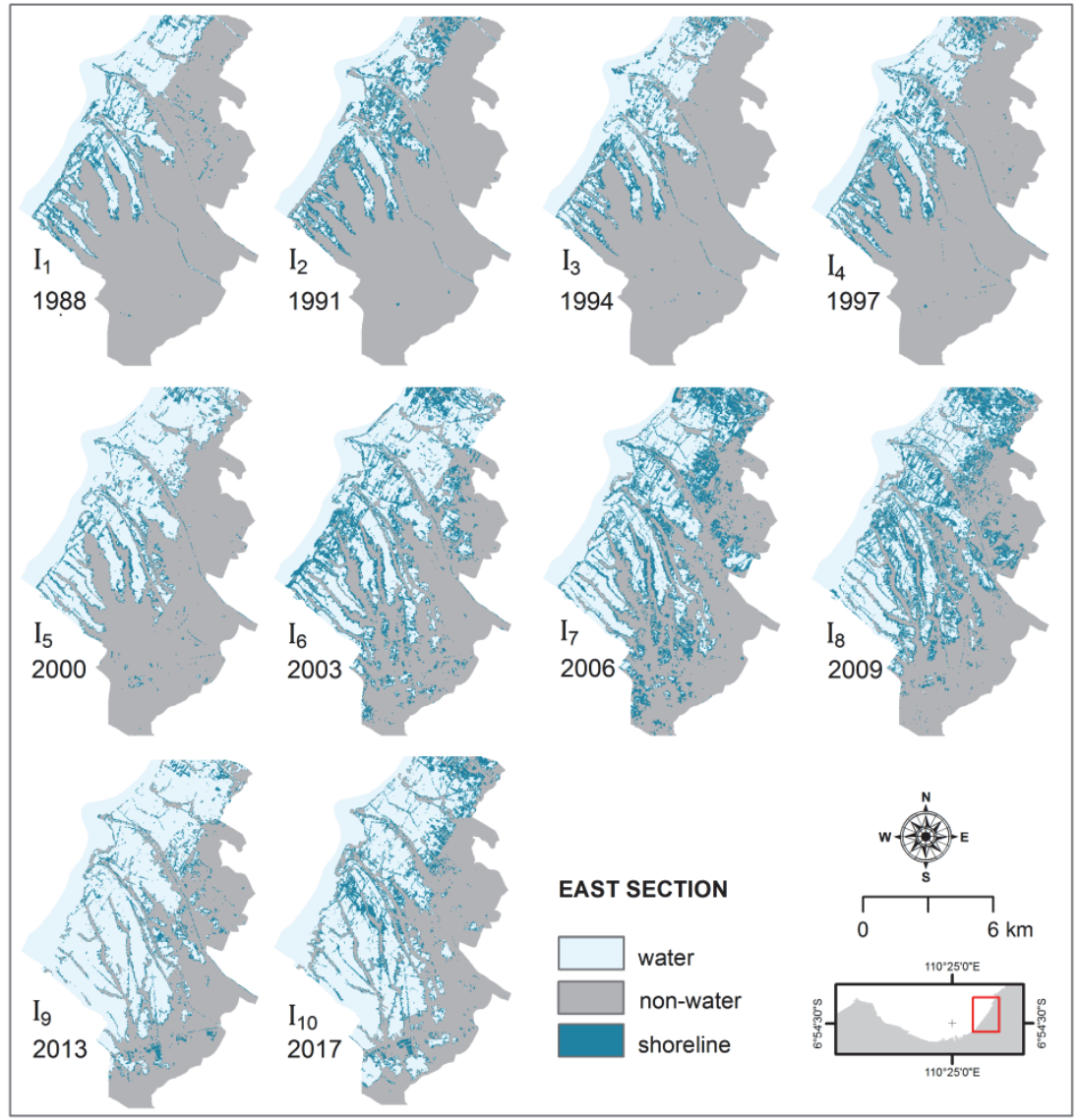

Figure 5A.5 Shoreline images of the east section. The extent of non-water area has decreased over three decades, while water area has expanded. In this section, coastal erosion and inundation has caused a substantial loss of coastal land 


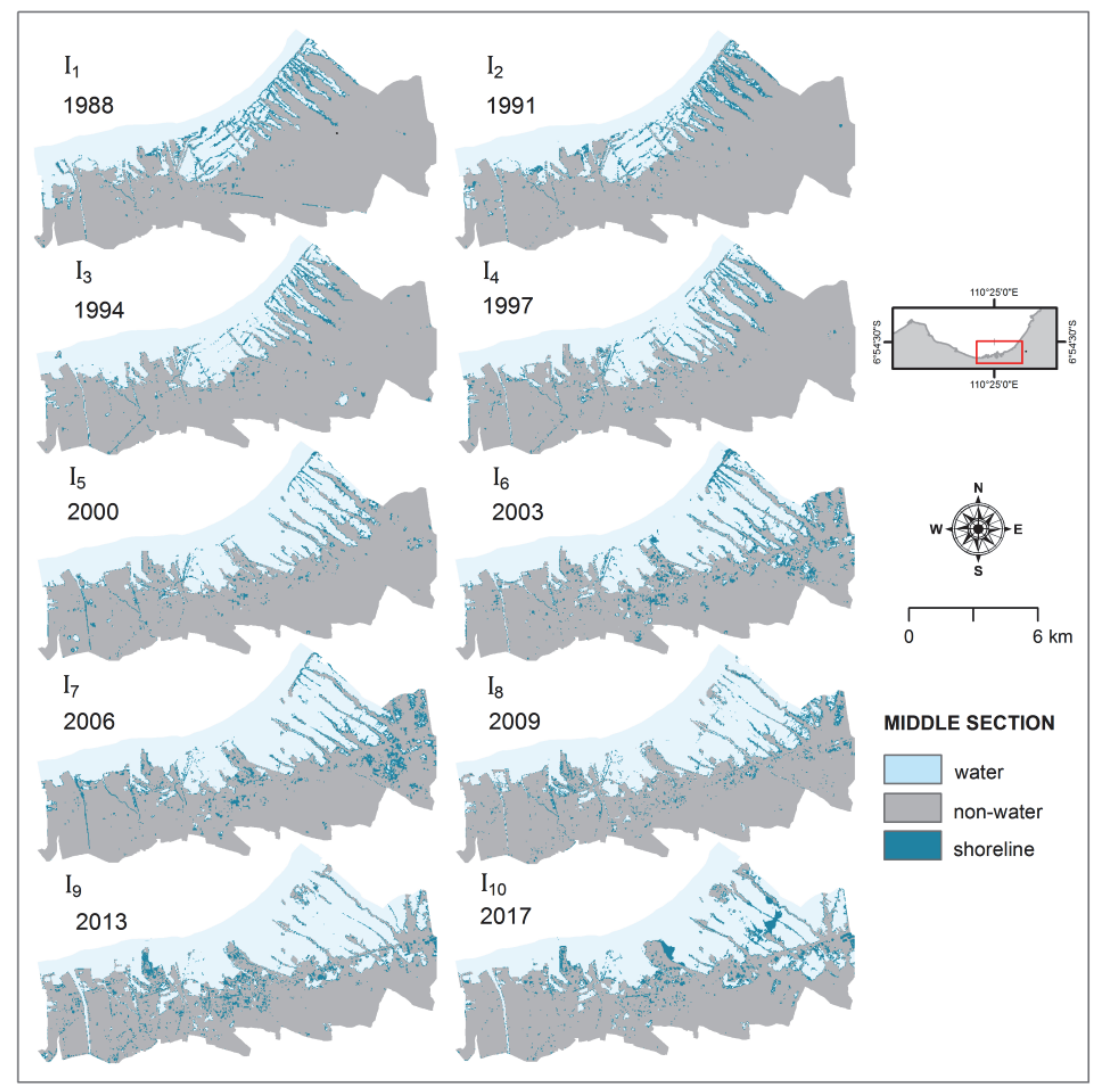

Figure 5A.6 Shoreline images of the middle section. An extensive change of shoreline is obvious due to reclamation activities for e.g. in the western part of the images while some other places gradually eroded started from 1994 


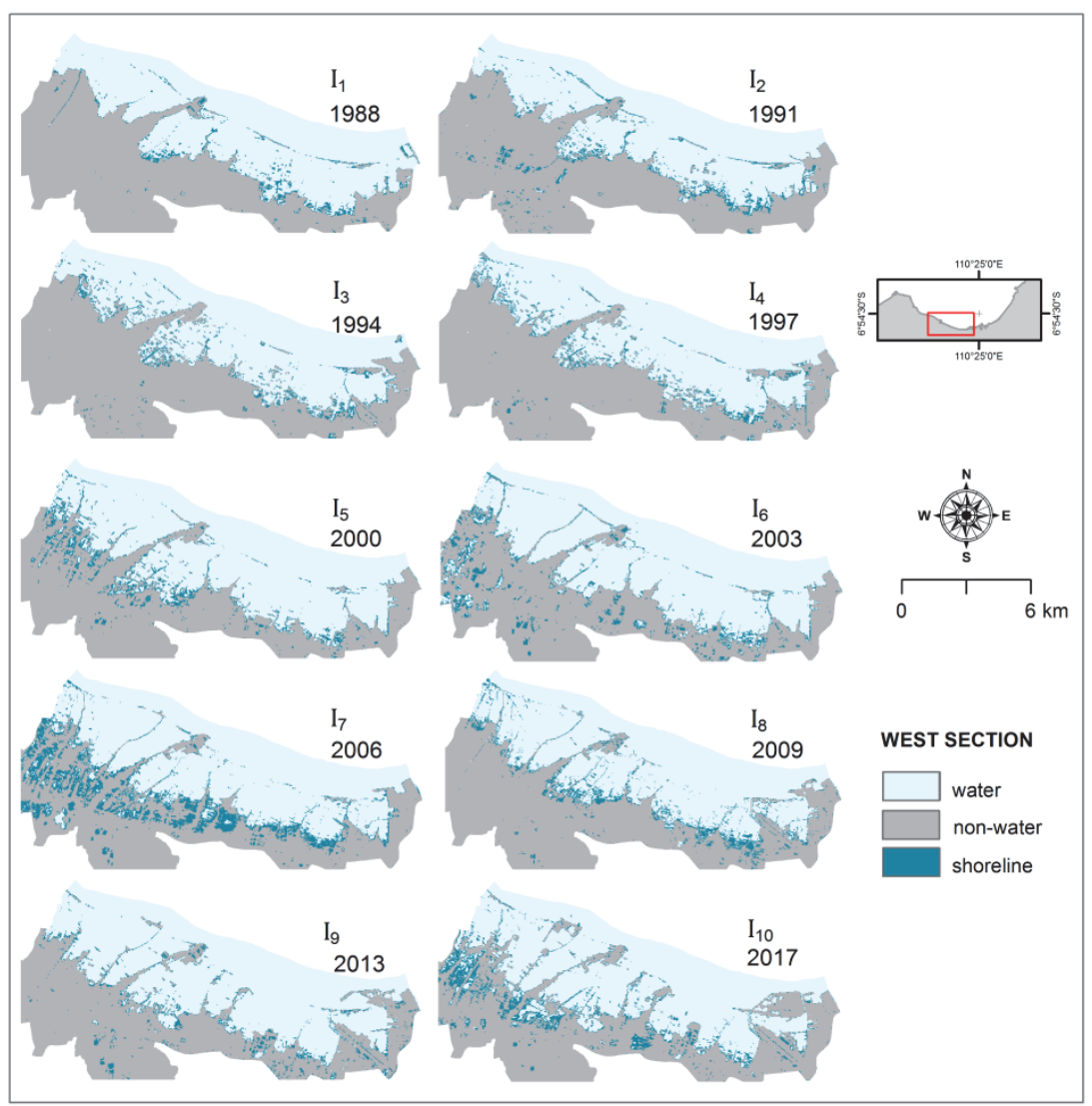

Figure 5A.7 Shoreline images of the west section. The changes of shoreline position in this section are relatively small, however small gain of non-water area can be seen in the eastern part of the image due to land reclamation project 


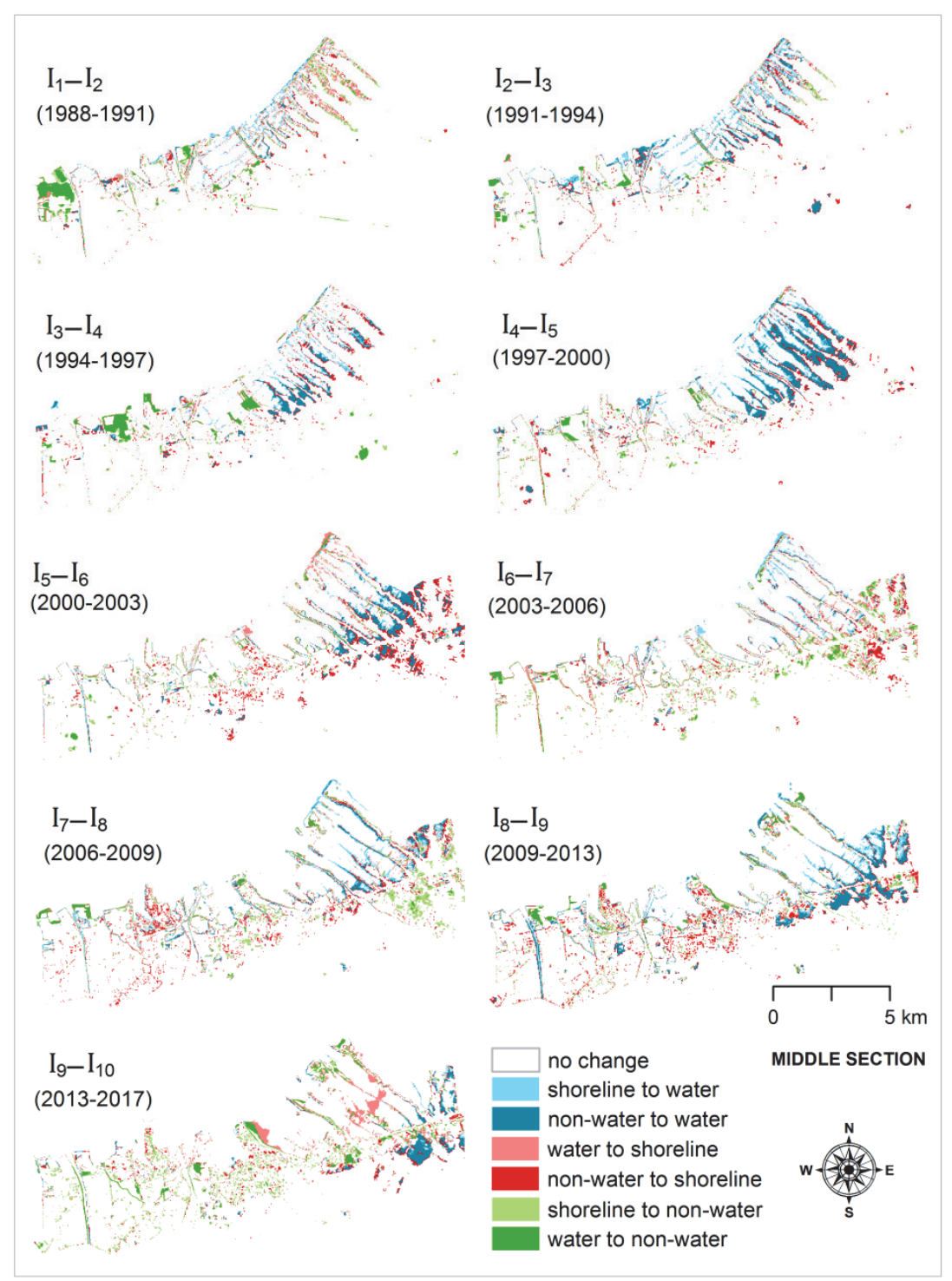

Figure 5A.8 The spatial distribution of shoreline changes in the middle section for consecutive dates. A large gain of non-water areas (in green) was obvious in the periods 1988-1991 and 1994-1997 (see the west part of the site), while a subtle change into water (in turquoise) was shown in the period 1997-2000 and 2009-2013. 


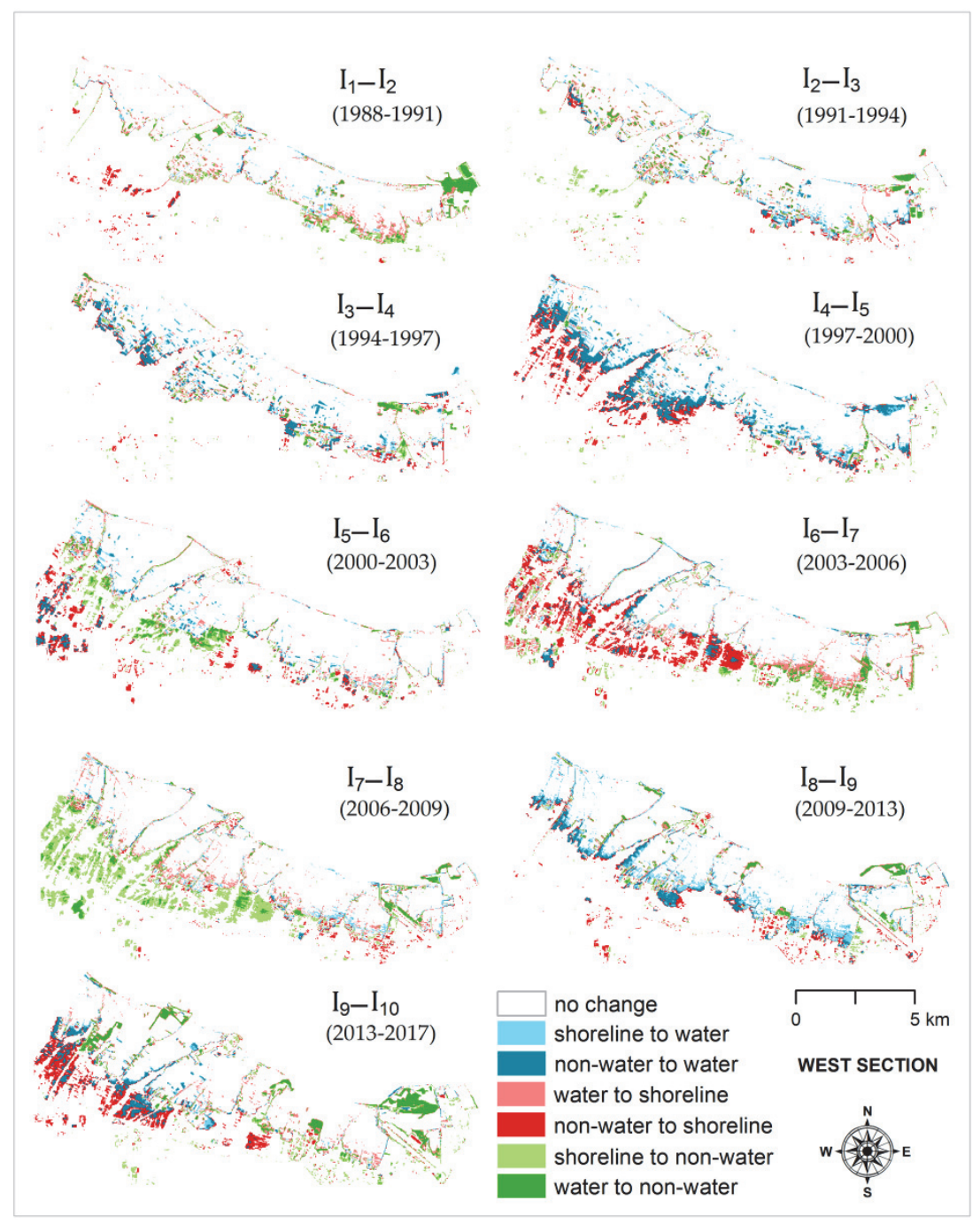

Figure 5A.9 The spatial distribution of shoreline changes in the west section for consecutive dates. A small gain of non-water can be seen in the periods 1988-1991 and 2013-2017 at the eastern part of the site while erosion due to the changes into water are visible in the periods 1997-2000 and 2009-2013. In general, the areas show small changes of non-water, water and shoreline margin indicating a steady condition of the coastal environment 


\section{Author's Publication}

\section{ISI Journal Publications}

Dewi, R.S., Bijker, W., Stein, A., Marfai, M.A., Fuzzy Classification for Shoreline Change Monitoring in a Part of the Northern Coastal Area of Java, Indonesia. Remote Sensing. 2016, 8, 190. doi:10.3390/rs8030190

Dewi, R.S., Bijker, W., Stein, A. Change Vector Analysis to Monitor the Changes in Fuzzy Shorelines. Remote Sensing. 2017, 9, 147, doi:10.3390/ rs9020147

Dewi, R.S., Bijker, W., Stein, A. Comparing Fuzzy Sets and Random Sets to Model the Uncertainty of Fuzzy Shorelines. Remote Sensing. 2017, 9, 885

Dewi, R.S., Bijker, W., Stein, A., Marfai, M.A., 2018. Transferability and Upscaling of Fuzzy Classification for Shoreline Change over 30 years. Remote Sensing. 2018. 10, 1377, doi:10.3390/rs10091377 